\title{
The Crematogaster (Hymenoptera, Formicidae, Myrmicinae) of Costa Rica
}

\author{
JOHN T. LONGINO
}

The Evergreen State College, Olympia, Washington 98505, USA

longinoj@evergreen.edu

\section{TABLE OF CONTENTS}

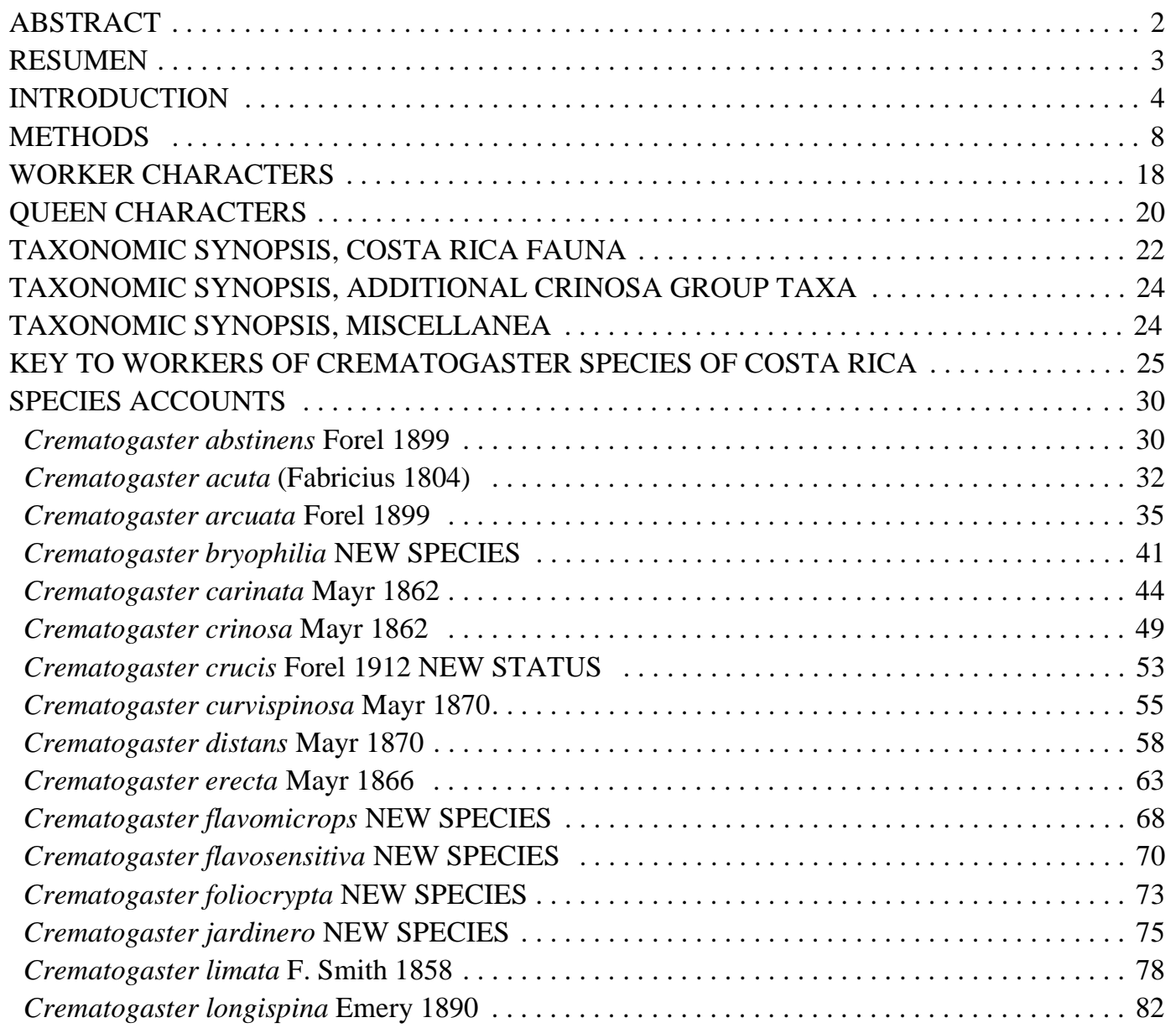


Crematogaster minutissima Mayr $1870 \ldots \ldots \ldots \ldots \ldots \ldots \ldots \ldots \ldots \ldots \ldots \ldots$

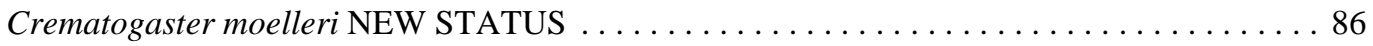

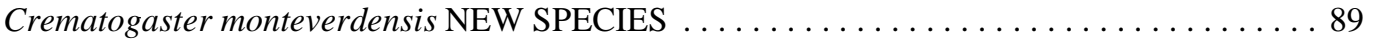

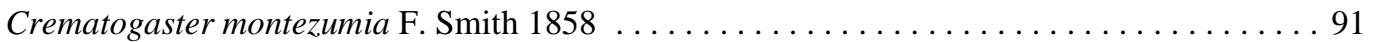

Crematogaster nigropilosa Mayr $1870 \ldots \ldots \ldots \ldots \ldots \ldots \ldots \ldots \ldots \ldots \ldots$

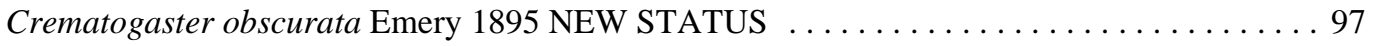

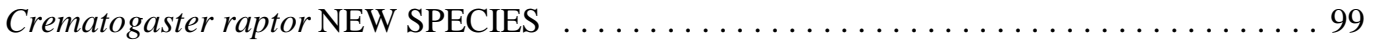

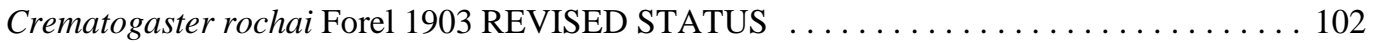

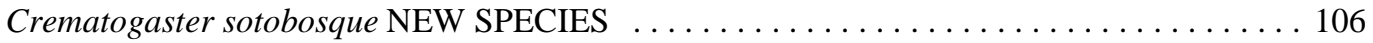

Crematogaster tenuicula Forel 1904 NEW STATUS . . . . . . . . . . . . . . . . . 118

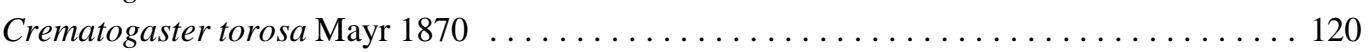

TAXONOMIC NOTES ON C. CRINOSA AND RELATED FORMS $\ldots \ldots \ldots \ldots \ldots \ldots$

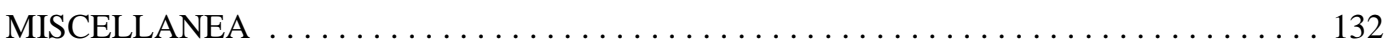

DIVERSITY AND RELATIVE ABUNDANCE $\ldots \ldots \ldots \ldots \ldots \ldots \ldots \ldots \ldots \ldots \ldots$

ACKNOWLEDGMENTS $\ldots \ldots \ldots \ldots \ldots \ldots \ldots \ldots \ldots \ldots \ldots \ldots \ldots \ldots \ldots \ldots$

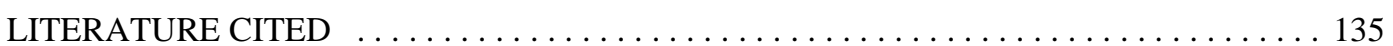

\begin{abstract}
The taxonomy and natural history of the ant genus Crematogaster are reviewed for the Costa Rican fauna. Thirtyone species are known, and a key is provided for these and two additional species from adjacent regions of Panama. Species boundaries are evaluated over their entire range when possible. The taxonomic history of the genus is one of unbridled naming of new species and subspecies, with no synthetic works or keys. Major taxonomic changes are proposed, with the recognition of several polytypic species with very broad ranges and the synonymization of the many names associated with them. Crematogaster pygmaea Forel 1904, suturalis Forel 1912, ornatipilis Wheeler 1918, erici Santschi 1929, and chacoana Santschi 1933 are synonymized under abstinens Forel 1899; centralis Santschi 1932 under acuta (Fabricius 1804); aruga Forel 1913 under arcuata Forel 1899; ludio Forel 1912, armandi Forel 1921, inca Wheeler 1925, and cocciphila Borgmeier 1934 under brasiliensis Mayr 1878; parabiotica Forel 1904 under carinata Mayr 1862; brevispinosa Mayr 1870, minutior Forel 1893, schuppi Forel 1901, recurvispina Forel 1912, sampaioi Forel 1912, striatinota Forel 1912, townsendi Wheeler 1925, and chathamensis Wheeler 1933 under crinosa Mayr 1862; barbouri Weber 1934 under cubaensis Mann 1920; antillana Forel 1893, sculpturata Pergande 1896, kemali Santschi 1923, accola Wheeler 1934, phytoeca Wheeler 1934, panamana Wheeler 1942, and obscura Santschi 1929 under curvispinosa Mayr 1870; descolei Kusnezov 1949 under distans Mayr 1870; projecta Santschi 1925 under erecta Mayr 1866; carbonescens Forel 1913 under evallans Forel 1907; palans Forel 1912, ascendens Wheeler 1925, and dextella Santschi 1929 under limata F. Smith 1858; agnita Wheeler 1934 under obscurata Emery 1895; amazonensis Forel 1905, autruni Mann 1916, and guianensis Crawley 1916 under stollii Forel 1885; surdior Forel 1885, atitlanica Wheeler 1936, and maya Wheeler 1936 under sumichrasti Mayr 1870; tumulifera Forel 1899 and arizonensis Wheeler 1908 under torosa Mayr 1870. The following taxa are raised to species: ampla Forel 1912, brevidentata Forel 1912, chodati Forel 1921, crucis Forel 1912, cubaensis Mann 1920, goeldii Forel 1903, malevolens Santschi 1919, mancocapaci Santschi 1911, moelleri Forel 1912, montana Borgmeier 1939, obscurata Emery
\end{abstract}


1895, rochai Forel 1903, russata Wheeler 1925, sericea Forel 1912, stigmatica Forel 1911, subtonsa Santschi 1925, tenuicula Forel 1904, thalia Forel 1911, uruguayensis Santschi 1912, and vicina Andre 1893. The following new species are described: bryophilia, flavomicrops, flavosensitiva, foliocrypta, jardinero, levior, monteverdensis, raptor, snellingi, sotobosque, and wardi.

Key words: Crematogaster, Costa Rica, Formicidae, key to species.

\section{RESUMEN}

La taxonomía y la historia natural del género de hormiga Crematogaster se revisan para la la fauna de Costa Rica. Treintayuno especies son conocidas del pais, y una llave se proporciona para estos y dos especie adicional de regiones adyacentes de Panamá. Las definiciones de las especies se evalúan sobre su alcance entera cuando posible. La historia taxonómico del género es uno de denominar desenfrenado de las especies y subespecies nuevas, sin trabajo o llaves sintéticos. Se proponen cambios taxonómicos mayores, con el reconocimiento de varias especies politípicas con alcances muy anchas y la sinónimizacion de los muchos nombres asociados con ellas. Crematogaster pygmaea Forel 1904, suturalis Forel 1912, ornatipilis Wheeler 1918, erici Santschi 1929, y chacoana Santschi 1933 se sinónimizaron bajo abstinens Forel 1899; centralis Santschi 1932 bajo acuta (Fabricius 1804); aruga Forel 1913 bajo arcuata Forel 1899; ludio Forel 1912, armandi Forel 1921, inca Wheeler 1925, y cocciphila Borgmeier 1934 bajo brasiliensis Mayr 1878; parabiotica Forel 1904 bajo carinata Mayr 1862; brevispinosa Mayr 1870, minutior Forel 1893, schuppi Forel 1901, recurvispina Forel 1912, sampaioi Forel 1912, striatinota Forel 1912, townsendi Wheeler 1925, y chathamensis Wheeler 1933 bajo crinosa Mayr 1862; barbouri Weber 1934 bajo cubaensis Mann 1920; antillana Forel 1893, sculpturata Pergande 1896, kemali Santschi 1923, accola Wheeler 1934, phytoeca Wheeler 1934, panamana Wheeler 1942, y obscura Santschi 1929 bajo curvispinosa Mayr 1870; descolei Kusnezov 1949 bajo distans Mayr 1870; projecta Santschi 1925 bajo erecta Mayr 1866; carbonescens Forel 1913 bajo evallans Forel 1907; palans Forel 1912, ascendens Wheeler 1925, y dextella Santschi 1929 bajo limata F. Smith 1858; agnita Wheeler 1934 bajo obscurata Emery 1895; amazonensis Forel 1905, autruni Mann 1916, y guianensis Crawley 1916 bajo stollii Forel 1885; surdior Forel 1885, atitlanica Wheeler 1936, y maya Wheeler 1936 bajo sumichrasti Mayr 1870; tumulifera Forel 1899 y arizonensis Wheeler 1908 bajo torosa Mayr 1870. Se elevan las siguientes al nivel de especie: ampla Forel 1912, brevidentata Forel 1912, chodati Forel 1921, crucis Forel 1912, cubaensis Mann 1920, goeldii Forel 1903, malevolens Santschi 1919, mancocapaci Santschi 1911, moelleri Forel 1912, montana Borgmeier 1939, obscurata Emery 1895, rochai Forel 1903, russata Wheeler 1925, sericea Forel 1912, stigmatica Forel 1911, subtonsa Santschi 1925, tenuicula Forel 1904, thalia Forel 1911, uruguayensis Santschi 1912, y vicina Andre 1893. Se describieron las especies nuevas: bryophilia, flavomicrops, flavosensitiva, foliocrypta, jardinero, levior, monteverdensis, raptor, snellingi, sotobosque, y wardi. 
The genus Crematogaster is a widespread and distinctive lineage of myrmicine ants (Wheeler 1910, Forel 1928, Buren 1959, 1968, Hölldobler and Wilson 1990). Most species are tropical, where they form dominant elements of the arboreal fauna. Some species groups have crossed the frost line, radiating in temperate zones, where they more often nest in the ground and beneath stones (Wheeler 1906).

The genus as a whole is clearly monophyletic, with a unique and apomorphic arrangement of postpetiole and gaster. The gaster has a tear drop shape, pointed posteriorly, and the postpetiole attaches to the dorsal surface of the fourth abdominal tergite. Thus the gaster is suspended beneath the postpetiole rather than being clearly posterior to it. The petiole has no dorsal node, and when the gaster is elevated the petiole fits flush against the propodeum. This combination of characters is probably related to defensive or offensive behavior in which workers wave their gasters in the air, exuding a droplet of venom onto the spatulate sting (Buren 1959). Not all species exhibit this behavior (D. Davidson, pers. comm.) but most do. Workers are monomorphic or exhibit continuous size polymorphism, but there is no distinct major worker caste. The antennae are 11-segmented with the exception of one lineage of Asian and African species, in which there are 10 segments. The antennae have a terminal club of 2-4 segments. The propodeum usually has a pair of dorsal spines (lack of spines is rare among New World species), but otherwise the workers lack armor.

At the species level the genus can appear somewhat monotonous because there is little variation in major shape characters. Nevertheless species diversity is high, both within local communities and globally. Species differ in details of petiole and postpetiole shape, overall pilosity characteristics, and surface sculpture. Because the genus is a common and conspicuous element of most faunas, especially in the tropics, and varies both within and among regions, 889 available names have been generated (Bolton 1995). Nearly all of these have accumulated as unconnected species descriptions and there are very few synthetic works (Buren's 1968 review of North American Crematogaster s.s. a notable exception). Attempts have been made to recognize subgenera, but they are not well supported nor well defined. The high species diversity and lack of higher level taxonomic structure in the genus has made it one of the intractable messes in the world of ant taxonomy, on par with Solenopsis and Pheidole. It is a group generally avoided by students of systematics seeking manageable projects.

There is an increasing need to provide biodiversity maps for specific regions, and the impetus for this study is Costa Rica's biodiversity inventory (Gámez, 1991). In this study I revise the alpha taxonomy and review the biology of the Crematogaster fauna of Costa Rica. Although not a global revision, and although some species boundaries are not well defined beyond Costa Rica, I feel that a regional work such as this is a necessary and beneficial approach to understanding such large and complex lineages. 
Hillis (1988) recognized three phases in the history of taxonomic understanding of the Rana pipiens complex: (1) a typological phase when valid names increased; (2) a "biological species" phase marked by extensive synonymy under widespread polytypic species, marked by a decrease in the number of valid names; and (3) a "phylogenetic species" phase during which the polytypic species resolve into complex mosaics of discrete species, and the number of valid names increases again. Although I am not a proponent of the phylogenetic species concept, the empirical progression in number of valid names does reflect progress. Following the first wave of typological description, a reevaluation is justified in which many names are synonymized under large polytypic species. An available name is considered a synonym until proven distinct, rather than the reverse. Thus a synonymization is not a strong statement that two forms are part of the same biological species, which is an unprovable null hypothesis, but instead is an inability to reject the null hypothesis of conspecificity. Further investigation may discover character or geographic evidence of species differences and require a revalidation of the synonym. Large polytypic species with many synonyms are expected to resolve into multiple species when more data are at hand.

The regional (rather than global) approach taken here results in a hybrid of the second and third phases. Some species found in Costa Rica are recognized as members of widespread polytypic species, and extensive synonymy is proposed based on little more than an examination of the types. Within Costa Rica, more extensive collections allow a more thorough examination of character variation, and a number of discrete sympatric or parapatric forms are revealed. These are usually rare or geographically restricted and were overlooked in the early typological description phase. In the present work they are described as new species. Similar faunistic studies in other regions will probably yield similar results, by finding a set of common widespread species that already have names and a set of rare or geographically localized species that are new.

\section{Natural History Overview}

Crematogaster are often common ants, and they play a major ecological role in Neotropical forests. Colonies may be large, blanketing forest canopies, or small, contained within a single dead twig. Large colonies are usually polydomous, with multiple nests. Most species nest in dead wood, from narrow gauge hollow stems to large dead branches or trunks. One species, $C$. stollii, nests in live stems. Although major Crematogaster lineages in the Asian and African tropics are specialized plant ants, and at least one or two species are plant ants in the Amazonian region, none are known to be specialized plant ants in Costa Rica. Crematogaster bryophilia often nests under epiphyte mats. Although many species can make carton from masticated plant fibers, most use relatively small amounts to form partitions inside the nest or to restrict the opening of a nest in dead wood. Several Costa Rican species use carton more extensively. Crematogaster stollii makes carton galleries on 
tree trunks and branches, connecting their nests in the live branch tips. These carton galleries are indistinguishable from those of Azteca forelii, an ant species with similar nesting behavior, and both are very similar to the galleries of the arboreal termites that are so common in lowland forests. Crematogaster montezumia and C. arcuata make external carton nests that encircle small stems. These nests are plain carton, and lack epiphytes. In contrast, two Costa Rican species make carton nests that sprout epiphytes, forming ant gardens. Crematogaster longispina makes loose ant gardens on tree trunks (Kleinfeldt 1978), and $C$. jardinero lives in the high canopy, forming "archipelago" clusters of discrete ant gardens.

Although most species are arboreal, a few nest in the leaf litter. Species that nest in the leaf litter are usually yellow, nocturnal, and rarely encountered. One leaf litter species, $C$. sotobosque, is brown, forages diurnally on low vegetation, and is moderately abundant in lowland wet forest.

Most species are monogynous; a few are polygynous. Ergatogynes or intercastes have been reported for C. minutissima (Holliday 1903), C. minutissima smithi, and a species tentatively identified as C. curvispinosa (Heinze et al. 1998, Heinze et al. 1999). The Heinze et al. studies of smithi revealed that these intercastes, morphologically intermediate between workers and queens, function mainly to provide trophic eggs for the colony. They never perform foraging, maintenance, or defensive duties. They mainly lay eggs, most of which are eaten by larvae. The ergatogynes lack a spermatheca and cannot be inseminated, but their eggs are viable and produce males if left to develop. Among the Costa Rican fauna, ergatogynes are known to occur in C. bryophilia, C. curvispinosa, and C. nigropilosa. Nests are often found with only ergatogynes, workers, and brood. It is unknown whether these are colony fragments, with queenright nests elsewhere, or whole colonies founded by ergatogynes.

Two categories of queens occur among the Costa Rica fauna. In one group the propodeum is tall and narrow and drops very steeply from the scutellum (Fig. 1A), and sculpture and pilosity characters are similar to workers. I refer to these as "normal" queens. These species appear to have typical colony founding behavior, with standard nuptial flights and claustral colony founding by individual queens, and they are the most abundant species in communities. In another group the propodeum has a shallower slope and extends well beyond the scutellum (Fig. 1B), and sculpture and pilosity characters often differ greatly from workers. In particular, queens are often highly polished and shiny. Queens in this group also show varying degrees of development of falcate mandibles. Costa Rican species having these distinctive queens are acuta, arcuata, distans, evallans, jardinero, montezumia, and raptor. I refer to these as the "acuta-group." These are all very low density species, and very little is known of their colony founding behavior. The morphology is similar to other ant lineages that are known to be temporary social parasites (Forel 1928, Hölldobler and Wilson 1990). Queens of temporary social parasites insinuate themselves into nests of other species, killing or incapacitating the host queen, and use the heterospe- 
cific worker force to establish their own colony. Two anecdotal observations are consistent with temporary social parasitism as a colony founding mechanism in the acuta-group. I observed a mixed nest in which a queen of $C$. montezumia occurred in a small nest with workers of $C$. curvispinosa, and Adrienne Nicotra, a student working at La Selva Biological Station, observed a queen of $C$. raptor in a small queenright nest of $C$. carinata. These are the only such observations so far, and the colony founding behavior of acuta-group species is in need of investigation.

A

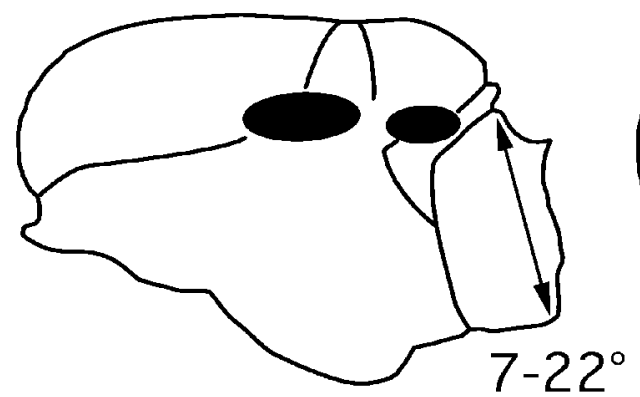

B

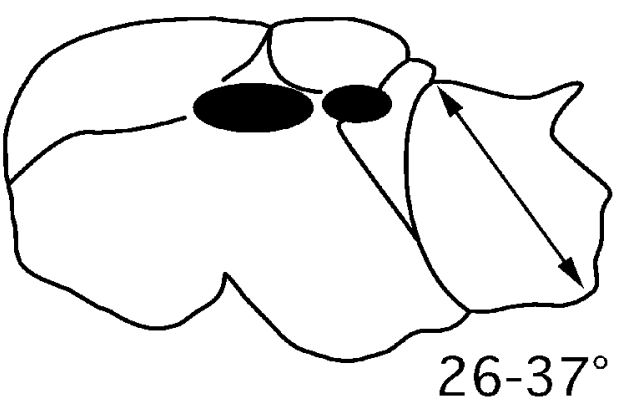

FIGURE 1. Lateral profiles of queen mesosoma, showing two categories of mesosoma shape. A. "Normal" queen with narrow, vertically oriented propodeum. B. "acuta-group" queen with broader, more obliquely sloping propodeum. Degree of propodeal slope is measured as the difference from perpendicular for a line drawn from the propodeal suture to the posterolateral propodeal lobe, when mesonotum and scutellum are roughly horizontal. Degree ranges are for 20 species with normal queens and seven acuta-group species.

Most species of Crematogaster, especially those with large polydomous colonies, are aggressive and territorial. Crematogaster carinata is exceptional in having large polydomous and polygynous colonies that overlap with many other ant species. Workers are not aggressive and may even share the same nest structures with other species. Forel (1898) observed C. carinata (as C. limata parabiotica) and Dolichoderus debilis Emery inhabiting the same nest in Colombia, and coined the term parabiosis to describe the phenomenon of mutual nest sharing. In Costa Rica, $C$. carinata can be found coinhabiting ant gardens with Odontomachus panamensis Forel and sharing nest space with $D$. debilis or D. inermis Mackay. The nesting behavior and taxonomic uncertainties in the complex are further discussed under the $C$. carinata species account. Crematogaster limata may also exhibit an ability to overlap non-aggressively with other species because it has been observed in close association with the large tropical ponerine ant Ectatomma tuberculatum (Olivier) (Wheeler 1986).

Crematogaster appear to be very generalized and omnivorous foragers. Individual scouts search for resources and recruit nestmates when resources are encountered. They rapidly recruit to baits of sugar or protein (e.g., tuna, dead insects). Although rarely preda- 
tors of active prey, I have often seen them attacking pupae or otherwise immobilized live prey. They readily tend Homoptera, and species vary in the degree of reliance on Homoptera. Crematogaster stollii appears to rely entirely on Homoptera and perhaps cryptic plant resources. Workers are found only inside of live stems or under their carton galleries and they never forage on the surface. Their chambers in live stems are packed with Coccoidea that are feeding from the inside of the stems. This phenomenon, in which ants live and feed entirely within live plant stems, with no external patrolling by the ants and no obvious myrmecophytic adaptations on the plant's part, has evolved convergently in several ant lineages, including species of Azteca and Myrmelachista.

In Costa Rica, Crematogaster are abundant in all lowland habitats. In mangroves, $C$. crinosa is often a dominant species. In lowland dry or wet forest sites, a community of over 15 species may occur. These are concentrated in second growth vegetation, forest edges, and forest canopy. Relatively few species are found in wet forest understory and forest floor litter. At higher elevations the dominant Crematogaster drop out by about 500 to $1000 \mathrm{~m}$, depending on the openness of the habitat. A few species, such as C. bryophilia, C. moelleri, and C. sumichrasti, are montane forest specialists that are more common at mid elevations than at sea level.

\section{METHODS}

Observations were made at 50x or 63x magnification with a dissecting microscope. Most measurements were made with a micrometer stage with digital output in increments of $0.0001 \mathrm{~mm}$. However, variation in specimen orientation, alignment of crosshairs with edges of structures, and interpretation of structure boundaries resulted in measurement accuracy to the nearest 0.01 to $0.005 \mathrm{~mm}$, depending on sharpness of the defined boundary (e.g., head width is measured more precisely than Weber's length because the latter requires the somewhat subjective choice of inflection point at the anterior pronotal projection). All measurements are presented in $\mathrm{mm}$. Three workers were measured for each species. An attempt was made to select a small, medium, and large worker, based on the entire geographic range of the species, and each from a different nest series. Dimensions of antennal segments were measured for only one specimen; other measurements were made for all three workers. Each species account has a measurement list in which each measurement acronym is followed by the three values for the three workers, in order, such that measurements for individual workers can be reconstructed. Antennal segment dimensions, which have only one value, are for the first worker in the sequence. Measurements are also provided for holotypes. One queen for each species, when available, was measured for head length and head width.

The following terminology and abbreviations are used (Fig. 2):

HL: head length; perpendicular distance from line tangent to rearmost points of vertex margin to line tangent to anteriormost projections of clypeus, in full face view. 
HW: head width; maximum width of head in face view, including eyes if they project beyond the sides of the head.

HC: head capsule width; maximum width of head in full-face view, excluding eyes; may be anterior or posterior to eyes.

SL: scape length; length of scape shaft from apex to basal flange, not including basal condyle and neck.
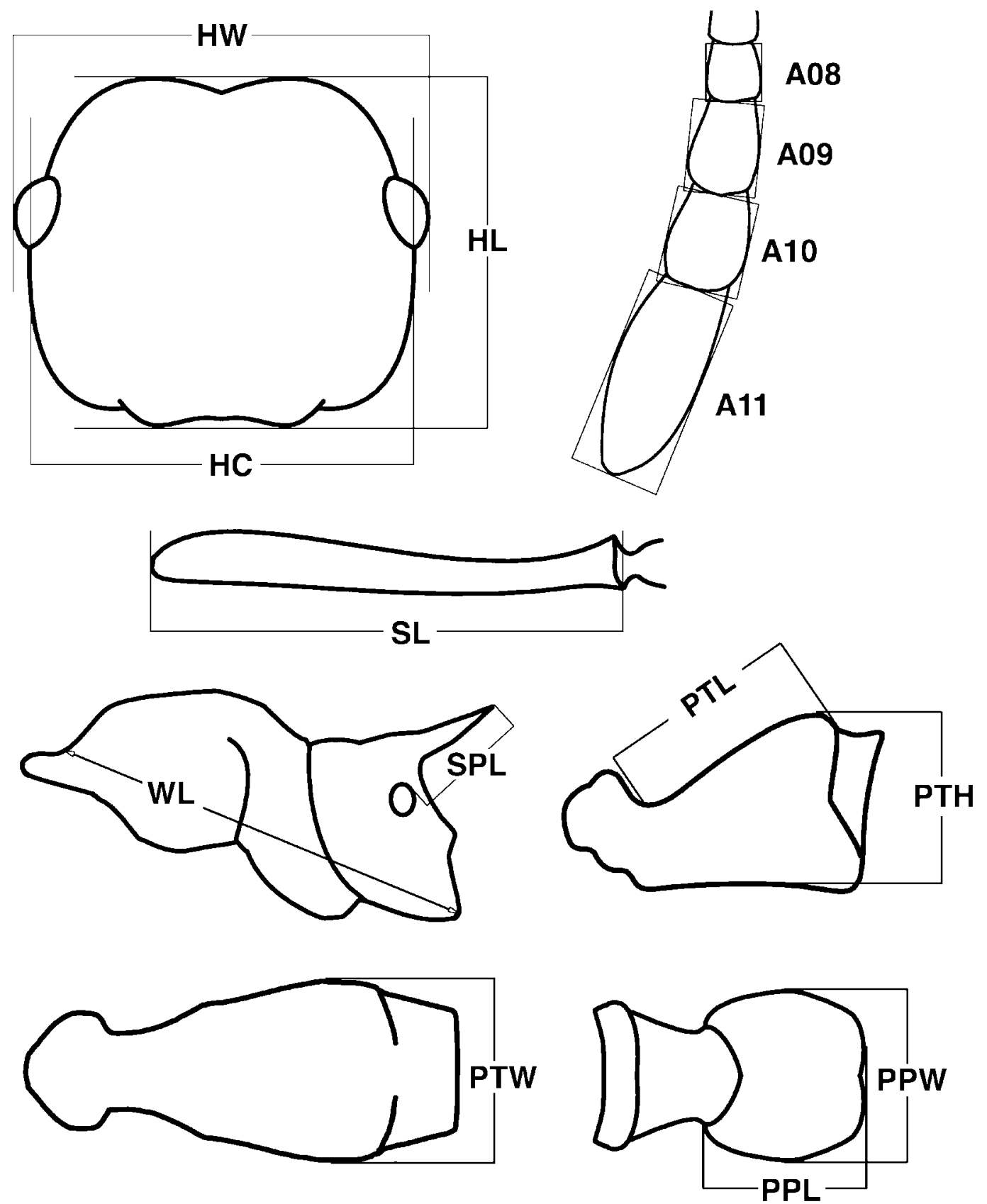

FIGURE 2. Standard measurements of Crematogaster workers. See text for definitions. 
EL: eye length, measured along maximum diameter.

A11L, A10L, A09L, A08L: length of 11 th to 8th antennal segment.

A11W, A10W, A09W, A08W: width of 11th to 8th antennal segment.

WL: Weber's length; viewing mesosoma in lateral profile, distance from approximate inflection point, where downward sloping pronotum curves into anteriorly projecting neck, to posteroventral propodeal lobes.

SPL: propodeal spine length; measured from tip of propodeal spine to closest point on outer rim of propodeal spiracle.

PTH: petiole height; viewed in lateral profile, perpendicular distance from ventral margin to highest point of posterolateral tubercles; if ventral margin is concave upward, measured from line tangent to uppermost portion of curve and oriented as close as possible to long axis of petiole.

PTL: petiole length; viewed in lateral profile and measured in same plane as anterodorsal face, distance from inflection point marking juncture of posterolateral lobes and cylindrical posterior portion of segment to anterior inflection point where petiole curves up to condyle or, if inflection point not visible, where petiole is obscured by posteroventral lobes of propodeum.

PTW: petiole width; maximum width of petiole in dorsal view.

PPL: postpetiole length; viewing at an angle that maximizes length (approximately parallel to fourth abdominal tergite), perpendicular distance from line tangent to anterior inflection point (narrowest point when postpetiole is hourglass-shaped where it joins the helcium, point immediately anterior to node when helcium is sharply differentiated from node as a distinct cylindrical stem) to line tangent to posteriormost lobes if bilobed, to posteriormost point if globular.

PPW: postpetiole width; maximum width of postpetiole, in same view as and perpendicular to postpetiole length.

CI: cephalic index; $100 * \mathrm{HW} / \mathrm{HL}$.

OI: ocular index; $100 * \mathrm{EL} / \mathrm{HL}$.

SI: scape index; $100 * \mathrm{SL} / \mathrm{HL}$.

SPI: propodeal spine index; $100 *$ SPI/WL.

PTHI: petiole height index; $100 *$ PTH/PTL.

PTWI: petiole width index; 100*PTW/PTL.

PPI: postpetiole width index; 100*PPW/PPL.

ACI: antennal club index;

$$
\frac{A 10 L \bullet A 10 W}{A 09 L \bullet A 09 W}-\frac{A 09 L \bullet A 09 W}{A 08 L \bullet A 08 W}
$$

This index attempts to quantify the degree of distinctness of the club. The product of segment length and width is a proxy of overall segment size, and the index measures relative change in size from segment 10 to 9 compared to relative change from 9 to 8 . A 
sharply differentiated two-segmented club will have segment 10 much larger than 9, and segment 9 about the same size as 8 , and the index will be greater than zero. A club in

which segments 10 to 8 gradually decrease in size will have similar first and second terms in the formula, and the index value will be near zero. A distinctly 3 -segmented club will have a value less than zero.

Collections are referred to by the following acronyms:

BMNH: The Natural History Museum, London, U.K.

INBC: Instituto Nacional de Biodiversidad, Costa Rica.

DEIC: Deutsches Entomologisches Institut, Eberswalde Finow, Germany.

JTLC: John T. Longino, personal collection, Olympia, WA, USA.

LACM: Los Angeles County Museum of Natural History, Los Angeles, CA, USA.

MCSN: Museo Civico de Storia Naturale "Giacomo Doria," Genoa, Italy.

MCZC: Museum of Comparative Zoology, Cambridge, MA, USA.

MHNG: Muséum d'Histoire Naturelle, Geneva, Switzerland.

MIZA: Museo del Instituto de Zoologia Agricola, Universidad Central de Venezuela, Maracay, Venezuela.

MZSP: Museu de Zoologia da Universidade de São Paulo, São Paulo, Brazil.

NHMB: Naturhistorisches Museum, Basel, Switzerland.

NMW: Naturhistorisches Museum, Vienna, Austria.

UCDC: University of California, Davis, CA, USA.

USNM: National Museum of Natural History, Washington, DC, USA.

ZMUC: Zoological Museum, University of Copenhagen, Denmark.

ZSMC: Zoologische Staatssammlung, Munich, Germany.

Lectotypes are designated from syntype series whenever doing so improves nomenclatural stability. All new species names in this work are nouns in aposition and thus invariant, in spite of any appearance or etymological comments that suggest otherwise. Traditional "Material Examined" lists are not provided with each species account, with the expectation that researchers will increasingly rely on electronic databases for specimenlevel details of collection data, repository, and determination history. The specimen list on which this particular study was based will be made avaliable on the Ants of Costa Rica website (www.evergreen.edu/ants). Table 1 provides a geographical summary of the material examined for this survey and augments the brief range description provided in each species account. All holotypes and paratypes associated with the new species described here have unique specimen-level identifiers affixed to each pin, and these specimen codes are listed in each species description. These are not to be confused with collection codes, which are "lot numbers" associated with particular collection events. Many different specimens may share the same collection code. 
TABLE 1. Geographic distribution of material examined for this study. Cell contents are number of collection events (collection codes) in a specimen database. Collection events may be single nest series, or a mixed series from a spatially and temporally restricted ecological sample (e.g., ants collected in a treefall, ground foragers from a day's collecting at one site, Winkler samples, Berlese samples, canopy fogging samples, a two-week Malaise sample). This table does not contain the full quantitative data set for La Selva Biological Station (Table 2).

\begin{tabular}{|c|c|c|c|c|c|c|c|c|c|c|c|c|c|c|c|}
\hline & & & & & \\
\hline Argentina & & & & & & 2 & & & & & & & & & \\
\hline Belize & & & & & & 6 & & & & & & & & & \\
\hline Bolivia & & & & & & & & & & & & & & & \\
\hline Beni & & 1 & & 4 & 6 & & & & & & & & & 3 & \\
\hline La Paz & & 1 & & 3 & & 1 & 1 & & & & & & & & \\
\hline Pando & & & & & & 1 & & & & & & & & & \\
\hline Santa Cruz & 1 & & 2 & & 1 & & & & & & & & & & 1 \\
\hline unknown & & 1 & & & & & & & & & & & & & \\
\hline Brazil & & & & & & & & & & & & & & & \\
\hline Acre & & & & 1 & & & & & & & & & & & \\
\hline Amapá & & & & & & & & & & & & & & & \\
\hline Amazonas & & 3 & & 11 & 1 & 1 & & 1 & 2 & & 2 & 3 & & 2 & 4 \\
\hline Bahia & 1 & 1 & & & & & 1 & & 1 & & & & & & 1 \\
\hline Ceará & & & & & & & & & & & & & & & \\
\hline Esp. Sant. & & & 1 & & & & & & & & & & & & \\
\hline Goias & & & & & & & 1 & & & & & & & & \\
\hline M. Grosso & 1 & & & & & 1 & & & & & & & & & \\
\hline M. Gerais & & & & & & & & & & & & & & & \\
\hline Pará & 1 & & & 2 & & 4 & 2 & 2 & 5 & & & & & 3 & 1 \\
\hline R. de Jan. & & & & & 1 & & & & & 1 & & & & & \\
\hline R. G. Nor. & & & & & & & & & & & & & & & \\
\hline R. G. Sul & & & & & & 1 & & & & & & & & & \\
\hline Rondônia & & 1 & & 1 & & & & & & & & & & & \\
\hline S. Catar. & & 2 & & & & & & & & & & & & & 1 \\
\hline São Paulo & & & 1 & & & & & 1 & & & & & & & \\
\hline unknown & & & & & & & & & & & & & & & \\
\hline Colombia & & & & & & & & & & & & & & & \\
\hline Antioquia & & & & & & 3 & 4 & 1 & & & & & & & 1 \\
\hline Atlántico & & & & & & 1 & & & & & & & & & \\
\hline Caquetá & & & & & & & & & & & & & & 1 & \\
\hline Casanare & 3 & & & & & & & & & & & & & & \\
\hline Cauca & & & & & & & 2 & & & & 2 & & & & \\
\hline Cesar & & & & & & 3 & 1 & & 1 & & & & & & \\
\hline Choco & & & 1 & 1 & 1 & & & & & & & & & & \\
\hline Cundinam. & & & & & & 1 & & & 1 & & & & & & 2 \\
\hline Guajira & & & & & & 2 & & & & & & & & & \\
\hline Huila & 4 & 1 & 1 & & 3 & 3 & 3 & 1 & & 4 & & & & & 1 \\
\hline
\end{tabular}

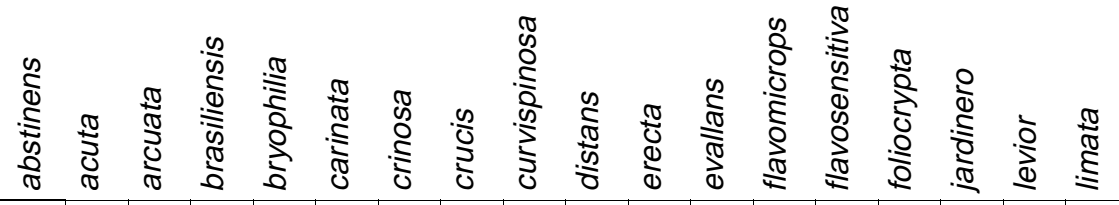


TABLE 1 (continued)

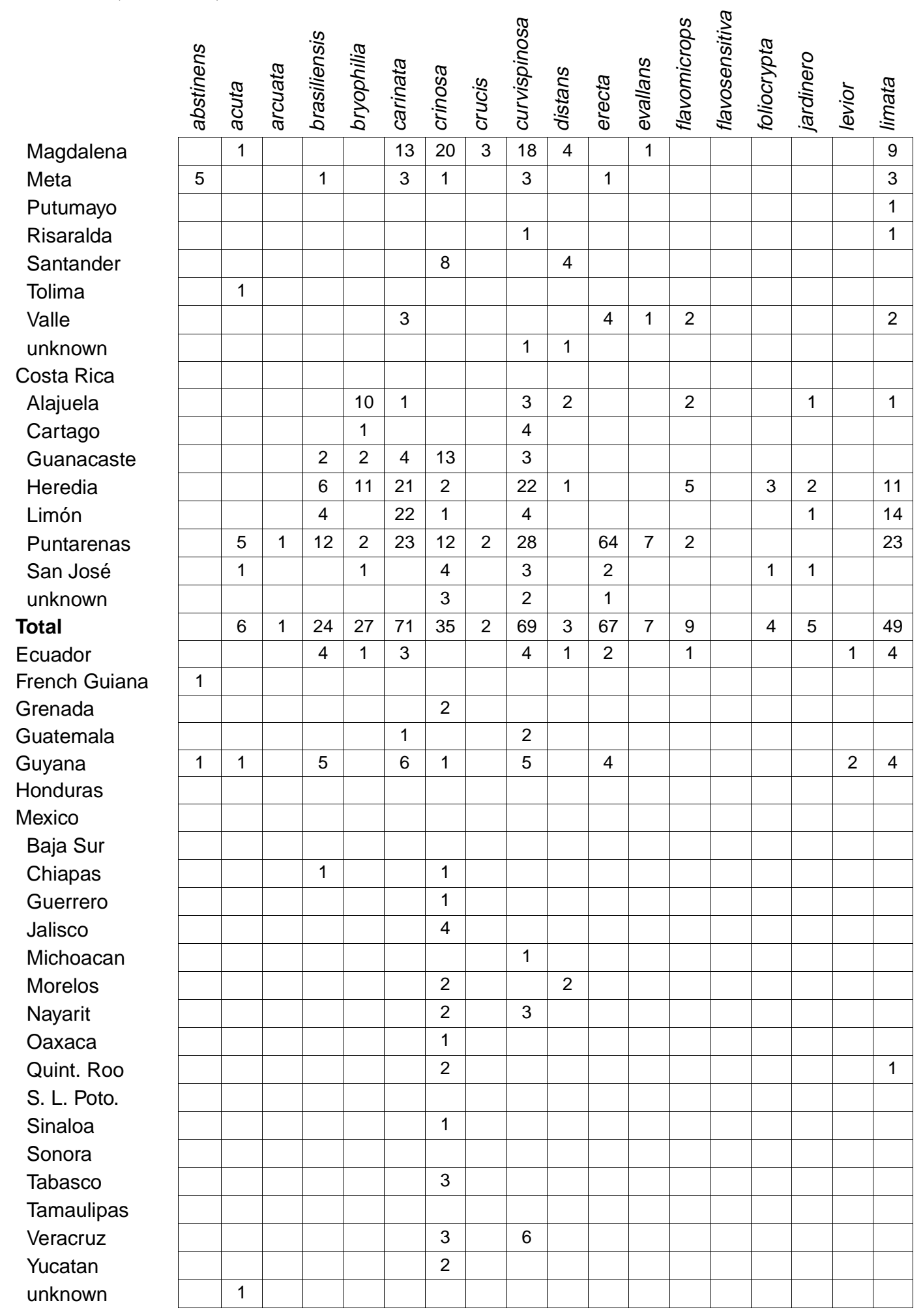

Magdalena

Meta

Putumayo

valle

unknown

Costa Rica

Alajuela

Cartago

Guanacaste

Puntarenas

San José

unknown

Tota

unador

Guyana

Honduras

Mexico

Jalisco

Michoacan

Morelos

Nayarit

Oaxaca

Tabasco

Tamaulipas

Veracruz

unknown 


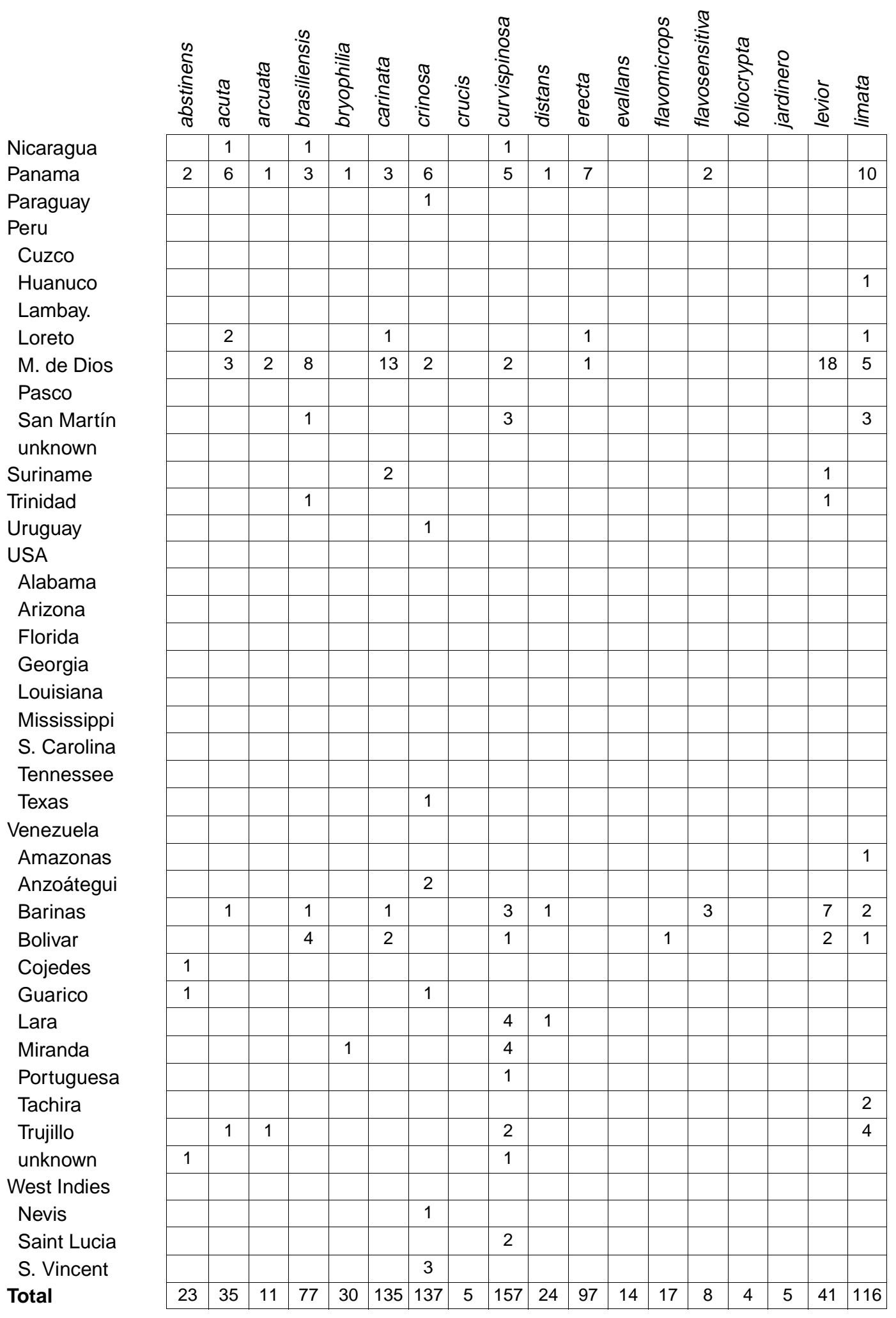


TABLE 1 (continued)

\begin{tabular}{|c|c|c|c|c|c|c|c|c|c|c|c|c|c|c|c|c|c|}
\hline & $\begin{array}{l}\frac{2}{2} \\
\frac{2}{2} \\
\frac{2}{2} \\
\frac{2}{2}\end{array}$ & 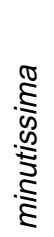 & 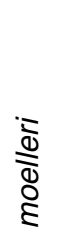 & 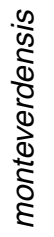 & 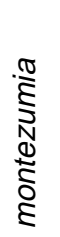 & 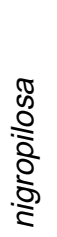 & 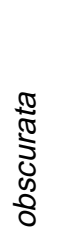 & $\frac{\grave{0}}{\frac{\pi}{2}}$ & $\begin{array}{l}\bar{d} \\
\frac{\delta}{d}\end{array}$ & $\begin{array}{l}\text { के } \\
\text { के } \\
\text { क }\end{array}$ & 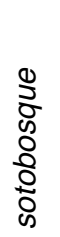 & $\begin{array}{l}: \equiv \\
\frac{9}{\omega}\end{array}$ & 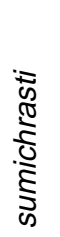 & 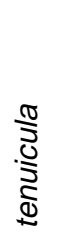 & 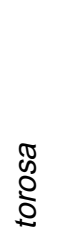 & $\frac{\sqrt{2}}{3}$ & Total \\
\hline \multirow{8}{*}{$\begin{array}{l}\text { Argentina } \\
\text { Belize } \\
\text { Bolivia } \\
\text { Beni } \\
\text { La Paz } \\
\text { Pando } \\
\text { Santa Cruz } \\
\text { unknown }\end{array}$} & & & & & 2 & & & & 6 & & & & & & 1 & & 11 \\
\hline & & & & & & & 2 & & & & & & 1 & & & & 9 \\
\hline & & & & & & & & & & & & & & & & & \\
\hline & & & & & & & & & & & & 1 & & & & & 15 \\
\hline & & & & & & 1 & & & 1 & & & & & & & & 8 \\
\hline & & & & & & & & & & & & & & & & & 1 \\
\hline & & & & & & & & & 2 & & & & & 1 & 3 & & 11 \\
\hline & & & & & & & & & & & & & & & & & 1 \\
\hline \multicolumn{18}{|l|}{ Brazil } \\
\hline \multirow{7}{*}{$\begin{array}{l}\text { Acre } \\
\text { Amapá } \\
\text { Amazonas } \\
\text { Bahia } \\
\text { Ceará } \\
\text { Esp. Sant. } \\
\text { Goias }\end{array}$} & & & & & & & & & & & & & & & & & 1 \\
\hline & & & & & & & & & & & & 1 & & & & & 1 \\
\hline & & & & & & 1 & & & & & 2 & 3 & & 5 & 1 & & 42 \\
\hline & & & & & & 1 & & & & & & & & & & & 6 \\
\hline & & & & & & & & & 1 & & & & & & & & 1 \\
\hline & & & & & & & & & & & & & & & & & 1 \\
\hline & & & & & & & & & & & & & & & & & 1 \\
\hline \multirow{3}{*}{$\begin{array}{l}\text { M. Grosso } \\
\text { M. Gerais } \\
\text { Pará }\end{array}$} & & & & & 1 & & & & 2 & & & & & & 1 & & 6 \\
\hline & & & & & & & & & 1 & & & & & & & & 1 \\
\hline & & & & & & 1 & & & 1 & & 1 & 1 & & 2 & & & 26 \\
\hline \multirow{2}{*}{$\begin{array}{l}\text { R. de Jan. } \\
\text { R. G. Nor. }\end{array}$} & & & & & & & & & & & & & & & & & 2 \\
\hline & & & & & & & & & 2 & & & & & & & & 2 \\
\hline \multirow{2}{*}{$\begin{array}{l}\text { R. G. Sul } \\
\text { Rondônia }\end{array}$} & & & & & 1 & & & & & & & & & & & & 2 \\
\hline & & & & & & 1 & & & & & & 2 & & 1 & & & 6 \\
\hline \multirow{3}{*}{$\begin{array}{l}\text { S. Catar. } \\
\text { São Paulo } \\
\text { unknown }\end{array}$} & & & 2 & & 2 & & & & & & & & & & & & 7 \\
\hline & & & & & & & & & & & & & & & & & 2 \\
\hline & & & & & 1 & & & & & & & & & & & & 1 \\
\hline \multicolumn{18}{|l|}{ Colombia } \\
\hline \multirow{2}{*}{$\begin{array}{l}\text { Antioquia } \\
\text { Atlántico }\end{array}$} & & & & & & & & & & & & & & & & & 9 \\
\hline & & & & & & & & & & & & & & & & & 1 \\
\hline \multirow{2}{*}{$\begin{array}{l}\text { Caquetá } \\
\text { Casanare }\end{array}$} & & & & & & & & & & & & & & & & & 1 \\
\hline & & & & & & & & & & & & & & & & & 3 \\
\hline Cauca & & & & & & & & & & & & 2 & & & & & 6 \\
\hline \multirow{4}{*}{$\begin{array}{l}\text { Cesar } \\
\text { Choco } \\
\text { Cundinam. } \\
\text { Guajira }\end{array}$} & & & & & & & & & & & & & & & & & 5 \\
\hline & & & & & & & & & & & 1 & & & & & & 4 \\
\hline & & & & & & 3 & & & & & & & & & & & 7 \\
\hline & & & & & & & & & 1 & & & & & & & & 3 \\
\hline \multirow{5}{*}{$\begin{array}{l}\text { Huila } \\
\text { Magdalena } \\
\text { Meta } \\
\text { Putumayo } \\
\text { Risaralda }\end{array}$} & & & & & & 3 & & & 5 & & & 1 & & & 8 & & 38 \\
\hline & & & & & 5 & 6 & & & 9 & & & & & & 1 & & 90 \\
\hline & & & & & & 1 & & & 3 & & & & & & 1 & & 22 \\
\hline & & & & & & & & & & & & & & & & & 1 \\
\hline & & & & & & & & & & & 2 & & & & & & 4 \\
\hline
\end{tabular}




\begin{tabular}{|c|c|c|c|c|c|c|c|c|c|c|c|c|c|c|c|c|c|}
\hline & $\begin{array}{c}\frac{0}{2} \\
\frac{2}{2} \\
\frac{2}{2} \\
0\end{array}$ & 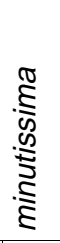 & 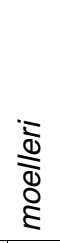 & 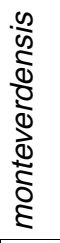 & 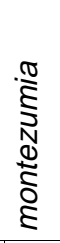 & 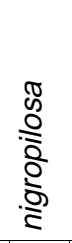 & 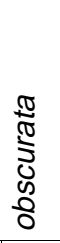 & ț & 胥 & ळ & \begin{tabular}{l}
0 \\
\multirow{2}{0}{} \\
$\infty$ \\
0 \\
0 \\
0 \\
0 \\
क
\end{tabular} & $\frac{\vdots}{\text { ஸ }}$ & 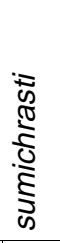 & 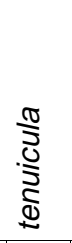 & 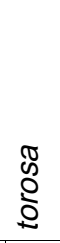 & 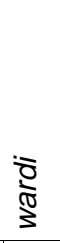 & Total \\
\hline \multirow{5}{*}{$\begin{array}{l}\text { Santander } \\
\text { Tolima } \\
\text { Valle } \\
\text { unknown } \\
\text { Costa Rica }\end{array}$} & & & & & & & & & 1 & & & & & & & & 13 \\
\hline & & & & & & 1 & & & & & & & & & & & 2 \\
\hline & & & & & & 3 & & & & & & & & & 2 & & 17 \\
\hline & & & & & & & & & & & & & & & & & 2 \\
\hline & \multicolumn{17}{|c|}{ Costa Rica } \\
\hline Alajuela & 1 & & & & & 9 & & & 1 & 5 & & & & & 1 & & 37 \\
\hline \multirow{7}{*}{$\begin{array}{l}\text { Cartago } \\
\text { Guanacaste } \\
\text { Heredia } \\
\text { Limón } \\
\text { Puntarenas } \\
\text { San José } \\
\text { unknown }\end{array}$} & 1 & & & & & 2 & & & & 1 & & & & & 1 & & 10 \\
\hline & 2 & 1 & & 4 & & 1 & 2 & & 6 & 1 & & 1 & & & 18 & & 60 \\
\hline & 12 & & 2 & & 2 & 15 & & 1 & & 3 & 18 & & 2 & & 5 & 7 & 151 \\
\hline & 10 & & & & & 4 & & 2 & & & 4 & & 1 & & 1 & & 68 \\
\hline & & & 3 & 3 & 1 & 30 & & 4 & 12 & 7 & 6 & 25 & 2 & 28 & 39 & 2 & 343 \\
\hline & 4 & & & & & 4 & & & & & 1 & & 4 & & 4 & 1 & 31 \\
\hline & & & & & 1 & 1 & & & 2 & & & & 2 & & 1 & & 13 \\
\hline \multirow{3}{*}{$\begin{array}{l}\text { Total } \\
\text { Ecuador } \\
\text { French Guiana }\end{array}$} & 30 & 1 & 5 & 7 & 4 & 66 & 2 & 7 & 21 & 17 & 29 & 26 & 11 & 28 & 70 & 10 & 713 \\
\hline & 1 & & & & 1 & 4 & & & & & 1 & 2 & & & & & 30 \\
\hline & & & & & & & & & & & & & & 1 & & & 2 \\
\hline \multirow{5}{*}{$\begin{array}{l}\text { Grenada } \\
\text { Guatemala } \\
\text { Guyana } \\
\text { Honduras } \\
\text { Mexico }\end{array}$} & & & & & & & & & & & & & & & & & 2 \\
\hline & & & & & & & 4 & & & & & 1 & 2 & & 3 & & 13 \\
\hline & & & & & & 1 & & & 6 & & & 2 & & 7 & 1 & & 46 \\
\hline & & & & & & & & & & & & & & & 2 & & 2 \\
\hline & & & & & & & & & & & & & & & & & \\
\hline \multirow{2}{*}{$\begin{array}{l}\text { Baja Sur } \\
\text { Chiapas }\end{array}$} & & & & & & & & & & & & & & & 6 & & 6 \\
\hline & & & & & & & & & & & & & & & 1 & & 3 \\
\hline $\begin{array}{l}\text { Cniapas } \\
\text { Guerrero }\end{array}$ & & & & & & & & & & & & & & & & & 1 \\
\hline \multirow{3}{*}{$\begin{array}{l}\text { Jalisco } \\
\text { Michoacan } \\
\text { Morelos }\end{array}$} & & & & & & & & & 1 & & & & 3 & & 8 & & 16 \\
\hline & & & & & & & & & & & & & & & 1 & & 2 \\
\hline & & & & & & & & & 1 & & & & & & 2 & & 7 \\
\hline Nayarit & & & & & & & & & 1 & & & & 1 & & 1 & & 8 \\
\hline \multirow{2}{*}{$\begin{array}{l}\text { Oaxaca } \\
\text { Quint. Roo }\end{array}$} & & & & & & & 1 & & & & & & & & & & 2 \\
\hline & & & & & & & & & & & & & & & & & 3 \\
\hline \multirow{2}{*}{$\begin{array}{l}\text { S. L. Poto. } \\
\text { Sinaloa }\end{array}$} & & & & & & & & & & & & & & & 1 & & 1 \\
\hline & & & & & & & & & & & & & & & 3 & & 4 \\
\hline \multirow{2}{*}{$\begin{array}{l}\text { Sonora } \\
\text { Tabasco }\end{array}$} & & & & & & & & & & & & & & & 6 & & 6 \\
\hline & & & & & & & & & & & & & & & & & 3 \\
\hline $\begin{array}{l}\text { Iabasco } \\
\text { Tamaulipas }\end{array}$ & & 1 & & & & & & & & & & & & & 4 & & 5 \\
\hline \multirow{3}{*}{$\begin{array}{l}\text { Veracruz } \\
\text { Yucatan } \\
\text { unknown }\end{array}$} & & 1 & & & 1 & & & & & & & & 4 & & 3 & & 18 \\
\hline & & & & & & & & & & & & & & & 2 & & 4 \\
\hline & & & & & & & & & & & & & & & & & 1 \\
\hline \multirow{3}{*}{$\begin{array}{l}\text { Nicaragua } \\
\text { Panama } \\
\text { Paraguay }\end{array}$} & 1 & & & & & 1 & & & & & & & & & & & 5 \\
\hline & & & & & & 4 & & & 2 & & 2 & 5 & & 2 & 3 & & 65 \\
\hline & & & & & & & & & & & & & & & 1 & & 2 \\
\hline
\end{tabular}


TABLE 1 (continued)

\begin{tabular}{|c|c|c|c|c|c|c|c|c|c|c|c|c|c|c|c|c|c|}
\hline & $\begin{array}{l}\frac{5}{2} \\
\frac{2}{9} \\
\frac{2}{2} \\
\frac{1}{2}\end{array}$ & 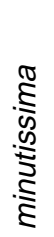 & $\begin{array}{l}\bar{\vdots} \\
\text { ఏ } \\
\vdots\end{array}$ & 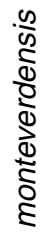 & 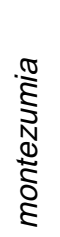 & 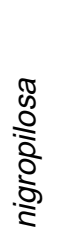 & 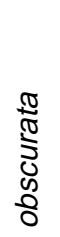 & $\frac{\grave{0}}{\frac{\pi}{2}}$ & 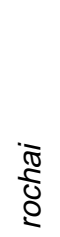 & ప্ & \begin{tabular}{l}
0 \\
\multirow{0}{0}{} \\
ஜ \\
0 \\
0 \\
0 \\
0 \\
क
\end{tabular} & $\frac{\vdots}{\text { 心 }}$ & 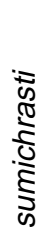 & 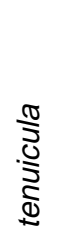 & 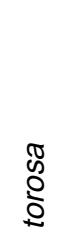 & 胥 & Total \\
\hline \multicolumn{18}{|l|}{ Peru } \\
\hline \multirow{4}{*}{$\begin{array}{l}\text { Cuzco } \\
\text { Huanuco } \\
\text { Lambay. } \\
\text { Loreto }\end{array}$} & & & & & & 1 & & & & & & & & & & & 1 \\
\hline & & & & & & 1 & & & & & 1 & & & & & & 3 \\
\hline & & & & & & & & & & & & & & & 1 & & 1 \\
\hline & & & & & & & & & & & & & & 1 & & & 6 \\
\hline \multirow{4}{*}{$\begin{array}{l}\text { M. de Dios } \\
\text { Pasco } \\
\text { San Martín } \\
\text { unknown }\end{array}$} & & & & & & 4 & & & & & 4 & 3 & & & 1 & & 66 \\
\hline & & & & & & 1 & & & & & 1 & & & & & & 2 \\
\hline & & & & & & & & & & & & 1 & & 3 & & & 11 \\
\hline & & & & & & & & & 1 & & & & & & & & 1 \\
\hline \multirow{4}{*}{$\begin{array}{l}\text { Suriname } \\
\text { Trinidad } \\
\text { Uruguay } \\
\text { USA }\end{array}$} & & & & & & & & & & & & & & & & & 3 \\
\hline & & & & & & & & & & & & & & & & & 2 \\
\hline & & & & & & & & & & & & & & & & & 1 \\
\hline & & & & & & & & & & & & & & & & & \\
\hline \multirow{2}{*}{$\begin{array}{l}\text { Alabama } \\
\text { Arizona }\end{array}$} & & 2 & & & & & & & & & & & & & & & 2 \\
\hline & & & & & & & & & & & & & & & 11 & & 11 \\
\hline \multirow{2}{*}{$\begin{array}{l}\text { Florida } \\
\text { Georgia }\end{array}$} & & 7 & & & & & & & & & & & & & & & 7 \\
\hline & & 1 & & & & & & & & & & & & & & & 1 \\
\hline & 3 & & & & & & & & & & & & & & & 3 \\
\hline \multicolumn{2}{|l|}{ Mississippi } & 1 & & & & & & & & & & & & & & & 1 \\
\hline \multicolumn{2}{|l|}{ S. Carolina } & 1 & & & & & & & & & & & & & & & 1 \\
\hline \multicolumn{2}{|l|}{ Tennessee } & 2 & & & & & & & & & & & & & & & 2 \\
\hline \multicolumn{2}{|l|}{ Texas } & 1 & & & & & & & & & & & & & 22 & & 24 \\
\hline \multicolumn{18}{|l|}{ Venezuela } \\
\hline \multirow{2}{*}{$\begin{array}{l}\text { Amazonas } \\
\text { Anzoátequi }\end{array}$} & & & & & & & & & & & & & & & & & 1 \\
\hline & & & & & & & & & 1 & & & & & & & & 3 \\
\hline Barinas & & & & & & 5 & & & & & & & & & & & 24 \\
\hline \multirow{2}{*}{$\begin{array}{l}\text { Bolivar } \\
\text { Cojedes }\end{array}$} & & & & & & & & & & & 1 & 1 & & 1 & & & 14 \\
\hline & & & & & & & & & & & & & & & & & 1 \\
\hline Guarico & & & & & & & & & 1 & & & & & & & & 3 \\
\hline \multirow{2}{*}{$\begin{array}{l}\text { Lara } \\
\text { Miranda }\end{array}$} & & & & & & 3 & & & & & & & & & & & 8 \\
\hline & & & & & & 1 & & & & & & & & & & & 6 \\
\hline \multirow{2}{*}{$\begin{array}{l}\text { Portuguesa } \\
\text { Tachira }\end{array}$} & & & & & & & & & & & & & & & & & 1 \\
\hline & & & & & & & & & & & & & & & & & 2 \\
\hline \multirow{2}{*}{$\begin{array}{l}\text { Trujillo } \\
\text { unknown }\end{array}$} & & & & & & & & & & & & & & & 1 & & 9 \\
\hline & & & & & & 1 & 1 & & & & & & & & & & 4 \\
\hline \multicolumn{18}{|l|}{ West Indies } \\
\hline Nevis & & & & & & & & & & & & & & & & & 1 \\
\hline Saint Lucia & & & & & & & & & & & & & & & & & 2 \\
\hline S. Vincent & & & & & & & & & & & & & & & & & 3 \\
\hline Total & 32 & 21 & 7 & 7 & 18 & 115 & 10 & 7 & 70 & 17 & 45 & 52 & 22 & 52 & 172 & 10 & 1593 \\
\hline
\end{tabular}


The terminal segments of the antenna are enlarged to form the antennal club. The club may be composed of the terminal two segments and sharply differentiated from segments eight and nine, or it may be composed of the terminal three or four segments, which gradually decrease in size. Although the number of segments in the club has been used as a subgeneric character (Santschi 1918), I find continuous interspecific variation (Figure 3) that does not correlate with other characters, and I do not use the character in the key.

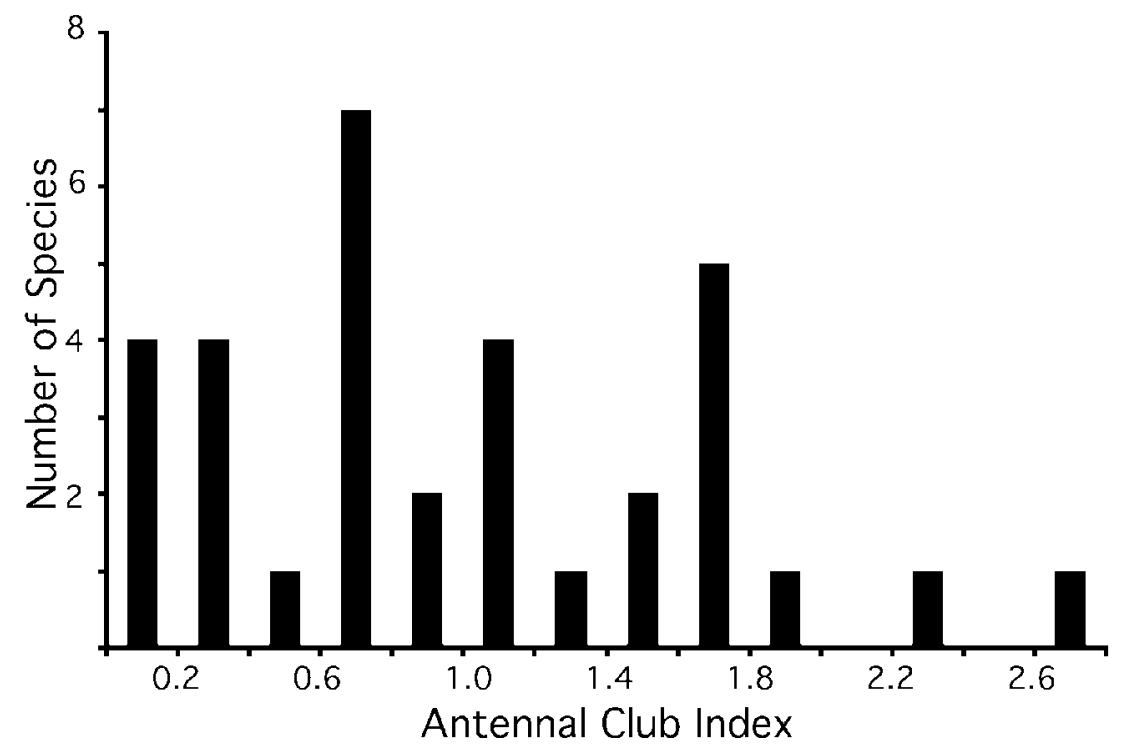

FIGURE 3. Variation in distinctness of antennal club among Costa Rican species. Distinctness of club varies continuously from a distinctly 3 -segmented club (low index values) to a sharply 2 -segmented club (high index values). See individual species accounts for index values for each species.

The petiole varies greatly in shape and seems to be one of the most useful characters for differentiating clusters of species (Plates 1-3). In dorsal view the petiole has a large, flat anterodorsal face. The posterior border is usually well defined by two posterolateral angles or tubercles, these usually surmounted by one or two setae. A transverse carina or ridge unites the posterolateral tubercles. A very much shorter posterior face drops to the cylindrical posterior aperture of the tergite, which tightly invests the anterior rim of the helcium (the specialized anterior portion of the postpetiole, which articulates with the petiole; see Bolton 1994). When the anterodorsal face of the petiole is viewed from above, perpendicular to the line of sight of the viewer (this can be achieved by pushing the gaster down or removing the metasoma entirely and remounting it) it may be (1) elongate and tapering anteriorly to a narrow neck just posterior to the condyles that articulate with the 
propodeum; (2) rectangular to quadrate, with subparallel sides and an abrupt constriction anteriorly; and (3) short with broadly convex sides, distinctly widest at the middle. Although these three character states are not always sharply differentiated and intermediate forms occur, clusters of species can be clearly placed into one of the three categories. A fourth condition is characteristic of the major radiation (or radiations?) of temperate zone species. The anterodorsal face is short, with strongly convex sides that are strongly expanded anteriorly, such that the petiole is widest anteriorly. Species with this character state (subgenus Crematogaster s.s., see Buren 1959) are restricted to the temperate zone and subtropics, and do not occur in Costa Rica.

The ventral margins of the petiole and postpetiole exhibit varying degrees of development of an anterior tooth. These anteroventral teeth are independent of each other, appearing on the petiole alone, on the postpetiole alone, on both, or on neither. They appear to be evolutionarily labile because they are not highly correlated with other characters and do not unite clusters of related species the way petiole shape seems to. Nevertheless, they are often reliable species-level characters: they correlate well with particular suites of characters that are hypothesized to be diagnostic for particular species. A clear view of the anteroventral margin of the petiole and postpetiole is often essential for species identification.

The postpetiole is comprised of the thickened rim of the anterior helcium, the narrow "neck" of the helcium, and the broadened and elevated node. The neck of the helcium may be short and cylindrical, forming a relatively sharp juncture with the node, like a stem on an apple. Alternatively, the neck may be relatively elongate and gradually tapering such that the juncture with the node is not sharply defined. In this case the dorsal view of the petiole is somewhat hour-glass or flask shaped. In the latter case, the node is globular, about as wide as long, and with no trace of a median longitudinal sulcus. In the former case the node is less globular, relatively more dorsally compressed, subquadrate in dorsal view, and usually distinctly wider than long. When the node is broad and subquadrate, it may exhibit some degree of development of a median longitudinal impression or sulcus. At extremes, the sulcus is very well defined, dividing the postpetiolar node into two distinct lobes, with a strong posterior emargination and a fully impressed sulcus.

Pilosity characters, like petiolar characters, are very useful and seem to unite clusters of related species. Pilosity on the face usually falls into one of three categories: (1) abundant long erect flexuous setae; (2) abundant short stiff setae, forming a stubble of straight or curved setae; or (3) largely or entirely bare, with a vestiture of sparse, very short, completely appressed hairs (a very dilute and appressed pubescence) and a small number of longer erect setae (Fig. 4). Pilosity on the meso and metasomal dorsum varies in density and may be composed of long flexuous or short stiff setae. Tibial and scape pilosity may be appressed or suberect and varies in length. When tibial pilosity is erect, it is usually subequal in length to the maximum width of the tibia, but in a few species there are 1-3 specialized longer setae that are about twice as long at the others. 

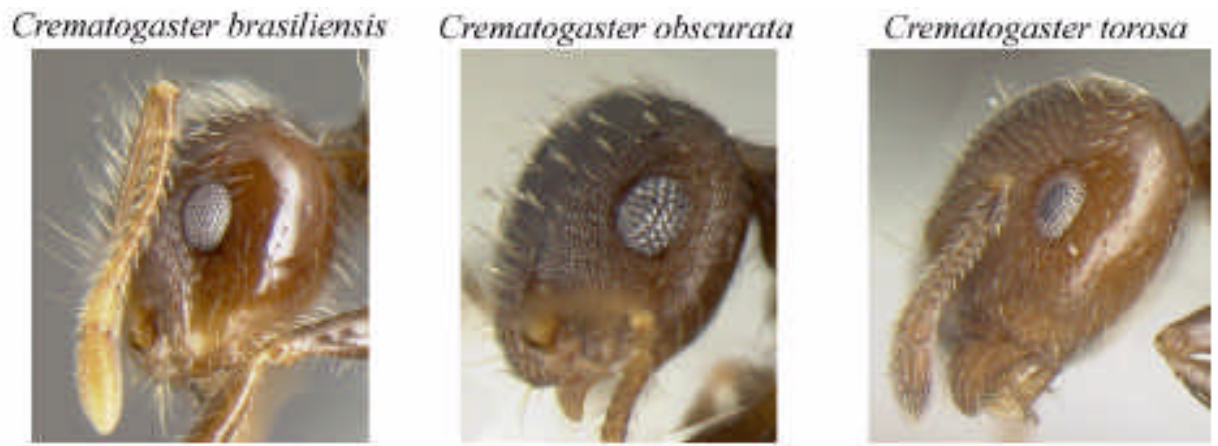

FIGURE 4. Major categories of face pilosity on Crematogaster workers. Crematogaster brasiliensis is typical of the limata group, with abundant long flexuous setae. Crematogaster obscurata has an abundant stubble of short, stiff setae. Crematogaster torosa is typical of the crinosa group, with a few erect setae underlain by short appressed pubescence.

Subgeneric classifications were proposed for Crematogaster by Santschi (1918), Emery (1922), and Wheeler (1922b). Wheeler's key was largely a translation of Santschi with few modifications. The main characters used to distinguish subgenera in the Neotropics were (1) the number of segments in the antennal club, (2) whether the anterodorsal face of the petiole was widest posteriorly or anteriorly, and (3) whether the postpetiolar dorsum had a median sulcus. In practice it is difficult to use any of these characters to sharply divide groups of species. Although I suspect these characters will prove phylogenetically informative, this work does not purport to establish phylogenetic hypotheses. Its purpose is to improve the species-level alpha taxonomy of the Neotropical species and provide a key for the Costa Rican fauna. Evaluating the status of subgenera must await further research, and they are ignored in this work.

\section{QUEEN CHARACTERS}

Queens are known for 27 of the 33 species that occur in or near Costa Rica. Normal queens are similar to workers in general shape, sculpture, and pilosity characters, differing in typical caste-specific traits: larger size, ocelli, enlarged mesosoma with additional sclerites, wings or wing scars, and enlarged gaster. As discussed in the Natural History Overview, acuta-group queens are more strongly differentiated from workers, often with highly polished integument and/or distinctive pilosity traits. There is variation in queen size (Fig. 5) and in the relationship of queen size to worker size (Fig. 6). Queens are given very cursory treatment in this work. Size relationships are depicted in Figures 5 and 6, and brief descriptions are provided in the species accounts. 


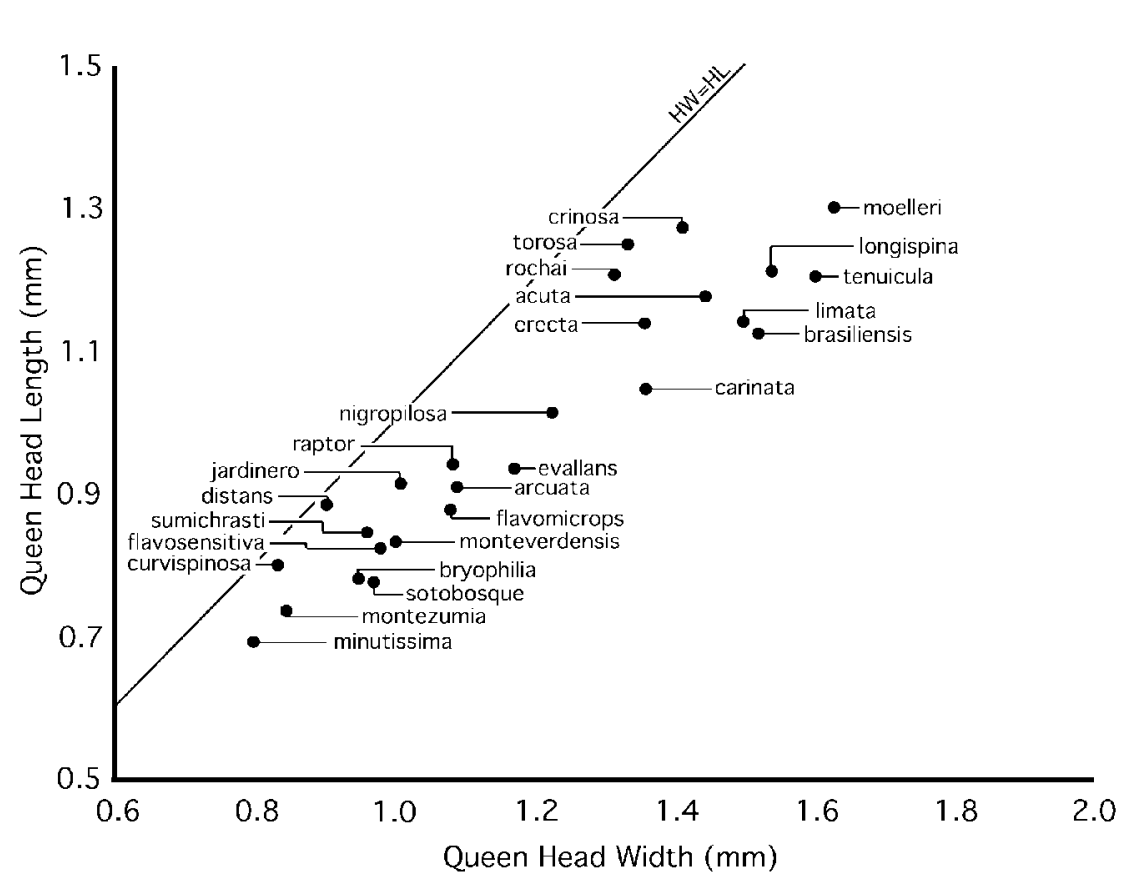

FIGURE 5. Head size measurements for Crematogaster queens. A single queen was measured for each species. Crematogaster stollii is an outlier at $\mathrm{HW}=2.27, \mathrm{HL}=1.91$.

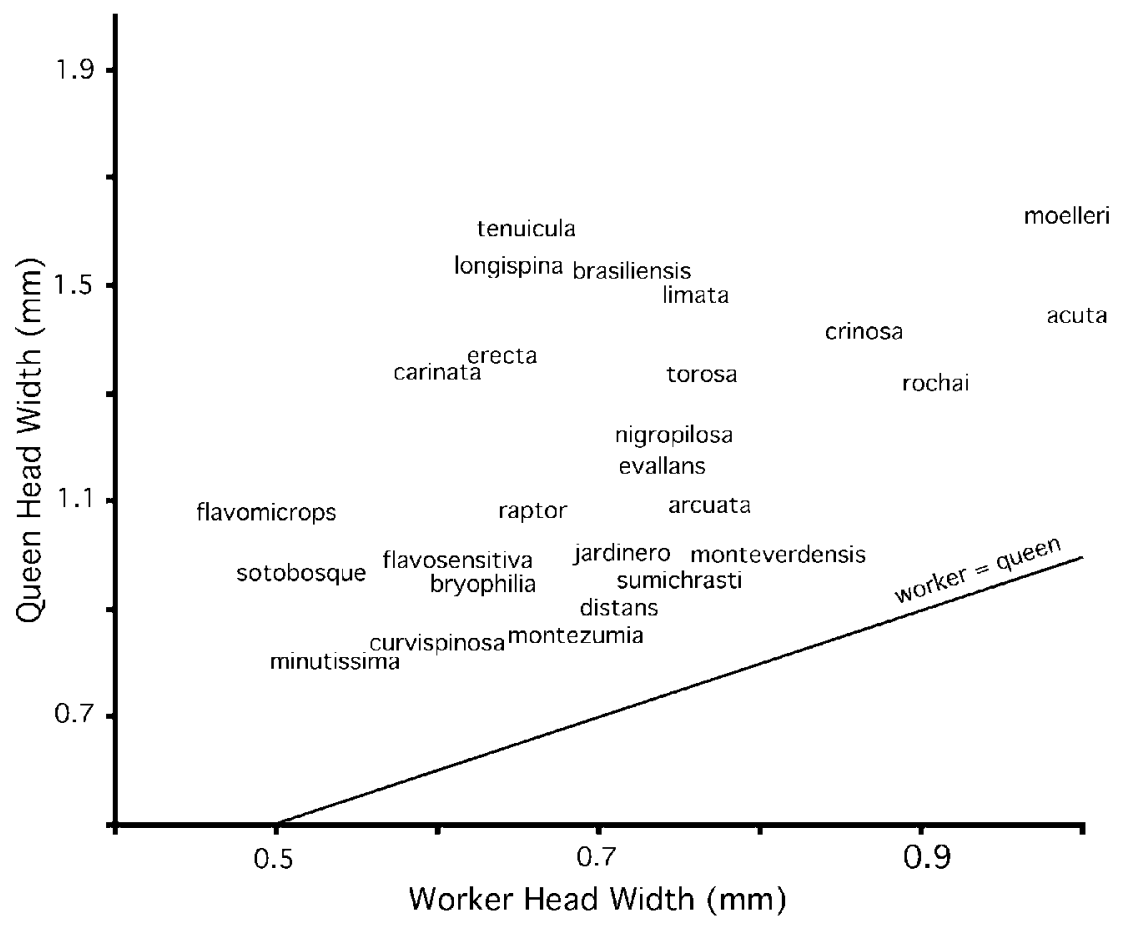

FIGURE 6. Relationship of queen head width to worker head width. A single queen and a single worker were measured for each species. Crematogaster stollii is an outlier at queen $\mathrm{HW}=2.27$ and worker HW greater than 1.9 in largest workers. Points are omitted to avoid clutter in the figure, but occur at the approximate midpoint of each species name. 
(Species with an asterisk have not been collected in Costa Rica but are known from nearby sites in

Panama: Volcan Chiriquí or Barro Colorado Island.)

*C. abstinens Forel 1899. Panama to Argentina.

= pygmaea Forel 1904. Brazil. NEW SYNONYMY

= suturalis Forel 1912. Venezuela. NEW SYNONYMY

= ornatipilis Wheeler 1918. Guyana. NEW SYNONYMY

= erici Santschi 1929. Argentina. NEW SYNONYMY

= chacoana Santschi 1933. Argentina. NEW SYNONYMY

C. acuta (Fabricius 1804). Mexico to southern Brazil, Bolivia.

= quadriceps $\mathrm{F}$. Smith 1858. Brazil.

= centralis Santschi 1932. NEW SYNONYMY

C. arcuata Forel 1899. Costa Rica to southern Brazil, Bolivia.

$=$ aruga Forel 1913. Brazil (Espirito Santo). NEW SYNONYMY

C. brasiliensis Mayr 1878. Nicaragua to Amazonian Brazil, Bolivia.

= ludio Forel 1912. Brazil (Ceará). NEW SYNONYMY

$=$ armandi Forel 1921. Brazil (Matto Grosso). NEW SYNONYMY

= inca Wheeler 1925. Peru. NEW SYNONYMY

= cocciphila Borgmeier 1934. Surinam. NEW SYNONYMY

C. bryophilia. Costa Rica, Panama. NEW SPECIES

C. carinata Mayr 1862. Costa Rica to Brazil (Rio de Janeiro), Bolivia.

= parabiotica Forel 1904. Colombia. NEW SYNONYMY

C. crinosa Mayr 1862. USA (Texas) to Argentina, Antilles.

= brevispinosa Mayr 1870. Colombia. NEW SYNONYMY

$=$ minutior Forel 1893. Antilles Islands, Saint Vincent. NEW SYNONYMY

= schuppi Forel 1901. Brazil (Rio Grande do Sul). NEW SYNONYMY

= striatinota Forel 1912. Colombia. NEW SYNONYMY

= recurvispina Forel 1912. Brazil (Rio de Janeiro). NEW SYNONYMY

= sampaioi Forel 1912. Brazil (Rio de Janeiro). NEW SYNONYMY

$=$ townsend $i$ Wheeler 1925. Peru. NEW SYNONYMY

= chathamensis Wheeler 1933. Ecuador (Galapagos). NEW SYNONYMY

C. crucis Forel 1912. Costa Rica, Colombia. NEW STATUS

C. curvispinosa Mayr 1870. Mexico to Argentina, Antilles.

$=$ antillana Forel 1893. Antilles. NEW SYNONYMY

= sculpturata Pergande 1896. NEW SYNONYMY

= kemali Santschi 1923. Brazil (Santa Catarina). NEW SYNONYMY

= fuliginea Santschi 1925. Brazil (Minas Gerais).

= accola Wheeler 1934. Mexico. NEW SYNONYMY

= phytoeca Wheeler 1934. Mexico. NEW SYNONYMY 
= panamana Wheeler 1942. Panama. NEW SYNONYMY

= obscura Santschi 1929. Argentina. NEW SYNONYMY

C. distans Mayr 1870. USA (Texas) to Argentina.

= paraensis Forel 1904. Brazil (Pará).

= parviceps Forel 1908. Brazil (Sao Paulo).

= pevsnerae Forel 1912. Venezuela.

= cordinoda Forel 1914. Colombia.

= vanda Borgmeier 1929. Brazil (Rio de Janeiro).

= descole $i$ Kusnezov 1949. Argentina. NEW SYNONYMY

C. erecta Mayr 1866. Costa Rica to Amazonian Brazil, Peru.

= virgula Forel 1899. Costa Rica, Panama.

= projecta Santschi 1925. Surinam. NEW SYNONYMY

C. evallans Forel 1907. Costa Rica, Colombia, Brazil (Espirito Santo, Rio de Janeiro).

= carbonescens Forel 1913. Brazil (Espirito Santo). NEW SYNONYMY

C. flavomicrops. Costa Rica to Ecuador, Brazil (Amazonas). NEW SPECIES

*C. flavosensitiva. Panama, Venezuela, Amazonian Brazil. NEW SPECIES

C. foliocrypta. Costa Rica. NEW SPECIES

C. jardinero. Costa Rica. NEW SPECIES

C. limata F. Smith 1858. Mexico to Bolivia and southern Brazil.

= palans Forel 1912. Panama. NEW SYNONYMY

= ascendens Wheeler 1925. Peru. NEW SYNONYMY

= dextella Santschi 1929. Panama. NEW SYNONYMY

C. longispina Emery 1890. Nicaragua, Costa Rica, Ecuador.

C. minutissima Mayr 1870. USA, Mexico, Costa Rica.

C. moelleri Forel 1912. Costa Rica, Brazil (Santa Catarina). NEW STATUS

C. monteverdensis. Costa Rica. NEW SPECIES

C. montezumia F. Smith 1858. Mexico to Argentina.

= sulcata Mayr 1870. Colombia.

$=$ ramulinida Forel 1899. Colombia.

= functa Forel 1911. Brazil (Sao Paulo).

= cristulata Santschi 1925. Brazil (Santa Catarina)

= proletaria Santschi 1933. Argentina.

C. nigropilosa Mayr 1870. Nicaragua to Bolivia, Brazil.

C. obscurata Emery 1895. USA (Florida), Mexico to Venezuela. NEW STATUS = agnita Wheeler 1934. Guatemala. NEW SYNONYMY

C. raptor. Costa Rica. NEW SPECIES

C. rochai Forel 1903. Mexico to Argentina. REVISED STATUS

C. snellingi. Costa Rica. NEW SPECIES

C. sotobosque. Costa Rica south to Amazonian Brazil and Peru. NEW SPECIES

C. stollii Forel 1885. Guatemala to Amazonian Brazil and Bolivia. 
= autruni Mann 1916. Brazil (Amazonas). NEW SYNONYMY

= guianensis Crawley 1916. Guyana. NEW SYNONYMY

= parvispina $($ Wheeler 1922). Guyana.

= hyperphyes Kusnezov 1953. Bolivia.

C. sumichrasti Mayr 1870. Mexico to Costa Rica.

= surdior Forel 1885. Guatemala. NEW SYNONYMY

= atitlanica Wheeler 1936. Guatemala. NEW SYNONYMY

= maya Wheeler 1936. Guatemala. NEW SYNONYMY

C. tenuicula Forel 1904. Costa Rica to Amazonian Brazil, Bolivia. NEW STATUS

C. torosa Mayr 1870. USA (Texas) at least to Colombia.

= tumulifera Forel 1899. Nicaragua. NEW SYNONYMY

= arizonensis Wheeler 1908. USA (Arizona). NEW SYNONYMY

C. wardi. Costa Rica. NEW SPECIES

\section{TAXONOMIC SYNOPSIS, ADDITIONAL CRINOSA GROUP TAXA}

C. ampla Forel 1912. Colombia, Bolivia. NEW STATUS

C. atra Mayr 1870. Mexico.

C. brevidentata Forel 1912. Barbados. NEW STATUS

C. chodati Forel 1921. Paraguay. NEW STATUS

C. goeldii Forel 1903. Brazil (Rio de Janeiro). REVISED STATUS

C. heathi Mann 1916. Brazil (Paraiba).

C. malevolens Santschi 1919. Argentina. NEW STATUS

C. montana Borgmeier 1939. Brazil (Petropolis). NEW STATUS

C. peristericus Menozzi 1925. Brazil (Rio Grande do Sul).

C. russata Wheeler 1925. Bolivia. NEW STATUS

C. sericea Forel 1912. Brazil (Sao Paulo). NEW STATUS

C. stigmatica Forel 1911. Brazil (Minas Gerais). NEW STATUS

C. subtonsa Santschi 1925. Brazil (Minas Gerais). NEW STATUS

C. thalia Forel 1911. Paraguay. NEW STATUS

C. unciata Santschi 1925. Brazil (Minas Gerais).

C. uruguayensis Santschi 1912. Uruguay. NEW STATUS

C. vicina Andre 1893. Jamaica. REVISED STATUS = wighti Wheeler 1908. Jamaica.

\section{TAXONOMIC SYNOPSIS, MISCELLANEA}

C. cubaensis Mann 1920. Cuba. NEW STATUS 


\section{KEY TO WORKERS OF CREMATOGASTER SPECIES OF COSTA RICA}

1 Face appearing somewhat bare, with dilute appressed pubescence, and usually six or fewer erect setae (Fig. 4); if more (up to 20), workers strongly polymorphic and propodeal spiracle very large (Fig. 7A, stollii); antennal scapes, when laid back, fail to reach posterior margin or only slightly surpass posterior margin; petiole in dorsal view only slightly longer than wide to distinctly wider than long (PTWI > 83), sides convex or straight and parallel, never long and gradually converging anteriorly...... 2

- $\quad$ Face with abundant erect to suberect pilosity; in some cases setae may be somewhat thickened, relatively short, and curved, but still with a relatively uniform vestiture of standing pilosity (Fig. 4); no underlying short appressed pubescence; scape length variable; petiole in dorsal view variable, subquadrate to elongate, with sides straight and subparallel to converging anteriorly, never with strongly convex sides .....

2 Postpetiole distinctly bilobed, much broader than long in dorsal view (PPI > 150), with broad median longitudinal sulcus; head somewhat elongate (CI 100-103); scapes when laid back just reach or slightly surpass posterior margin of head; face completely devoid of erect setae. distans

- $\quad$ Postpetiole subcircular or subquadrate, not broadly bilobed (PPI < 150), median sulcus absent or weakly impressed; head of larger workers distinctly wider than long (CI > 107); scapes variable; face usually with at least one pair of erect setae.

3 Propodeal spiracle very large (Fig. 7A); face with up to 20 erect setae stollii

-. $\quad$ Propodeal spiracle smaller (Fig. 7B); face usually with 6 or fewer erect setae ........ 4

4 Pilosity on fourth abdominal tergite composed of abundant filiform flexuous setae, a combination of long erect setae and abundant, long, suberect pubescence....... crucis

- Pilosity on fourth abdominal tergite a combination of completely appressed pubescence, and, when present, a variable number of erect setae; erect setae short, weakly to strongly flattened and stiff ....

5 Promesonotum with at least humeral setae long and filiform; dorsal face of propodeum short, not distinctly differentiated from posterior face.................................... 6

- $\quad$ Promesonotum with dorsal setae short and stiff; dorsal face of propodeum differentiated or not.

6 Promesonotum with 7-10 medium length flexuous setae .............................moelleri

- Only humeral setae long and filiform, other dorsal setae shorter and stiff ....... erecta

7 All except the largest workers (HW $>1 \mathrm{~mm}$ ) without differentiated dorsal and posterior faces of propodeum (Fig. 7C); fourth abdominal tergite completely lacking erect setae; anteroventral petiolar tooth well developed, acute and projecting .........rochai 
- $\quad$ All workers, even small ones, usually with short, differentiated dorsal face of propodeum (Fig. 7D); fourth abdominal tergite always with at least a few erect setae; anteroventral petiolar tooth variable

Anteroventral petiolar tooth relatively well-developed and sharp (Fig. 7E); fourth abdominal tergite with abundant setae that are uniformly distributed crinosa

- Anteroventral petiolar tooth relatively less well-developed, forming a right or only weakly acute angle rather than a projecting tooth (Fig. 7F); fourth abdominal tergite with moderately abundant setae that are more dense anterolaterally, often leaving a median strip relatively clear of setae. torosa

9 Petiole in dorsal view elongate and regularly tapering anteriorly; PTWI $<73$; postpetiolar node tall, globular, usually about as wide as long, rarely wider (PPI 85-124), with no median sulcus; face with abundant long or medium length erect setae, face setae never short and stubble-like; color brown to black, never yellow or distinctly bicolored; face smooth and shiny, not punctate or striate (limata complex) ........... 10

- Petiole in dorsal view relatively shorter, usually subquadrate to rectangular, not tapering anteriorly (if somewhat tapering anteriorly, color yellow or distinctly bicolored, or face with sparse erect setae and abundant shorter curved setae); PTWI > 67; postpetiole variable in dorsal view; face setae, color, and face sculpture variable.. 17

10 Propodeal spines very long, directed upward and outward, SPI usually $>34$, if in the range 29-33 (small specimens of nigropilosa) then hind tibia with appressed pilosity

- Propodeal spines shorter (SPI < 32), if in the range 29-33 (large specimens of limata) then hind tibiae with erect pilosity; propodeal spines usually directed posteriorly

11 Hind tibia with abundant erect setae; setae on face light yellow longispina Hind tibia with appressed pilosity; setae on face dark amber nigropilosa

12 Setae on mesosomal dorsum dark amber; mesosoma highly polished, with sculpture confined to lateral carinae of mesonotum; carinae on dorsal and posterior faces of mesonotum meet at strongly angular to tuberculate juncture; tibiae with a combination of appressed short pilosity and scattered long erect setae sotobosque

- $\quad$ Setae on mesosomal dorsum light amber to whitish; mesosoma less highly polished, with varying degrees of carinulae and rugulae on pronotum and katepisternum; carinae on dorsal and posterior face of mesonotum may meet at angle, but not produced as a tubercle; tibial pilosity variable, but usually comprised of abundant long erect setae

13 Hind tibia with abundant medium-length subdecumbent setae, no long erect setae; petiole with angular anteroventral tooth; postpetiole with no ventral tooth ..... foliocrypta

- Hindtibiawithabundantlongerectsetae;ventralmarginsofpetioleandpostpetiolevariable 14 


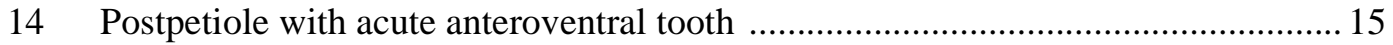

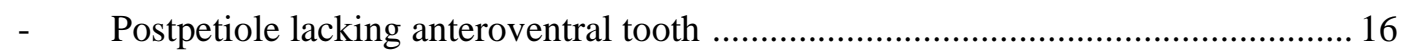

15 Petiole relatively triangular in lateral view (PTHI >60), usually lacking anteroventral tooth; posterodorsal tubercles distinctly higher than posterodorsal margin of tergite (Fig. 7G) tenuicula

- $\quad$ Petiole relatively elongate (PTHI < 60 in Central America, variable and often higher in South America), with angular to acute anteroventral tooth; posterodorsal border of petiole low, posterodorsal tubercles little higher than posterodorsal margin of tergite (Fig. $7 \mathrm{H}$ ) brasiliensis

16 Petiole with angular anteroventral tooth; propodeal spines short (SPI $<21)$.carinata Petiole usually lacking anteroventral tooth; propodeal spines long (SPI > 25). limata

17 Face largely punctate or otherwise heavily sculptured, with smooth and shiny portion restricted to a median strip

- Face largely smooth and shining, with at most small areas of punctation between eye

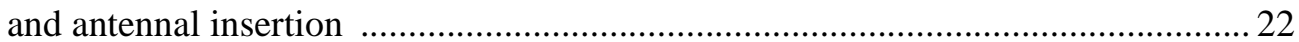

18 Tibiae with abundant erect setae; size relatively large (WL > 0.70) …................... 19

- $\quad$ Tibial pilosity fully appressed, not erect; size relatively smaller $(\mathrm{WL}<0.73) \ldots \ldots . .21$

19 Dorsal setae on mesosoma and fourth abdominal tergite dark amber; propodeum somewhat inflated; propodeal spines very thin and needle-like (Fig. 7I,J) ..... arcuata

- Dorsal setae whitish; propodeum less inflated; propodeal spines more broadly tapering to base (Fig. 7K,L,M,N).

20 Propodeal spines relatively thinner and less diverging, more posteriorly directed in dorsal view (Fig. 7K,L); dorsal and posterior faces of propodeum not well differentiated, more or less in same plane; anteroventral margin of petiole with a low, rounded tumosity but lacking distinct angle or tooth; anteroventral margin of postpetiole with bluntly rounded projection, lacking sharp tooth evallans

- $\quad$ Propodeal spines stout and diverging (Fig. 7M,N); dorsal and posterior faces of propodeum differentiated, not in same plane; anteroventral margin of petiole developed as distinct right to acute angle; anteroventral margin of postpetiole with sharp, acute tooth acuta

21 Propodeum somewhat inflated, with propodeal spines reduced to small denticles; anteroventral petiolar tooth lacking montezumia

- $\quad$ Propodeum not inflated; propodeal spines well-developed; anteroventral petiolar tooth well-developed. obscurata

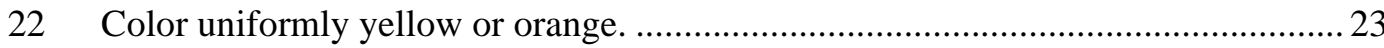

- Color amber to dark brown or black, or bicolored with dark head and gaster, lighter mesosoma 28

23 Mid and hind tibiae with one or more very long erect setae, much longer than maximum tibia width

- $\quad$ Mid and hind tibiae with appressed to suberect setae, none longer than maximum 
24 Propodeal spines upturned; erect setae on pronotal humeri and posterolateral mesonotum very long, subequal in length, longer than setae on anterolateral mesonotum (Fig. 7O) sumichrasti

- $\quad$ Propodeal spines directed posteriorly; erect setae on pronotal humeri and anterolateral mesonotum the longest, longer than setae on posterolateral mesonotum (Fig. 7P)

flavosensitiva

25 Eyes very small $(\mathrm{OI}<23)$; erect setae on face and mesosomal dorsum relatively short, somewhat stiffened, forming a stubble; propodeal spines short, upturned

flavomicrops

- $\quad$ Eyes larger (OI > 24), erect setae on face and mesosoma longer and thinner; propodeal spines variable

26 Pair of setae on posterolateral mesonotum subequal in length to humeral setae; propodeal spines relatively long, upturned monteverdensis

- $\quad$ Propodeal spines of variable length, upturned or directed posteriorly; humeral setae much longer than any setae on mesonotum

27 Propodeal spines short (SPI 15-18); mesosoma relatively compact in lateral profile (Fig. 7Q) minutissima

- $\quad$ Propodeal spines long (SPI 18-21); mesosoma more elongate in lateral profile (Fig. 7R) wardi

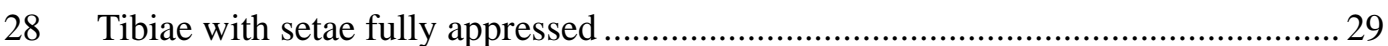

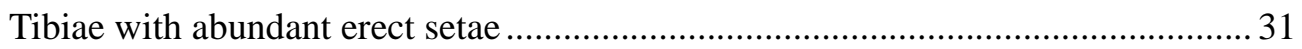

29 Postpetiole much wider than long (PPI > 138); setae on face short, flattened, curved or slanted toward median axis; anteroventral margin of petiole lacking angle or tooth; ventral margin of postpetiole with rounded lobe, without acute tooth

abstinens

- $\quad$ Postpetiole more globular (PPI < 132); setae on face of variable length and stiffness, but not strongly curved or slanting toward median axis; anteroventral margin of petiole with subacute tooth or at least blunt lobe; ventral margin of postpetiole with obtuse to acute tooth

30 Propodeal spines regularly tapering from base to tip (Fig. 7S) ... bryophilia

- Propodeal spines in dorsal view with bases thickened, directed outward, tips short, abruptly narrowed and directed posteriorly (Fig. 7T) curvispinosa

31 Propodeal spines forming angular tumosities, not spiniform, or with at most a minute spiniform denticle raptor Propodeal spines distinctly spiniform 32

32 Ventral margin of postpetiole with acute to right angled tooth; propodeal spines relatively long and upturned (SPI 19-23); postpetiole gradually constricted toward helcium; mesosoma often light brown, contrasting with dark brown head and gaster..... snellingi 
- Ventral margin of postpetiole flat, completely lacking tooth; propodeal spines relatively short and posteriorly directed (SPI 13-18); postpetiolar node abruptly constricted, with clearly defined juncture with cylindrical stem of helcium; head, mesosoma, and gaster uniformly dark brown. jardinero
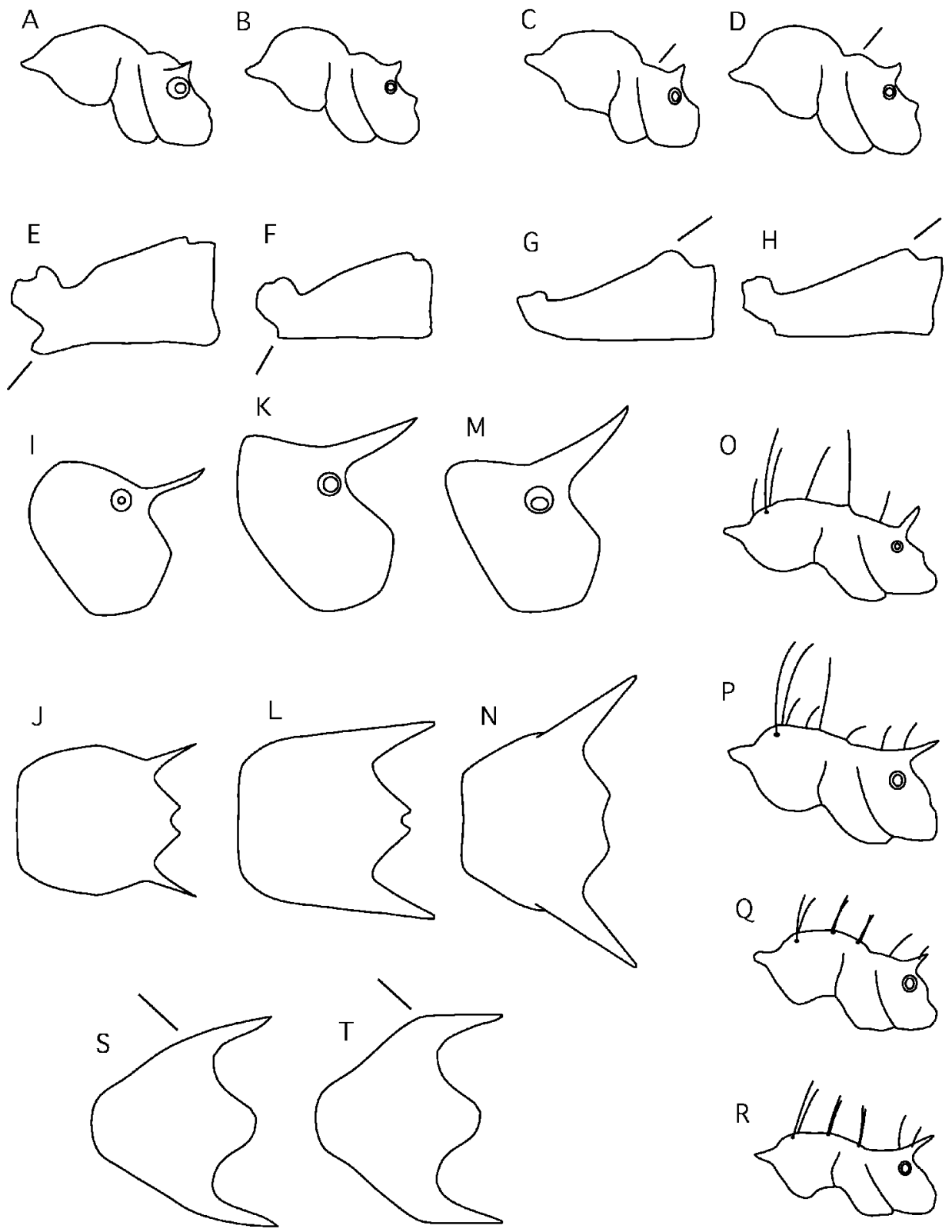

FIGURE 7. Illustrations for key to Crematogaster of Costa Rica. A-D, O-R: lateral view of mesosoma. E-H: lateral view of petiole. I-N: paired lateral and dorsal views of propeum. S-T: dorsal view of propodeum. 


\section{Crematogaster abstinens Forel 1899}

Plate 7

Crematogaster abstinens Forel 1899:85. Syntype worker: Panama, Peña Blanca (Champion) [label: V. de Chiriquí, 2-3000ft, Champion] [MHNG] (examined). Emery 1922:133: combination in C. (Orthocrema).

Crematogaster pygmaea Forel, 1904a:37. Syntype worker: Brazil, Ceará (Diaz da Rocha) [MHNG] (examined). Emery, 1922:135: combination in C. (Orthocrema). Forel, 1909:259: variety of brevispinosa. Forel, 1912:235; Emery, 1922:135: revived status as species. NEW SYNONYMY

Crematogaster abstinens var. suturalis Forel, 1912:216. Syntype workers: Venezuela, Zig Zag, between La Guayra and Caracas (Forel) [MHNG] (examined). Emery, 1922:133: combination in $C$. (Orthocrema). NEW SYNONYMY

Crematogaster ornatipilis Wheeler, W.M. 1918:25. Syntype workers: Guyana, near penal settlements in Bartica District, 15-20 Sep 1917, beaten from vegetation (Beebe) [MCZC] (examined). Emery, 1922:135: combination in C. (Orthocrema). NEW SYNONYMY

Crematogaster (Orthocrema) quadriformis st. erici Santschi, 1929a:291. Syntype workers: Argentina, Córdoba, Alta Gracia, La Granja (C. Bruch) [NHMB] (examined). NEW SYNONYMY

Crematogaster (Orthocrema) abstinens st. chacoana Santschi, 1933:111, fig. 6. Holotype worker: Argentina, Chaco, Charata (J. Bosq) No.1775 [NHMB] (examined). NEW SYNONYMY

\section{Range}

Panama, Colombia, Venezuela, Guyana, French Guiana, Brazil, Bolivia, Argentina.

\section{Description of worker}

Color red brown.

Head subquadrate, flattened to weakly emarginate posteriorly; mandibles shiny, smooth, with coarse elongate piligerous puncta; face smooth and highly polished medially, punctate on malar space and between antennal insertion and eye, with a few concentric rugulae around antennal insertion; scapes with abundant long subdecumbent pubescence, lacking differentiated long, erect setae; antennal club 2-segmented; anterior border of clypeus shallowly convex; clypeus shiny, smooth medially, with longitudinal rugulae laterally; face with dense stubble of 40-50 short, flattened, amber setae; face setae distinctly curved or slanted toward median axis; ventral surface of head smooth and shiny with sparse suberect to subdecumbent pilosity.

In lateral view, dorsal profile of pronotum, mesonotum, and propodeum forming a continuous curve; dorsal and posterior faces of propodeum in same plane, sloping to petiolar insertion; propodeal spines projecting posterodorsally; propodeal spiracle relatively large; pronotal dorsum largely smooth and shining with faint longitudinal carinulae; mesonotal dorsum with weak, longitudinal carinulae laterally, smooth and shiny medially; propodeal suture strongly impressed medially but less visible in side view because lateral mesonotal carinulae continue onto dorsal face of propodeum; mesonotal carinulae usually 
have slight tooth at propodeal suture; long flat posterodorsal face of propodeum punctate anteriorly, smooth and shiny posteriorly; propodeal spines short, thin, and sharp; side of pronotum and dorsolateral propodeum smooth and shining; katepisternum and ventrolateral propodeum punctate; promesonotum with about 15 straight, stiff setae of subequal length, those on humeri longest, approximately $0.17 \mathrm{~mm}$ long; propodeal spine with one seta at base, subequal in length to spine; legs with sparse, appressed to subdecumbent pilosity and no erect setae.

Petiole in side view trapezoidal; side densely punctate; lacking anteroventral tooth or angle; dorsal face short, wider than long, with convex sides, widest at midlength, faintly microareolate or smooth and shining; posterolateral tubercles low, not at all elevated above posterodorsal margin of tergite, each with a long, stiff seta; postpetiole in dorsal view much wider than long, with slight posterior emargination; anterolateral margins of postpetiolar node dropping abruptly to short, cylindrical neck of helcium; ventral margin of postpetiole with small rounded lobe, lacking sharp anteroventral tooth; dorsum and sides of postpetiole with microareolate sculpture and with 6-8 stiff setae; fourth abdominal tergite with very faint, areolate microsculpture, shiny, with about 50 stiff erect setae evenly dispersed over surface.

A Bolivian collection is generally more robust and more heavily sculptured. The mandibles are striate rather than smooth, the face punctation extends posteriorly along medial border of eye, and the mesosoma is generally more punctate throughout.

\section{Measurements}

HL 0.561, 0.519, 0.648; HW 0.630, 0.567, 0.740; HC 0.594, 0.535, 0.700; SL 0.424, 0.398, 0.503; EL 0.152, 0.149, 0.201; A11L 0.217; A11W 0.102; A10L 0.094; A10W 0.092; A09L 0.048; A09W 0.072; A08L 0.041; A08W 0.057; WL 0.620, 0.570, 0.782; SPL 0.109, 0.100, 0.139; PTH 0.123, 0.114, 0.151; PTL 0.154, 0.187, 0.282; PTW 0.207, 0.177, 0.256; PPL 0.137, 0.126, 0.160; PPW 0.208, 0.175, 0.260; CI 112, 109, 114; OI 27, 29, 31; SI 76, 77, 78; PTHI 80, 61, 54; PTWI 134, 95, 91; PPI 152, 139, 163; SPI 18, 18 , 18; ACI 1.02 .

\section{Queen}

The queen of abstinens is unknown.

\section{Biology}

Crematogaster abstinens occurs in wet or dry forest habitats, but is more common in the latter. I have never collected this species myself and have no first-hand knowledge of its biology. It has been taking by sweeping on Barro Colorado Island, and by sweeping at night in Brazil (Mato Grosso). Ward collected ground foragers in Bolivia. 


\section{Comments}

The combination of (1) shiny face, (2) subquadrate dorsal face of petiole, (3) appressed tibial pilosity, (4) very wide postpetiole, and (5) abundant short stiff setae on face that curve toward the median axis uniquely characterize this species. Crematogaster obscurata is somewhat similar but has a punctate face.

I was able to compare directly the types of abstinens, pygmaea, and suturalis with material that Bill and Emma Mackay collected in Colombia. They were all essentially identical. I examined the types of Wheeler's ornatipilis prior to having additional material for comparison, but my notes and drawings are a close match to the Colombian material, and Wheeler himself considered the species close to abstinens. The Bolivian material that I have for current examination was collected by Phil Ward after my examination of the types of chacoana and erici, both from Argentina. My museum notes for chacoana and erici describe specimens that were more robust and more heavily punctate than abstinens from northern South America, thus matching the Bolivian specimens. Until more is known of character variation in South America, I am treating the more punctate forms as geographic variants of a broadly defined polytypic abstinens.

\section{Crematogaster acuta (Fabricius 1804)}

Plate 3, 6

Formica acuta Fabricius 1804:411. Holotype worker: Guyana, Essequibo [ZMUC] (examined). Wheeler, G. C. and Wheeler, J. 1952:258: description of larva. Roger, 1862:291: combination in Crematogaster. Santschi 1918:182: combination in C. (Euchrema).

Crematogaster quadriceps Smith, F. 1858:140. Holotype worker: Brazil (not examined). Synonymy by Roger, 1862:291.

Crematogaster (Eucrema) acuta var. centralis Santschi, 1932:412. Syntype worker, queen: Panama, Juan Diaz, 11 June 1930 (A. Bierig) [NHMB] (examined). NEW SYNONYMY

\section{Range}

Mexico to southern Brazil, Bolivia.

\section{Description of worker}

Color dark red brown to black.

Head subquadrate, with compound eyes projecting beyond lateral margins in full face view; mandibles shiny, coarsely striate; clypeus shiny, smooth or with widely spaced weak rugulae; face punctatorugose over much of surface [Central American and northern South American material punctate with rugae very feeble; grading into forms in Amazonia, southeastern Brazil, Peru, and Bolivia with more pronounced, almost clathrate rugae and reduced punctation], with variably developed anteromedian strip on face smooth and shiny; vertex margin shallowly emarginate; scapes with abundant long, suberect setae that are almost as long as width of scape; scape etched, subopaque; antennal club not well 
defined, terminal 3-5 segments gradually lengthening and becoming increasingly densely

pubescent; face with abundant long erect whitish setae; malar spaces and ventral surface of head with abundant short erect to suberect setae.

In lateral view, dorsal profile of promesonotum strongly convex, mesonotum differentiated from pronotum, projecting and forming elevated anterior boss; propodeal suture broad, well impressed; mesonotum meeting dorsal face of propodeum at angle, dorsal and posterior faces of propodeum distinct; propodeal spines stout, conical, evenly tapering to sharp points, much longer than dorsal face of propodeum, projecting posterodorsally and divergent; side of pronotum evenly punctate and medially impressed; katepisternum evenly punctate; anepisternum punctate to rugose; side of propodeum punctate, somewhat swollen, with distinct longitudinal sulcus beneath spiracle and shorter, oblique sulcus anterodorsal to opening of metapleural gland; promesonotal dorsum and dorsal face of propodeum with variable sculpture, punctatorugose with varying density of puncta and varying strength of clathrate rugae, paralleling variation in face sculpture; posterior face of propodeum grades from shallowly microareolate and opaque to completely smooth and shiny; propodeal spines smooth and shiny; promesonotum with abundant long whitish setae, abundant shorter setae on dorsal face of propodeum and propodeal spine, no setae on posterior face of propodeum; legs with abundant erect to suberect setae on all surfaces, longer and more erect on tibia than on femur.

Petiole robust, in side view trapezoidal, side strongly to faintly punctate; anteroventral tooth pronounced, forming right to acute angle; dorsal face rectangular, longer than wide, faintly microaerolate to smooth and shining; posterolateral tubercles vary from simple gibbosities to short, acute, posteriorly directed teeth; postpetiole with acute anteriorly directed ventral tooth, in dorsal view subquadrate, posterior margin emarginate, with weak to pronounced longitudinal median sulcus; anterolateral margin nearly perpendicular to stem of helcium, node of postpetiole separated from helcium by a distinct sulcus; fourth abdominal tergite with faintly microareolate sculpture; petiole, postpetiole, and fourth abdominal tergite with abundant erect to suberect whitish setae of variable length.

\section{Measurements}

HL 0.873, 0.860, 0.980; HW 0.997, 0.951, 1.135; HC 0.906, 0.876, 1.052; SL 0.960, 0.900, 1.085; EL 0.191, 0.187, 0.222; A11L 0.347; A11W 0.133; A10L 0.171; A10W 0.125; A09L 0.119; A09W 0.105; A08L 0.094; A08W 0.079; WL 1.169, 1.104, 1.295; SPL 0.420, 0.384, 0.552; PTH 0.260, 0.244, 0.300; PTL 0.416, 0.359, 0.460; PTW 0.318, 0.283, 0.343; PPL 0.270, 0.246, 0.329; PPW 0.343, 0.323, 0.405; CI 114, 111, 116; OI 22, 22, 23; SI 110, 105, 111; PTHI 63, 68, 65; PTWI 76, 79, 75; PPI 127, 131, 123; SPI 36, 35, 43; ACI 0.03 .

\section{Queen (Costa Rica)}

In lateral profile dorsal face of propodeum sloping obliquely from postscutellum, such 
that most of propodeum is posterior to scutellum (in contrast to normal queens, in which dorsal face of propodeum drops steeply from postscutellum and much of propodeum appears ventral to scutellum and postscutellum, Fig. 1); scape etched and subopaque as in worker, but entire remainder of head, mesosoma, legs, petiole, postpetiole, and fourth abdominal tergite smooth and shining; propodeal spines long, acute; petiole and postpetiole robust, generally similar to worker in shape but lacking anteroventral petiolar tooth and ventral postpetiolar tooth; antennae, head, mesosomal dorsum, legs, petiole, and postpetiole with abundant long erect to suberect whitish setae; side of pronotum with abundant setae anterodorsally, a dense fringe of short setae along ventral margin, and lacking setae posteroventrally; katepisternum, anepisternum, and side of propodeum lacking setae; fourth abdominal tergite with sparse erect to suberect whitish setae; size characters as in Figures 4 and 5.

\section{Biology}

My field observations in Costa Rica, Colombia, and Venezuela suggest that this species prefers open disturbed habitats. Many collections are from roadside vegetation, pasture edges, and young second growth forest. Perfecto collected the species in an area of hurricane-flattened forest on the Atlantic coast of Nicaragua. The species occurs in wet and seasonally dry climates. My highest elevational record is $1000 \mathrm{~m}$ in Bolivia, but most records are from below $500 \mathrm{~m}$. Colonies are very large, but not high density, and the species is only occasionally encountered.

I have observed nests on four different occasions, and each time they have been large, polydomous colonies nesting in dead wood. One nest was in dead Piper stems, one in chambers in fence posts along a fencerow, one in dead Cecropia branches, and one in the exposed dead core of a living tree trunk. In this last example, the dead part was dry and brittle, and one section was riddled with holes and filled with workers. There were few large chambers, and the workers seemed distributed evenly, like filling the spaces of a sponge. In addition to workers there were abundant alate females scattered throughout the wood, and I found a single male. There was very little brood. I could only excavate a small portion of the dead trunk, and it looked as though the colony continued up the side of the tree and deep into the dead core.

Workers have been collected by sweeping during the day and at night, and they have been collected at tuna baits. In Peru, Davidson has observed them foraging on the ground and invading myrmecophytic Triplaris trees. When nests are disturbed workers emerge in great numbers, wave their gasters in the air, and exude copious quantities of a white frothy material from the tip of the gaster. However, they rarely bite.

Nothing is known of colony founding, but queens exhibit a morphology often associated with social parasitism (see Natural History Overview). 


\section{Comments}

Crematogaster acuta and the similar species $C$. evallans share a unique combination of characters: largely punctate face, erect tibial pilosity, and abundant clear to whitish (not amber, as in arcuata) long erect setae on the face and mesosomal dorsum. The two species may be distinguished by several characters (see Key), but perhaps the most discrete is the acute ventral postpetiolar tooth on acuta, contrasted with a bluntly rounded lobe on evallans.

\section{Crematogaster arcuata Forel 1899}

Crematogaster sulcata r. arcuata Forel, 1899: 84, pl. 4, fig. 3. Syntype workers: Panama, Volcan de Chiriqui, 3-4000ft (Champion) [MCSN, MHNG] (examined, MHNG worker here designated LECTOTYPE).

Crematogaster arcuata Forel. Forel 1913:234: raised to species, combination in C. (Physocrema). Emery, 1922: 134: combination in C. (Orthocrema). Santschi, 1922:244; Kempf, 1972: 83: combination in $C$. (Neocrema).

Crematogaster (Physocrema) arcuata var. aruga Forel, 19131: 234. Syntype workers: Brazil, Espirito Santo (von Ihering No.16787) [MHNG] (examined). Emery, 1922: 134: combination in $C$. (Orthocrema). Kempf, 1972: 83: combination in C. (Neocrema). NEW SYNONYMY

\section{Range}

Costa Rica to southern Brazil, Bolivia.

\section{Description of worker}

Color dark red brown to black.

Head subquadrate, with compound eyes projecting beyond lateral margins in full face view; mandibles striate; clypeus emarginate anteriorly and often with anteromedian impression, convex, shiny, with widely spaced weak rugulae that are longitudinal to transversely arcing; face punctatorugose over much of surface, with variably developed anteromedian strip on face smooth and shiny; scapes with a combination of erect and subdecumbent setae, setae abundant, as long as width of scape or greater; antennal club not well defined, terminal 3-5 segments gradually lengthening and becoming increasingly densely pubescent, or in some cases relatively distinctly 3 -segmented; face with abundant long erect amber to black setae, both on dorsal surface and projecting from sides, forming a black crown in full face view; malar spaces and ventral surface of head with abundant short erect to suberect setae.

In lateral view, dorsal profile of promesonotum low, weakly convex, mesonotum differentiated from pronotum, projecting and forming elevated anterior boss; propodeal suture broad, well impressed; mesonotum meeting dorsal face of propodeum at angle, dorsal and posterior faces of propodeum distinct; propodeum strongly swollen, large relative to promesonotum, nearly as wide as pronotum in dorsal view; propodeal spines thin, almost needle-like, of variable length but usually long; side of pronotum evenly punctate 
and medially impressed; katepisternum evenly punctate; anepisternum punctate to rugose; side of propodeum faintly microareolate to smooth and shining, always with much weaker sculpture than side of pronotum and katepisternum; promesonotal dorsum and dorsal face of propodeum punctatorugose; posterior face of propodeum smooth and shiny; promesonotum and dorsal face of propodeum with abundant long coarse black to amber setae, no setae on posterior face of propodeum; legs with combination of abundant suberect and decumbent setae.

Petiole in side view subtriangular, strongly to faintly punctate; anteroventral tooth weak to absent; dorsal face rectangular, longer than wide, smooth and shiny on anterior two thirds, faintly microaerolate on posterior third, with row of four coarse black setae across posterior margin; postpetiole with short ventral tooth, postpetiole in dorsal view subquadrate, wider than long, posterior margin emarginate, with weak to pronounced longitudinal median sulcus, and abundant long coarse black setae; fourth abdominal tergite with faint microareolate sculpture; fourth abdominal tergite with abundant erect coarse black setae.

\section{Measurements}

HL 0.701, 0.629, 0.785; HW 0.772, 0.661, 0.867; HC 0.679, 0.600, 0.773; SL 0.776, 0.733, 0.860; EL 0.166, 0.147, 0.184; A11L 0.287; A11W 0.131; A10L 0.148; A10W 0.110; A09L 0.107; A09W 0.085; A08L 0.080; A08W 0.066; WL 0.880, 0.829, 0.948; SPL 0.187, 0.206, 0.302; PTH 0.201, 0.177, 0.224; PTL 0.289, 0.283, 0.330; PTW 0.228, 0.191, 0.253; PPL 0.187, 0.184, 0.212; PPW 0.285, 0.243, 0.285; CI 110, 105, 110; OI 24, 23, 23; SI 111, 117, 110; PTHI 70, 63, 68; PTWI 79, 67, 77; PPI 152, 132, 134; SPI 21, 25 , 32; ACI 0.07 .

\section{Queen (Venezuela)}

In lateral profile dorsal face of propodeum sloping obliquely from postscutellum, such that most of propodeum is posterior to scutellum (in contrast to normal queens, in which dorsal face of propodeum drops steeply from postscutellum and much of propodeum appears ventral to scutellum and postscutellum, Fig. 1); face covered with widely-spaced clathrate rugae, interspaces shiny; pronotum similarly rugose anteriorly, grading to finer striae and dense punctation on sides; mesonotum longitudinally reticulate rugose; upper anepisternum longitudinally rugose striate, remainder of anepisternum and katepisternum smooth and shiny; dorsal and upper lateral face of propodeum rugose, posterior and lower lateral face smooth and shiny; propodeal spines distinct, sharp; petiole, postpetiole, and fourth abdominal tergite smooth and shining; dorsal face of petiole proportionally shorter than petiole of worker, only slightly longer than wide; abundant short amber to whitish erect setae on entire dorsum including face, mesosoma, petiole, postpetiole, and fourth abdominal tergite; size characters as in Figures 4 and 5. 
The relatively few collections of this species have been from forested sites, sea level to $1000 \mathrm{~m}$ elevation, in moist to wet forest habitats and cerrado. The only known Costa Rican collection is from the Osa Peninsula. The one nest I have observed was on a roadside in Venezuela. It was in an area of small farms and coffee plantations, with a dense stand of a zingiberaceous plant along the roadside. The ants inhabited a loose-weave carton nest that enveloped several leaves in the clump of zingibers. I found a single colony queen in the center of the carton nest. Workers have been collected from low vegetation. Davidson has observed workers tending Homoptera and visiting extrafloral nectaries in Peru.

\section{Comments}

The very thin, almost needle-like propodeal spines uniquely identify this species. Additional characters are largely punctate face, amber dorsal setae, and erect tibial pilosity. The rugae on the face of the lectotype form a concentric pattern. Specimens from elsewhere are variable in the strength and orientation of face sculpture. The syntypes of aruga are within the range of variation for arcuata, with facial rugae somewhat reduced relative to the average condition.

\section{Crematogaster brasiliensis Mayr 1878}

Figure 4, Plate 1

Crematogaster brasiliensis Mayr, 1878:875. Syntype workers: Brazil, Pará, Prainha, $1^{\circ} 48 ' \mathrm{~S}$ $53^{\circ} 29^{\prime} \mathrm{W}$, on Tococa guianensis Aubl. (Trail \#5); Brazil, Amazonas, Barcelos, $0^{\circ} 58^{\prime} \mathrm{S} 62^{\circ} 57^{\prime} \mathrm{W}$, on Clidemia tococoidea (DC.) Gleason (Trail \#27) [type data from Benson and Setz 1985] [NMW] (examined, Trail \#5 worker here designated LECTOTYPE). Forel, 1912:217: description of queen. Emery, 1922:136: combination in C. (Orthocrema).

Crematogaster limata r. ludio Forel, 1912:217. Syntype workers: Brazil, Ceara (Diaz da Rocha) [MHNG] (examined). Wheeler, W.M. 1921b:151: description of queen. Emery, 1922:136: combination in $C$. (Orthocrema). Forel, 1913:233: variety of brasiliensis. NEW SYNONYMY

Crematogaster armandi Forel, 1921: 208. Syntype worker, queen: Brazil, Matto Grosso, from an orchid pseudobulb (Chodat from Moore) [MHNG] (examined). Kempf, 1972: 84: combination in $C$. (Orthocrema). NEW SYNONYMY

Crematogaster (Eucrema) inca Wheeler, W.M. 1925:27. Syntype worker: Peru, Chaquimayo (Holmgren) [MCZC, possibly also Royal Museum of Stockholm]. NEW SYNONYMY

Crematogaster (Orthocrema) brasiliensis var. cocciphila Borgmeier, 1934:102. Holotype worker, paratype workers, queen: Surinam, Paramaribo, common ants visiting especially the inflorescences of various plants, also tending coccids (Bunzli) [MZSP] (examined). NEW SYNONYMY

Range

Nicaragua to Amazonian Brazil, Bolivia. 
Color red brown; workers monomorphic in size.

Mandibles smooth and shining; clypeus varying from feebly striate, with 5 or more longitudinal carinulae, to nearly smooth and shining; head about as long as wide, subquadrate, with broadly convex sides and flat to weakly emarginate posterior border; antenna with terminal two segments enlarged to form a club, third segment from end somewhat enlarged, blurring distinction between two and three-segmented club; scapes with abundant long erect setae; when scapes laid back from antennal insertions, they surpass margin of vertex; face largely smooth and shining, with variable extent of striated region between antennal insertion and eye, and whorled above antennal insertion; face covered with abundant long flexuous white setae, no appressed pubescence; in face view abundant setae project from lateral and posterior margins.

Promesonotum in profile somewhat flattened dorsally, short anterior face of pronotum rises to dorsal face, dorsal faces of pronotum and mesonotum subequal in length, horizontal, forming single flat surface or meeting at a slightly produced angle, dorsal and posterior faces of mesonotum meeting at distinct angle, posterior face dropping to propodeal suture; propodeal suture deep in dorsal view but obscured in profile due to lateral carinulae that bridge the suture; lateral carinulae often with minute triangular tooth at propodeal suture; propodeal spines medium length, projecting posteriorly; in lateral view propodeum appears to have distinct dorsal and posterior faces because profile is horizontal from propodeal suture onto propodeal spines, but medially there is a single declivity from propodeal suture to petiolar insertion; pronotal dorsum with variably developed longitudinal carinulae, strongest laterally, becoming weaker medially, interspaces smooth and shining, in some cases almost entirely smooth and shining with no carinulae; anterodorsal face of mesonotum with weak, subparallel lateral carinae, these continue onto posterodorsal face as stronger carinae that converge posteriorly, interspace concave, smooth and shining; propodeal declivity smooth and shining; side of pronotum smooth and shining; katepisternum weakly to distinctly punctate or punctatorugose; side of propodeum very faintly sculptured; mesosomal dorsum with abundant long flexuous white setae, setae on pronotal humeri longest; femora and tibiae with abundant long erect setae.

Petiole in side view elongate, trapezoidal, weakly punctate to nearly smooth; anteroventral margin with a short right angle to somewhat rounded tooth; posterior ring-like aperture that receives postpetiole large, dorsal margin at nearly same level as posterolateral lobes of dorsal face when petiole viewed in profile with ventral margin horizontal (in contrast to tenuicula, in which posterior aperture is smaller and posterolateral lobes of dorsal face are distinctly higher than dorsal margin of aperture); dorsal face of petiole smooth and shining, elongate, widest posteriorly, regularly tapering anteriorly, with long flexuous setae along posterior border; postpetiole with distinct, subacute, short anteroventral tooth, globular in dorsal view, with abundant erect setae; fourth abdominal tergite smooth and shining, with abundant long flexuous erect white setae, no appressed pubescence. 


\section{Variation}

The most striking variation is in worker size polymorphism. In South America various degrees of size polymorphism occur, and collections from Amazonian Brazil can be strongly polymorphic. The small workers are similar to specimens from Central America, while the large workers have heads wider than long, the scapes do not surpass the vertex margin, and the mesonotum is produced dorsally, projecting above the pronotum.

Other morphological characters vary discordantly across the range. The petiole in side view is relatively long and low in Central America, becoming shorter in South America. Specimens from South America often have longer propodeal spines, the spines may be somewhat elevated, and the dorsal face of the propodeum may be longer and more differentiated from the posterior face.

\section{Measurements}

HL 0.646, 0.601, 0.897; HW 0.713, 0.642, 1.026; HC 0.665, 0.594, 0.995; SL 0.657, 0.622, 0.798; EL 0.165, 0.163, 0.207; A11L 0.284; A11W 0.118; A10L 0.149; A10W 0.086; A09L 0.074; A09W 0.057; A08L 0.067; A08W 0.044; WL 0.740, 0.723, 1.092; SPL 0.151, 0.135, 0.198; PTH 0.140, 0.125, 0.227; PTL 0.248, 0.264, 0.354; PTW 0.170, 0.154, 0.259; PPL 0.186, 0.133, 0.215; PPW 0.168, 0.145, 0.248; CI 110, 107, 114; OI 26, 27, 23; SI 102, 103, 89; PTHI 56, 47, 64; PTWI 69, 58, 73; PPI 90, 109, 115; SPI 20, 19 , 18; ACI 1.61 .

\section{Queen (Costa Rica)}

A normal queen (dorsal face of propodeum drops steeply from postscutellum and much of propodeum appears ventral to scutellum and postscutellum, Fig. 1) with general shape, sculpture, and pilosity characters of the worker; size characters as in Figures 4 and 5 .

\section{Biology}

This species prefers lowland wet to moist forest habitats, and may occur in mature forest or second growth vegetation. In Costa Rica and other northern Neotropical sites that I have visited, two other limata group species, limata and carinata, are usually much more abundant. For example, at La Selva Biological Station in Costa Rica, carinata, limata, and brasiliensis occurred in 24, 11, and 4 fogging events, respectively, out of a total of 52 (Longino et al. 2002).

Foragers may be encountered during the day or at night. They are generalized omnivores, recruiting to protein or carbohydrate baits and visiting extrafloral nectaries.

The species is a generalized cavity nester, most often nesting in dead branches or dead vine stems that are lodged in low vegetation. It may also nest occasionally in live stems and in myrmecophytes such as Cordia nodosa and Triplaris, but its nesting in these cavities appears to be opportunistic rather than any specialized preference. Workers may build small amounts of thin, brittle carton that cover or restrict nest entrances. Colonies may be 
polydomous, and aggregations of workers and brood may be found in ephemeral cavities such as beneath aroid leaves appressed to trunks and beneath bark flaps. Most often nests contain only workers and brood, but I have twice found nests with workers, brood, and a single physogastric queen, suggesting monogyny.

One of these nests was in an elongate scar on the trunk of a small understory tree (Erythrochiton lindenii, Rutaceae). The scar was covered with thin, brittle, mud-like carton. I found one physogastric queen among the workers and brood, and a thorough search did not reveal any other reproductives.

Another nest was in a live stem of a large-stemmed shrub in the Asteraceae. The trailside herb had stems that had been extensively hollowed out by a stem-boring lepidopteran larva, and one of the stems had been cut by machete, leaving a $13 \mathrm{~mm}$ diameter, exposed, necrotic end. A brasiliensis nest occupied the cavity in this cut stem, and the workers had constructed a carton baffle over the cut end. The large lumen was almost completely closed by carton, except for a small entrance hole just large enough for workers.

Colonies may be subject to parasitism by Microdon (Syrphidae). One nest I collected at La Selva Biological Station contained three large Microdon larvae in addition to workers and brood.

\section{Comments}

Species in the limata complex (brasiliensis, carinata, limata, and tenuicula in Costa Rica) all have abundant erect flexuous setae on the face, moderate length to short propodeal spines that are directed posteriorly, and elongate tapering petioles. The four species can be difficult to separate. They differ primarily in the nature of the ventral processes of the petiole and postpetiole. Crematogaster brasiliensis has distinct anteroventral processes on both the petiole and postpetiole. Crematogaster limata and carinata lack postpetiolar processes. In Costa Rica, brasiliensis and tenuicula are relatively distinct because tenuicula lacks an anteroventral petiolar process and the petiole is higher and more triangular in side view. These two species converge and become more difficult to distinguish in South America. Crematogaster brasiliensis may also be confused with foliocrypta, but foliocrypta has appressed rather than erect tibial pilosity.

I was able to compare the syntypes of brasiliensis directly with a collection from a Cordia nodosa plant near Manaus (P. S. Ward \#9140). This nest series exhibited size polymorphism and the syntypes matched the smaller workers. The measurements for the lectotype were HL 0.68, HW 0.81, SL 0.69.

I have not been able to examine the types of Crematogaster brasiliensis arawak Weber, 1938:208. The original description is insufficient to place arawak among the various species related to $C$. limata. I examined a "cotype" of Wheeler's inca from the MCZC. The specimen is labeled "Callanga," while the published type locality is Peru, Chaquimayo. The Callanga specimen is a large worker of brasiliensis and I am assuming the inca type is the same. 


\section{Holotype worker}

Costa Rica, Prov. Heredia, La Selva Biological Station, $10^{\circ} 26^{\prime} \mathrm{N}, 84^{\circ} 01^{\prime} \mathrm{W}, 50 \mathrm{~m}, 6$ Mar 1993 (INBio-OET, Project ALAS collection code FPM/03/03) [INBC, specimen code INBIOCRI001225782].

\section{Paratypes}

One worker, same locality and date as holotype, ALAS collection code FPM/03/08 [BMNH, specimen code INBIOCRI001225726]; one worker, same locality and date, ALAS collection code FPM/03/12 [MHNG, specimen code INBIOCRI001276067]; one worker, same data [NHMB, specimen code INBIOCRI001276068]; one worker, same locality and date, ALAS collection code FPM/03/25 [LACM, specimen code INBIOCRI001275035]; one worker, same locality, 17 Mar 1993 (Longino, collection code JTL3586) [UCDC, specimen code INBIOCRI001271923]; same data [MCZC, specimen code JTLC000001378]; same data [USNM, specimen code JTLC000001379].

Crematogaster JTL-015: Longino et al. 2002.

\section{Range}

Costa Rica, Panama, Venezuela, Ecuador.

\section{Description of worker}

Color light to dark brown, gaster darker than rest of body, mandibles straw yellow, often contrasting with darker head capsule.

Mandibles smooth and shiny; face smooth and shiny; scapes with abundant long subdecumbent setae and scattered long, erect setae; antennal club 2-segmented; anterior margin of clypeus very weakly convex; clypeus shiny with 2-4 longitudinal rugulae; face with moderately abundant, medium length setae; in full face view a few short setae projecting from posterior margin of head, none from lateral margins; ventral surface of head smooth and shiny with sparse subdecumbent pilosity.

In lateral view, pronotum rises steeply, curves into weakly convex dorsal surface of promesonotum, dropping posteriorly to propodeal suture; mesonotum slightly differentiated, raised slightly relative to pronotum; dorsal and posterior faces of propodeum not differentiated, sloping evenly from mesonotum to petiolar insertion; propodeal suture impressed medially, appearing shallow in lateral view because lateral carinulae bridge suture; propodeal spines of medium length, spiniform, upturned; side of pronotum smooth and shiny; katepisternum and side of propodeum microareolate/punctate, with variable degree of smooth shiny spaces, particularly medial katepisternum and lateral propodeum; pronotal dorsum with faint microareolate sculpture overlain by weak longitudinal rugulae; 
mesonotum with relatively strong lateral carinulae that extend onto propodeum, medial area smooth and shining to weakly sculptured; propodeal declivity weakly areolate punctate anteriorly, grading to smooth and shiny posteriorly; invariably with pair of long flexuous setae on humeri, shorter pair on mesonotum, and seta on base of propodeal spine, variable number of additional setae may be present on promesonotum (series from Osa Peninsula with relatively abundant dorsal setae of variable length); legs with appressed pubescence, no erect setae.

Petiole in side view triangular; side with feeble to well-impressed microareolate/punctate sculpture; anteroventral tooth varying from low, obtuse angle to distinct subacute tooth; dorsal face subquadrate, longer than wide, smooth and shining; posterodorsal face short; posterolateral tubercles each with a long seta; postpetiole in dorsal view globular, or slightly wider than long with weak posterior emargination; postpetiole with small obtuse to subacute anteroventral tooth; dorsum smooth and shiny; with 4 or more erect setae; fourth abdominal tergite smooth and shiny with 20-30 long erect setae (more than 50 on series from Osa Peninsula).

\section{Measurements}

Holotype: HL 0.505, HW 0.530, HC 0.492, SL 0.389, EL 0.114, WL 0.512, SPL 0.054, PTH 0.128, PTL 0.169, PTW 0.145, PPL 0.139, PPW 0.156, CI 105, OI 23, SI 77, PTHI 76, PTWI 86, PPI 112, SPI 11.

Other specimens: HL $0.580,0.535,0.635$; HW 0.633, 0.584, 0.710; HC 0.572, 0.522, 0.647; SL 0.458, 0.460, 0.536; EL 0.133, 0.120, 0.158; A11L 0.236; A11W 0.108; A10L 0.102; A10W 0.097; A09L 0.042; A09W 0.065; A08L 0.038; A08W 0.058; WL 0.639, 0.570, 0.708; SPL 0.097, 0.118, 0.109; PTH 0.153, 0.125, 0.163; PTL 0.194, 0.184, 0.236; PTW 0.174, 0.142, 0.184; PPL 0.152, 0.133, 0.170; PPW 0.181, 0.138, 0.222; CI 109, 109, 112; OI 23, 22, 25; SI 79, 86, 84; PTHI 79, 68, 69; PTWI 90, 77, 78; PPI 119, 104, 131; SPI 15, 21, 15; ACI 2.39 .

\section{Queen}

A normal queen (dorsal face of propodeum drops steeply from postscutellum and much of propodeum appears ventral to scutellum and postscutellum, Fig. 1); color light to dark brown, gaster darker than rest of body; mandibles smooth and shiny; face smooth and shiny; scapes with abundant long subdecumbent setae and scattered long, erect setae; terminal four segments of antenna gradually enlarged, forming club; anterior margin of clypeus flat to weakly emarginate; clypeus shiny with faint etchings laterally; face with abundant, long flexuous setae; in full face view sparse setae project from lateral and posterior margins of head posterior to eyes, none from lateral margins anterior to eyes; ventral surface of head smooth and shiny with sparse suberect pilosity; pronotal dorsum at right angle to anterior collar, short, vertical, continuous with vertical anterior face of mesonotum; moderately abundant flexuous erect setae on dorsal mesonotum and scutellum; one 
long seta on side of propodeum anterior to propodeal spine; propodeal spine short, triangular; femora with subdecument setae; tibia with combination of subdecument and long suberect setae; petiole similar to worker but dorsal face more tapered anteriorly, anteroventral tooth absent or a small, ventrally-directed obtuse triangle; postpetiole with no ventral tooth or a minute denticle, postpetiole subquadrate in dorsal view, posterior margin gently convex with faint medial emargination; fourth abdominal tergite smooth and shiny; postpetiole and fourth abdominal tergite with abundant erect flexuous setae; size characters as in Figures 4 and 5.

\section{Etymology}

This species is named for its tendency to nest beneath epiphyte mats in montane forests, which are often dominated by bryophytes.

\section{Biology}

Crematogaster bryophilia prefers montane wet forest habitats, where it nests in mature forest canopy. It nests in dead branches but unlike most Crematogaster species also frequently nests beneath epiphyte mats. Most collections of $C$. bryophilia that I have observed are from the Atlantic slope of Costa Rica. At La Selva Biological Station, in lowland rainforest, it is relatively rare. It occurred in 7 of 52 canopy fogging events, and I have only once found it there by manual search (a nest was in a thin dead branch of a tall Erythrina tree [Fabaceae]). Upslope from La Selva in Braulio Carrillo National Park I collected a nest that was $20 \mathrm{~m}$ high in a Licania tree (Chrysobalanaceae). There was a moss-covered branch and along the branch was a patch of flat, pale green lichen. Beneath this lichen patch were a single colony queen, most of the workers, and all of the brood. Workers occurred in galleries beneath the moss, extending about one half meter to each side of the lichen patch. I did not see any workers on the surface of the moss mat or on foliage. Perhaps the lichen provided an improved microhabitat, being warmer and drier than the surrounding moss. Near Turrialba I found an aggregation of workers, brood, and alate queens under a bark flap on a Psidium guajava tree (Myrtaceae) in a brushy pasture at the edge of mature forest. The workers were foraging in columns on the Psidium trunk and branches. In the Peñas Blancas Valley east of Monteverde, a montane wet forest site at $800 \mathrm{~m}$ elevation, I have collected the species on over five occasions. I observed one nest in a thin dead branch, several in internodes of Cecropia insignis saplings (Cecropiaceae), one in the hollow stem of a small Guarea (Meliaceae), and one under an epiphyte clump in a recently felled Licaria tree (Lauraceae). I found nests under epiphyte mats at Estacion Cacao in Guanacaste Conservation Area and at Sirena in Corcovado National Park. Nests may contain alate queens and tiny pale males. Twice I have found ergatogynes, once alone in a nest with workers, and once along with a single physogastric colony queen.

Beyond Costa Rica I have records of collections from montane areas in Panama, Venezuela, and Ecuador. The specimens from Venezuela were intercepted with orchids at a U. S. quarantine station, suggesting association with epiphytes. 
This species is infrequent in collections, and most of my collections have been by discovering nests, finding workers in fresh treefalls, or finding nocturnal foragers. It is not among the species routinely found in baiting studies, sweep samples, or Malaise traps. Yet my nest collections are relatively frequent, suggesting the species can be common if you know where to look. It is a habitat and elevational specialist, perhaps a largely nocturnal forager, and perhaps doing much of its foraging under epiphytes, all factors contributing to its apparent rarity.

\section{Comments}

Crematogaster bryophilia is uniquely characterized by the combination of (1) shiny face, (2) subquadrate dorsal face of petiole, (3) appressed tibial pilosity, (4) moderate length erect filiform setae on face, and (5) "normal" propodeal spines (as opposed to curvispinosa's spines with swollen bases). It is unclear what its affinities are. The subquadrate petiole and appressed petiolar pilosity are like curvispinosa and obscurata. The smooth integument and long filiform setae are like the limata group.

\section{Crematogaster carinata Mayr 1862}

Plate 1

Crematogaster carinata Mayr, 1862:768. Syntype workers: Brazil, Rio de Janeiro (Novara) [NMW, MCSN] (examined, NMW worker here designated LECTOTYPE). Emery, 1922:136: combination in $C$. (Orthocrema).

Crematogaster (species not indicated): Forel 1898:380 (description of parabiosis).

Crematogaster limata r. parabiotica Forel, 1904b:683. Syntype worker: Colombia, Magdalena, Orihueca, parabiotic with Dolichoderus debilis (coll. Forel) [MHNG] (examined, worker here designated LECTOTYPE). Forel, 1912:217: description of queen. Emery, 1922:136: combination in C. (Orthocrema). Wheeler, W.M. 1921b:152; Wheeler, W.M. 1923:3; Kutter, 1931:61; Santschi, 1939:161; Kempf, 1972:88: subspecies of limata. NEW SYNONYMY

Crematogaster parabiotica Forel (part): Wheeler, W.M. 1921 a.

Crematogaster cf. limata parabiotica Forel (part): Davidson 1988, Seidel et al. 1990, Davidson et al. 1990.

\section{Range}

Costa Rica to Brazil (Rio de Janeiro), Bolivia.

\section{Description of worker}

Color red brown; mandibles, antennal club, and tarsi usually lighter yellow; workers monomorphic in size.

Mandibles smooth and shining; clypeus usually with 5-6 longitudinal carinulae, these may be more abundant, making clypeus uniformly striate, or they may be nearly absent, making clypeus smooth and shining, especially medially; head about as long as wide, subquadrate, with emarginate posterior border; antenna with distinct two-segmented club, or 
third segment from end somewhat enlarged, blurring distinction between two and threesegmented club; scapes with abundant long erect setae; when scapes laid back from antennal insertions, they slightly surpass margin of vertex; face largely smooth and shining, with variable extent of striated region between antennal insertion and eye, and whorled above antennal insertion; face covered with abundant long flexuous white setae, no appressed pubescence; in face view abundant setae project from lateral and posterior margins.

Promesonotum in profile forming evenly convex surface, varying from flattish to forming peak at juncture of pro and mesonotum; propodeal suture deep in dorsal view but obscured in profile due to lateral carinulae that bridge the suture; posterior mesonotum curves smoothly into horizontal dorsal face of propodeum; propodeal spines short, projecting posteriorly such that they are more or less in same plane as dorsal face of propodeum; dorsal and posterior face of propodeum appear well differentiated in lateral view, the dorsal face confluent with the horizontal spines, the posterior face sloping down to petiolar insertion, but faces less differentiated medially; pronotal dorsum with variably developed longitudinal carinulae, strongest laterally, becoming weaker medially, interspaces smooth and shining; mesonotal dorsum with two strong, subparallel lateral carinae, interspace smooth and shining or with faint longitudinal carinulae; dorsal face of propodeum striatorugose, rugulae extending onto spines, posterior face smooth and shining; side of pronotum smooth and shining; katepisternum and ventral portion of side of propodeum variously punctatorugose; dorsal portion of side of propodeum smooth and shining; mesosomal dorsum with abundant long flexuous white setae, setae on pronotal humeri longest; femora and tibiae with abundant long erect setae.

Petiole in side view subtrapezoidal, varying in length and degree of narrowing anteriorly, weakly punctate to nearly smooth; anteroventral tooth well developed, often forming a right-angle to short acute tooth; dorsal face of petiole smooth and shining, elongate, widest posteriorly, regularly tapering anteriorly, with a long flexuous seta on each posterolateral tubercle and varying number of short setae along posterior border; postpetiole lacking ventral tooth, globular in dorsal view, with abundant erect setae; fourth abdominal tergite smooth and shining, with abundant long flexuous erect white setae, no appressed pubescence.

\section{Measurements}

HL 0.561, 0.528, 0.657; HW 0.604, 0.563, 0.722; HC 0.565, 0.507, 0.664; SL 0.485, 0.512, 0.612; EL 0.130, 0.139, 0.175; A11L 0.215; A11W 0.101; A10L 0.113; A10W 0.089; A09L 0.068; A09W 0.064; A08L 0.051; A08W 0.051; WL 0.615, 0.585, 0.744; SPL 0.077, 0.109, 0.148; PTH 0.148, 0.137, 0.166; PTL 0.207, 0.213, 0.250; PTW 0.144, 0.138, 0.174; PPL 0.169, 0.129, 0.178; PPW 0.162, 0.119, 0.166; CI 108, 107, 110; OI 23, 26, 27; SI 86, 97, 93; PTHI 71, 64, 66; PTWI 70, 65, 70; PPI 96, 92, 93; SPI 13, 19, 20; ACI 0.64 . 
A normal queen (dorsal face of propodeum drops steeply from postscutellum and much of propodeum appears ventral to scutellum and postscutellum, Fig. 1) with general shape, sculpture, and pilosity characters of the worker; size characters as in Figures 4 and 5 .

\section{Biology}

Crematogaster carinata is a biologically complex species and there is almost certainly some degree of genetic structuring that is not readily revealed by external morphology. This species and its close relative $C$. levior often have large polygynous colonies that blanket large sections of forest, with various degrees of mutual foraging and nesting with other unrelated ant species. Forel observed this species nesting with Dolichoderus debilis in Colombia, and coined the term parabiosis for the mutual sharing of nest space and foraging columns by multiple species (Forel 1898). Further examples of parabiosis involving carinata (as parabiotica) were described by Wheeler (1921a).

In the Atlantic lowland forests of northeastern Costa Rica, including coastal strand vegetation, C. carinata forms large polygynous, perhaps even unicolonial colonies. Columns of workers are spread over second growth vegetation and multiple crowns of trees, with small clusters of physogastric queens, brood, and workers dispersed in dead twigs and branches and under epiphytes. There is no obvious colony center, and it is difficult to discern colony boundaries. At La Selva Biological Station it is one of the most common species in the canopy. It occurred in 24 of 52 canopy fogging events. In an old treefall I once found a small aroid with a carinata nest in and around the root ball. The ants had covered the roots with a mass of carton material to form a nest volume about the size of a large orange. Inside were abundant workers, brood, and 43 dealate queens. Some of these queens had torn remnants of wings, suggesting they never left the nest for a nuptial flight and perhaps never mated. In general when multiple queens are found in nests they are evenly distributed in the nest volume, individually or in pairs. Brood is segregated by size. I observed a similar occurrence of large polygynous colonies in the Santa Marta region of Colombia, the same site as Forel's original observations of parabiosis. In contrast to these observations of polygyny, discrete nests with single physogastric queens seem to be the rule in the Pacific and southeastern Atlantic lowlands of Costa Rica, and at some sites in Venezuela.

On occasion I find aggregations of workers only, with no brood. All the dead sticks in a patch of forest understory will be filled with workers. The nest aggregation will be bounded, with all nests within about a meter of each other, but no colony center or area with brood can be found.

In different parts of its range, in both polygynous and monogynous forms, Crematogaster carinata may form parabiotic associations with other ants. In the La Selva forest canopy it cohabits large ant gardens with Odontomachus panamensis. Because the ant gar- 
dens are conspicuous and packed with Crematogaster workers and brood, it can appear that the Crematogaster are a specialized associate with Odontomachus, but closer inspection reveals that the ant gardens are nodes of higher Crematogaster density in a sea of thinly spread Crematogaster nests. It is possible that the ants in Odontomachus nests are genetically and behaviorally differentiated from those in the diffuse polydomous colonies, but I have not found any evidence for this based on external morphology.

In the Pacific lowlands of Costa Rica I have twice seen parabiotic associations between carinata and Dolichoderus species. At Carara I observed a parabiotic association between carinata and D. debilis. Several nests were in a cluster of dead branches. Crematogaster workers and brood were distributed in multiple chambers, and one chamber contained a single physogastric queen. The nests of the two species were contiguous and interdigitated, with interconnections among chambers, but they were still largely segregated. In general the Crematogaster occupied smaller and more peripheral chambers, while the Dolichoderus occupied larger chambers in the center of the branches. In some peripheral chambers I found workers of both species together, but these chambers never contained brood. Any chamber with brood always contained only one species. In Corcovado National Park I observed parabiotic foraging involving carinata and D. inermis Mackay. Workers of both species were using the same foraging trails, and both species occurred together in clusters of non-foraging workers. Davidson has multiple observations of parabiotic foraging between carinata and D. debilis in Peru (pers. comm.), and many similar observations are reported by Forel (1898) and Wheeler (1921a).

Wherever I have observed carinata it makes use of carton construction to a variable extent. Construction may be as small as a $2 \mathrm{~cm}$ diameter shelter over a single scale insect. Several times I have seen a $5-10 \mathrm{~cm}$ wide globular mass of carton extending from the end of a rotten stick or investing epiphyte roots, extending the nest volume. In very humid areas these small carton nests may sprout epiphyte seedlings and in some cases form small ant gardens. Workers form large and more fully developed ant gardens only when in the presence of a larger parabiotic associate.

Workers may be found foraging day or night, and they are generalized omnivores. I have seen them scavenging dead or wounded insects, they recruit to carbohydrate and protein baits, and they are frequent visitors at extrafloral nectaries.

\section{Comments}

Costa Rican species in the limata complex are brasiliensis, carinata, limata, and tenuicula. All have abundant erect flexuous setae on the face, moderate length to short posteriorly directed propodeal spines, and elongate tapering petioles. The four species can be difficult to separate. They differ primarily in the nature of the ventral processes of the petiole and postpetiole. Crematogaster carinata has a squared-off anteroventral petiolar process and no postpetiolar process. Both brasiliensis and tenuicula have ventral postpetiolar processes. Crematogaster limata usually lacks a petiolar process but can be very like 
carinata in some cases. Crematogaster limata is a larger ant with longer propodeal spines. Crematogaster carinata may also be confused with foliocrypta, but foliocrypta has appressed rather than erect tibial pilosity.

Crematogaster carinata is also very similar to the South American species Crematogaster levior Longino (see Miscellanea). The two species are not cleanly separable on morphological grounds. In this revision I have restricted $C$. levior to a specialized parabiotic associate of Camponotus femoratus (Fabricius). Crematogaster levior and Camponotus femoratus inhabit ant gardens throughout Amazonian South America. All Crematogaster material collected from these ant gardens has the worker pronotum completely smooth and shining. In contrast, I have identified as carinata all material with longitudinal carinulae on the pronotum. However, on purely morphological grounds there is continuous variation from strongly carinate forms, to forms with faint traces of carinulae, to the completely smooth pronotum of levior. Crematogaster levior is polygynous and polydomous like some populations of carinata. Crematogaster levior is always parabiotic with Camponotus femoratus, while $C$. carinata is facultatively parabiotic with other large ants in the genera Dolichoderus and Odontomachus.

Further evidence for separate species has been found by D. Davidson at her study site at Cocha Cashu Biological Station in Amazonian Peru. In early studies of ant gardens and their ants (Davidson 1988, Seidel et al. 1990, Davidson et al. 1990) I helped identify the Crematogaster and I failed to differentiate levior and carinata. More recent observations on behavior and defensive chemistry suggest discrete sympatric forms, with levior inhabiting ant gardens with Camponotus and carinata found outside those gardens (Davidson pers. comm.). Davidson has discovered that levior has lost its chemical defense and instead relies on the defensive capabilities of $C$. femoratus. In contrast, carinata has retained chemical defenses. Reflecting the differences in defensive chemistry, levior does not elevate the gaster when disturbed; carinata does. Crematogaster carinata is often found living parabiotically with Dolichoderus debilis, and in this case it is the Dolichoderus that has lost its chemical defense, relying on the Crematogaster. Davidson's observations on carinata in Peru not withstanding, one should not assume that carinata exhibits the same behavior and defensive chemistry throughout the range. It would be worth investigating whether carinata at La Selva Biological Station, which lives in ant gardens with the aggressive species Odontomachus panamensis, exhibits behavior and chemistry more like levior. In contrast, the carinata from Costa Rica's Pacific slope, which is monogynous and parabiotic with non-aggressive Dolichoderus, might be like Peruvian carinata.

Forel's brief description of parabiotica was followed by a list of specimens: Colombia, Magdalena, Orihueca, parabiotic with Dolichoderus debilis (Forel); Para (Göldi); Costa Rica (Pittier); and Brazil, Amazonas, Jurua, Jurua Miry, among leaf bases of Tillandsia No. 5734 (Ule). I examined the Colombian and Ule's Brazilian material under parabiotica at MHNG. The Colombian material had carinate pronota and matched my collections from 
the Santa Marta area. Ule's Brazilian material, probably from ant gardens, had smooth pronota. Forel's published description of parabiotica suggested that the Ule specimens might be a separate variety. Among the specimens at MHNG a worker from Orihueca has "typus" written on the label. Other labels have "cotypus" or no indication of type status. It appears that Forel based the description primarily on the Colombian material and I am forced to treat the Orihueca specimen as the lectotype of parabiotica and synonymize it under Mayr's carinata. The Ule specimens I identify as levior. Following this hypothesis of species boundaries, Wheeler's (1921a) discussion of parabiosis included observations of carinata living parabiotically with Dolichoderus, and levior living parabiotically with Camponotus femoratus.

Within carinata, there is pronounced variation in the degree of anterior narrowing of the petiole in side view, strength of pronotal carinulae, size of propodeal spines, and some details of queen size and petiole shape. Crematogaster levior is more likely to be a "good" species, in terms of phylogeny and/or genetic similarity. Crematogaster carinata, with its greater geographic range and morphological variability, is more likely to be a set of allopatric or parapatric species, or even a set of broadly sympatric cryptic species.

\section{Crematogaster crinosa Mayr 1862}

Plate 3,5

Crematogaster crinosa Mayr, 1862:767. Syntype workers: Brazil, Rio de Janeiro (Novara) [NMW] (examined). Mayr, 1887:627: description of queen, male. Emery, 1922:134: combination in $C$. (Orthocrema).

Crematogaster brevispinosa Mayr, 1870a:403. Holotype worker: Colombia, S. Fé de Bogotá (Lindig) [NMW] (examined). Wheeler, G. C. and Wheeler, J. 1952:260: description of larva. Santschi, 1918:182: combination in C. (Orthocrema). NEW SYNONYMY

Crematogaster brevispinosa var. minutior Forel, 1893:399. Syntype worker, queen: Antilles Islands, Saint Vincent (H. H. Smith) [MHNG] (examined). Emery, 1922:134: combination in C. (Orthocrema). Forel, 1897:300: race of brevispinosa. NEW SYNONYMY

Crematogaster brevispinosa var. schuppi Forel, 1901a:299. Syntype worker, queen: Brazil, Rio Grande do Sul, Porto Alegre (Schupp) [MHNG] (examined). Emery, 1922:134: combination in C. (Orthocrema). NEW SYNONYMY

Crematogaster brevispinosa var. striatinota Forel, 1912:211. Syntype worker: Colombia, Magdalena, Rio Frio near Santa Marta, from the wood of a steamboat from Magdalena (Forel) [MHNG] (examined). NEW SYNONYMY

Crematogaster brevispinosa r. recurvispina Forel, 1912:212. Syntype workers: Brazil, Rio de Janeiro (Sampaio, Naegeli) [MHNG] (examined). Emery, 1922:134; Santschi, 1925:230: combination in $C$. (Orthocrema). NEW SYNONYMY

Crematogaster brevispinosa r. sampaioi Forel, 1912:213. Syntype worker, queen, male: Brazil, Rio de Janeiro (Sampaio) [MHNG] (examined). Emery, 1922:134: combination in C. (Orthocrema). NEW SYNONYMY

Crematogaster (Orthocrema) brevispinosa st. sericea var. semisericea Santschi, 1923:249. Worker: Argentina, Formosa, Guayculec (Joergensen) [NHMB] (examined). Unavailable name.

Crematogaster (Orthocrema) brevispinosa subsp. townsendi Wheeler, W.M. 1925:25. Syntype 


\section{Range}

Throughout the Neotropics, from southern Texas to Argentina and on numerous Caribbean islands.

\section{Description of worker (Costa Rica)}

Color red brown to black; workers usually with pronounced size polymorphism.

In face view head subquadrate, wider than long in larger workers, with emarginate posterior margin; mandibles coarsely striate, striae faint to pronounced; clypeus smooth and shiny or faintly granular or finely longitudinally striate; scapes short, in face view not attaining posterior margin of head when laid back; terminal three segments of antenna gradually lengthening and broadening, becoming increasingly densely pubescent, terminal two segments very much larger, so that antennal club appears two-segmented; scapes with short appressed pubescence, sometimes subdecumbent, never erect, with no differentiated long erect setae (occasionally a long seta on very large workers); face with sparse appressed to subdecument pubescence and sparse short erect setae; face smooth and shining or with variably developed fine longitudinal striation, most common on anterior face and space between eye and antennal insertion, occasionally extending posteriorly and medially, but always with at least median strip sublucid.

Promesonotal profile forming a single, somewhat flat-topped convexity; in large workers promesonotal suture visible, a dorsolateral arch that extends far forward, showing that dorsal pronotum is short and much of promesonotal dorsum composed of mesonotum (approaching queen condition); in small workers promesonotal suture effaced, visible only as oblique anterolateral impressions; propodeum with short but distinctly differentiated dorsal face, such that propodeal suture distinctly visible in lateral view as v-shaped impression; propodeum with long sloping posterior face; propodeal spines short, upturned; promesonotal dorsum and dorsal face of propodeum faintly punctate with varying development of longitudinal or transversely whorled rugulae or striations, lateral carinulae bridge propodeal suture, rarely forming a small triangular denticle; posterior face of propodeum smooth and shining or faintly microareolate; lateral pronotum with faint microsculpture; katepisternum and lateral propodeum faintly punctate to microareolate; promesonotum and bases of propodeal spines with highly variable number but usually abundant short stiff flattened setae; femora and tibiae with appressed to subdecumbent pubescence, no erect setae.

Petiole in lateral view subtriangular, often with slightly concave ventral margin, with strongly developed, anteriorly projecting, acute anteroventral tooth; side faintly granular or microareolate; dorsal face of petiole smooth and shining to faintly microareolate, about 
as wide as long, subquadrate or more often with convex sides, widest about one third distance from anterior margin, with one or more stiff setae on posterolateral tubercles; postpetiole with no ventral tooth, in dorsal view globular to subquadrate, usually slightly broader than long, rarely with faintly impressed posteromedian sulcus, with four or more stiff setae; fourth abdominal tergite smooth and shining or faintly microareolate, with abundant vestiture of short, stiff, flattened, erect setae, evenly distributed over surface of tergite (not clustered or concentrated anterolaterally).

\section{Measurements}

HL 0.801, 0.616, 1.052; HW 0.869, 0.701, 1.156; HC 0.837, 0.664, 1.123; SL 0.537, 0.454, 0.697; EL 0.175, 0.147, 0.252; A11L 0.248; A11W 0.138; A10L 0.097; A10W 0.113; A09L 0.055; A09W 0.078; A08L 0.034; A08W 0.066; WL 0.844, 0.688, 1.146; SPL 0.134, 0.095, 0.168; PTH 0.174, 0.142, 0.203; PTL 0.239, 0.206, 0.343; PTW 0.253, 0.224, 0.323; PPL 0.198, 0.182, 0.254; PPW 0.246, 0.205, 0.328; CI 108, 114, 110; OI 22, 24, 24; SI 67, 74, 66; PTHI 73, 69, 59; PTWI 106, 109, 94; PPI 124, 113, 129; SPI 16, 14 , 15 ; ACI 0.64 .

\section{Queen}

A normal queen (dorsal face of propodeum drops steeply from postscutellum and much of propodeum appears ventral to scutellum and postscutellum, Fig. 1) with general shape, sculpture, and pilosity characters of the worker; size characters as in Figures 4 and 5.

\section{Biology}

Crematogaster crinosa is an extremely widespread and generalized species that prefers highly insolated habitats. It is common in seasonally dry areas, less common in wet forests. In wet forest habitats it is typically found in the high canopy or in disturbed areas. It may form monodominant populations in mangrove forests.

Colonies are large and polydomous and it is usually difficult to locate colony boundaries. Nests are found in almost any kind of cavity, and columns of workers move from nest to nest. Nests can be in live or dead branches, in small rotten knots, under bark flaps, in cavities in fence posts, opportunistically in ant plants, and thinly dispersed in multiple small bark cavities. Workers, brood, and alate sexuals are dispersed across nests. Small amounts of carton construction are used to form baffles inside of nest cavities and to restrict nest entrances, but large external carton nests are never constructed.

Although new alate queens are relatively common in nests, I have rarely encountered physogastric colony queens. In my collecting experience, I have never found a colony that was obviously polygynous, with many dealate queens dispersed in many nests. However, I am treating Forel's minutior as a synonym of crinosa, and minutior from St. Vincent Island in the West Indies forms large polygynous, polydomous colonies in coastal areas (Forel 
1893).

In Colombia I observed the beginning of a nuptial flight just after dusk. I found a dense aggregation of males and workers under a bark flap, and the males were just beginning to fly.

Workers are omnivorous. They are attracted to protein and carbohydrate baits, they scavenge dead or injured insects, they visit extrafloral nectaries, and they tend Homoptera. When nests are disturbed they can be aggressive and will bite. Workers are continuously polymorphic, with a broad range of worker sizes.

Ecological equivalents are torosa and rochai. I can detect very few behavioral or ecological differences among these species. Crematogaster crinosa is the only member of the group that regularly dominates mangrove habitats. Mangrove forests in Costa Rica are sometimes dominated by Azteca, sometimes by $C$. crinosa. I found a similar situation in the Santa Marta area of Colombia. I have only one record of rochai from mangroves (a voucher collection from Adams' studies of mangrove communities, Adams 1994), and I have no record of torosa from mangroves. Other than in mangroves, crinosa is less abundant relative to torosa or rochai. For example, a collecting trip to a wildlife refuge in southern Texas yielded 13 separate collections of torosa but only one of crinosa. In northwestern Costa Rica, torosa and rochai are far more abundant than crinosa. Based on museum collections, crinosa seems to be the most common member of the crinosa group on various Caribbean and Pacific islands.

\section{Comments}

Members of the crinosa complex are among the most frequently encountered Neotropical ants, particularly in open or seasonally dry habitats. They are geographically variable and taxonomically difficult, and species boundaries are poorly defined (see Taxonomic Notes on C. crinosa and Related Forms). Crematogaster crinosa, rochai, and torosa are three very similar species that occur together in Costa Rica. They are difficult to distinguish and workers may not always be clearly identified. All three have the face with sparse erect setae over short appressed pubescence, the mesosomal dorsum and fourth abdominal tergite with short, stiff erect setae (or erect setae absent), the dorsal face of the petiole short with convex sides, and the propodeal spines short and upturned. Crematogaster crinosa can be differentiated from rochai throughout the range, because crinosa has a dense, even covering of erect setae on the fourth abdominal tergite, while rochai completely lacks these setae or has only a small cluster on each anterolateral humerus. Distinguishing crinosa from torosa is more difficult. In Costa Rica, torosa also has abundant erect setae on the fourth abdominal tergite, but these are usually clustered laterally and anterolaterally, leaving a median strip free of setae. Also, crinosa always has a long, sharp anteroventral petiolar process, while torosa more often has a short, blunt or squared-off process. Crematogaster crinosa can also be confused with erecta and moelleri, but these have flexuous erect setae on the pronotal humeri. 
The workers of recurvispina are small, with few setae on mesosoma and fourth abdominal tergite, and a strong anteroventral petiolar tooth. These may just be small workers of crinosa. A brief examination of the schuppi types revealed a queen and a minim worker. The queen had a strong anteroventral petiolar tooth, was abundantly setose, and had a quadrate head. It is probably crinosa. The other synonymies are all based on examination of medium-size to large workers that match the general features of crinosa as defined here.

\section{Crematogaster crucis Forel 1912 NEW STATUS}

Plate 3, 4

Crematogaster brevispinosa r. crucis Forel, 1912:212. Syntype workers: Colombia, Magdalena, Santa Cruz near Santa Marta, in a hollow branch, along with Azteca (Forel) [MHNG] (examined). Emery, 1922:134: combination in C. (Orthocrema).

\section{Range}

Colombia, Costa Rica.

\section{Description of worker (Costa Rica)}

Color varying within populations, uniformly orange brown, or bicolored with orange brown head and mesosoma and darker gaster, or uniformly dark red brown; workers of relatively uniform small size, lacking pronounced size polymorphism.

In face view head subquadrate, with emarginate posterior margin; mandibles smooth and shining with sparse large puncta; clypeus smooth and shiny or faintly etched; scapes short, in face view not attaining posterior margin of head when laid back; antennal club two-segmented; scapes with subdecumbent pubescence, with no differentiated long erect setae; face with sparse appressed to subdecument pubescence and sparse long erect flexuous setae; face smooth and shining.

Promesonotal profile forming a single continuous arch; dorsal face of propodeum short, visible in dorsal view; lateral carinae bridge propodeal suture such that in lateral view suture not visible, lateral profile forms a single sloping declivity from about middle of mesonotum to petiolar insertion; propodeal spines short, upturned; promesonotal dorsum and sides of pronotum completely smooth and shining, katepisternum with medial space smooth and shining, variable development of weak puncta and rugulae around edges; dorsal face of propodeum (a narrow transverse strip forming posterior wall of propodeal suture and extending onto bases of propodeal spines) rugulose; posterior face of propodeum smooth and shining; lateral face of propodeum largely smooth and shining, with faint longitudinal rugulae ventrally; mesosomal dorsum covered with subdecumbent long pubescence, pronotal humeri each with a long flexuous seta, pairs of shorter erect setae variably present on anterior mesonotum, posterior mesonotum near propodeal suture, 
and sides of propodeum midway between propodeal suture and propodeal spine; femora and tibiae with appressed pubescence, no erect setae.

Petiole in lateral view subtriangular, with slightly convex dorsal face, completely smooth and shining; anteroventral petiolar tooth strongly developed, anteriorly projecting, long and thin but with blunt tip; dorsal face of petiole smooth and shining, about as wide as long, with convex sides, widest about one third distance from anterior margin, posterolateral tubercles with a few short appressed hairs, occasionally with an inconspicuous longer suberect hair; postpetiole lacking ventral tooth, dorsum globular, smooth and shiny, with a few erect hairs; fourth abdominal tergite smooth and shining, somewhat lanose, with abundant pilosity that is a combination of suberect and subdecumbent long flexuous hairs.

\section{Measurements}

HL 0.707, 0.549, 0.632; HW 0.762, 0.588, 0.679; HC 0.741, 0.555, 0.649; SL 0.480, 0.394, 0.450; EL 0.160, 0.138, 0.154; A11L 0.241; A11W 0.138; A10L 0.119; A10W 0.133; A09L 0.058; A09W 0.081; A08L 0.039; A08W 0.069; WL 0.764, 0.570, 0.681; SPL 0.109, 0.081, 0.100; PTH 0.164, 0.134, 0.162; PTL 0.201, 0.137, 0.178; PTW 0.217, 0.176, 0.206; PPL 0.185, 0.141, 0.153; PPW 0.207, 0.162, 0.176; CI 108, 107, 107; OI 23, 25, 24; SI 68, 72, 71; PTHI 82, 98, 91; PTWI 108, 128, 116; PPI 112, 115, 115; SPI 14, 14 , 15 ; ACI 1.62 .

\section{Queen}

The queen of this species is unknown.

\section{Biology}

I know this species from very few collections. In the lowland wet forest of the Osa Peninsula, I collected workers twice from columns in recent treefalls. Ward collected a nest in Tayrona National Park near Santa Marta, Colombia, at the habitat edge between beach and dry forest. The colony was in $5 \mathrm{~mm}$ diameter dead twigs of Coccoloba (Polygonaceae). Adult males were found in the nests along with workers and brood. Workers were foraging in the same area as an active Azteca colony. Forel reported that the type specimens were from a hollow branch, "along with Azteca." Thus two of the few known collections were collected with Azteca, raising the possibility of a specialized association.

\section{Comments}

Costa Rican material, the type specimens, and additional material from the type locality are very similar. This species exhibits the general habitus of the crinosa complex, and in particular the face has sparse erect setae over short appressed pubescence, but it differs in having long flexuous setae on the mesosoma and fourth abdominal tergite. In Costa Rica there is no other species with which it can be confused. 
In addition to the material reported here as crucis, I have examined three collections (departments of Valle and Choco in Colombia, Madre de Dios in Peru) that are obviously related to crucis, with the same habitus and long flexuous setae on the fourth abdominal tergite, but differing in details of sculpture and pilosity. Further collections will be necessary to assess whether this is best interpreted as intra versus interspecific variation.

\section{Crematogaster curvispinosa Mayr 1870}

Plate 2, 8

Crematogaster curvispinosa Mayr, 1862:768. Holotype worker: Brazil, Rio de Janeiro (Novara) [NMW] (examined). Forel, 1911a:301: description of queen from Brazil, São Paulo, Ypiranga (v. Ihering). Forel, 1912:216: report of male. Emery, 1922:134: combination in C. (Orthocrema).

Crematogaster curvispinosa var. antillana Forel, 1893: 399. Syntype workers: St. Vincent, Richmond Estate, near sea level, in a rotten stump, ants numerous, in a cavity about 3in X 1/2 X 1/ 3, with larvae, but could find no female; and Morne a Garou, 1500-2000 ft, forest, beaten from foliage (H. H. Smith) [MHNG] (examined). Forel, 1912: 216: report of queens from Martinique and Castries, Santa Lucia; Rio Frio Colombia (Forel). Emery, 1922: 134: combination in C. (Orthocrema). NEW SYNONYMY

Crematogaster sculpturata Pergande, 1896:876. Syntype workers: Mexico, Tepic (Eisen and Vaslit) [MCZC, USNM] (examined). Wheeler, W.M. 1934:171: worker redescribed. Emery, 1922:136: combination in C. (Orthocrema). NEW SYNONYMY

Crematogaster (Orthocrema) curvispinosa var. kemali Santschi, 1923:250. Syntype worker and ergatogyne: Brasil, Santa Catarina, Blumenau (Reichensperger) [NHMB] (examined). NEW SYNONYMY

Crematogaster (Orthocrema) fuliginea Santschi, 1925:231. Syntype worker: Brazil, Minas Gerais (E. Luja). Synonymy by Santschi, 1929b:88.

Crematogaster (Orthocrema) curvispinosa var. obscura Santschi, 1929a:293. Syntype worker: Argentina, Jujuy (Neiva) [NHMB] (examined). Unresolved junior primary homonym of $C$. obscura Smith, F. 1857:76. NEW SYNONYMY

Crematogaster sculpturata subsp. phytoeca Wheeler, W.M. 1934:173. Syntype worker, queen, male: Mexico, Veracruz, Mirador, in Tillandsia streptophylla (Nos. 213, 519, 550, 606), in T. dasyliriifolia (362), in T. balbisiana (620, 651), in Conostegia xalapensis (209a, 209b), in internodes of Cecropia schiedeana (253), in hollow stems (564) (Skwarra) [LACM] (Skwarra \#362, \#651 examined). Non-type material listed by Wheeler: Tamarindo, in thorns of Acacia sphaerocephala; Camaron, in T. balbesiana $(675,688)$, in T. pruinosa (628a), in pseudobulbs of Schomburgkia tibicinis (479). Mirador (209a) includes an "ergatomorphic female." NEW SYNONYMY

Crematogaster (Orthocrema) sculpturata subsp. accola Wheeler 1934:175. Syntype worker: Mexico, Veracruz: Mirador, in Tillandsia streptophylla (Nos. 595, 662), in Conostegia xalapensis $(13,104)$ (Skwarra). NEW SYNONYMY

Crematogaster (Orthocrema) curvispinosa var. panamana Wheeler, W.M. 1942:195. Syntype worker, queen: Panama, Tumba Muerte Road, near Las Sabanas, in thorns of Acacia penonomensis (Wheeler). NEW SYNONYMY

\section{Range}

Throughout Neotropics, from southern Mexico to northern Argentina, Antilles. 
Color usually dark red brown to black.

Mandibles smooth and shiny; face largely smooth and shiny, with variable extent of microareolate sculpture around antennal insertions; scapes with 5-10 long, erect, delicate setae and abundant long decumbent setae; antennal club 2-segmented; clypeus with 2-4 longitudinal rugae; face with 20-30 short, stiff, erect setae; ventral surface of head with 0few erect setae.

In lateral view, dorsal profile of pronotum, mesonotum, and propodeum usually forming continuous curve, mesonotum sometimes somewhat elevated, forming weak promesonotal suture, dorsal and posterior faces of propodeum in same plane, sloping to petiolar insertion; propodeal spines projecting posterodorsally; pronotal dorsum with clathrate sculpture forming a lattice of longitudinal and transverse carinae with smooth and shiny interspaces; mesonotal dorsum with two elevated longitudinal carinae laterally, irregular clathrate rugulae medially; propodeal suture impressed medially but not visible in side view because lateral mesonotal carinae continue onto dorsal face of propodeum; mesonotal carina may have slight tooth at propodeal suture; dorsal face of propodeum with faint aerolate rugulose sculpture, posterior face smooth and shining; in dorsal view propodeal spines highly distinctive, with bases broad, weakly tapering, divergent, then abruptly bent to form short, sharp, posteriorly directed tips; side of pronotum flat, largely smooth and shining, with faint line of punctation dorsally; medial portion of katepisternum with variable extent smooth and shining, perimeter strip and anepisternum punctate to faintly microareolate; side of propodeum with variable extent and strength of punctate sculpture, densest ventrally, becoming smoother dorsally; setae on mesosomal dorsum stiff, relatively short, of variable length, longest approximately $0.16 \mathrm{~mm}$ long, dorsum of pronotum with anterior row of four setae, anterolateral and posterolateral dorsum of mesonotum (at propodeal suture) each with a seta; propodeal spine with 1-2 setae at angle where spine bends posteriorly; additional short setae variably present on mesosomal dorsum; legs with dilute appressed pubescence and no erect setae.

Petiole in side view trapezoidal; side faintly microareolate/punctate; anteroventral tooth produced, forming a right angle or more often acute; dorsal face subrectangular, somewhat longer than wide or more often almost as wide as long, smooth and shining; posterolateral tubercles each with two stiff setae; postpetiole globular, with no trace of median sulcus or posterior emargination; with small anteroventral tooth; dorsum smooth and shining or faintly microareolate; with 4-6 stiff erect setae; fourth abdominal tergite smooth and shining, with 15-25 stiff erect setae and very dilute short appressed pubescence; although setae of fourth abdominal tergite vary in density, length, and stiffness; one specimen from Santarem is an outlier with about 40 distinctly shorter, stiff erect setae.

\section{Measurements}

HL 0.572, 0.586, 0.632; HW 0.610, 0.580, 0.664; HC 0.565, 0.561, 0.626; SL 0.513, 
0.523, 0.576; EL 0.142, 0.152, 0.140; A11L 0.236; A11W 0.105; A10L 0.126; A10W 0.091; A09L 0.050; A09W 0.060; A08L 0.046; A08W 0.056; WL 0.626, 0.602, 0.678; SPL 0.125, 0.154, 0.180; PTH 0.159, 0.150, 0.166; PTL 0.185, 0.194, 0.217; PTW 0.177, 0.161, 0.187; PPL 0.158, 0.154, 0.184; PPW 0.188, 0.164, 0.205; CI 107, 99, 105; OI 25, 26, 22; SI 90, 89, 91; PTHI 86, 77, 76; PTWI 96, 83, 86; PPI 119, 106, 111; SPI 20, 26, 27 ; ACI 2.66.

\section{Queen}

A normal queen (dorsal face of propodeum drops steeply from postscutellum and much of propodeum appears ventral to scutellum and postscutellum, Fig. 1) with general shape, sculpture, and pilosity characters of the worker; size characters as in Figures 4 and 5 .

\section{Biology}

Crematogaster curvispinosa is a very common but inconspicuous ant. It is most common in brushy habitats, road edges, young second growth, and other highly disturbed areas. Colonies are small, and there is no evidence of polydomy. They are most often found nesting in narrow gauge dead stems. Nests may occur in dead grass stalks or vine stems that are only $2 \mathrm{~mm}$ outside diameter. They also occur opportunistically in single chambers of antplants such as Cecropia, Cordia alliodora, Triplaris, and myrmecophytic melostomes.

Colonies are small, a few dozen workers at most. Ergatogynes are common, and the reproductive structure of colonies is variable. Along with workers and brood, I have collected nests that contained (1) no apparent reproductive, (2) one ergatogyne, (3) one physogastric queen, or, in one case, (4) two ergatogynes and one physogastric queen. I have never seen a nest with multiple queens, or multiple ergatogynes in the absence of a queen. In one case I collected a nest with workers, brood, and one ergatogyne and kept it alive in the laboratory for about one year. The colony was not closely monitored or cared for, but sporadic feeding and observations yielded a surprising result. After about two months I found the ergatogyne wandering alone outside the nest tube, and she soon died. What remained in the tube were some adult workers, several large larvae, some queen pupae, and one callow alate queen. There was no worker brood. Several months later there were some adult males in the nest, but my notes are incomplete regarding other contents. Nearly a year from the time of collection the nest contained 14 queens, some with ragged wing stubs but most fully alate, a few workers, and a brood pile. Thus the colony began with an ergatogyne, workers, and brood, went through a bottleneck with only workers and unmated queens (no males), then later reconstituted a colony capable of producing new queens and workers. There were no other nests of curvispinosa in the laboratory, and the laboratory was in the United States, far from the native range of curvispinosa, so contamination from other colonies or access to males from other colonies was not possible. It 
appears that $C$. curvispinosa can produce female offspring from only workers and virgin queens. This is similar to Soulié's (1960) observation of thelytokous parthenogenesis in $C$. scutellaris.

Crematogaster curvispinosa can tolerate nesting in close proximity to larger ant species. Twice I have found curvispinosa nesting in the same hollow stem with another ant species, Camponotus in one case and Dolichoderus in another, with the two nests separated by only a narrow sawdust plug. Colonies can occupy single Cecropia internodes that are sandwiched between internodes occupied by Azteca.

Workers appear to forage day and night. Isolated foragers are common on low vegetation, and they are frequent visitors at extrafloral nectaries.

\section{Comments}

This species has uniquely shaped propodeal spines, with broad divergent bases and an abrupt transition to small posteriorly directed tips. Other characters include abundant short stiff setae on the face, clathrate or lattice-like sculpture on the pronotum, and appressed tibial pilosity. In Costa Rica the species cannot be confused with any others. Crematogaster curvispinosa appears relatively uniform over a broad range, usually with no closely related species. Only in Peru have I found what appear to be two morphospecies with the same general habitus as curvispinosa but differing in details of sculpture and pilosity.

The type worker of curvispinosa is headless, but it is clearly the widespread species I have called curvispinosa. The diagnostic characters are clearly visible: clathrate sculpture on pronotum, raised mesonotum, broad-based curving spines, punctate petiole with ventral tooth, and stiff erect setae throughout.

Santschi's obscura is a junior primary homonym. At NHMB I found a single worker with a label matching the published type locality for obscura, but the worker was identified as "obunea," not obscura. There is no published record of the name obunea in Crematogaster. There was no Crematogaster material labeled obscura at NHMB, and I presume Santschi erred in matching his labeling to the published description. I assume the worker labeled "obunea" is the holotype of Santschi's obscura (not Smith's).

The type of Santschi's kemali is lighter-colored than normal, but otherwise matches the characters of curvispinosa. I have not examined the types of Wheeler's accola and panamana, but it is clear from the descriptions that they fall within the range of variation of curvispinosa as defined here.

\section{Crematogaster distans Mayr 1870}

Plate 3,4

Crematogaster distans Mayr, 1870a:402. Lectotype worker: Colombia (Lindig) [NMW] (examined). Emery, 1922:134: combination in C. (Orthocrema). Santschi, 1918:182; Kempf, 1972:83: combination in C. (Neocrema). Kempf, 1968:392: description of queen. 
Crematogaster distans r. paraensis Forel, 1904a:37. Syntype workers: Brazil, Para (Göldi) [MHNG] (examined). Synonymy by Kempf, 1968:390.

Crematogaster distans subsp. parviceps Forel, 1908b:369. Syntype workers: Brazil, Sao Paulo (von Ihering) [MHNG] (examined). Emery, 1922:135: combination in C. (Orthocrema). Synonymy by Kempf, 1968:390.

Crematogaster distans r. pevsnerae Forel, 1912:218. Syntype workers: Venezuela, Zig Zag (Forel) [MHNG] (examined). Emery, 1922:135: combination in C. (Orthocrema). Synonymy by Kempf, 1968:390 [Kempf suggested probable synonymy; Bolton (1995) interpreted as formal synonymy].

Crematogaster distans var. cordinoda Forel, 1914c:12. Type worker a "variant of the type series of distans" (Kempf 1968:393). Emery, 1922:135: combination in C. (Orthocrema). Synonymy by Kempf, 1968:390.

Crematogaster distans subsp. vanda Borgmeier, 1929:209. Holotype worker: Brazil, Rio de Janeiro, Niterói (Bartholdy). Synonymy by Kempf, 1968:390.

Crematogaster (Neocrema) descolei Kusnezov, 1949:587, figs. 1-4. Holotype queen: Argentina, Prov. Jujuy, near Ledesma, road to Valle Grande, subtropical mesophyl forest, 2-12-1928 (Kusnezov No. 3310). NEW SYNONYMY

\section{Range}

The species complex occurs from southern USA (Texas) to Argentina (see Comments).

\section{Description of worker (Costa Rica)}

Color dark red brown to black.

Mandible largely smooth and shiny, with very faint striae; clypeus emarginate anteriorly, convex, smooth and shiny; face smooth and shiny; scape with moderately abundant, short, fully appressed pilosity and no erect setae; terminal 2-3 segments of antenna sequentially longer and more densely pubescent, especially terminal two, forming 2-segmented club; face and ventral surface of head with sparse short appressed pubescence and no erect setae; no erect setae projecting from sides of head in full face view.

In lateral view, promesonotum compressed, pronotum short but strongly convex, mesonotum projecting above pronotum and propodeum, dropping steeply to propodeal suture; propodeum with short, weakly differentiated dorsal face; propodeal suture deep, Vshaped, but suture partially obscured in lateral view by small lateral carinulae that bridge suture; propodeal spines short, conical, upturned; side and most of dorsum of mesosoma with faint punctation or weak microareolate sculpture, becoming smooth and shiny on posterior face of propodeum; mesonotum with a pair of short, stiff, erect setae, otherwise erect setae lacking on mesosoma; legs with sparse, fully appressed pubescence.

Petiole in side view subtrapezoideal, with faint microareolate surface sculpture; anteroventral tooth a shallow, obtuse gibbosity, not produced or angulate; dorsal face subrectangular, slightly longer than wide, smooth and shiny, anterolateral portions somewhat produced as lobes, anteromedian region depressed, sides approximately parallel anteriorly, converging posteriorly; postpetiole with small acute ventral tooth, postpetiole in dorsal view bilobed, wider than long, with longitudinal median sulcus, posterior margin emargin- 
ate; fourth abdominal tergite with faint microareolate sculpture; pair of stiff setae on posterodorsal petiole, two pairs on postpetiole, and about 20 stiff setae on fourth abdominal tergite.

\section{Measurements}

HL 0.699, 0.627, 0.698; HW 0.712, 0.649, 0.696; HC 0.671, 0.610, 0.653; SL 0.563, 0.479, 0.564; EL 0.143, 0.157, 0.167; A11L 0.284; A11W 0.135; A10L 0.135; A10W 0.107; A09L 0.069; A09W 0.086; A08L 0.046; A08W 0.069; WL 0.784, 0.686, 0.773; SPL 0.147, 0.140, 0.127; PTH 0.212, 0.187, 0.195; PTL 0.299, 0.258, 0.288; PTW 0.297, 0.295, 0.289; PPL 0.194, 0.180, 0.203; PPW 0.321, 0.286, 0.320; CI 102, 104, 100; OI 20, 25, 24; SI 81, 76, 81; PTHI 71, 72, 68; PTWI 99, 114, 100; PPI 165, 159, 158; SPI 19, 20 , 16 ; ACI 0.56 .

\section{Queen (Costa Rica)}

In lateral profile dorsal face of propodeum sloping obliquely from postscutellum, such that most of propodeum is posterior to scutellum (in contrast to normal queens, in which dorsal face of propodeum drops steeply from postscutellum and much of propodeum appears ventral to scutellum and postscutellum, Fig. 1); entire body, including scape, mandible, face, mesosoma, petiole, postpetiole, and fourth abdominal tergite extremely smooth and shiny, glass-like; propodeal spines completely absent; petiole and postpetiole robust, generally similar to worker in shape but completely lacking anteroventral petiolar tooth of any kind; remarkably devoid of erect setae or pubescence, funiculus and terminal segments of tarsi with typical subdecumbent pubescence, but no trace of pubescence or erect setae anywhere else on body; size characters as in Figures 4 and 5.

\section{Biology}

I have only three records of $C$. distans from Costa Rica, two older museum collections from the Central Valley, and one collection from La Selva Biological Station in the Atlantic lowlands. It is clear from material elsewhere in the range of the species that distans prefers seasonally dry, open or brushy habitats.

In general, distans has very large colonies that are low density. The one La Selva collection I observed was from a recent treefall. A large dead trunk had fallen, bringing a large Bauhinia vine tangle down with it. Crematogaster distans dominated the treefall, with columns of abundant workers spread throughout and streaming back to the canopy along lianas. I did not find any nest center or brood, but I did find two alate queens along with a worker aggregation in a hollow stick. In the Santa Marta region of Colombia I observed a distans nest in a dead stick, and on another occasion I found workers tending Coccoidea on Cnidoscolus (Euphorbiaceae). In a second growth forest in Venezuela I observed columns of workers descending a tree trunk and spreading out onto an Inga sapling, where large numbers of workers were tending scale insects. 
Nothing is known of colony founding, but queens exhibit a morphology often associated with social parasitism (see Natural History Overview). Kusnezov (1949) described descolei from a single alate queen and suggested that it was a workerless social parasite because of the small size and shiny integument. Kempf (1968) refuted this by reporting worker-associated colonies. The discovery of a colony of distans at La Selva with queens identical to descolei confirms the synonymy of descolei under distans. It is possible that Crematogaster distans is a temporary social parasite, requiring colonies of host species to establish new colonies of its own, but it is not workerless.

\section{Comments}

This species can at first be confused with crinosa and relatives because of the bare face, general lack of erect setae, and short upturned propodeal spines. The strongly bilobed postpetiole and the robust petiole with subrectangular dorsal face set it apart. There is a subtle mesosomal shape difference that is difficult to define, but involves a relatively compact and elevated promesonotum. These mesosomal and petiolar shape characters, along with the small shiny queens, are more like acuta and relatives than crinosa. Other than the superficial similarity to crinosa relatives, there are no other Costa Rican species with which it can be confused.

The distans complex occurs from southern Texas in the United States south to Argentina. Members of the complex share a characteristic mesosoma, petiole, and postpetiole shape, but they vary in details of surface sculpture and pilosity. The queens are small and with highly polished and smooth integument, but varying in details of pilosity and petiole shape. Kempf (1968) made a start in understanding this group, and a few additional notes are added here, but more material, especially queens associated with workers, is needed to make further progress. In the following paragraphs I outline geographic variation as I currently understand it, based on the few collections I have been able to examine and the published work of Kempf.

A single specimen from Hidalgo Co., Texas, USA, has a punctate face, a pair of setae on face, and no erect setae on mesosoma. A series from San Luis Potosí, Mexico, has a punctate face, a pair of setae on face, a pair on mesonotum, and a seta on each propodeal spine. The two worker syntypes of corvina Mayr 1870, from "Mexico," have punctate faces. One worker has a row of four setae on the pronotum, five on the mesonotum, two on the base of one propodeal spine, and one on base of the other. The other worker has one on the pronotum, seven on the mesonotum, three on one side and one on the other side of the dorsal face of the propodeum. These punctate forms at the northern limit of the range I identify as corvina, but it is clear there is considerable variation in pilosity, and they may grade into forms further south. Punctate faces reappear on two forms from South America: scelerata Santschi from Argentina and scelerata taperensis Borgmeier from Brazil, Pernambuco State. These are nearly identical to corvina but with a more developed anteroventral petiolar tooth. Thus punctate faces seem to occur at the margins of the range 
of the lineage. Like other amphitropical distributions, it is unknown whether this pattern is due to shared ancestry and some form of centripetal speciation, in which new forms replace older forms in the center of the range, or convergence due to similar selection pressures in marginal habitats.

Two series from Morelos, Mexico have most of face smooth but with distinct patches of punctation posteroventral to eyes and between eyes and antennal insertions. Thus they are intermediate in this character between corvina and other distans-like forms to the south. They have a pair of setae on the face, 2-4 setae on mesonotum, and a seta on each propodeal spine. The types of parviceps, from Sao Paulo state, Brazil, have similar facial sculpture, a combination of smooth and punctate. All remaining forms have the face completely shiny.

The series from Costa Rica and two series from Panama have one pair of setae on the mesonotum and none on the face, pronotum, or propodeum. The dorsal face of the petiole is relatively elongate, proportionally longer than the material from further north. The Costa Rican series from La Selva Biological Station has associated alate queens. These queens are identical in every respect to descolei Kusnezov. Crematogaster descolei was described from a single alate queen from Argentina. The queens are strikingly elegant, like glass figures, with no trace of setae or pubescence on most of body. The dorsal face of the petiole is proportionately quite long.

Material from Colombia and Venezuela, from which I have examined about ten worker collections from a variety of localities, shows a great deal of variation. Some collections from Venezuela appear identical to Costa Rican and Panamanian material. Others from the Santa Marta area of Colombia are also very similar, but have relatively shorter petioles. Finally, some collections from the Santa Marta area and departments of Antioquia, Huila, and Santander are very pilose, with multiple pairs of setae on both the pronotum and mesonotum, and multiple setae on the dorsal face and spine of the propodeum. Two of these collections have queens associated with them. The queens are quite similar in shape to the Costa Rican and descolei queens, but have abundant erect setae on the face and dorsal surfaces, and the petiole is shorter.

Kempf (1968) described his broad view of distans based on many collections, mostly from southern South America. He described worker characteristics and variation that match the less pilose forms from Venezuela, Colombia, Panama, and Costa Rica. In his figure of the dorsal face of a worker petiole, it appears relatively short, like the short-petiole material from Colombia, rather than the long-petiole material from Venezuela and Costa Rica. He described the queen of distans, based on collections from Rio de Janeiro and Sao Paulo states. He described the queen as being nearly identical to descolei, with the same general shape and degree of hairlessness, but with a relatively shorter petiole. He stated that descole $i$ was a probable synonym of distans.

It is possible there are multiple sympatric forms in the Neotropics, with queens being much more differentiable than workers. Putting the above observations together suggests 
the possibility there are at least three forms: (1) descolei-like, the queens of which are hairless and long petiolate, (2) a widespread form with hairless queens and short petioles, and (3) a setose form, with abundant setae on queens and workers. But much more queen-associated material and some thorough morphometrics will be needed to confirm or modify these patterns. I have followed the "synonym until proven distinct" approach by formally synonymizing descolei under distans. But future work on the complex will require a reevaluation of all the synonymized forms.

\section{Crematogaster erecta Mayr 1866}

Plate 3, 4

Crematogaster erecta Mayr, 1866:902, pl. 20, fig. 12. Lectotype worker: "Insel St. Joseph" [Kempf (1968) examined types in Riksmuseum, Stockholm; designated lectotype, suggested Islas Las Perlas, Panama, as source]. Emery, 1922:135: combination in C. (Orthocrema).

Crematogaster virgula Forel, 1899:85, pl. 4, fig. 4. Syntype workers: Costa Rica (Pittier, Tonduz); Panama, Bugaba (Champion) [MHNG] (Champion workers examined). Forel, 1908a:48: description of queen [MHNG] (examined). Emery, 1922:136: combination in C. (Orthocrema). Kempf, 1968:381: synonym of erecta.

Crematogaster (Orthocrema) brevispinosa st. projecta Santschi, 1925:230. Holotype worker: Surinam [NHMB] (examined). NEW SYNONYMY

\section{Range}

Costa Rica to Amazonian Brazil, Peru.

\section{Description of worker}

Color red brown to black; workers of relatively uniform size, lacking pronounced size polymorphism.

In face view head subquadrate, about as wide as long, with emarginate posterior margin; mandibles shiny, smooth or with faint striae; clypeus convex, smooth and shiny or more often with weak longitudinal rugulae that converge anteromedially; scapes just attaining posterior margin of head when laid back from insertions; terminal three segments of antenna gradually lengthening and broadening, becoming increasingly densely pubescent, terminal two segments very much larger, so that antennal club appears two-segmented; scapes with short appressed pubescence, sometimes subdecumbent, never erect, with no differentiated long erect setae; face with sparse appressed to subdecument pubescence and two short erect setae about midway between posterior border and posteriormost points of frontal carinae; malar spaces and space between eyes and antennal insertions with fine longitudinal striae, rest of face smooth and shining.

Promesonotal profile forming a single convexity, mesonotum slightly elevated posteriorly, dropping abruptly to propodeal suture; propodeal suture deep in dorsal view but not visible in lateral view due to lateral carinulae that bridge the suture, these carinulae with small denticle; dorsal and posterior faces of propodeum in same plane, sloping from pro- 
podeal suture to petiolar insertion, dorsal face a narrow anterior band with irregular rugulose sculpture, long posterior face smooth and shining; propodeal spines upturned, medium length, narrowly acute and spiniform; promesonotal dorsum with weak sculpture, usually with more or less longitudinally oriented rugulae or striae; side of pronotum smooth and shining, katepisternum weakly punctatorugose, often smooth and shining medially; side of propodeum largely smooth with faint longitudinal rugulae ventrally; pronotal humeri each with a long, relatively flexuous seta, two pairs of shorter, stiffer erect setae on mesonotum, occasionally a pair of short erect setae on dorsolateral propodeum; femora and tibiae with appressed to subdecumbent pubescence, no erect setae.

Petiole in lateral view subtriangular, sublucid, with faint microsculpture, ventral margin slightly concave, dorsal margin slightly convex; anteroventral petiolar tooth strongly developed, triangular, acute, curving ventrally; dorsal face of propodeum smooth and shiny, about as wide as long, sides convex, widest point of petiole about midlength; posterolateral tubercles each with a stiff erect posteriorly directed seta; postpetiole lacking ventral tooth, globular in dorsal view, about as long as wide, with about four erect posteriorly directed setae; fourth abdominal tergite smooth and shining, with sparse appressed pubescence and abundant long stiff flattened erect setae that are evenly distributed across tergite.

\section{Measurements}

HL 0.580, 0.596, 0.848; HW 0.640, 0.643, 0.886; HC 0.619, 0.610, 0.881; SL 0.471, 0.481, 0.626; EL 0.137, 0.154, 0.208; A11L 0.218; A11W 0.123; A10L 0.105; A10W 0.091; A09L 0.056; A09W 0.067; A08L 0.044; A08W 0.057; WL 0.640, 0.631, 0.890; SPL 0.117, 0.104, 0.184; PTH 0.143, 0.126, 0.196; PTL 0.187, 0.166, 0.313; PTW 0.188, 0.193, 0.280; PPL 0.171, 0.180, 0.220; PPW 0.171, 0.168, 0.252; CI 110, 108, 104; OI 24, 26, 25; SI 81, 81, 74; PTHI 76, 76, 63; PTWI 101, 116, 89; PPI 100, 93, 115; SPI 18, 16, 21; ACI 1.05 .

\section{Queen}

A normal queen (dorsal face of propodeum drops steeply from postscutellum and much of propodeum appears ventral to scutellum and postscutellum, Fig. 1) with general shape, sculpture, and pilosity characters of the worker; size characters as in Figures 4 and 5 .

\section{Biology}

Crematogaster erecta is a widespread species that occurs in a range of habitats including wet forest, seasonal dry forest, and thorn scrub. It seems to be more common in second growth or disturbed habitats than in mature forest. In Costa Rica it only occurs in the wet forests of the southern Pacific lowlands, on the Osa Peninsula and vicinity. Where it occurs it is abundant. Its nesting and foraging behavior is similar to C. crinosa and relatives, and it seems to be an ecological cognate to these. 
Mature colonies are very large and may blanket the habitat, with no clear colony boundaries. These large polydomous colonies are sometimes clearly polygynous, with multiple dealate queens dispersed among nests, and other times large areas seem to have workers and brood only, or workers, brood and alate sexuals. In areas with large colonies, workers can dominate the vegetation during the day, with columns of workers streaming along vines, across shrubs, and up and down tree trunks. At Sirena guard station in Corcovado National Park, C. erecta is extremely abundant on the buildings themselves (where it is a house pest), on clothes lines, and in all the surrounding second growth vegetation. Workers form temporary bivouacs in almost any small plant cavity, and the colony takes the form of a vast network of columns connecting nodes of clustered workers in plant cavities. These nodes vary in size, from $2 \mathrm{~cm}$ long dead twigs containing a dozen workers to large dead branchs with thousands of workers.

Colony founding seems to be claustral and single-queened, because I have multiple collections of lone foundresses from dead stems. Thus, polygyny in large colonies must be secondary, because pleometrotic foundress associations are not found.

Foraging is primarily diurnal. Foraging ceases at night, but workers will continue visiting a bait long into the night if it is discovered during the day and remains rewarding. At night the workers do not always return to a nest center. Instead they coalesce into the above mentioned nodes and scattered worker aggregations. Early in the morning dew-covered clusters of immobile workers occur throughout the habitat, slowly remobilizing as the sun rises and the environment warms up. Workers are omnivorous, recruiting to carbohydrate and protein baits, scavenging on dead or injured insects, and visiting extrafloral nectaries. They are aggressive around resources and will defend them from other insects. I once observed workers spend several hours cleaning a small lizard carcass, revealing that they will forage on carrion.

\section{Comments}

This species shares most of the characters of crinosa relatives (face with sparse erect setae over short appressed pubescence, sparse erect setae on mesosomal dorsum, short upturned propodeal spines) but differs in the presence of long flexuous rather than short stiff setae on the pronotal humeri. Similar species are crinosa, torosa, rochai, and moelleri. With practice some general habitus characters differentiate it from these four. The propodeal spines are a bit thinner and longer and the size polymorphism less pronounced. The flexuous rather than stiff humeral setae differentiate it from the first three. Crematogaster moelleri also has flexuous setae on the mesosoma, but on moelleri all the setae on the mesosomal dorsum are long and flexuous, rather than just those on the humeri.

\section{Crematogaster evallans Forel 1907}

Crematogaster evallans Forel, 1907b:6 (footnote). Syntype workers: Rio de Janeiro (Naegeli) 
[MHNG, MCSN] (examined, MHNG worker here designated LECTOTYPE). Emery, 1922:137: combination in C. (Eucrema).

Crematogaster evallans var. carbonescens Forel, 19131:233. Syntype workers: Brazil, Espirito Santo (von Ihering No. 16795) [MHNG] (examined). Emery, 1922:137: combination in $C$. (Eucrema). NEW SYNONYMY

\section{Range}

Costa Rica, Colombia, Brazil (Espirito Santo, Rio de Janeiro).

\section{Description of worker}

Color dark red brown to black.

Head subquadrate, posterior margin emarginate, with compound eyes projecting beyond lateral margins in full face view; mandibles striate; clypeus emarginate anteriorly, convex, with faint microareolate surface sculpture and widely spaced weak rugulae that converge anteromedially; face punctate over much of surface, with variably developed anteromedian strip on face smooth and shiny; scape surface etched, subopaque; scape with abundant erect setae, setae as long as width of scape or greater; antennal club not well defined, terminal 3-5 segments gradually lengthening and becoming increasingly densely pubescent, often appearing distinctly 3-segmented; face with abundant long erect fine whitish setae, both on dorsal surface and projecting from sides; malar spaces and ventral surface of head with abundant short erect to suberect setae.

In lateral view, dorsal profile of promesonotum moderately convex, mesonotum differentiated from pronotum, projecting and forming elevated anterior boss; propodeal suture a deep crease medially, visible in dorsal view, but thin lateral carinulae bridge suture, such that in lateral view suture appears broad, shallowly impressed; dorsal and posterior faces of propodeum not well differentiated, together in nearly the same plane as mesonotal dorsum; propodeal spines thin, long, sharp; side of pronotum evenly punctate and medially impressed; anepisternum and katepisternum evenly punctate; side of propodeum faintly microareolate to smooth and shining, always with much weaker sculpture than side of pronotum and katepisternum; promesonotal dorsum uniformly punctate, sometimes overlaying faint traces of clathrate rugae; dorsal and posterior faces of propodeum faintly microareolate, often fading to smooth and shiny posteriorly; promesonotum and dorsal face of propodeum with abundant long whitish setae; legs with combination of abundant suberect and decumbent setae.

Petiole in side view subtriangular, uniformly punctate; anteroventral tooth a shallow, obtuse gibbosity, not produced or angulate; dorsal face rectangular, about twice as long as wide, smooth and shiny on anterior two thirds, grading to faintly microaerolate posteriorly; postpetiole with short, blunt ventral tooth, postpetiole in dorsal view subquadrate, wider than long, with longitudinal median sulcus, posterior margin emarginate; anterolateral margin nearly perpendicular to stem of helcium, node of postpetiole separated from helcium by a distinct sulcus; fourth abdominal tergite with faint microareolate sculpture; 
abundant erect long whitish setae on posterodorsal petiole, postpetiole, and fourth abdominal tergite.

\section{Measurements}

HL 0.686, 0.634, 0.667; HW 0.742, 0.686, 0.693; HC 0.688, 0.631, 0.662; SL 0.664, 0.624, 0.655; EL 0.170, 0.152, 0.152; A11L 0.279; A11W 0.116; A10L 0.133; A10W 0.101; A09L 0.090; A09W 0.075; A08L 0.058; A08W 0.063; WL 0.791, 0.731, 0.758; SPL 0.202, 0.185, 0.188; PTH 0.193, 0.178, 0.182; PTL 0.277, 0.231, 0.241; PTW 0.213, 0.199, 0.195; PPL 0.198, 0.185, 0.189; PPW 0.292, 0.251, 0.254; CI 108, 108, 104; OI 25, 24, 23; SI 97, 98, 98; PTHI 70, 77, 76; PTWI 77, 86, 81; PPI 147, 136, 134; SPI 26, 25, 25 ; ACI 0.14 .

\section{Queen}

In lateral profile dorsal face of propodeum sloping obliquely from postscutellum, such that most of propodeum is posterior to scutellum (in contrast to normal queens, in which dorsal face of propodeum drops steeply from postscutellum and much of propodeum appears ventral to scutellum and postscutellum, Fig. 1); entire body, including scape, mandible, face, mesosoma, petiole, postpetiole, and fourth abdominal tergite smooth and shiny; propodeal spines long, acute; petiole and postpetiole robust, generally similar to worker in shape but completely lacking anteroventral petiolar tooth of any kind, and petiole relatively shorter, dorsal face only slightly longer than broad; appendages, dorsal surfaces of head, mesosoma, and postpetiole, and posterodorsal surface of petiole with abundant erect whitish setae; queens from Colombia, Dept. Magdalena relatively less pilose, with setae very sparse on fourth abdominal tergite; queens from Dept. Huila much more pilose, almost lanose over entire body, including fourth abdominal tergite; also, queens from Dept. Magdalena have relatively larger heads then queens from Dept. Huila; size characters as in Figures 4 and 5.

\section{Biology}

Crematogaster evallans is found in wet forest habitats. Like other relatives of $C$. acuta, it appears to have large colonies that are at low density and infrequently encountered. In Costa Rica I have observed it several times in Corcovado and Manuel Antonio national parks, usually as a rapid column of workers descending a tree and fanning out onto the ground or low vegetation. In one case I saw worn trails in the moss on a tree trunk, suggesting a large colony with regularly used trunk trails. I have seen only one nest, which was at a site near Santa Marta in Colombia, along a road edge. Multiple dead branches were lodged in a vine tangle about $4 \mathrm{~m}$ high in a small tree. A large colony occupied all the dead branches. The branches had been hollowed out by termites, and abandoned termite carton filled the interiors. Workers and alate queens were thinly scattered throughout the branches. There were few large aggregations of workers, and few of the 
nests contained any brood. There was no obvious colony center, and it is likely that these branches contained only part of a much larger colony that occurred higher in the tree. The nests contained numerous inquiline beetles and at least one silverfish (Atelurinae).

Nothing is known of colony founding, but queens exhibit a morphology often associated with social parasitism (see Natural History Overview).

\section{Comments}

Crematogaster evallans and the similar species $C$. acuta share a unique combination of characters: largely punctate face, erect tibial pilosity, and abundant clear to whitish (not amber, as in arcuata) long erect setae on the face and mesosomal dorsum. The two species may be distinguished by several characters (see Key), but perhaps the most discrete is the acute ventral postpetiolar tooth on acuta, contrasted with a bluntly rounded lobe on evallans.

\section{Crematogaster flavomicrops NEW SPECIES}

\section{Holotype worker}

Costa Rica, Prov. Heredia, La Selva Biological Station, $10^{\circ} 26^{\prime} \mathrm{N}, 84^{\circ} 01^{\prime} \mathrm{W}, 50 \mathrm{~m}, 15$ Jul 1986 (Longino, collection code JTL1386-s) [INBC, specimen code LACM ENT 144384].

\section{Paratypes}

Four workers, same locality as holotype, 10 May 1974 (Talbot and VanDevender) [LACM, specimen code LACM ENT 144385]; one worker, same locality, 1 Jul 1993 (INBio-OET, Project ALAS collection code B/02/139) [BMNH, specimen code INBIOCRI001233311]; one worker, same locality, 1 Mar 1994 (INBio-OET, Project ALAS collection code B/12/419) [UCDC, specimen code INBIOCRI001242455]; same data [MCZC, specimen code INBIOCRI001242451]; same data [USNM, specimen code INBIOCRI001242452]; same data [MHNG, specimen code INBIOCRI001242453]; same data [NHMB, specimen code INBIOCRI001242454].

Crematogaster JTL-011: Longino et al. 2002.

\section{Range}

Costa Rica, Colombia, Venezuela, Ecuador, Brazil (Amazonas).

\section{Description of worker}

Color yellow orange; workers monomorphic in size.

Mandibles feebly striate on proximal half, smooth and shining with large piligerous puncta on distal half; clypeus with two longitudinal carinulae at anterior margin, anterior 
margin gently convex to straight; head slightly longer than wide, subquadrate, with flat posterior border; antenna with terminal two segments enlarged to form a club; scapes with

abundant suberect flexuous setae; when scapes laid back from antennal insertions, they barely surpass margin of vertex; face smooth and shining; face covered with abundant, short, moderately stiffened, amber setae, no appressed pubescence; in face view short setae project from lateral and posterior margins; eye small, 5-6 ommatidia across long axis.

Promesonotum in lateral profile short, convex, forming an evenly curved arch; propodeal suture deep in dorsal view but partially obscured in profile by lateral carinulae that bridge the suture; propodeum with short, differentiated dorsal face and longer posterior face; propodeal spines short, spiniform, upturned; pronotal dorsum largely smooth and shining, with traces of longitudinal carinulae laterally; mesonotum with lateral carinae that converge toward propodeal suture; medial mesonotum concave, smooth and shining; dorsal face of propodeum feebly rugulose, posterior face smooth and shining; side of pronotum smooth and shining; katepisternum and side of propodeum shining, largely smooth with traces of feeble carinulae; mesosomal setae somewhat stiffened, abundant, forming a stubble over promesonotum and propodeal dorsum, variable length, humeral seta $0.14 \mathrm{~mm}$; tibiae with abundant short subdecumbent to erect setae, none longer than maximum tibial width.

Petiole in side view trapezoidal, faintly microareolate; anteroventral tooth small, rounded to subacute; dorsal face of petiole smooth and shining, subquadrate, about as wide as long, with a pair of setae on each posterolateral tubercle; postpetiole without anteroventral tooth, postpetiole in dorsal view globular, wider than long, with 6-8 setae; fourth abdominal tergite smooth and shining, with abundant medium-length suberect somewhat stiffened amber setae, no appressed pubescence.

\section{Variation}

Specimens from San Vito area in the southern mountains of Costa Rica are more robust, with the posterior face of propodeum partially punctate. In South America, there is a tendency for the lateral carinulae of mesonotum to form angle or tuberculate juncture dividing dorsal and posterior faces. In Venezuela, Brazil, and Ecuador the propodeal spines are less upturned. In Venezuela and Brazil the dorsal pilosity of the mesosoma is less dense, approaching the condition seen in minutissima. A collection from Venezuela has a very small alate queen, like minutissima, while a collection from Colombia has very large alate queens. This parallels variation in queen size seen in the minutissima complex in North America, and it remains to be seen whether this is inter versus intraspecific variation. The relatively small worker eye is a consistent character uniting these specimens.

\section{Measurements}

Holotype: HL 0.462, HW 0.464, HC 0.441, SL 0.350, EL 0.095, WL 0.472, SPL 
Other specimens: HL $0.479,0.583,0.610$; HW 0.488, 0.583, 0.613; HC 0.466, 0.545, 0.585; SL 0.359, 0.480, 0.460; EL 0.107, 0.111, 0.123; A11L 0.206; A11W 0.090; A10L 0.090; A10W 0.080; A09L 0.039; A09W 0.055; A08L 0.031; A08W 0.046; WL 0.523, 0.621, 0.642; SPL 0.110, 0.085, 0.121; PTH 0.125, 0.144, 0.155; PTL 0.160, 0.174, 0.194; PTW 0.149, 0.173, 0.185; PPL 0.121, 0.149, 0.149; PPW 0.163, 0.184, 0.180; CI 102, 100, 100; OI 22, 19, 20; SI 75, 82, 75; PTHI 78, 83, 80; PTWI 93, 99, 95; PPI 135, 123, 121 ; SPI 21, 14, 19; ACI 1.85 .

\section{Queen}

A normal queen (dorsal face of propodeum drops steeply from postscutellum and much of propodeum appears ventral to scutellum and postscutellum, Fig. 1) with general shape, sculpture, and pilosity characters of the worker; size characters as in Figures 4-5.

\section{Etymology}

This species is named for its yellow coloration and small eyes.

\section{Biology}

Crematogaster flavomicrops occurs in lowland to mid-montane wet forest habitats. It is not common, and is most often encountered in Berlese samples or Winkler samples of sifted leaf litter from the forest floor. It has been twice collected in rotten wood on Isla Gorgona in Colombia (M. Baena, pers. comm.).

\section{Comments}

The combination of yellow coloration and very small eyes uniquely identify this species. Also, the dorsal pilosity is abundant and somewhat short and stubble-like. Similar species are minutissima and wardi, which have larger eyes and sparser, longer, more flexuous dorsal setae. It is also similar to cubaensis (a Cuban endemic), which has similarly abundant short pilosity but larger eyes.

\section{Crematogaster flavosensitiva NEW SPECIES}

Plate 2

\section{Holotype worker}

Venezuela, Est. Barinas, Ticoporo Forest Reserve, 240m, 804'N, 7048'W, 26 Aug 1987 (Longino, collection code JTL1863) [MIZA, specimen code JTLC000001758].

\section{Paratypes}

One worker, same data as holotype [BMNH, specimen code JTLC000001380]; one worker, same data [UCDC, specimen code JTLC000001381]; one worker, same data 
[LACM, specimen code JTLC000001382]; one worker, same data [MCZC, specimen code JTLC000001383]; one worker, same data [MHNG, specimen code JTLC000001384]; one worker, same data [NHMB, specimen code JTLC000001385]; one worker, same data [USNM, specimen code JTLC000001386].

\section{Range}

Panama, Venezuela, Amazonian Brazil.

\section{Description of worker}

Color yellow orange; workers monomorphic in size.

Mandibles feebly striate on proximal half, smooth and shining with large piligerous puncta on distal half; clypeus with two longitudinal carinulae at anterior margin, anterior margin convex; head about as long as wide, subcircular; antenna with terminal two segments enlarged to form a club; scapes with abundant long erect setae, longest setae longer than twice maximum width of scape; when scapes laid back from antennal insertions, they distinctly surpass margin of vertex; face smooth and shining; face covered with abundant long flexuous white to amber setae, most setae about $0.10 \mathrm{~mm}$ long, a few twice as long on some specimens, no appressed pubescence; in face view abundant setae project from lateral and posterior margins.

Dorsal profile of mesosoma forming unbroken, shallowly convex surface from anterior pronotum to propodeal spines, then curving down to petiolar insertion; propodeal suture moderately impressed in dorsal view but obscured in profile due to lateral carinulae that bridge the suture; propodeum with short, weakly differentiated dorsal face and long posterior face; propodeal spines medium length, spiniform, posteriorly directed, weakly curving upward; pronotal dorsum with longitudinal carinulae and a few transverse carinulae anteriorly, producing incipient clathrate sculpture, interspaces smooth and shining; mesonotum with strong subparallel lateral carinae that extend across propodeal suture onto propodeum; medial mesonotum concave, smooth and shining; dorsal face of propodeum differentiated by weak to moderately developed punctate or punctatorugose sculpture; posterior face flat to concave, smooth and shining; side of pronotum smooth and shining; katepisternum and side of propodeum shining, largely smooth with traces of feeble microareolate sculpture and carinulae; mesosomal dorsum with flexuous white to amber setae, pair of humeral setae very long, to $0.26 \mathrm{~mm}$, pair of setae nearly as long on anterolateral mesonotum, other setae shorter, scattered over promesonotum and dorsal face of propodeum; tibiae with abundant long erect setae, of variable length, one or more tibial setae very long, much longer than maximum tibial width.

Petiole in side view trapezoidal, punctate, with acute anteroventral tooth; dorsal face of petiole smooth and shining, rectangular, longer than wide, with about four setae along posterior border; postpetiole with acute anteroventral tooth, postpetiole in dorsal view subquadrate and wider than long, with 6-8 erect setae; fourth abdominal tergite smooth and shining, with abundant long flexuous white to amber setae, no appressed pubescence. 
Holotype: HL 0.582, HW 0.619, HC 0.549, SL 0.538, EL 0.161, WL 0.615, SPL 0.152, PTH 0.147, PTL 0.225, PTW 0.173, PPL 0.147, PPW 0.190, CI 106, OI 28, SI 92, PTHI 65, PTWI 77, PPI 129, SPI 25.

Other specimens: HL 0.557, 0.504, 0.532; HW 0.614, 0.537, 0.566; HC 0.540, 0.479, 0.490; SL 0.532, 0.485, 0.504; EL 0.153, 0.137, 0.144; A11L 0.243; A11W 0.100; A10L 0.111; A10W 0.083; A09L 0.057; A09W 0.063; A08L 0.037; A08W 0.051; WL 0.598, 0.509, 0.542; SPL 0.142, 0.126, 0.140; PTH 0.156, 0.116, 0.138; PTL 0.205, 0.181, 0.208; PTW 0.166, 0.143, 0.146; PPL 0.140, 0.122, 0.139; PPW 0.184, 0.161, 0.159; CI 110, 107, 106; OI 27, 27, 27; SI 96, 96, 95; PTHI 76, 64, 66; PTWI 81, 79, 70; PPI 131, 132, 114; SPI 24, 25, 26; ACI 0.66.

\section{Queen}

A normal queen (dorsal face of propodeum drops steeply from postscutellum and much of propodeum appears ventral to scutellum and postscutellum, Fig. 1) with general shape, sculpture, and pilosity characters of the worker; size characters as in Figures 4 and 5 .

\section{Etymology}

This species is named for its yellow coloration and the presence of long sensory setae on the legs.

\section{Biology}

Crematogaster flavosensitiva occurs in lowland seasonal to wet forest habitats. The few known collections are from Winkler samples of sifted litter from the forest floor or from baits on or near the forest floor. The type series is from a nest that was in a rotten fruit exocarp in the leaf litter.

\section{Comments}

The presence of one or two extremely long flexuous setae on the hind tibia (much longer than the underlying suberect pilosity) is unique to two species, sumichrasti and flavosensitiva. The propodeal spines are upturned in sumichrasti, directed posteriorly in flavosensitiva. Although not known from Costa Rica, this species has been collected numerous times on Barro Colorado Island in Panama. It is related to flavomicrops, minutissima, monteverdensis, sumichrasti, and wardi, sharing with all these (1) yellow coloration; (2) shiny face; (3) abundant erect flexuous setae on face, mesosoma, and tibiae; and (4) subquadrate dorsal face of petiole. 


\section{Holotype worker}

Costa Rica, Prov. Heredia, 22km N Volcan Barva, 500m, $10^{\circ} 20^{\prime} \mathrm{N}, 84^{\circ} 04^{\prime} \mathrm{W}, 11 \mathrm{Mar}$ 1985 (Longino, collection code JTL0183) [INBC, specimen code INBIOCRI002280524].

\section{Paratypes}

One worker, same data as holotype [BMNH, specimen code JTLC000001387]; same data [UCDC, specimen code JTLC000001388]; same data [LACM, specimen code JTLC000001389]; same data [MCZC, specimen code JTLC000001390]; same data [MHNG, specimen code JTLC000001391]; same data [NHMB, specimen code JTLC000001392]; same data [USNM, specimen code JTLC000001393].

\section{Range}

Costa Rica.

\section{Description of worker}

Color red brown; workers monomorphic in size.

Mandibles smooth and shining; clypeus feebly striate, with 5 or more longitudinal carinulae, weakly convex, anterior margin straight; head about as long as wide, subcircular, with broadly convex sides and posterior border, posterior border with small, shallow median emargination; antenna with terminal two segments enlarged to form a club, third segment from end somewhat enlarged, blurring distinction between two and three-segmented club; scapes with abundant long erect setae; when scapes laid back from antennal insertions, they surpass margin of vertex; face largely smooth and shining, with variable extent of striated region between antennal insertion and eye, and whorled above antennal insertion; face covered with abundant long flexuous white setae, no appressed pubescence; in face view with moderately abundant suberect setae projecting from lateral and posterior margins.

Promesonotum in profile somewhat flattened dorsally, short anterior face of pronotum rises to dorsal face, dorsal faces of pronotum and mesonotum subequal in length, horizontal, forming single flat surface or meeting at a slightly produced angle, dorsal and posterior faces of mesonotum meeting at distinct angle, posterior face dropping to propodeal suture; propodeal suture deep in dorsal view but obscured in profile due to lateral carinulae that bridge the suture; lateral carinulae with or without minute triangular tooth at propodeal suture; propodeal spines medium length, projecting posteriorly; propodeum with differentiated dorsal and posterior faces; pronotal dorsum with sparse longitudinal carinulae, strongest laterally, becoming weaker medially, interspaces smooth and shining; anterodorsal face of mesonotum with weak, subparallel lateral carinae, these continue onto posterodorsal face as stronger carinae that converge posteriorly, interspace concave, smooth and shining; dorsal face of propodeum with a few coarse rugae, shining; posterior face smooth 
and shining; side of pronotum smooth and shining; katepisternum uniformly punctate; bulla of metapleural gland longitudinally carinulate, area around propodeal spiracle smooth and shining; mesosomal dorsum with a row of long flexuous white setae on anterior pronotum, a pair of long setae on anterior mesonotum, scattered shorter setae elsewhere, setae on pronotal humeri longest; femora and tibiae with abundant medium-length subdecumbent setae (unlike limata and relatives, which have long suberect setae).

Petiole in side view elongate, trapezoidal, shallowly but distinctly and uniformly punctate; anteroventral margin with a short right angle tooth; dorsal face of petiole smooth and shining, elongate, widest posteriorly, gradually tapering to gibbosities formed by petiolar spiracles, more abruptly constricted anterior to gibbosities, with two long flexuous setae along posterior border, sparse shorter setae on posterior border and sides; postpetiole with ventral margin flat, lacking anteroventral tooth, globular in dorsal view, with two long erect setae posteriorly, two medium-length setae anterodorsally, sparse short setae elsewhere; fourth abdominal tergite smooth and shining, with abundant long flexuous erect white setae, no appressed pubescence.

\section{Measurements}

Holotype: HL 0.643, HW 0.723, HC 0.631, SL 0.686, EL 0.166, WL 0.789, SPL 0.169, PTH 0.171, PTL 0.307, PTW 0.156, PPL 0.178, PPW 0.173, CI 112, OI 26, SI 107, PTHI 56, PTWI 51, PPI 97, SPI 21.

Other specimens: HL 0.591, 0.563, 0.654; HW 0.673, 0.622, 0.730; HC 0.611, 0.537, 0.657; SL 0.664, 0.631, 0.688; EL 0.163, 0.152, 0.181; A11L 0.265; A11W 0.119; A10L 0.145; A10W 0.089; A09L 0.074; A09W 0.060; A08L 0.063; A08W 0.052; WL 0.743, 0.692, 0.786; SPL 0.158, 0.138, 0.161; PTH 0.168, 0.135, 0.178; PTL 0.281, 0.255, 0.321; PTW 0.143, 0.127, 0.171; PPL 0.166, 0.152, 0.162; PPW 0.167, 0.142, 0.184; CI 114, 110, 112; OI 28, 27, 28; SI 112, 112, 105; PTHI 60, 53, 55; PTWI 51, 50, 53; PPI 101, 93, 114; SPI 21, 20, 20; ACI 1.55 .

\section{Queen}

The queen of this species is unknown.

\section{Etymology}

This species is named for its habit of constructing cryptic carton nests between leaves.

\section{Biology}

Crematogaster foliocrypta is known from only four collections, all from Braulio Carrillo National Park on the Atlantic slope of Costa Rica. The habitat where the species occurs is $500 \mathrm{~m}$ elevation rainforest. Two of the collections are workers obtained in mixed collections of foragers. One collection is from a cluster of very distinctive nests. The ants had constructed flat carton nests between leaves of small saplings, pulling two or more 
leaves together and sealing the edges, completely concealing the disk-like carton nest. I saw five of these nests in one small area. Often there were scale insects on the leaves inside the nest, and most nests I saw had spiders associated with them. The carton itself was composed entirely of filamentous material molded into passageways. The nests contained workers and brood, including some large larvae that were possibly queens, but none of the nests contained adult queens or males. A final collection was from the canopy of a Licania tree (Chrysobalanaceae). A small group of workers was in a dead stick, and other workers were scattered in small clusters throughout the crown.

G. B. Edwards of the Florida State Collection of Arthropods identified the spiders as immatures of the salticid genus Cotinusa. He and colleagues alerted me to the fact that a species of Cotinusa has been reported inhabiting a nest of Tapinoma melanocephalum (Fabricius) (Shepard and Gibson 1972). These spiders have stridulatory organs, and it has been suggested that the stridulation may be related to communication with ants (Maddison 1987).

\section{Comments}

The general habitus of this species allies it with the limata complex (brasiliensis, carinata, limata, and tenuicula in Costa Rica). It shares with these species the abundant erect flexuous setae on the face, the moderate length to short propodeal spines that are posteriorly directed, and the elongate tapering petiole. In contrast to all other limata complex species, it has appressed rather than erect tibial pilosity.

\section{Crematogaster jardinero NEW SPECIES}

Plate 2, 8

\section{Holotype worker}

Costa Rica, Prov. Heredia, 22km N Volcan Barva, 500m, $10^{\circ} 20^{\prime} \mathrm{N}, 84^{\circ} 04^{\prime} \mathrm{W}, 12 \mathrm{Mar}$ 1985 (Longino, collection code JTL0195) [INBC, specimen code JTLC000001402].

\section{Paratypes}

One alate queen, same data as holotype [INBC, specimen code JTLC000001394]; one worker and one alate queen, same data [BMNH, specimen code JTLC000001395]; one worker and one alate queen, same data [UCDC, specimen code JTLC000001396]; one worker and one alate queen, same data [LACM, specimen code JTLC000001397]; one worker and one alate queen, same data [MCZC, specimen code JTLC000001398]; one worker and one alate queen, same data [MHNG, specimen code JTLC000001399]; one worker and one alate queen, same data [NHMB, specimen code JTLC000001400]; one worker and one alate queen, same data [USNM, specimen code JTLC000001401]. 
Costa Rica.

\section{Description of worker}

Color dark red brown to black.

Mandibles striate, shiny; clypeus emarginate anteriorly, flat, shiny; face smooth and shiny; scapes clavate, with apical third distinctly wider than basal two thirds, with abundant long erect setae, longest erect setae longer than width of scape; terminal three segments of antenna enlarged, especially apical two, thus intermediate between a two and three-segmented club; face with abundant long erect amber setae; in full face view abundant setae projecting from posterior margin of head but not from sides.

In lateral view, pronotum rising steeply, curving into flat and more gently sloping posterodorsal face, which smoothly joins flat mesonotal dorsum, which slopes downward to propodeal suture, mesonotum very slightly produced, such that promesonotal suture visible as a very faint impression; propodeal suture broad and shallow, v-shaped; dorsal and posterior faces of propodeum distinct; propodeal spines broad-based but abruptly narrowing to short, narrowly acute spines; side of pronotum and dorsolateral propodeum smooth and shiny; katepisternum and ventrolateral propodeum with faint areolate rugose sculpture, sublucid; promesonotal dorsum and dorsal face of propodeum with faint irregular areolate rugose sculpture and etchings, sublucid, rugulae more pronounced on mesonotum than propodeum; posterior face of propodeum smooth and shiny; pronotum and mesonotum each with an anterior row of long, flexuous, erect, amber setae, pronotal row usually of four setae and mesonotal row usually of two; femora with sparse, long, subdecumbent setae; tibiae with similar subdecumbent setae and several pairs of long erect setae that are longer than width of tibia.

Petiole in side view trapezoidal, with microareolate sculpture; anteroventral tooth well-developed, triangular, acute; dorsal face rectangular, slightly longer than wide, smooth and shiny, with pair of long setae on posterior margin; portion of petiole posterior to dorsal face relatively well developed, forming a distinct cylindrical collar; postpetiole with no ventral tooth; postpetiole in dorsal view subquadrate/globular, about as wide as long, slightly wider anteriorly than posteriorly, posterior margin flat to very weakly convex, dorsum convex; fourth abdominal tergite smooth and shiny; postpetiole and fourth abdominal tergite with abundant long erect flexuous amber setae.

\section{Measurements}

Holotype: HL 0.691, HW 0.727, HC 0.663, SL 0.592, EL 0.154, WL 0.802, SPL 0.144, PTH 0.181, PTL 0.246, PTW 0.196, PPL 0.171, PPW 0.208, CI 105, OI 22, SI 86, PTHI 74, PTWI 80, PPI 122, SPI 18.

Other specimens: HL 0.683, 0.641, 0.717; HW 0.716, 0.692, 0.783; HC 0.666, 0.627, 0.698; SL 0.590, 0.557, 0.629; EL 0.147, 0.152, 0.175; A11L 0.260; A11W 0.111; A10L 
0.097; A10W 0.098; A09L 0.069; A09W 0.075; A08L 0.058; A08W 0.056; WL 0.788, 0.758, 0.829; SPL 0.108, 0.098, 0.141; PTH 0.173, 0.169, 0.180; PTL 0.240, 0.233, 0.255; PTW 0.205, 0.192, 0.216; PPL 0.182, 0.172, 0.164; PPW 0.214, 0.205, 0.219; CI 105, 108, 109; OI 22, 24, 24; SI 86, 87, 88; PTHI 72, 73, 71; PTWI 85, 82, 85; PPI 118, 119, 134; SPI 14, 13, 17; ACI 0.24 .

\section{Queen}

In lateral profile dorsal face of propodeum sloping obliquely from postscutellum, such that most of propodeum is posterior to scutellum (in contrast to normal queens, in which dorsal face of propodeum drops steeply from postscutellum and much of propodeum appears ventral to scutellum and postscutellum, Fig. 1); entire body (head, mesosoma, petiole, postpetiole, fourth abdominal tergite, appendages) polished, very smooth and shiny; mandible smooth and shiny; anterior margin of clypeus emarginate; clypeus flat; antennal club three-segmented; scapes clavate as in worker, with abundant long erect setae; face, mesonotum, scutellum, posterior face of petiole, postpetiole, fourth abdominal tergite, femora, and tibiae with moderately abundant long erect amber to whitish setae; dorsal face of pronotum perpendicular, at right angle to anterior collar, but not recessed beneath mesonotum as in raptor, and with anterolateral gibbosities; propodeal spines very long, narrow, parallel-sided, with blunt tips; petiole similar in form to worker but with shorter dorsal face, dorsal face about as wide as long, slightly wider anteriorly than posteriorly; postpetiole with no ventral tooth; postpetiolar dorsum trapezoidal, wider than long, wider anteriorly than posteriorly, with hint of posterior emargination and median sulcus, when viewed at certain angles; size characters as in Figures 4 and 5.

\section{Etymology}

This species is named after the Spanish word for gardener, in reference to its construction of ant gardens.

\section{Biology}

Crematogaster jardinero is an ant garden inhabitant that occurs in primary wet forest on the Atlantic slope of Costa Rica. The most extensive observations of this species are from work I carried out with Operation Raleigh in 1985, at a 500m site in the Zona Protectora of Braulio Carrillo National Park. While working in the canopy I discovered an "archipelago" of ant gardens. A larger central garden was in an Inga longispica crown (Fabaceae), and a constellation of smaller gardens was scattered in the same crown and an adjacent crown of Dipholis crotonoides (Sapotaceae). The large nest in the Inga was mosscovered, and looked like the oldest one. All gardens sprouted a diverse assemblage of epiphytes. The most abundant species was an aroid with thick, white, fleshy roots, which seemed to form the scaffolding of most of the nests. There were about 20 epiphyte species total, including Piperaceae, Gesneriaceae, Bromeliaceae, and Orchidaceae. When gardens 
were removed, the tree stems beneath them were densely clustered with scale insects. No scale insects were visible on any exposed stems; they only occurred where sheltered by the carton material of the gardens.

I dissected ten gardens, including the large central garden, and failed to find any concentrated area of brood or a physogastric queen. Curiously, after I finished the dissections and had returned to camp, I found a physogastric queen and one attending worker on my clothing. I presume she crawled or was shaken onto my clothing during the dissection, and I cannot say from which garden she came. However, the presence of this single physogastric queen after dissections of ten gardens suggests monogyny. Workers, brood, males, and alate queens were dispersed evenly throughout the matrix of each garden. The fact that the larvae were highly dispersed could indicate that they feed on something produced by the garden itself, rather than relying on an external food source that is harvested and delivered to them by workers. The arrangement was reminiscent of nests of the Attini, where larvae are evenly distributed in fungus gardens, rather than the more typical concentration of brood in discrete piles.

The Crematogaster were tolerant of other ant species on their gardens. Small nests of Tapinoma and Pseudomyrmex were found in dead sticks lodged in the garden epiphytes.

A second colony of this species was collected by Bill Haber at Laguna Poco Sol. This site is in the Cordillera de Tilarán, about $60 \mathrm{~km}$ west of the Braulio Carrillo site, at a similar elevation. He collected a small ant garden and delivered it to me in a plastic bag. I found a similar assemblage of epiphytes, and a similarly even dispersion of workers, brood, and alate queens in the nest.

Other collections of the species are from a mixed collection of foraging workers from another site in Braulio Carrillo National Park, where trees were being felled along a road cut, and an old collection from Hamburg Farm, a lowland rainforest site in Limon Province. The latter were collected by F. Nevermann and deposited in the MCZ at Harvard.

\section{Comments}

Crematogaster jardinero is uniquely characterized by the combination of (1) shiny face with erect setae, (2) subquadrate dorsal face of petiole, (3) erect tibial pilosity, (4) dark coloration, (5) short posteriorly directed propodeal spines, and (6) lack of anteroventral propodeal process. It can be confused with limata and relatives but differs in the more subquadrate, less tapering dorsal face of the petiole. The general habitus of the workers and the small shiny queen with posteriorly produced propodeum suggest a closer relationship to distans, acuta, and other species with "acuta-like" queens.

\section{Crematogaster limata F. Smith 1858}

Plate 1,6

Crematogaster limatus Smith, F. 1858:139. Syntype worker, queen, male: Brazil, Amazonas, Ega 
(=Tefe) [BMNH] (examined). Wheeler, W.M. 1921b:151: combination in C. (Orthocrema).

Crematogaster limata var. palans Forel, 1912:216. Syntype workers: Panama (Christophersen)

[MHNG] (examined). Wheeler, W.M. 1921b:151: description of queen. Emery, 1922:136: combination in C. (Orthocrema). Wheeler, W.M. 1942:197: description of male. NEW SYNONYMY

Crematogaster (Eucrema) inca subsp. ascendens Wheeler, W. M. 1925: 28. Syntype workers: Peru, Santa Ana, 3000ft, 3 Aug 1911, Yale Peruvian Expedition [MCZC, possibly also Royal Museum of Stockholm] (MCZC specimens examined). NEW SYNONYMY

Crematogaster (Orthocrema) limata st. dextella Santschi, 1929b:88, fig. 2. Syntype workers: Panama, Canal Zone, Barro Colorado Island, 17 VII. 1927 (G. C. Wheeler) [NHMB] (examined). Wheeler, G.C. and Wheeler, J. 1952:258: description of larva. NEW SYNONYMY

\section{Range}

Mexico to Bolivia and southern Brazil.

\section{Description of worker}

Color red brown; workers monomorphic in size.

Mandibles smooth and shining; clypeus varying from striate, with 5 or more longitudinal carinulae, to nearly smooth and shining, especially medially; head about as long as wide, subquadrate, with emarginate posterior border; antenna with terminal two segments enlarged to form a club, third segment from end somewhat enlarged, blurring distinction between two and three-segmented club; scapes with abundant long erect setae; when scapes laid back from antennal insertions, they surpass margin of vertex; face largely smooth and shining, with variable extent of striated region between antennal insertion and eye, and whorled above antennal insertion; face covered with abundant long flexuous white setae, no appressed pubescence; in face view abundant setae project from lateral and posterior margins.

Promesonotum in profile often formed of three planes, horizontal pronotal dorsum, somewhat elevated and downward sloping anterodorsal face of mesonotum, and more steeply sloping posterodorsal face of mesonotum; on smaller workers profile becomes more smoothly convex; propodeal suture deep in dorsal view but obscured in profile due to lateral carinulae that bridge the suture; posterior mesonotum curves smoothly into horizontal dorsal face of propodeum; propodeal spines long, projecting posteriorly such that they are more or less in same plane as dorsal face of propodeum, sometimes somewhat elevated; dorsal and posterior face of propodeum well differentiated, the dorsal face confluent with the horizontal spines, the posterior face sloping down to petiolar insertion; pronotal dorsum with variably developed longitudinal carinulae, strongest laterally, becoming weaker medially, interspaces smooth and shining, in some cases almost entirely smooth and shining with no carinulae; anterodorsal face of mesonotum with weak, subparallel lateral carinae, these continue onto posterodorsal face as stronger carinae that converge posteriorly, lateral carinae of the two faces meet at angulate to somewhat tuberculate juncture, interspace smooth and shining; dorsal face of propodeum faintly carinulate, posterior face smooth and shining; side of pronotum smooth and shining; katepisternum weakly to dis- 
tinctly punctate; side of propodeum very faintly sculptured; mesosomal dorsum with abundant long flexuous white setae, setae on pronotal humeri longest; femora and tibiae with abundant long erect setae.

Petiole in side view subtriangular, weakly punctate to nearly smooth; anteroventral tooth usually absent or produced as a short right angle tooth (tooth more developed in South America than Central America); dorsal face of petiole smooth and shining, elongate, widest posteriorly, regularly tapering anteriorly, with long flexuous setae along posterior border; postpetiole lacking ventral tooth, globular in dorsal view, with abundant erect setae; fourth abdominal tergite smooth and shining, with abundant long flexuous erect white setae, no appressed pubescence.

\section{Measurements}

HL 0.676, 0.583, 0.720; HW 0.761, 0.634, 0.791; HC 0.726, 0.594, 0.739; SL 0.663, 0.616, 0.766; EL 0.161, 0.151, 0.192; A11L 0.296; A11W 0.140; A10L 0.130; A10W 0.098; A09L 0.083; A09W 0.081; A08L 0.069; A08W 0.062; WL 0.746, 0.681, 0.852; SPL 0.231, 0.177, 0.245; PTH 0.180, 0.158, 0.187; PTL 0.267, 0.248, 0.276; PTW 0.163, 0.144, 0.176; PPL 0.182, 0.165, 0.185; PPW 0.195, 0.165, 0.196; CI 113, 109, 110; OI 24, 26, 27; SI 98, 106, 106; PTHI 67, 64, 68; PTWI 61, 58, 64; PPI 107, 100, 106; SPI 31, 26, 29; ACI 0.32 .

\section{Queen}

A normal queen (dorsal face of propodeum drops steeply from postscutellum and much of propodeum appears ventral to scutellum and postscutellum, Fig. 1) with general shape, sculpture, and pilosity characters of the worker; size characters as in Figures 4 and 5 .

\section{Biology}

Crematogaster limata is an extremely generalized species. It occurs most abundantly from sea level to $1000 \mathrm{~m}$ elevation, where it can be found in wet forest or dry forest, second growth or mature vegetation. It is most abundant in disturbed vegetation in wet forest areas. It is most often encountered near ground level, along roadsides, at forest edges, or in the understory of second growth vegetation. I rarely find it in mature forest.

Nests occur in almost any kind of small cavity. I most often find them in dead sticks, but other nest sites have included cavities in live stems of various plant species, an abandoned mud nest of a sphecid wasp, live internodes of Cecropia saplings, and rotting cacao pods.

Colonies may be small, with a single queen in a single nest. Larger colonies may fill many sticks and cavities scattered through a volume of a cubic meter or more, with a central nest containing the queen and abundant brood, and peripheral nests containing workers and brood or very often large aggregations of workers alone, with no brood. Colonies may 
be monogynous or polygynous. Many colonies that I have observed have contained a single queen, but polygynous colonies are also relatively common. One nest at Hitoy Cerere Biological Reserve in Costa Rica contained 21 physogastric queens. Foundress queens are usually found alone; but I once observed a pair of founding queens together in a small stick, suggesting that pleometrosis occurs at least occasionally.

Workers are omnivorous foragers. They recruit to baits and frequently tend extrafloral nectaries and Homoptera. Workers can be found foraging day or night.

Wheeler (1986) observed a behavioral association between $C$. limata and the large ponerine ant Ectatomma tuberculatum on Barro Colorado Island in Panama. Ectatomma tuberculatum nests in the ground at the bases of trees. The nest entrance is surmounted by a $2-3 \mathrm{~cm}$ wide thatch tube that extends about $15 \mathrm{~cm}$ up the side of a tree trunk or smaller plant stem. Wheeler observed that polydomous $C$. limata nests were often located near the mouths of E. tuberculatum nests, and that $C$. limata carried out periodic "raids" into the these nests. The raids were abrupt and short-lived, with workers streaming into and out of a nest entrance for about an hour. Peak flux rates were about 170 workers entering and 170 workers exiting per 15 minute observation period. Wheeler writes "Encountering an $E$. tuberculatum, the smaller $C$. limata climbed up one of the larger ant's legs and onto its thorax and head. The E. tuberculatum worker stood still as the $C$. limata licked the dorsal surface, especially the head. E. tuberculatum did not react aggressively to the intruders. Occasionally, an E. tuberculatum worker opened her jaws as the C. limata licked the extended mouthparts. Then the $C$. limata worker climbed down and quickly left the nest." Although Wheeler failed to observe the phenomenon during a brief visit to Finca La Pacifica in the dry forest habitat of northwestern Costa Rica, where she examined five $E$. tuberculatum nests, I suspect that the phenomenon occurs in Costa Rica. In the Atlantic lowlands I have seen several instances of large $C$. limata colonies with nests clustered in and around nest entrances of E. tuberculatum.

In the Santa Marta region, many $C$. limata nests contained abundant inquiline beetles in the genus Gnostus (Ptinidae).

\section{Comments}

Species in the limata complex (brasiliensis, carinata, limata, and tenuicula in Costa Rica) all have abundant erect flexuous setae on the face, moderate length to short propodeal spines that are posteriorly directed, and elongate tapering petioles. The four species can be difficult to separate. They differ primarily in the nature of the ventral processes of the petiole and postpetiole. Crematogaster limata has neither petiolar nor postpetiolar processes, differentiating it from the other three. The propodeal spines are large relative to those of carinata and brasiliensis. Crematogaster limata may also be confused with foliocrypta, but foliocrypta has appressed rather than erect tibial pilosity. 
Crematogaster longispina Emery, 1890:53 [Also described as new by Emery, 1894:57]. Holotype worker: Costa Rica, Prov. Limon, Jimenez [MCSN] (examined). Santschi, 1918:182: combination in C. (Eucrema) [misspelled here as longissima]. Emery, 1922:136; Santschi, 1923:250: combination in $C$. (Orthocrema).

\section{Range}

Nicaragua, Costa Rica, Ecuador.

\section{Description of worker}

Color dark red brown to black, head and gaster darker than mesosoma, tarsi, and terminal 2-3 segments of antenna yellow or at least much lighter brown.

Mandibles smooth and shiny; in full face view anterior margin of clypeus weakly convex; clypeus convex, shiny; face smooth and shiny; scapes smooth and shiny, slightly clavate, with abundant curved erect setae, setae about as long as width of scape; terminal 2-3 segments of antenna gradually lengthening to form club, becoming increasingly densely pubescent, terminal two segments the largest and most conspicuous; face with abundant erect flexuous setae; in full face view with abundant setae projecting from sides and posterior margin of head, both anterior and posterior to eyes; ventral surface of head with moderately abundant suberect setae.

In lateral view, promesonotum elongate, pronotum forming sigmoidal curve as it rises from anterior collar to weakly convex dorsal surface, continuous with anterior half of mesonotum, posterior half of mesonotum dropping steeply to propodeal suture; promesonotum elevated above propodeum; mesonotum with pair of pronounced lateral carinae, rounded and smooth anteriorly, becoming sharper posteriorly and converging to join small lateral carinulae that bridge propodeal suture; dorsal and posterior faces of propodeum differentiated, meeting at an angle; propodeal spines large, long, narrowly acute and spiniform, projecting upward and strongly diverging; side of pronotum always smooth and shining, pronotal dorsum smooth and shining or with faint longitudinal etching; katepisternum smooth and shining or with variably developed faint microareolate sculpture; side of propodeum smooth and shining or with faint microsculpture; dorsal face of propodeum smooth and shining to finely and faintly longitudinally striate; posterior face of propodeum smooth and shining; pair of long erect flexuous setae on pronotal humeri and anterior mesonotum, shorter erect setae scattered over promesonotum, dorsolateral margins of propodeum, and onto propodeal spines; legs with abundant short erect setae, setae shorter than width of tibiae.

Petiole in side view elongate, smooth and shining or with faint microsculpture, with variably developed small anteroventral tooth; in dorsal view, dorsal face of petiole long triangular, strongly and regularly converging anteriorly, widest posteriorly, smooth and shin- 
ing, with seta projecting from side near spiracle, and 1-2 setae on posterolateral corners;

petiole with slight bulge at petiolar spiracle, visible in both dorsal and along ventral margin in lateral view; ventral margin of postpetiole with denticle; postpetiole in dorsal view globular, with 2 pairs erect setae; fourth abdominal tergite smooth and shining or with faint microareolate sculpture, with abundant long flexuous erect setae.

\section{Measurements}

HL 0.660, 0.655, 0.761; HW 0.646, 0.634, 0.776; HC 0.593, 0.570, 0.700; SL 0.738, 0.717, 0.812; EL 0.149, 0.150, 0.168; A11L 0.282; A11W 0.106; A10L 0.142; A10W 0.079; A09L 0.083; A09W 0.057; A08L 0.061; A08W 0.049; WL 0.830, 0.798, 0.944; SPL 0.278, 0.309, 0.427; PTH 0.147, 0.142, 0.178; PTL 0.290, 0.276, 0.326; PTW 0.161, 0.170, 0.202; PPL 0.175, 0.147, 0.184; PPW 0.171, 0.159, 0.213; CI 98, 97, 102; OI 23, 23, 22; SI 112, 109, 107; PTHI 51, 51, 55; PTWI 56, 62, 62; PPI 98, 108, 116; SPI 33, 39, 45 ; ACI 0.79 .

\section{Queen}

A normal queen (dorsal face of propodeum drops steeply from postscutellum and much of propodeum appears ventral to scutellum and postscutellum, Fig. 1); head and mesosoma often covered with wax layer; color red brown, usually with lighter yellow scapes, antenna tips, and legs; head pilosity and sculpture characters as in worker; terminal 5 segments of antenna gradually enlarging to form club, the last two largest and most conspicuous; pronotal dorsum short, perpendicular, forming continuous profile with large mesonotum; propodeal spine variable, low and broadly triangular with blunt tip or somewhat produced with well-defined acute tip; abundant medium length setae on dorsal mesonotum and scutellum, anterolateral pronotum, lower katepisternum, and clustered around base of propodeal spine; femora and tibiae with abundant erect setae; petiole subtriangular in side view, anteroventral tooth small, bluntly obtuse to subacute; in dorsal view, dorsal face of petiole strongly convex posteriorly, strongly tapering anteriorly, with distinct tumosities at petiolar spiracle, with small erect seta projecting laterally near spiracle, and long erect seta on each posterolateral corner; postpetiole with no ventral tooth, subtrapezoidal in dorsal view, smooth and shiny, widest anteriorly, with a dorsal pair and posterior pair of long setae; fourth abdominal tergite smooth and shiny with sparse erect setae; size characters as in Figures 4 and 5.

\section{Biology}

Crematogaster longispina occurs in very humid conditions in wet forest. Although it occurs at sea level, it is more common at elevations slightly higher, around $500 \mathrm{~m}$. It forms small carton nests, usually no more than $10-15 \mathrm{~cm}$ across, on low vegetation and tree trunks. The carton is very loose and friable, and falls away easily on disturbance. These carton nests often host an array of sprouting epiphytes, and are penetrated by roots from 
epiphytes growing in the vicinity. Nests are usually packed with workers and brood, one or more physogastric queens (polygyny is common), and scattered coccoid Homoptera on the penetrating roots. Nests are locally abundant, occurring on many adjacent trunks or scattered through low vegetation. The nest dispersion and polygyny suggest polydomy and perhaps unicoloniality. In spite of many observations of nests, I have never observed adult males or alate queens.

Kleinfeldt (1978) studied a colony or colonies of C. longispina at La Selva Biological Station in Costa Rica, investigating its relationship to a common ant garden inhabiting epiphyte, Codonanthe crassifolia (Gesneriaceae).

The site at La Selva where Kleinfeldt carried out her study has been increasingly developed as a laboratory clearing, and the surrounding landscape has seen increasing deforestation. Crematogaster longispina no longer occurs at Kleinfeldt's study site, and in fact appears very rare at La Selva. I have only encountered it near the back edge of the La Selva station property, along a stream margin in a deep forested ravine. This species may require constantly high humidity levels and be particularly sensitive to habitat fragmentation and edge effects, especially at low elevations.

\section{Comments}

The combination of very long, divergent propodeal spines and abundant erect tibial setae uniquely identify this species. Crematogaster nigropilosa has similar large spines, but the pilosity on the tibiae is appressed.

\section{Crematogaster minutissima Mayr 1870}

Crematogaster minutissima Mayr, 1870b:995. Syntype worker, queen: "Aus Texas im Stockholmer Museum" [NMW, label on syntype worker "Texas" "Belfrage" "Stock"] (examined). Wheeler, W.M. 1908b:484: description of male. Wheeler, G.C. and Wheeler, J. 1960:14: description of larva. Emery, 1922:135: combination in C. (Orthocrema).

\section{Range}

USA, Mexico, Costa Rica.

\section{Description of worker (Costa Rica)}

Color yellow orange; workers monomorphic in size.

Mandibles feebly striate on proximal half, smooth and shining with large piligerous puncta on distal half; clypeus with two longitudinal carinulae at anterior margin, anterior margin gently convex to straight; head slightly longer than wide, subquadrate, with flat posterior border; antenna with terminal two segments enlarged to form a club, third segment from end somewhat enlarged, blurring distinction between two and three-segmented club; scapes with abundant suberect flexuous setae; when scapes laid back from antennal 
insertions, they barely surpass margin of vertex; face smooth and shining, with a few concentric carinulae around antennal insertion; face covered with abundant, medium-length, suberect, moderately stiffened, amber setae, no appressed pubescence; in face view short setae project from lateral and posterior margins.

Promesonotum in lateral profile convex, forming an evenly curved arch; propodeal suture deep in dorsal view but partially obscured in profile by lateral carinulae that bridge the suture; propodeum with very short, weakly differentiated dorsal face and long posterior face; propodeal spines short, spiniform, upturned; pronotal dorsum with sparse longitudinal carinulae, interspaces smooth and shining; mesonotum with parallel lateral carinae that converge toward propodeal suture, continue across suture, and onto bases of propodeal spines; medial mesonotum concave, smooth and shining; posterior face of propodeum flat to concave, smooth and shining; side of pronotum smooth and shining; katepisternum and side of propodeum shining, largely smooth with traces of feeble carinulae; promesonotum with somewhat stiffened, amber, erect setae in three ranks, four across anterior pronotum (humeral pair $0.21 \mathrm{~mm}$, longer than medial pair), two at anterior mesonotum $(0.17 \mathrm{~mm})$, and two at mesonotal midlength $(0.13 \mathrm{~mm})$; propodeal dorsum with two long setae, short inconspicuous setae sparsely scattered elsewhere on mesosomal dorsum, including on propodeal spines; tibiae with abundant short subdecumbent setae, none longer than maximum tibial width.

Petiole in side view trapezoidal, faintly microareolate, with longitudinal carinula at level of spiracle; anteroventral tooth small, rounded; dorsal face of petiole smooth and shining, subquadrate, longer than wide, with about six long amber setae along posterior border; postpetiole with small subacute anteroventral tooth, postpetiole in dorsal view subquadrate, wider than long, with emarginate posterior margin, abundant long setae; fourth abdominal tergite smooth and shining, with abundant long suberect somewhat stiffened amber setae, no appressed pubescence.

\section{Measurements}

HL 0.538, 0.535, 0.577; HW 0.538, 0.542, 0.606; HC 0.497, 0.499, 0.539; SL 0.438, 0.430, 0.483; EL 0.149, 0.142, 0.165; A11L 0.219; A11W 0.103; A10L 0.085; A10W 0.078; A09L 0.047; A09W 0.058; A08L 0.040; A08W 0.053; WL 0.570, 0.547, 0.602; SPL 0.093, 0.081, 0.104; PTH 0.141, 0.130, 0.139; PTL 0.196, 0.198, 0.193; PTW 0.163, 0.162, 0.162; PPL 0.137, 0.134, 0.135; PPW 0.190, 0.173, 0.200; CI 100, 101, 105; OI 28, 27, 29; SI 81, 80, 84; PTHI 72, 66, 72; PTWI 83, 82, 84; PPI 139, 129, 148; SPI 16, 15, 17 ; ACI 1.15 .

\section{Queen (Florida)}

A normal queen (dorsal face of propodeum drops steeply from postscutellum and much of propodeum appears ventral to scutellum and postscutellum, Fig. 1) with general shape, sculpture, and pilosity characters of the worker; size characters as in Figures 4-5. 
The one Costa Rican record of this species is from Santa Rosa National Park in the seasonally dry northern Pacific lowlands. I collected a series of nocturnal foragers from low vegetation in the second growth forest around the administrative headquarters. In the USA the species is known to occur in a variety of habitats across the southern and central USA, nesting in dead wood on the ground. Where there is moist leaf litter they may be collected in Winkler samples of sifted leaf litter.

\section{Comments}

In Costa Rica Crematogaster minutissima is uniquely characterized by the combination of (1) yellow coloration; (2) humeral setae of mesosomal dorsum long, flexuous, and longer than any other mesosomal setae; (3) relatively short propodeal spines; and (4) relatively compact promesonotum. Similar Costa Rican species are wardi and flavomicrops.

Crematogaster minutissima and its subspecies missouriensis Emery 1895 and smithi Creighton 1950 (see also Creighton 1939) are small yellow ants with short, upturned propodeal spines, promesonotal setae in three ranks decreasing in length from front to back, dorsal face of petiole subquadrate, about as wide as long, scapes just reaching margin of vertex, and tibiae lacking the extremely long setae of sumichrasti and flavosensitiva. It occurs throughout the southern United States and south to northwestern Costa Rica. Within these parameters there is variation in overall size, degree of development of the anteroventral petiolar and postpetiolar teeth, strength of punctate sculpture on katepisternum and side of petiole, and queen size. This variability is the basis for the subspecies missouriensis from the central United States and smithi from the southwestern United States. Taxonomic actions involving the two subspecies are postponed due to current research on the group by M. Deyrup (pers. comm.).

Crematogaster cubaensis and its synonym barbouri, restricted to Cuba, are similar to the population of small minutissima in Florida, but the promesonotum has a scruffy appearance, with abundant erect setae that are not clearly arranged in three ranks.

Crematogaster wardi is a parapatric version of minutissima that occurs in wet forest habitats in Costa Rica. It has longer scapes, the promesonotum is longer and flatter, the three ranks of setae on the promesonotum are more nearly equal length, the propodeal spines are longer and directed posteriorly, and the dorsal face of the petiole is distinctly longer than wide.

\section{Crematogaster moelleri NEW STATUS}

Crematogaster brevispinosa r. moelleri Forel, 1912:214. Syntype worker, male: Brazil, Santa Catarina, Blumenau (Möller) [MHNG] (examined). Emery, 1922:134; Santschi, 1923:250: combination in $C$. (Orthocrema). 
Costa Rica, Brazil (Santa Catarina).

\section{Description of worker}

Color red brown, gaster darker.

In face view head subquadrate, about as wide as long, with emarginate posterior margin; mandibles shiny, smooth or with faint striae; clypeus convex, smooth and shiny; scapes falling short or just attaining posterior margin of head when laid back from insertions; terminal three to four segments of antenna gradually lengthening and broadening, becoming increasingly densely pubescent, terminal two segments very much larger than proximal segments, so that antennal club appears two-segmented; scapes with abundant long subdecumbent to suberect pubescence, with no differentiated long erect setae; face with abundant long subdecumbent to suberect pubescence, 1-5 medium length filiform erect setae on face posterior to frontal carinae; malar spaces and space between eyes and antennal insertions with fine longitudinal striae, rest of face smooth and shining.

Promesonotal profile forming a single convexity, mesonotum slightly elevated posteriorly, dropping abruptly to propodeal suture (not elevated, sloping gradually to suture in Braulio Carrillo worker); propodeal suture deep in dorsal view but not visible in lateral view due to lateral carinulae that bridge the suture, these carinulae with small denticle (carinulae reduced and lacking denticle on Braulio Carrillo worker, such that propodeal suture more v-shaped in lateral view); dorsal and posterior faces of propodeum in same plane, sloping from propodeal suture to petiolar insertion, anterior half of face faintly and irregularly punctatorugose, becoming smooth and concave posteriorly; propodeal spines upturned, medium length, narrowly acute and spiniform; promesonotal dorsum with weak sculpture, usually with more or less longitudinally oriented rugulae or striae, interspaces smooth and shining; side of pronotum faintly striate anteriorly, becoming smooth and shining posteriorly; katepisternum punctatorugose (punctate on Braulio Carrillo specimen), sublucid; side of propodeum faintly longitudinally striate or etched ventrally, smooth dorsally; promesonotal dorsum with 7-11 medium length flexuous setae, those on pronotal humeri longest; anterodorsal propodeum with $0-1$ erect flexuous setae; femora and tibiae with abundant subdecumbent pubescence, no erect setae.

Petiole in lateral view subtrapezoidal, sublucid, with faint microsculpture; anteroventral petiolar tooth strongly developed, triangular, acute, with blunt tip (tooth smaller on Braulio Carrillo worker); dorsal face of propodeum smooth and shiny, subquadrate, about as wide as long, sides flat to somewhat convex, widest point of petiole about midlength; posterolateral tubercles each with an erect posteriorly directed seta; postpetiole with small sharp ventral denticle (lacking on Braulio Carrillo worker), globular to subquadrate in dorsal view, about as long as wide, posterior margin rounded to emarginate, with 2-8 erect setae; fourth abdominal tergite smooth and shining, with sparse subdecumbent to suberect pubescence and abundant long erect setae that are evenly distributed across tergite, erect setae stiffer than those on mesosoma. 
HL 0.908, 0.702, 0.921; HW 0.996, 0.812, 1.031; HC 0.933, 0.738, 0.989; SL 0.710, 0.570, 0.709; EL 0.174, 0.172, 0.170; A11L 0.303; A11W 0.136; A10L 0.125; A10W 0.120; A09L 0.082; A09W 0.090; A08L 0.074; A08W 0.078; WL 0.993, 0.786, 1.038; SPL 0.138, 0.102, 0.153; PTH 0.208, 0.179, 0.224; PTL 0.243, 0.180, 0.266; PTW 0.238, 0.196, 0.209; PPL 0.201, 0.161, 0.229; PPW 0.233, 0.203, 0.255; CI 110, 116, 112; OI 19, 25, 18; SI 78, 81, 77; PTHI 86, 99, 84; PTWI 98, 109, 79; PPI 116, 126, 111; SPI 14, 13 , 15 ; ACI 0.75 .

\section{Queen (Costa Rica)}

A normal queen (dorsal face of propodeum drops steeply from postscutellum and much of propodeum appears ventral to scutellum and postscutellum, Fig. 1) with general shape, sculpture, and pilosity characters of the worker; size characters as in Figures 4 and 5 .

\section{Biology}

Crematogaster moelleri inhabits montane moist to wet forest habitats in Costa Rica. It is known from few collections. In the Monteverde community area, near the continental divide in the Cordillera de Tilarán, I observed workers foraging on a tree trunk in a garden area. Suzanne Koptur collected workers twice from extrafloral nectaries of Inga trees. At $1000 \mathrm{~m}$ elevation on the Atlantic slope of the Cordillera Volcanica Central, in the Zona Protectora of Braulio Carrillo National Park, the ALAS project collected workers in one Malaise trap and an alate queen in another.

\section{Comments}

This species shares most of the characters of crinosa relatives (face with sparse erect setae over short appressed pubescence, sparse erect setae on mesosomal dorsum, short upturned propodeal spines) but differs in the presence of long flexuous rather than short stiff setae on the mesosomal dorsum. Similar Costa Rican species are crinosa, torosa, rochai, and erecta. The flexuous dorsal setae differentiate it from the first three. Crematogaster erecta has flexuous setae on the pronotal humeri but the other dorsal setae are short and stiff. Also, erecta has a general habitus difference: the propodeal spines are a bit thinner and longer and the size polymorphism less pronounced.

When I observed moelleri in the field in Monteverde it looked and acted like typical crinosa group species such as crinosa or torosa, but workers moved very slowly. I noted at the time that it was odd to see a crinosa group colony at an elevation as high as Monteverde, where I had never seen crinosa group species before. I assumed it was torosa or one of the other common species at the upper edge of its elevational range, but on laboratory examination I was surprised to find a morphologically distinct form. The additional Koptur samples from Monteverde and the ALAS collections from another montane site 
reinforced its distinctness from lowland forms. Thus it appears to be a low density species that occurs in a narrow elevational band, in wet to moist forests just above the typical range of the abundant lowland forms in the crinosa group.

I examined the MHNG syntypes of moelleri long before seeing the Costa Rican material, and made these notes: "This series is similar to crinosa but has erecta tendencies. The pilosity is very like erecta, with long flexuous hairs on head and humeri, hairs on fourth abdominal tergite long but stiff, underlying pubescence long and suberect. The scapes are relatively short, like crinosa, failing to reach vertex margin. The propodeal spine is short and upturned, more like crinosa than erecta. Strong petiolar tooth. Variable in size (more like crinosa) and red-brown color (fading due to age, or more reddish in life?). There are the faintest traces of metanotal tooth where the carinae extend onto propodeum (also present on some crinosa.) Overall, most like a very hairy crinosa." This matches closely the above description from Costa Rican material. It remains to be seen whether the concordance in morphology represents convergence due to shared environmental conditions or shared phylogenetic history.

\section{Crematogaster monteverdensis NEW SPECIES}

\section{Holotype worker}

Costa Rica, Prov. Guanacaste, 3km N Santa Elena, 1500m, 10²0'N, 845' W, 26 Jun 1991 (Longino, collection code JTL2938) [INBC, specimen code JTLC000001403].

\section{Paratypes}

One dealate queen, same data as holotype [INBC, specimen code JTLC000001404]; worker and queen, same data [BMNH, specimen code JTLC000001405]; worker and queen, same data [LACM, specimen code JTLC000001406]; worker and queen, same data [MCZC, specimen code JTLC000001407]; worker and queen, same data [MHNG, specimen code JTLC000001408]; worker and queen, same data [NHMB, specimen code JTLC000001409]; worker and queen, same data [USNM, specimen code JTLC00001410]; worker and queen, same data [UCDC, specimen code JTLC000001411].

\section{Range \\ Costa Rica.}

\section{Description of worker}

Differing from sumichrasti in the following respects: tibiae with abundant suberect setae, but more uniform in length and none longer than maximum width of tibia (sumichrasti has one or more long macrosetae, subequal in length to twice maximum tibia width); pronotal dorsum with stronger longitudinal carinulae; dorsal and posterior faces of 
mesonotum meeting at an angle but angle less strongly produced, not tuberculate; dorsal pilosity generally shorter.

\section{Measurements}

Holotype: HL 0.702, HW 0.739, HC 0.685, SL 0.584, EL 0.192, WL 0.777, SPL 0.145, PTH 0.178, PTL 0.239, PTW 0.210, PPL 0.183, PPW 0.228, CI 105, OI 27, SI 83, PTHI 74, PTWI 88, PPI 125, SPI 19.

Other specimens: HL 0.726, 0.639, 0.718; HW 0.799, 0.686, 0.772; HC 0.732, 0.636, 0.699; SL 0.605, 0.554, 0.601; EL 0.199, 0.182, 0.208; A11L 0.248; A11W 0.135; A10L 0.114; A10W 0.119; A09L 0.076; A09W 0.093; A08L 0.057; A08W 0.074; WL 0.840, 0.719, 0.832; SPL 0.145, 0.134, 0.156; PTH 0.195, 0.184, 0.181; PTL 0.249, 0.222, 0.228; PTW 0.220, 0.206, 0.224; PPL 0.180, 0.151, 0.176; PPW 0.246, 0.220, 0.235; CI 110, 107, 108; OI 27, 28, 29; SI 83, 87, 84; PTHI 78, 83, 79; PTWI 88, 93, 98; PPI 137, 146, 134; SPI 17, 19, 19; ACI 0.24 .

\section{Queen}

A normal queen (dorsal face of propodeum drops steeply from postscutellum and much of propodeum appears ventral to scutellum and postscutellum, Fig. 1) with general shape, sculpture, and pilosity characters of the worker; size characters as in Figures 4 and 5 .

\section{Etymology}

This species is named after its type locality.

\section{Biology}

Crematogaster monteverdensis inhabits moist forest areas in the Monteverde community area in the Cordillera de Tilarán and at a similar elevation on Cerro Cacao in the Cordillera de Guanacaste. I first encountered the species in Monteverde, where I observed workers and the small, dealate queens foraging together on the outside walls of a house. Subsequent collections were from nests in dead branches, either in recent treefalls or on the ground. These collections were generally located at pasture/forest edges. Nests were polygynous, with multiple dealate queens. Workers could be recruited to baits of mixed honey and solid vegetable oil. I have never seen alate queens, and one nest collection contained small apterous males similar to Wheeler's description of the males of atitlanica (Wheeler 1936, see under sumichrasti).

\section{Comments}

The two closely related species monteverdensis and sumichrasti are uniquely characterized by the combination of yellow coloration, relatively long, upturned propodeal spines, and long flexuous posterolateral mesonotal setae that are subequal in length to 
humeral setae. The only difference is that Crematogaster sumichrasti has one or two extremely long setae on the tibiae.

I identified monteverdensis specimens first as sumichrasti until I discovered the consistent differences in tibial pilosity and promesonotal profile. Crematogaster sumichrasti seems to have a microparapatric distribution with monteverdensis, because typical sumichrasti occur just downslope from Monteverde, at 700m elevation on the road down to the PanAmerican Highway.

\section{Crematogaster montezumia F. Smith 1858}

Plate 6

Crematogaster montezumia Smith, F. 1858:139, pl. 1, fig. 1. Syntype worker, queen, male: Mexico [BMNH]. Forel, 1912:220: combination in C. (Physocrema). Emery, 1922:135: combination in C. (Orthocrema). Santschi, 1922:244; Kempf, 1972:83: combination in C. (Neocrema).

Crematogaster sulcata Mayr, 1870a:403. Syntype workers: Colombia, Santa Fe de Bogotá (Lindig) [NMW, MHNG] (examined). Forel, 1899:84: description of queen. Santschi, 1922:244: combination in C. (Neocrema). Emery, 1922:135: combination in C. (Orthocrema). Forel, 1901b:65; Santschi, 1922:244: junior synonym of montezumia. Forel, 1904a:36; Emery, 1922:135: revived from synonymy as variety of montezumia. Kempf, 1968:386: junior synonym of montezumia.

Crematogaster sulcata var. ramulinida Forel, 1899:84 (footnote). Syntype workers: Colombia, Magdalena, Sierra Nevada de Santa Marta, near San Antonio (Forel) [MHNG, MCSN] (examined). Emery, 1922:135: combination in C. (Orthocrema). Forel, 1904a:36; Forel, 1912:220: variety of montezumia. Kempf, 1968:386: junior synonym of montezumia.

Crematogaster montezumia var. functa Forel, 1911a:300. Syntype worker: Brazil, Sao Paulo, Bahnhof Cubatao (Lüderwaldt) [MHNG] (examined). Emery, 1922:135: combination in C. (Orthocrema). Kempf, 1968:386: junior synonym of montezumia.

Crematogaster (Neocrema) montezumia st. cristulata Santschi, 1925:233. Syntype worker, queen: Brazil, Santa Catarina [NHMB] (examined). Kempf, 1968:386: junior synonym of montezumia.

Crematogaster (Neocrema) montezumia var. proletaria Santschi, 1933:113. Syntype worker, queen: Argentina, Misiones, Profundidad (Ogloblin) [NHMB] (examined). Kempf, 1968:386: junior synonym of montezumia.

Range

Mexico to Argentina.

\section{Description of worker (Costa Rica)}

Color dark red brown to black.

Mandibles smooth and shiny, becoming striate near base; clypeus emarginate anteriorly, convex, shiny; face punctate over much of surface, with variably developed anteromedian strip on face smooth and shiny; scapes with a combination of erect and subdecumbent setae, setae abundant, as long as width of scape or greater; terminal three segments of antenna gradually lengthening and becoming increasingly densely pubescent, 
terminal two segments the largest and most conspicuous, so that antennal club appears two-segmented; face with abundant erect amber setae; in full face view abundant setae projecting from posterior margin and sides of head posterior to eye, absent anterior to eye.

In lateral view, pronotum short but strongly convex, mesonotum differentiated from pronotum, somewhat projecting and forming elevated anterior boss; propodeal suture deeply impressed, in some cases obscured in lateral view by small lateral carinulae that bridge suture; mesonotum and dorsal face of propodeum in about the same plane; dorsal and posterior faces of propodeum distinct; propodeum strongly swollen, large relative to promesonotum; propodeal spines very short, acute, sharp; side of pronotum and katepisternum with faint microareolate microsculpture, sublucid; side of propodeum smooth and shining; promesonotal dorsum and dorsal face of propodeum punctate, overlain with clathrate rugae; posterior face of propodeum smooth and shiny; promesonotum and dorsal face of propodeum with abundant amber to whitish erect setae of variable lengths, no setae on posterior face of propodeum; legs with relatively sparse, short, fully decumbent setae.

Petiole in side view triangular, with faint microareolate sculpture; anteroventral tooth completely absent; dorsal face rectangular, longer than wide, smooth and shiny on anterior two thirds, faintly microaerolate on posterior third, with row of setae across posterior margin; postpetiole with blunt ventral tooth, postpetiole in dorsal view subquadrate, wider than long, posterior margin emarginate, with longitudinal median sulcus, and four pairs erect setae; fourth abdominal tergite with faint microareolate sculpture; fourth abdominal tergite with abundant erect setae.

\section{Measurements}

HL 0.621, 0.563, 0.621; HW 0.681, 0.608, 0.670; HC 0.613, 0.566, 0.601; SL 0.593, 0.522, 0.570; EL 0.175, 0.146, 0.189; A11L 0.264; A11W 0.127; A10L 0.125; A10W 0.097; A09L 0.062; A09W 0.070; A08L 0.055; A08W 0.065; WL 0.728, 0.626, 0.708; SPL 0.055, 0.048, 0.107; PTH 0.181, 0.147, 0.162; PTL 0.269, 0.208, 0.250; PTW 0.184, 0.155, 0.187; PPL 0.177, 0.142, 0.183; PPW 0.235, 0.206, 0.229; CI 110, 108, 108; OI 28, 26, 30; SI 95, 93, 92; PTHI 67, 71, 65; PTWI 68, 75, 75; PPI 133, 145, 125; SPI 8, 8, 15; ACI 1.58.

\section{Queen (Costa Rica)}

In lateral profile dorsal face of propodeum sloping obliquely from postscutellum, such that most of propodeum is posterior to scutellum (in contrast to normal queens, in which dorsal face of propodeum drops steeply from postscutellum and much of propodeum appears ventral to scutellum and postscutellum, Fig. 1); entire body (head, mesosoma, petiole, postpetiole, fourth abdominal tergite, appendages) polished, very smooth and shiny; mandible smooth and shiny, apical tooth of masticatory margin long and narrowly acute, much longer than other teeth; anterior margin of clypeus emarginate; clypeus with a broad anteromedian concavity; antennal club three-segmented; scapes with combination of long 
decumbent setae and long erect setae; face, pronotal dorsum, and anterior mesonotum with abundant erect white setae, sparser erect setae on remainder of mesosomal dorsum, posterior petiole, postpetiole, and fourth abdominal tergite; propodeal spines present, narrowly acute; femora with sparse long appressed pilosity; tibiae with abundant suberect setae; petiole similar to worker, with no anteroventral tooth, dorsal face subrectangular, slightly wider anteriorly than posteriorly, with anterolateral humeri somewhat produced as gibbosities and anteromedian area concave; size characters as in Figures 4 and 5.

\section{Biology}

Crematogaster montezumia inhabits wet to dry forest habitats throughout the mainland Neotropics. In Costa Rica it occurs in very low density, but abundant museum collections and my own collecting in the Santa Marta area of Colombia suggest a higher density in some South American localities. Most of my observations of the species have been from brushy second growth vegetation or forest edges.

Nests are in small to large carton nests that the workers construct and vigorously defend (Emery 1890, Forel 1899, Forel 1901b, Luederwaldt 1926). The nests are in dry, exposed areas and do not contain epiphytes. Luederwaldt (1926) includes photographs of three nests. Nests I have observed have been on relatively thin branches. One I observed in Corcovado National Park in Costa Rica was on a shrub overhanging a river. The nest was $15-20 \mathrm{~cm}$ long, $10 \mathrm{~cm}$ wide, of black carton, and it contained workers, brood and many alate queens. During a field trip to the Santa Marta area of Colombia I discovered several nests. One nest was in dry forest near a beach margin. The nest was in a knot in a small tree out in an open field. When I disturbed the nest the workers responded by quickly swarming out and running over the knot with prominent gaster-flagging. The nest contained workers, brood, and a single queen.

Another nest was in a scrubby second growth area with pastures. A carton nest was partly covered by a dead Cecropia leaf draped over a $13 \mathrm{~mm}$ diameter live stem of Guazuma (Sterculiaceae). Under the nest was a dense accumulation of scale insects, but no scales were exposed on the plant stems or leaves. The nest was filled with workers, brood, and one colony queen. Workers were spread over the surrounding vegetation, often moving in files, and there were small satellite nests scattered around the main nest.

A third nest was in dry forest, and they were nesting in a peculiar way. They were on a small shrub that was possibly Pisonia (Nyctaginaceae). Stems had opposite leaves with a pair of sharp recurved spines at each node, often with opposite short leafy branches at each node. On one branch, each node for 5-10 nodes had a circular hole at the base of the side branch, entering a tiny chamber only a few millimeters deep. The chambers were all occupied by workers, and one chamber was slightly larger than the others and contained workers, a small amount of brood, and a queen. A search in surrounding holes and dead stems and branches yielded no more, suggesting the colony was rather small, perhaps limited to the small number I observed. 
At La Selva Biological Station nests of montezumia have never been found, but an alate queen was obtained in a canopy fogging sample. The only other Atlantic slope collection I have seen was a dealate queen I found in a small nest of $C$. curvispinosa. A small grass stalk contained the montezumia queen and a small number of workers of curvispinosa.

The queens are shiny and with falcate mandibles, and as discussed in the Natural History Overview this combination of characters is often associated with social parasitism. The observation of the lone queen together with curvispinosa workers is suggestive of a parasitic lifestyle, in which colonies of host species are usurped to provide a worker force that helps establish the colony of the parasitic species. The observation of what appeared to be an incipient colony in Colombia showed no evidence of social parasitism, although it is possible that the queen had started with a heterospecific host colony and it had been completely extirpated and replaced by the montezumia workers. Alternatively, the tiny queens could be an adaptation for nest founding in extremely small spaces, such as the small cavities in the Pisonia stem.

\section{Comments}

Crematogaster montezumia is distinctive in having a somewhat inflated propodeum, with propodeal spines reduced to short denticles. Only one other species in Costa Rica, raptor, has greatly reduced propodeal spines. Crematogaster raptor has a shiny face, in contrast to montezumia's punctate face.

\section{Crematogaster nigropilosa Mayr 1870}

Plate 1, 5

Crematogaster nigropilosa Mayr, 1870a:405. Syntype workers: Colombia, Santa Fé de Bogotá (Lindig) [NMW] (examined). Mayr, 1887:624: description of queen from Santa Catarina, Brazil. Emery, 1922:136: combination in C. (Orthocrema).

\section{Range}

Nicaragua to Bolivia, Brazil.

\section{Description of worker (Costa Rica)}

Color dark red brown to black.

Mandibles smooth and shiny; in full face view anterior margin of clypeus weakly convex; clypeus convex, shiny, with 4-5 thin longitudinal carinulae; face smooth and shiny; scapes with longitudinal carinulae and faint etching, subopaque, with a combination of abundant subdecumbent setae and abundant long erect setae, erect setae much longer than width of scape; terminal 4-5 segments of antenna gradually lengthening to form club, becoming increasingly densely pubescent, terminal two segments the largest and most conspicuous; face with abundant erect amber to black setae, often forming a dense brush 
on face; in full face view with a crown of dark setae projecting from sides and posterior margin of head posterior to eyes, sparse short curved setae projecting from sides of head anterior to eyes; ventral surface of head with sparse suberect setae.

In lateral view, pronotum rising above anterior collar to gently convex dorsal surface, mesonotum flat, strongly sloping, with anteriorly raised boss and well developed anterolateral tubercles, relatively long such that pronotum elevated above propodeum; propodeal suture deep medially, appearing shallow in lateral view because of pronounced lateral carinae that bridge suture; dorsal face of propodeum horizontal, well differentiated from and about as long as sloping posterior face; propodeal spines very large, broadly triangular at base, gradually tapering to outermost seta, beyond which spine more abruptly tapers to long, acute tip (size of spine beyond outermost seta highly variable); side of pronotum smooth and shiny; anepisternum smooth and shiny; katepisternum smooth and shiny medially, with microareolate sculpture around margins; side of propodeum smooth and shiny dorsally, faintly rugulose and microareolate ventrally; pronotal dorsum with about 7 thin longitudinal carinulae, interspaces smooth and shining; mesonotum with strong lateral carinae, converging posteriorly, medial space smooth and shining; dorsal face of propodeum with carinulae that are longitudinal anteriorly, sweep outward onto bases of propodeal spines, several curved transverse carinulae between spines at juncture of dorsal and posterior faces (specimens from the Osa Peninsula have weaker sculpture overall, pronotal carinulae nearly absent, dorsal and lateral faces of propodeum largely smooth and shining); posterior face smooth and shining; setae on mesosomal dorsum long, stout, blackish, on average 4 on anterior pronotum, 2 on anterior mesonotum, 2 (shorter) on posterior mesonotum, 2 on base of each propodeal spine, with variation of plus or minus a seta at each position; legs with abundant suberect pubescence/short pilosity, no long erect setae.

Petiole in side view trapezoidal, smooth and shiny or with faint microareolate sculpture; anteroventral tooth small but usually distinct, forming a right to obtuse angle; dorsal face elongate, tapering anteriorly, smooth and shiny or faintly microaerolate, with two long dark setae on each posterolateral tubercle; postpetiole with no ventral tooth, postpetiole in dorsal view globular, well separated from petiole by cylindrical anterior peduncle; fourth abdominal tergite smooth and shining; postpetiole and fourth abdominal tergite with abundant long erect dark setae.

\section{Measurements}

HL 0.716, 0.631, 0.814; HW 0.747, 0.653, 0.864; HC 0.680, 0.606, 0.810; SL 0.848, 0.709, 0.958; EL 0.160, 0.160, 0.182; A11L 0.334; A11W 0.124; A10L 0.171; A10W 0.113; A09L 0.081; A09W 0.080; A08L 0.070; A08W 0.067; WL 0.904, 0.731, 1.078; SPL 0.332, 0.242, 0.318; PTH 0.227, 0.158, 0.258; PTL 0.384, 0.301, 0.394; PTW 0.202, 0.154, 0.240; PPL 0.248, 0.178, 0.243; PPW 0.235, 0.199, 0.302; CI 104, 103, 106; OI 22, 25, 22; SI 118, 112, 118; PTHI 59, 53, 65; PTWI 53, 51, 61; PPI 95, 112, 124; SPI 37, 33 , 29; ACI 1.60. 


\section{Queen (Costa Rica)}

A normal queen (dorsal face of propodeum drops steeply from postscutellum and much of propodeum appears ventral to scutellum and postscutellum, Fig. 1); head pilosity and sculpture characters as in worker; terminal 4 segments of antenna gradually enlarging to form club, the last two largest and most conspicuous; pronotal dorsum short, perpendicular, forming curving obtuse to sharp right angle with anterior collar, recessed beneath bulging mesonotum; propodeal spine broadly conical, short, with acute tip, 0-1 setae on side of propodeum anterior to spine; dorsal mesonotum and scutellum with abundant erect setae; tibiae with scattered long erect setae (in contrast to workers); petiole in lateral view similar to worker but more robust, shorter and taller; dorsal face of petiole subquadrate, sides straight to slightly convex, longer than wide, abruptly constricted anteriorly to narrow peduncle; postpetiole with no ventral tooth, in dorsal view subtrapezoidal, wider than long, widest anteriorly; postpetiole with abundant long setae of variable length; fourth abdominal tergite with even vestiture of abundant, stiff, moderate length erect setae; size characters as in Figures 4 and 5.

\section{Biology}

Crematogaster nigropilosa occurs in a wide variety of habitats and elevations, with the exception of extremely dry areas. It is common in low to mid elevation rainforests, and may be found in moist microhabitats in seasonally dry areas. Although most abundant at low to middle elevations, it also can occur at high elevation cloud forest sites where virtually no other ants are found. I collected a worker in a Winkler sample at $2400 \mathrm{~m}$ elevation on Volcan Barva in Costa Rica, and Peck collected the species at 2600m in Chiriquí province, Panama.

Nests are often in soft bits of dead wood or small hollow plant stems. The nests are usually on the forest floor or within a few meters of the forest floor in shaded areas and understory. I have also seen nests in rotten stumps, in chambers in rotting walls of abandoned houses in rainforest, and occasionally in internodes of Cecropia saplings. Nests contain a worker population ranging from a few dozen to about 300. Ergatogynes are very common. Nests exhibit a range of reproductive structures. Some have a standard complement of workers, brood, and one colony queen. Others have the colony queen plus one or more ergatogynes. An example is a colony I collected in its entirety from two adjacent internodes of a Cecropia sapling. The colony contained one dealate queen, 28 alate queens, 11 adult males, 13 ergatogynes, 324 workers, and brood. Nests may be queenless, containing only workers, brood, and one or more ergatogynes. Often these queenless nests appear to be the only nest in the vicinity, with no indication of being part of a polydomous colony. Although most of the nests I have observed have been monogynous or lacking a queen, one nest collection from Venezuela was polygynous. A lab colony kept for about one year was comprised of workers and one ergatogyne. The colony continually produced males as the worker population gradually declined to extinction. Thus a queenless colony fragment is at least able to produce males. 
Foragers may be found day or night. They occur on extrafloral nectaries and have been taken at tuna baits on the ground.

\section{Comments}

The combination of very long, divergent propodeal spines and appressed tibial setae uniquely identify this species. Crematogaster longispina has similar large spines, but the pilosity on the tibiae is erect.

\section{Crematogaster obscurata Emery 1895 NEW STATUS}

Figure 4, Plate 2, 6

Crematogaster victima var. obscurata Emery, 1895:287 (footnote). Holotype worker: Venezuela [no specific locality] [MCSN] (examined). Emery, 1922:136: combination in C. (Orthocrema). Crematogaster (Orthocrema) agnita Wheeler 1934:175. Syntype worker, queen: Guatemala, Zacapa ("an uncommonly arid locality"), 12 Dec 1911, in hollow twigs (Wheeler) [LACM; probable syntype workers with same data at NHMB, identified as sculpturata by Santschi]. NEW SYNONYMY

\section{Range}

USA (Florida), Mexico, Guatemala, Belize, Costa Rica, Venezuela.

\section{Description of worker}

Color red brown, gaster and face darker than rest of body.

Mandibles shiny, longitudinally striate, striae faint to pronounced; face with conspicuous microaerolate sculpture over most of surface, with a smooth shiny strip medially, extent of medial strip variable; scapes with abundant long subdecumbent to suberect pubescence, lacking differentiated long, erect setae; antennal club 2-segmented; clypeus shiny with 2-4 longitudinal rugulae; face with dense stubble of 30-40 short, stiff, erect setae; ventral surface of head smooth and shiny with sparse suberect to subdecumbent pilosity.

In lateral view, dorsal profile of pronotum, mesonotum, and propodeum forms continuous curve, dorsal and posterior faces of propodeum in same plane, sloping to petiolar insertion; propodeal spines projecting posterodorsally; pronotal dorsum with clathrate sculpture forming a lattice of longitudinal and transverse carinae with smooth and shiny interspaces; mesonotal dorsum with low, longitudinal carinulae laterally, microareolate sculpture medially; propodeal suture impressed medially but not visible in side view because lateral mesonotal carinulae continue onto dorsal face of propodeum; mesonotal carinulae have slight tooth at propodeal suture; dorsal face of propodeum very short, only visible in dorsal view, differentiated from posterior face by transverse carina, dorsal and posterior faces with faint microaerolate sculpture; propodeal spines short, thin, and sharp; side of mesosoma mostly microareolate/punctate, with variable degree of weakening of 
sculpture on side of pronotum, becoming entirely smooth and shining in some cases; setae on mesosomal dorsum stiff, relatively short, of variable length, longest approximately $0.14 \mathrm{~mm}$ long, dorsum of pronotum with anterior row of four setae, anterolateral and posterolateral dorsum of mesonotum (at propodeal suture) each with a seta; propodeal spine with one long seta at base, subequal in length to spine; additional shorter setae dispersed among primary setae; legs with appressed to subdecumbent pubescence and no erect setae.

Petiole in side view trapezoidal; side densely microareolate/punctate; with acute anteroventral tooth; dorsal face subquadrate, about as wide as long, faintly microareolate or smooth and shining; posterodorsal face short, densely microareolate; posterolateral tubercles each with two stiff setae; postpetiole in dorsal view subrectangular, wider than long, with slight posterior emargination; postpetiole with small anteroventral tooth; dorsum and sides with microareolate sculpture; with 4-6 stiff erect setae; fourth abdominal tergite with very faint, areolate microsculpture, shiny, with about 50 stiff erect setae evenly dispersed over surface.

\section{Measurements}

HL 0.593, 0.555, 0.622; HW 0.633, 0.608, 0.657; HC 0.584, 0.542, 0.611; SL 0.539, 0.511, 0.546; EL 0.161, 0.145, 0.162; A11L 0.242; A11W 0.119; A10L 0.116; A10W 0.109; A09L 0.061; A09W 0.065; A08L 0.041; A08W 0.067; WL 0.646, 0.580, 0.671; SPL 0.137, 0.116, 0.130; PTH 0.161, 0.150, 0.162; PTL 0.173, 0.163, 0.191; PTW 0.196, 0.166, 0.186; PPL 0.149, 0.124, 0.135; PPW 0.210, 0.173, 0.196; CI 107, 110, 106; OI 27, 26, 26; SI 91, 92, 88; PTHI 93, 92, 85; PTWI 113, 102, 97; PPI 141, 140, 145; SPI 21, 20 , $19 ;$ ACI 1.75 .

\section{Queen}

I have not observed the syntype queen of Wheeler's agnita, and I have seen no other queens of obscurata. Given the similarity of obscurata to steinheili, I assume it has queens like those of steinheili, which are normal queens (dorsal face of propodeum drops steeply from postscutellum and much of propodeum appears ventral to scutellum and postscutellum, Fig. 1) with general shape, sculpture, and pilosity characters of the worker.

\section{Biology}

Crematogaster obscurata occurs in dry forest habitats and beach margins. Mark Deyrup recently discovered a nest in the Florida keys, where it is most likely a recent introduction. I have collected the species twice in Costa Rica, both collections from Santa Rosa National Park in the seasonally dry habitats of Guanacaste Province. One collection was made while collecting at night in second growth dry forest near the park administrative headquarters. An aggregation of workers was in a tree knot. The second collection was from Playa Naranjo, at the upper beach edge. Small necrotic spots in live stems of a small Gliricidia sepium tree (Fabaceae) contained aggregations of workers only, with no brood 
or sexuals. The collection was made in the late afternoon, and the workers were not foraging. Even when the cavities were disturbed, the workers remained quiescent, appressed to the walls. The types of Wheeler's agnita were collected in hollow twigs, and workers have been twice intercepted in U.S. quarantine stations, in both cases in Oncidium orchids from Guatemala.

\section{Comments}

The combination of punctate face, appressed tibial pilosity, and normal propodeal spines (as opposed to spines that are reduced to denticles or tubercles) uniquely identify this species in Costa Rica.

The type of obscurata was compared directly with specimens from Costa Rica during a visit to MCSN, and the above description was later based on material from Costa Rica, Guatemala, and Mexico.

Crematogaster obscurata is part of a complex of species that occurs throughout the Neotropics. It is essentially a darker version of $C$. steinheili Forel, a yellow species that occurs on many Caribbean islands. In South America, versions of this complex include victima $\mathrm{F}$. Smith 1858 and victima cisplatinalis Mayr 1877. These South American forms differ only in small details of color, sculpture, and pilosity. One character the South American forms exhibit is that the pronotal dorsum is densely punctate beneath the clathrate sculpture, rather than shiny or weakly microareolate. The entire lineage favors xeric regions.

\section{Crematogaster raptor NEW SPECIES}

Plate 2, 8

\section{Holotype worker}

Costa Rica, Prov. Limón, Tortuguero, 5m, 10³5'N, 83³1'W, 2 Jul 1985 (Longino, collection code JTL0346) [INBC, specimen code JTLC000001412].

\section{Paratypes}

One worker, same data as holotype [BMNH, specimen code JTLC000001413]; one worker, same data [LACM, specimen code JTLC000001414]; one worker, same data [MCZC, specimen code JTLC000001415]; one worker, same data [MHNG, specimen code JTLC000001416]; one worker, same data [NHMB, specimen code JTLC000001417]; one worker, same data [UCDC, specimen code JTLC000001418]; one worker, same data [USNM, specimen code JTLC000001419].

Crematogaster JTL-001: Longino et al. 2002.

\section{Range}

Costa Rica. 


\section{Description of worker}

Color dark red brown to black.

Mandibles striate, shiny; clypeus weakly emarginate anteriorly, convex dorsally, shiny; face smooth and shiny; scapes with a combination of erect and subdecumbent setae, setae abundant, of variable length, longest erect setae longer than width of scape; terminal three segments of antenna enlarged, forming distinct three-segmented club; face with abundant erect flexuous white setae; in full face view abundant setae projecting from posterior margin and sides of head.

In lateral view, promesonotum forming a single, somewhat flat-topped convexity, rising steeply anteriorly, dropping steeply posteriorly, and slightly impressed at promesonotal suture; propodeal suture deep and broad, v-shaped; dorsal and posterior faces of propodeum distinct; propodeal spines in the form of broad, low, nearly right angles rather than spiniform, the vertex of the angle forming a variably developed short acute tooth; side of pronotum and dorsolateral propodeum smooth and shiny; katepisternum and ventrolateral propodeum with variably developed faint areolate rugose sculpture; promesonotal dorsum and dorsal face of propodeum with faint irregular rugae and etchings, sublucid; posterior face of propodeum smooth and shiny; promesonotum and dorsal face of propodeum with abundant whitish erect flexuous setae of variable lengths, no setae on posterior face of propodeum; legs with abundant erect and suberect setae.

Petiole robust, in side view trapezoidal, with microareolate sculpture; anteroventral tooth well-developed, deep, forming a strong right to slightly obtuse angle; dorsal face rectangular, longer than wide, slightly wider posteriorly than anteriorly, smooth and shiny, with row of setae across posterior margin; postpetiole with very small ventral tooth, blunt to acute; postpetiole in dorsal view subquadrate, wider than long, posterior margin emarginate, with longitudinal median sulcus; fourth abdominal tergite smooth and shiny; postpetiole and fourth abdominal tergite with abundant whitish erect flexuous setae.

\section{Measurements}

Holotype: HL 0.671, HW 0.689, HC 0.618, SL 0.639, EL 0.157, WL 0.791, SPL 0.070, PTH 0.205, PTL 0.287, PTW 0.226, PPL 0.185, PPW 0.226, CI 103, OI 23, SI 95, PTHI 71, PTWI 79, PPI 122, SPI 9.

Other specimens: HL 0.630, 0.627, 0.685; HW 0.663, 0.667, 0.708; HC 0.596, 0.591, 0.617; SL 0.598, 0.595, 0.631; EL 0.147, 0.168, 0.182; A11L 0.279; A11W 0.139; A10L 0.145; A10W 0.114; A09L 0.074; A09W 0.080; A08L 0.051; A08W 0.060; WL 0.733, 0.752, 0.788; SPL 0.078, 0.074, 0.081; PTH 0.196, 0.181, 0.217; PTL 0.251, 0.265, 0.314; PTW 0.200, 0.205, 0.259; PPL 0.182, 0.159, 0.192; PPW 0.211, 0.139, 0.243; CI 105, 106, 103; OI 23, 27, 27; SI 95, 95, 92; PTHI 78, 68, 69; PTWI 80, 77, 82; PPI 116, 87, 127; SPI 11, 10, 10; ACI 0.86 . 
In lateral profile dorsal face of propodeum sloping obliquely from postscutellum, such that most of propodeum is posterior to scutellum (in contrast to normal queens, in which dorsal face of propodeum drops steeply from postscutellum and much of propodeum appears ventral to scutellum and postscutellum, Fig. 1); entire body (head, mesosoma, petiole, postpetiole, fourth abdominal tergite, appendages) polished, very smooth and shiny; mandible smooth and shiny, subfalcate, basal and masticatory margins not differentiated, masticatory margin with a large, sharp apical tooth preceded by a series of small denticles; anterior margin of clypeus emarginate; clypeus flat; antennal club three-segmented; scapes with abundant long erect setae; face, mesosomal dorsum, petiole, postpetiole, fourth abdominal tergite, and legs with abundant long erect white setae, those on tibiae particularly long, much longer than width of tibia; dorsal face of pronotum perpendicular, at right angle to anterior collar, recessed beneath mesonotum; propodeal spines absent; petiole trapezoidal in lateral view, with ventrally directed, triangular, anteroventral tooth; dorsal face subrectangular, slightly longer than wide; posterodorsal face longer than typical of other Crematogaster, portion of petiole posterior to dorsal face forming a cylinder about two thirds length of dorsal face; postpetiole with short, acute ventral tooth; postpetiolar dorsum globular (unlike worker), dorsally convex and posterior margin rounded, not emarginate; size characters as in Figures 4 and 5.

\section{Etymology}

This species is named after the raptorial nature of the queen mandibles.

\section{Biology}

Crematogaster raptor occurs in lowland wet forest habitats. I first collected the species in Corcovado National Park on the Osa Peninsula. In a study of visitors to the extrafloral nectaries of a Passiflora species, the new shoots of one plant were always occupied by this species of Crematogaster. After following activity on this plant for two years, I traced the workers back to their nest. The nest was a small mass of carton wedged between a rotten stick and a live stem, about $1.5 \mathrm{~m}$ above the ground. This collection yielded workers only.

I encountered a second colony while collecting on Cerro Tortuguero on the north Atlantic coast. Workers and brood were densely packed in a dead, square-stemmed vine. The vine, $2-3 \mathrm{~cm}$ diameter, was fragmented and nothing but a thin papery shell. Also associated with the fragmented vine was a globular carton nest about $10 \mathrm{~cm}$ wide. The carton was mainly a shell with a few internal partitions, and was bare of epiphytes. Workers were tending Homoptera on various branches around the nest. In addition to workers and brood, I found two teneral winged queens and a male in the carton nest.

At La Selva Biological Station, the species is known from a single queen. Adrienne Nicotra discovered a small single-queened colony of $C$. carinata in a live stem of Siparuna 

This observation, along with the shininess of the queen and the strongly falcate mandibles, suggest temporary social parasitism as a mechanism of colony founding.

The only other collection of $C$. raptor is stray workers taken during nocturnal collecting in forest along the Rio Pacuare, at 200m elevation.

\section{Comments}

The salient feature of this species is the greatly reduced propodeal spines, which are no more than low tumosities or ridges. The only other Costa Rican species with such reduced propodeal spines is montezumia, which has a partially punctate face and appressed tibial pilosity. In contrast, raptor has a shiny face and erect tibial pilosity.

This species is very similar to indefensa Kempf 1968. It shares with indefensa a lack of propodeal spines and a shiny queen with falcate mandibles. It differs in the presence of abundant flexuous setae and a more robust petiole. Crematogaster indefensa is known from a $1000 \mathrm{~m}$ elevation site in Bolivia.

\section{Crematogaster rochai Forel 1903 REVISED STATUS}

Crematogaster rochai Forel, 1903:255. Syntype worker, queen, male: Brazil, Ceara (Diaz da Rocha) [MHNG] (examined). Emery, 1922:134: combination in C. (Orthocrema). Forel, 1912:213; Gallardo, 1934:21: race/subspecies of brevispinosa.

\section{Range}

Widespread in Neotropics from southern Mexico to Argentina.

\section{Description of worker (Costa Rica)}

Differing from crinosa and torosa by the following combination of characters: dorsal and posterior face of propodeum in nearly the same plane, such that the propodeal suture appears very shallow with no posterior wall, the propodeum forming a single declivity from the propodeal suture to the petiolar insertion (very large workers have a short dorsal face that drops to propodeal suture); promesonotum strongly arched, not flattened; anteroventral petiolar tooth long, sharply acute, triangular to spine-like; fourth abdominal tergite completely lacking erect setae.

\section{Measurements}

HL 0.851, 0.519, 1.139; HW 0.915, 0.535, 1.238; HC 0.905, 0.509, 1.207; SL 0.559, 0.375, 0.681; EL 0.198, 0.114, 0.257; A11L 0.247; A11W 0.123; A10L 0.110; A10W 0.104; A09L 0.062; A09W 0.078; A08L 0.045; A08W 0.060; WL 0.913, 0.500, 1.259; SPL 0.098, 0.069, 0.158; PTH 0.200, 0.121, 0.265; PTL 0.271, 0.158, 0.407; PTW 0.279, 0.166, 0.343; PPL 0.232, 0.128, 0.286; PPW 0.262, 0.167, 0.352; CI 108, 103, 109; OI 23, 


\section{Queen (Costa Rica)}

A normal queen (dorsal face of propodeum drops steeply from postscutellum and much of propodeum appears ventral to scutellum and postscutellum, Fig. 1) with general shape, sculpture, and pilosity characters of the worker; size characters as in Figures 4 and 5 .

\section{Biology}

Crematogaster rochai has a biology very similar to crinosa and torosa. It occurs primarily in open, seasonally dry areas, highly disturbed areas, pasture edges, and beach margins. It occasionally occurs in mangroves, although crinosa is the more common mangrove inhabitant. I have never collected it in rainforest areas.

Nests are large, polydomous, and distributed in a wide variety of plant cavities. Dead branches and knots in living trees are most often used. In Guanacaste Province in Costa Rica colonies may occupy ant acacias and may invade acacias occupied by Pseudomyrmex. I have seen workers distributed in small chambers scattered in the corky bark of Tabebuia trees (Bignoniaceae) and Erythrina trees (Fabaceae). Workers often construct small carton baffles to restrict nest entrances and small carton pavilions that shelter Homoptera on surrounding vegetation.

Foraging is primarily diurnal. Workers are generalized scavengers and they frequently visit extrafloral nectaries. Often columns of workers move between nests.

I often find cockroach egg cases scattered in the nest chambers of $C$. rochai, at a much higher density than in the environment generally. The nature of the relationship between cockroaches and the crinosa group would be worth investigation.

\section{Comments}

This is a member of the crinosa complex and may not always be distinguishable from crinosa and torosa. See under crinosa for further discussion. In Costa Rica rochai always has the fourth abdominal tergite completely devoid of erect setae, and the anteroventral petiolar process is long and sharp. Costa Rican material also lacks a differentiated dorsal face of the propodeum, but material from central and southern South America develops a stronger propodeal suture, thus approaching the condition in other crinosa group material. Also, southern material often has one to five erect setae on the anterolateral portions of the fourth abdominal tergite. 
Plate 1,8

\section{Holotype worker}

Costa Rica, Prov. Puntarenas, Corcovado National Park, Llorona, 5m, 8 ${ }^{\circ} 35^{\prime} \mathrm{N}$, $83^{\circ} 42^{\prime} \mathrm{W}, 2$ Jan 1982 (Longino, collection code JTL2Jan82/2100) [INBC, specimen code JTLC000001420].

\section{Paratypes}

One worker, same data as holotype [BMNH, specimen code JTLC000001421]; one worker, same data [LACM, specimen code JTLC000001422]; one worker, same data [MCZC, specimen code JTLC000001423]; one worker, same data [MHNG, specimen code JTLC000001424]; one worker, same data [NHMB, specimen code JTLC000001425]; one worker, same data [UCDC, specimen code JTLC000001426]; one worker, same data [USNM, specimen code JTLC000001427].

Crematogaster JTL-009: Longino et al. 2002.

\section{Range}

Costa Rica.

\section{Description of worker}

Color varies from dark red brown to variously bicolored (see Variation); workers monomorphic in size.

Mandibles striate; clypeus with two longitudinal carinulae at anterior margin, anterior margin gently convex; head longer than wide, with posterior margin rounded laterally, weakly impressed medially; antenna with terminal two segments enlarged to form a club, third segment from end somewhat enlarged, blurring distinction between two and threesegmented club; scapes with abundant long erect setae of variable length, some longer than maximum scape width; when scapes laid back from antennal insertions, they barely surpass margin of vertex; face smooth and shining; face covered with an even covering of shorter curved setae and longer straight setae, setae flexuous to somewhat stiffened, light to dark amber (see Variation), no appressed pubescence; in face view abundant setae project from lateral and posterior margins.

Pronotum in lateral profile convex, rounding into flat dorsal face of mesonotum, posterior face of mesonotum short, dropping to propodeal suture; propodeal suture deep in dorsal view but partially obscured in profile due to lateral carinulae that bridge the suture; propodeum with or without differentiated dorsal face (see Variation); propodeal spines long, spiniform, upturned; pronotal dorsum smooth and shining or in robust specimens with traces of longitudinal carinulae; dorsal face of mesonotum with strong lateral carinae, terminating posteriorly at angular juncture with carinulae extending down posterior face 
and across propodeal suture; medial mesonotum concave, smooth and shining; dorsal face of propodeum, when differentiated, with longitudinal carinulae; posterior face flat to concave, smooth and shining; side of pronotum smooth and shining; katepisternum and side of propodeum shining, largely smooth with traces of feeble carinulae around margins of katepisternum; a pair of long setae on pronotal humeri $(0.28 \mathrm{~mm})$, pairs of setae on anterolateral mesonotum, posterolateral mesonotum, and dorsolateral propodeum midlength between spines and propodeal suture, these three pairs subequal in length $(0.15 \mathrm{~mm})$, anteromedian pronotum with a pair of setae that are variably developed, often shorter than mesonotal setae and slanted posteriorly, shorter setae variably dispersed on mesosomal dorsum, including on propodeal spines; mesosomal setae light to dark amber, flexuous; tibiae with abundant erect to subdecumbent setae, of variable length, some tibial setae subequal to maximum width of tibia.

Petiole in side view trapezoidal, smooth and shining, with rounded anteroventral tooth; dorsal face of petiole smooth and shining, longer than wide, varying in shape, with sides that gradually taper toward petiolar insertion or sides that are subparallel to level of petiolar spiracles then more abruptly tapering to insertion; posterolateral tubercles with 23 amber setae; postpetiole anteroventrally angulate or in robust specimens somewhat developed as subacute tooth; postpetiole in dorsal view globular, longer than wide, somewhat teardrop shaped, with 6-8 amber setae; fourth abdominal tergite smooth and shining, with abundant long flexuous to somewhat stiffened suberect amber setae, no appressed pubescence.

\section{Variation}

Workers from the Peñas Blancas Valley on the Atlantic slope are dark red brown, gradually becoming lighter yellow on tarsi and antennal club. Workers from elsewhere on the Atlantic slope and from Carara on the Pacific slope tend to have the mesosoma, petiole, postpetiole, and legs lighter red brown, with head and gaster darker brown. Workers from sea level on the Osa Peninsula have the mesosoma, petiole, and postpetiole light redbrown, head slightly darker, gaster much darker, and the legs and tips of antennae almost yellow. The yellow coxae sharply contrast with the red brown mesosoma.

Workers from montane habitats are generally more robust. In some cases the mesonotum is somewhat raised anteriorly, meeting pronotum at an angle. The anteroventral postpetiolar tooth is more developed. The dorsal face of the propodeum is more differentiated and sculptured with longitudinal carinulae. The dorsal setae of head, mesosoma, and fourth abdominal tergite are dark amber. Workers become less robust and lighter colored at low elevations, reaching an extreme in workers from coastal forests of the Osa Peninsula. Workers from the Osa and from the Peñas Blancas Valley are quite distinct, but seem to be connected by a series of intermediates. 
Holotype: HL 0.507, HW 0.542, HC 0.489, SL 0.448, EL 0.137, WL 0.598, SPL 0.116, PTH 0.135, PTL 0.180, PTW 0.137, PPL 0.147, PPW 0.146, CI 107, OI 27, SI 88, PTHI 75, PTWI 76, PPI 99, SPI 19.

Other specimens: HL 0.507, 0.602, 0.639; HW 0.545, 0.636, 0.650; HC 0.496, 0.582, 0.592; SL 0.448, 0.535, 0.576; EL 0.141, 0.149, 0.154; A11L 0.218; A11W 0.101; A10L 0.111; A10W 0.095; A09L 0.052; A09W 0.061; A08L 0.043; A08W 0.055; WL 0.591, 0.698, 0.722; SPL 0.113, 0.158, 0.161; PTH 0.150, 0.182, 0.175; PTL 0.201, 0.228, 0.221; PTW 0.151, 0.178, 0.190; PPL 0.137, 0.146, 0.168; PPW 0.160, 0.194, 0.191; CI 107, 106, 102; OI 28, 25, 24; SI 88, 89, 90; PTHI 75, 80, 79; PTWI 75, 78, 86; PPI 117, 133, 114; SPI 19, 23, 22; ACI 1.98.

\section{Queen}

The queen of snellingi is unknown.

\section{Etymology}

This species is named for Roy Snelling of the Los Angeles County Museum of Natural History. Roy has been a long-term mentor and collaborator.

\section{Biology}

Crematogaster snellingi occurs in lowland and mid-montane wet forest habitats on both sides of Costa Rica. It is an infrequently collected species and I have never found a nest. Most collections are scattered foragers found on low vegetation at night. I have encountered diurnal foragers only when they are visiting extrafloral nectaries. In Corcovado, I once attracted a few workers to baits of mixed honey and vegetable shortening placed out on the ground at night. I also have obtained workers in Winkler samples of sifted leaf litter from the forest floor.

\section{Comments}

The combination of (1) shiny face with erect setae, (2) subquadrate dorsal face of petiole, (3) erect tibial pilosity, (4) dark coloration at least on head and abdomen, (5) relatively long upturned propodeal spines, and (6) acute to right-angle anteroventral propodeal tooth uniquely characterize this species. It can be confused with limata and relatives but differs in the more subquadrate, less tapering dorsal face of petiole and the relatively upturned spines. In some ways it is like a small, darkly colored sumichrasti.

\section{Crematogaster sotobosque NEW SPECIES}

Plate 1, 5

\section{Holotype worker}

Costa Rica, Prov. Heredia, La Selva Biological Station, $10^{\circ} 26^{\prime} \mathrm{N}, 84^{\circ} 01^{\prime} \mathrm{W}, 50 \mathrm{~m}, 23$ 
Oct 1991 (Longino, collection code JTL3136-s) [INBC, specimen code INBIOCRI001237410].

\section{Paratypes}

One queen, same data as holotype and on same pin [INBC, specimen code INBIOCRI001237410]; one worker and one queen on same pin, same data [LACM, specimen code INBIOCRI001218088]; two workers, same locality, 17 Jul 1986 (Longino, collection code JTL1391-s) [BMNH, specimen code JTLC000001217]; one worker, same locality, 25-29 Jun 1999 (INBio-OET, Project ALAS collection code W/14/013) [MCZC, specimen code INBIOCRI002720738]; one worker, same data [MHNG, specimen code INBIOCRI002720739]; one worker, same data [NHMB, specimen code INBIOCRI002720740]; one worker, same data [UCDC, specimen code INBIOCRI002720741]; one worker, same data [USNM, specimen code INBIOCRI002720742].

Crematogaster JTL-006: Longino et al. 2002.

Range

Costa Rica south to Amazonian Brazil and Peru.

\section{Description of worker}

Color brown with contrasting yellow mandibles and antennal club, legs lighter than body but not as yellow as mandibles and club.

Mandible smooth and shiny; anterior margin of clypeus weakly convex; clypeus convex, smooth and shiny; face smooth and shiny; scapes with abundant long erect setae of variable lengths, many setae much longer than scape width; terminal three segments of antenna differentiated, larger than preceding segments, terminal two segments largest and most conspicuous, appearing as two-segmented club; face with abundant medium length erect dark setae; in full face view a row of dark erect setae project from posterior margin of head, fine short curved setae project from sides of head anterior to eyes.

In lateral profile pronotum rises from anterior collar to flat-topped promesonotal dorsum, then drops steeply to propodeal suture; no trace of promesonotal suture; juncture of dorsal and posterior face of promesonotum with pair of projecting tubercles, formed from apices of pair of strong carinae on posterior face, carinae converging posteriorly and continuing across propodeal suture; dorsal and posterior faces of propodeum not differentiated, sloping continuously from propodeal suture to petiolar insertion; propodeal spines broad based, medium length, tapering to long acute tips, slightly curving upward; entire mesosoma smooth and shining, with no other sculptural elements besides pair of carinae on posterior mesonotum; promesonotal dorsum with three pairs of setae, one on humeri, one midlength, and one on mesonotal tubercles, progressively shorter from anterior to posterior, with very long humeral setae and relatively short setae on mesonotal tubercles; 
setae dark; one or two dark setae on each propodeal spine; legs with suberect pubescence and scattered long erect setae.

Petiole in side view trapezoidal, smooth and shiny; anteroventral tooth small but usually distinct, forming a rounded angle; dorsal face elongate, tapering anteriorly, smooth and shiny, with a single long dark seta on each posterolateral corner; postpetiole with no ventral tooth, in dorsal view globular, widest posteriorly and tapering anteriorly, well separated from petiole by anterior peduncle, with two pairs of long dark setae; fourth abdominal tergite smooth and shining, with sparse, very long erect dark setae.

\section{Measurements}

Holotype: HL 0.519, HW 0.565, HC 0.508, SL 0.557, EL 0.145, WL 0.639, SPL 0.182, PTH 0.152, PTL 0.250, PTW 0.145, PPL 0.175, PPW 0.162, CI 109, OI 28, SI 107 , PTHI 61, PTWI 58, PPI 93, SPI 28.

Other specimens: HL 0.466, 0.466, 0.549; HW 0.514, 0.501, 0.595; HC 0.459, 0.452, 0.525; SL 0.507, 0.532, 0.584; EL 0.128, 0.130, 0.135; A11L 0.239; A11W 0.111; A10L 0.132; A10W 0.081; A09L 0.054; A09W 0.064; A08L 0.038; A08W 0.045; WL 0.571, 0.560, 0.660; SPL 0.128, 0.121, 0.147; PTH 0.128, 0.134, 0.154; PTL 0.207, 0.196, 0.255; PTW 0.123, 0.126, 0.146; PPL 0.138, 0.148, 0.168; PPW 0.142, 0.125, 0.157; CI 110, 108, 108; OI 27, 28, 25; SI 109, 114, 106; PTHI 62, 68, 61; PTWI 60, 64, 57; PPI 103, 84, 93; SPI 22, 22, 22; ACI 1.07.

\section{Queen}

A normal queen (dorsal face of propodeum drops steeply from postscutellum and much of propodeum appears ventral to scutellum and postscutellum, Fig. 1); mandibles smooth and shiny; clypeus smooth and shiny; scape with abundant suberect setae; antennal club as in worker; abundant long erect setae on face, ventral surface of head; in full face view abundant curved setae projecting from posterior and lateral margins of head, both posterior and anterior to eye; large, conspicuous ocellate puncta moderately abundant on face, very abundant on mesonotum and scutellum, sparse on side of pronotum, anepisternum, and katepisternum, interspaces smooth and shining; abundant medium-length flexuous erect setae on mesonotum and scutellum, sparser but conspicuously present on side of pronotum, anepisternum, and katepisternum; propodeum coarsely rugose, rugae generally longitudinally oriented, becoming effaced on oval region above petiolar insertion; propodeal spines long, narrowly acute, spiniform; propodeal spiracle very large; sides of propodeum and propodeal spines with abundant erect setae; legs with abundant suberect setae, on both femora and tibiae; petiole shape as in worker but more robust, relatively shorter and wider in dorsal view, sides faintly punctate, dorsal face with abundant setae along posterior margin; postpetiole without ventral tooth, in dorsal view subquadrate to globular, widest anteriorly, with abundant erect setae; fourth abdominal tergite smooth and shiny with abundant long erect setae; size characters as in Figures 4 and 5. 
This species is named after the Spanish word for forest understory, reflecting its favored habitat.

\section{Biology}

Crematogaster sotobosque occurs in lowland and mid-montane mature wet forest habitats. Workers are frequently collected in Winkler samples of sifted leaf litter from the forest floor, and dealate queens are occasionally encountered as well. Workers forage on low vegetation in the forest understory. I usually find foragers at night, but have also seen them during the day in heavily shaded forest. Foragers are solitary and usually very thinly dispersed over the vegetation. I have attracted workers to sugar baits and to dead mosquitoes, but I never see large aggregations of foragers.

Although observations are few, nests appear to be diffusely spread in the forest leaf litter. In one case I baited a worker with a dead mosquito and followed it back to a small carton shelter in the leaf litter around the base of a fern. The shelter contained only workers, with no brood or sexuals, but a search of the surrounding litter yielded a lone queen with a packet of brood in a hollow stick. There were no workers with her, but she was only a few centimeters from the carton shelter. On other occasions I have found aggregations of workers in small shelters in the leaf litter, between dead leaves, with small amounts of carton construction, but have been unable to find any chambers with brood or sexuals in the vicinity. These observations of broodless worker bivouacs is tantalizing and suggests an interesting nesting and foraging behavior.

\section{Comments}

The combination of smooth and highly polished body surface, amber dorsal setae, and suberect tibial pilosity uniquely identifies this species. In some ways it is like a small version of nigropilosa, with smaller propodeal spines.

\section{Crematogaster stollii Forel 1885}

Plate 3,4

Crematogaster stollii Forel, 1885:373. Syntype workers: Guatemala, Retaluleu (Stoll) [MHNG] (examined). Forel, 1899:83: description of queen. Santschi, 1918:182: combination in C. (Neocrema). Santschi, 1922:244: combination in C. (Oxygyne). Emery, 1922:136; Kempf, 1972:89: combination in $C$. (Orthocrema).

Crematogaster stollii var. amazonensis Forel, 1904b: 682. Syntype workers: Brazil, Amazonas, Cachveira Juruá, in Cecropia No.5587 (Ule); and Pará (Göldi) [MHNG] (examined). Emery, 1922:136: combination in $C$. (Orthocrema). NEW SYNONYMY

Crematogaster (Crematogaster) stolli subsp. autruni Mann, 1916: 441. Syntype workers: Brazil, near Manaos (Mann). Emery, 1922: 136: combination in C. (Orthocrema). NEW SYNONYMY 
Crematogaster stolli var. guianensis Crawley, 1916:369. Syntype workers: Guyana (G. E. Bodkin). Emery, 1922:136: combination in C. (Orthocrema). NEW SYNONYMY

Tranopeltoides parvispina Wheeler, W. M. 1922a:12, fig. 3. Holotype queen: Guyana Kaieteur, 8 Aug 1911 (F. E. Lutz). Kempf, 1960:174: junior synonym of stollii.

Crematogaster hyperphyes Kusnezov, 1953:215. Syntype worker, queen, male: Bolivia, Chapare. Kempf, 1968:384: junior synonym of stollii.

\section{Range}

Guatemala to Amazonian Brazil and Bolivia.

\section{Description of worker}

Color red with darker gaster, legs usually contrastingly lighter yellow brown; workers with pronounced size polymorphism.

In face view head subquadrate, wider than long in larger workers, with emarginate posterior margin; mandibles coarsely striate, shining; clypeus relatively flat, often with concave anteromedian impression, mostly smooth and shining with variable degree of weak etching laterally, frontoclypeal suture broad, deeply impressed, smooth and shining, such that posterior clypeus appears slightly raised relative to face; malar spaces longitudinally striate, striae forming concentric rings around antennal insertions, grading to fine longitudinal striae posteriorly, then to smooth and shining on posterior face, extent of striation variable; face with 10-20 medium length erect setae, amber colored, slightly stiff, underlain by sparse appressed pubescence; scapes with subdecumbent to suberect pubescence, largest workers often with 1-3 long erect setae; scapes short, in face view not attaining posterior margin of head when laid back; terminal four segments of antenna gradually lengthening and broadening, becoming increasingly densely pubescent, terminal two segments may be relatively more differentiated than proximal segments, thus club may appear two-segmented or indistinctly 3-4 segmented.

Promesonotum forming a single convexity in small workers; in large workers mesonotum elevated, differentiated from pronotum, flat to slightly concave, forming a slightly elevated boss at promesonotal suture, sloping posteriorly to broadly V- or U-shaped propodeal suture; posterior wall of propodeal suture steep, rising to long sloping declivity formed by posterior face of propodeum, posterior face usually sculpturally differentiated into anterior and posterior halves, with the anterior portion sculptured and flat, the posterior portion smooth, shiny, and concave; the anterior portion sometimes slightly elevated, meeting posterior half at broadly obtuse angle, thus forming weakly differentiated dorsal and posterior faces; propodeal spine short, broad-based, upturned, shorter in Costa Rica than in South America; propodeal spiracle very large, extending from base of propodeal spine to upper edge of metapleural gland bulla, with pronounced swollen ring around orifice; sculptural details highly variable within populations and across range, in Costa Rica pronotal dorsum irregularly punctatorugose and sublucid to subopaque, in parts of South America becoming finely striate and subopaque, striae longitudinal or variously oblique or whorled; in Costa Rica side of pronotum with faint microsculpture, sublucid, in parts of 
range in South America subopaque; in Costa Rica katepisternum and side of propodeum with irregular longitudinal rugae, interspaces smooth and shiny or weakly punctate, in South America rugae become less prominent, punctation more so, some specimens evenly punctate, opaque, with no rugae; area around propodeal suture coarsely rugose, lateral carinulae lacking in Costa Rica, becoming more developed in South America, but not obscuring propodeal suture in side view; in Costa Rica anterior half of posterior face of propodeum weakly punctatorugose, sublucid, becoming more punctate and subopaque in South America; promesonotal dorsum and dorsal propodeum anterior to spines covered with abundant, medium length amber setae, setae stiff but not flattened; femora and tibiae with long appressed to subdecumbent pubescence, small workers lacking erect setae, large workers with 0-5 differentiated erect setae on front tibiae, 0-2 on middle tibiae.

Petiole in lateral view subtriangular, faintly sculptured if at all, sublucid, ventral margin concave, dorsal margin convex; anteroventral petiolar tooth large, acute, with blunt tip; dorsal face subquadrate, about as long as wide, sides flat to slightly convex, face smooth and shining to faintly microareolate; two or more erect setae projecting from sides, about two posteriorly directed setae on each posterolateral tubercle; postpetiole lacking ventral tooth (a few South American collections with small ventral tooth), in dorsal view wider than long, subquadrate but with strongly convex sides, posterior margin emarginate, variably developed posteromedian sulcus, dorsum faintly microareolate, with five or more erect setae; fourth abdominal tergite smooth and shining or with faint microareolate sculpture, with sparse appressed short pubescence and abundant medium length amber erect setae distributed evenly over surface, erect setae stiff, somewhat flattened, flatter than more filiform setae of mesosoma.

\section{Measurements}

HL 1.574, 0.779, 1.555; HW 1.880, 0.860, 1.826; HC 1.782, 0.828, 1.753; SL 0.933, 0.526, 0.878; EL 0.357, 0.183, 0.399; A11L 0.385; A11W 0.209; A10L 0.190; A10W 0.168; A09L 0.121; A09W 0.135; A08L 0.086; A08W 0.116; WL 1.886, 0.858, 1.929; SPL 0.224, 0.081, 0.156; PTH 0.413, 0.180, 0.395; PTL 0.487, 0.229, 0.494; PTW 0.472, 0.245, 0.500; PPL 0.392, 0.177, 0.345; PPW 0.514, 0.269, 0.529; CI 119, 110, 117; OI 23, 23, 26; SI 59, 68, 56; PTHI 85, 79, 80; PTWI 97, 107, 101; PPI 131, 152, 153; SPI 12, 9, 8; ACI 0.32 .

\section{Queen}

A normal queen (dorsal face of propodeum drops steeply from postscutellum and much of propodeum appears ventral to scutellum and postscutellum, Fig. 1) with general shape, sculpture, and pilosity characters of the worker; size characters as in Figures 4 and 5 . 
Crematogaster stollii occurs in lowland moist to wet forest habitats throughout the wet Neotropics. It may prefer seasonally dry habitats over very wet forest. For example, in Costa Rica it is relatively common on the Pacific slope but I have never seen it on the much wetter Atlantic slope. Colonies occur in both mature forest and in large trees along fencerows. It can be relatively common in agricultural landscapes where large trees occur along roadsides, pasture margins, and ravines.

Workers vary greatly in size, and the largest workers are the giants among the New World species. Crematogaster stollii has a highly distinctive nesting behavior, unlike any other Crematogaster species known to me. Workers construct carton tunnels that extend from the ground up the trunks of large live trees. The tunnels radiate out in the crown and extend out to the tips of branches. Forel (1885) reported Stoll's observations of the carton tunnels that this species constructs, and the fact that the workers exude a drop of white fluid from the gaster when disturbed. Stoll was never able to find the nest center, but supposed it to be inside the branches. I have made additional observations of stollii, and can expand on Stoll's observations.

The carton material is composed of short, coarse plant fibers. The tunnels are $1-2 \mathrm{~cm}$ broad and flattened, less than $1 \mathrm{~cm}$ high. At first glance the tunnels are very similar to the ubiquitous nasutiform termite tunnels that cover tree trunks in the habitats where stollii flourishes. However, close inspection reveals a coarser material with visible plant fragments, rather than the fine grained, mud-like material produced by termites. Occasionally stollii incorporates head capsules of its own dead workers in the carton. Construction is always in the form of tunnels, with no larger globular structures or external nests of any kind.

Colonies are very large, and may cover several contiguous trees. Tunnels always extend down to the ground. Short excavations reveal that the tunnels continue down the trunk and onto large roots well below ground level. Tree species used by stollii are highly varied and include Ficus, Brosimum (Moraceae), Erythrina, Inga, Pithecellobium saman (Fabaceae), Pouteria (Sapotaceae), Apeiba tibourbou, Luehea seemanii (Tiliaceae), Enalagma (Bignoniaceae), and Bravaisia integerrima (Acanthaceae).

I have never seen workers exposed on the surface. Beneath the carton tunnels workers can be found scattered along runways and in clusters in small pits. The pits are excavated a few millimeters into the trunk. The runway floors and the walls of the pits are black and damp, and abundant white entomobryid Collembola are always present. Low densities of coccoid Homoptera occur in the pits and along the runways. Where the tunnels extend out to branch tips, they cover entrance holes into the branch interiors. Branch tips are hollowed out and packed with coccoid Homoptera and workers. Thus a tree that appears clean from the outside, with little surface activity, can actually host an enormous population of Homoptera on the inside of most of its branch tips. Presumably the ants are using the Homoptera as their main food source, but this needs investigation. Like Stoll, I have never 
found a nest center. In one case I examined a Bravaisia integerrima tree that had been pushed over by a bulldozer. It was covered with the remains of a $C$. stollii colony. A large knot high up on the trunk revealed that the trunk was hollow, and galleries entered the hollow trunk. Males were present in the knot, and in many small pits beneath the tunnels. I dug into the root ball of the tree and turned up the occasional worker in the soil, but I failed to find any concentration of workers or brood.

When the carton is opened and the workers disturbed, they raise their gasters and exude large, frothy droplets of white liquid. The smell is very acrid and is similar to the odor of other highly chemically defended Crematogaster.

Nuptial flights are presumably nocturnal because queens and males are routinely taken at blacklights. Queens and males have large ocelli, a feature of nocturnal fliers. I am unaware of any collection of queens associated with workers, and the identification of the queens is based on large size and similar morphology to workers.

A striking convergence of nesting behavior is found in the widespread Neotropical ant species Azteca forelii (Dolichoderinae). This species makes carton tunnels on tree trunks and branches, and the branch tips are hollowed out and filled with workers, brood, and coccoid Homoptera. Azteca forelii is broadly sympatric with stollii, and usually occurs in the same habitats. The carton tunnels are so similar that I cannot determine which species inhabits a nest without opening the carton and finding workers. Like stollii, the behavior of A. forelii is unique among the diverse genus Azteca.

Mercado (1962) reported an association between $C$. stollii and the stingless bee Trigona compressa (Latr.). The study is short and anecdotal, stating "A colony of these bees contains about 10,000 to 15,000 workers. Completely surrounding a natural hive of $T$. compressa one finds a nest of Crematogaster stolli ants. The anthill has a population twice or thrice that of the bees. Both bee and ant colonies have a single entrance divided by a fragile partition of wax and resins. The entrance for the bees is $4 \mathrm{~cm}$, more conspicuous and $3 \mathrm{~cm}$ of diameter. The ants penetrate to the inferior part of the entrance and go down through a net of tunnels, in the tree trunk until penetrating the humiferous crest next to the tree base. [an illustration makes it clear that the net of tunnels is on the tree, not in it]... every colony of Trigona compressa found by myself so far was associated with a colony of Crematogaster stolli. When someone wants to collect the honey of these bees, at the first impact of the ax the ants become cross and practically cover the trunk with an ant sheet, furiously biting the invader. When the natural hive is opened, the ants never touch the spilled honey, nor the brood, neither the bees. If one allows time for them to reorganize they will start all over again, in harmonic association."

\section{Comments}

Crematogaster stollii has the habitus of crinosa complex species, with worker polymorphism, a broad head with emarginate posterior border, short scapes, and differentiated appressed pubescence and erect setae on the face. The setae on the mesosoma are longer 
and more filiform than most crinosa complex species. The giant spiracle is distinctive and alone is sufficient to differentiate workers from any other New World species. The large spiracle may be associated with the closed, high-humidity environment in which stollii workers live. Since workers never forage outside, water loss may never be a problem and thus a small water-conserving spiracle may be unnecessary.

The various subspecies and varieties of stollii have been based on details of color, degree of striation and punctation on the face and promesonotum, and size of propodeal spines. I see no evidence of sharply differentiated sympatric, allopatric or parapatric forms, and I interpret the variation as geographic variation within one polytypic species.

\section{Crematogaster sumichrasti Mayr 1870}

Plate 2, 7

Crematogaster sumichrasti Mayr, 1870b:993. Syntype workers: Mexico (Sumichrast, Norton) [NMW] (examined, Norton worker here designated LECTOTYPE). Forel, 1908a:46: description of queen, male. Emery, 1922:136: combination in C. (Orthocrema).

Crematogaster sumichrasti st. surdior Forel, 1885:375. Syntype worker, queen: Guatemala, Antigua (Stoll) [MHNG] (examined). Emery, 1922:136: combination in C. (Orthocrema). Dalla Torre, 1893:87: raised to species. Forel, 1899:82; Emery, 1922:136; Kempf, 1972:89: race/subspecies of sumichrasti. NEW SYNONYMY

Crematogaster (Apterocrema) atitlanica Wheeler, W. M. 1936:47, fig. 1. Syntype male, queen: Guatemala, northern shore Lake Atitlan, one colony under stone, open sandy spot near Tsanjuyo; one colony under stone, grassy meadow, near Panajachel (Wheeler) [LACM] (examined). Wheeler, G. C. and Wheeler, J. 1960:13: description of larva. NEW SYNONYMY

Crematogaster (Orthocrema) sumichrasti subsp. maya Wheeler, W.M. 1936:48, fig. 1. Syntype workers: [same colonies as syntypes of atitlanica; see above] (examined). NEW SYNONYMY

\section{Range}

Mexico to Costa Rica.

\section{Description of worker}

Color yellow orange; workers monomorphic in size.

Mandibles striate; clypeus with two to four longitudinal carinulae at anterior margin, anterior margin gently convex; head about as long as wide, subquadrate, with emarginate posterior border; antenna with terminal two segments enlarged to form a club, third segment from end somewhat enlarged, blurring distinction between two and three-segmented club; scapes with abundant long erect setae; when scapes laid back from antennal insertions, they barely surpass margin of vertex; face smooth and shining, with variable extent of striated region between antennal insertion and eye, and whorled above antennal insertion; face covered with abundant long flexuous white setae, no appressed pubescence; in face view abundant setae project from lateral and posterior margins. 
Pronotum in lateral profile convex; dorsal face of mesonotum long, flat, somewhat produced, posterolateral margins almost tuberculate, posterior face short, dropping abruptly to propodeal suture; propodeal suture deep in dorsal view but may be more or less obscured in profile due to lateral carinulae that bridge the suture; propodeum with very short, weakly differentiated dorsal face and long posterior face; propodeal spines long, spiniform, upturned; pronotal dorsum mostly smooth and shining, with faint traces of longitudinal carinulae; dorsal face of mesonotum with strong parallel lateral carinae, terminating posteriorly at almost tuberculate juncture with carinulae extending down posterior face, across suture, and onto bases of propodeal spines; medial mesonotum concave, smooth and shining; posterior face of propodeum flat to concave, smooth and shining; side of pronotum smooth and shining; katepisternum and side of propodeum shining, largely smooth with traces of feeble carinulae; mesosomal dorsum with abundant long flexuous amber setae, setae on pronotal humeri and posterolateral mesonotal tubercles very long, subequal in length, longer than anterolateral mesonotal setae; tibiae with abundant long erect setae, of variable length, one or more tibial setae very long, subequal to twice maximum tibial width.

Petiole in side view trapezoidal, smooth and shining or faintly microareolate, with minute right-angle or rounded anteroventral tooth; dorsal face of petiole smooth and shining, longer than wide, widest posteriorly, sides weakly convex, gradually converging to level of petiolar spiracles, abruptly narrowed anterior to spiracles, with about six long amber setae along posterior border; postpetiole with minute subacute to right-angle anteroventral tooth, postpetiole in dorsal view subquadrate and wider than long, with abundant long erect setae; fourth abdominal tergite smooth and shining, with abundant long flexuous erect amber setae, no appressed pubescence.

\section{Measurements}

HL 0.675, 0.563, 0.750; HW 0.751, 0.606, 0.789; HC 0.673, 0.544, 0.730; SL 0.608, 0.525, 0.664; EL 0.182, 0.161, 0.189; A11L 0.245; A11W 0.138; A10L 0.102; A10W 0.121; A09L 0.067; A09W 0.093; A08L 0.052; A08W 0.069; WL 0.801, 0.625, 0.883; SPL 0.157, 0.119, 0.151; PTH 0.181, 0.149, 0.197; PTL 0.244, 0.196, 0.253; PTW 0.220, 0.163, 0.231; PPL 0.189, 0.152, 0.192; PPW 0.242, 0.197, 0.258; CI 111, 108, 105; OI 27, 29, 25; SI 90, 93, 89; PTHI 74, 76, 78; PTWI 90, 83, 91; PPI 128, 130, 134; SPI 20, 19, 17 ; ACI 0.24 .

\section{Queen}

A normal queen (dorsal face of propodeum drops steeply from postscutellum and much of propodeum appears ventral to scutellum and postscutellum, Fig. 1) with general shape, sculpture, and pilosity characters of the worker; size characters as in Figures 4 and 5 . 
Crematogaster sumichrasti occurs in a wide variety of habitats. It is most common in highly disturbed or urban areas at mid elevation sites, but can occur rarely in mature forest sites and low elevation sites.

Nests are in almost any kind of small cavity. I have collected nests from dead sticks and from cavities in the live stems of Acalypha (Euphorbiaceae). Ward collected nests in Mexico from dead sticks, a live vine stem, and from a swollen-thorn ant acacia. Skwarra (1934a,b), in her study of arboreal ant communities in the state of Veracruz, Mexico, found the species abundantly in a wide variety of nest sites including Cecropia internodes, orchid pseudobulbs, and between overlapping leaves of bromeliads. The types of Forel's surdior were tending aphids beneath the leaf-sheaths of banana (Forel 1885). The types of Wheeler's atitlanica and maya were collected beneath stones in a very dry, open area in Guatemala.

Colonies are polygynous and can have large numbers of dealate queens. Skwarra reported one colony with 31 dealate queens and 962 workers, and another colony with 164 dealate queens and about 1200 workers.

In Costa Rica, sumichrasti is very common in urban areas in and around the capital, San José. I have found it as an abundant ant in the backyard patios and gardens of several hotels and other dwellings. In these circumstances I have observed columns of workers and dispersed foragers on the vegetation, active both day and night. It is a somewhat less abundant ant along the upper parts of the road from the PanAmerican Highway to Monteverde, where I found small nests in dead sticks along the road edge. A collection that seemed out of place relative to my other observations was a small colony in a live stem of an Acalypha shrub in Hitoy Cerere Biological Reserve, a lowland rainforest site on the southern Atlantic slope. This small colony contained 23 workers and one dealate queen. Finally, a lone worker was collected in a mature wet forest site at $1000 \mathrm{~m}$ elevation in Braulio Carrillo National Park, on the Atlantic slope of the Cordillera Volcanica Central. The ALAS project carried out an intensive program of sampling at this site, and out of 100 two-week Malaise samples obtained from a set of 20 traps, one sumichrasti worker was found.

\section{Comments}

In Costa Rica, sumichrasti is distinguished from the similar monteverdensis by the presence of one or more very long flexuous setae on the tibiae and by a more pronounced, almost tuberculate development of the juncture of the dorsal and posterior faces of the mesonotum. The only other species with similarly long macrosetae on the tibiae is flavosensitiva. The propodeal spines are upturned in sumichrasti, directed posteriorly in flavosensitiva.

I discovered the tibial pilosity character long after I had examined the types of sumichrasti, surdior, and atitlanica, and thus I am not positive of the character states on these 
types. However, six other collections from Mexico and Guatemala that I have recently examined all share the long tibial setae and tuberculate mesonotum characteristic of Costa Rica sumichrasti. Wheeler's illustration of subspecies maya shows a tuberculate mesosoma more like sumichrasti than monteverdensis. Forel's surdior was differentiated from sumichrasti mainly on the basis of color, but among the above mentioned Guatemalan and Mexican collections there is considerable variation in color, from light yellow to dark brown. Until there is further knowledge of character variation in northern Central America, I choose to consider maya and surdior synonyms of a widespread sumichrasti. In Costa Rica, collections are thorough enough to recognize a separate, microparapatric endemic species, monteverdensis. It is likely that similar patterns will emerge when additional collections are obtained and examined from other localities.

I have also chosen to treat Wheeler's atitlanica as a synonym of sumichrasti. Wheeler was collecting on the north shore of Lake Atitlan in Guatemala, in an area of open sandy soil in hot, dry conditions. He discovered two nests of Crematogaster under stones within about a mile of each other. Each of them contained about 100 adult workers, a small amount of brood, a large number of tiny apterous males, and one or three apterous adult queens respectively. The males and queens were apterous even in the pupal stage. Wheeler considered the workers nearly identical to sumichrasti (which did not stop him from describing them as a new subspecies). The queens and males were also very similar to sumichrasti, differing only in their aptery and, in the case of the males, in details of coloration. Wheeler surmised that the queens and males were workerless social parasites that had invaded and killed the host queen, and that what he was observing was the worker remnants of a sumichrasti colony rearing the brood of the social parasites. He discussed other cases of workerless parasites in ants in which one of the sexes was apterous or had reduced flight capacity. He considered this case to be unique because both sexes were apterous, and he assumed that the queens must mate with their brothers and disperse overland to other host colonies. He commented that in spite of aptery there seemed to be no modification of queen thorax volume or structure. He erected a new subgenus, Apterocrema, and a new species, atitlanica, to hold these putative workerless parasites.

I feel that Occam's razor should be used to trim Wheeler's hypothesis, and that such an elaborate scenario should not be adopted until more evidence for it is marshaled. Until further evidence to the contrary, a more parsimonious explanation is intraspecific plasticity in queen and male development patterns. I have found similar apterous males in monteverdensis, and the small polygynous queens of sumichrasti are not too different from the facultatively produced ergatogynes found in other Crematogaster species such as nigropilosa and curvispinosa. Given the frequency of ergatogynes in the genus as a whole and general indications of developmental plasticity, I suggest that social parasitism is unlikely to be the source of these apterous males. It is more likely to be an intraspecific phenomenon, perhaps facultative and associated with polygyny. We may discover that apterous males occur sporadically in a variety of species. 
Crematogaster longispina r. tenuicula Forel, 1904a:36. Syntype workers: Brazil, Para (Göldi)

[MHNG] (examined). Emery, 1922:136: combination in C. (Orthocrema).

Range

Costa Rica to Amazonian Brazil, Bolivia.

\section{Description of worker}

Color pale yellow brown to dark red brown; workers monomorphic in size.

Mandibles smooth and shining; clypeus smooth and shining; head about as long as wide, subquadrate, with broadly convex sides and flat to weakly emarginate posterior border; antenna with terminal two segments enlarged to form a club, third segment from end somewhat enlarged, blurring distinction between two and three-segmented club; scapes with abundant long erect setae; when scapes laid back from antennal insertions, they surpass margin of vertex; face largely smooth and shining, with variable extent of striated region between antennal insertion and eye, and whorled above antennal insertion; face covered with abundant long flexuous white setae, no appressed pubescence; in face view abundant setae project from lateral and posterior margins.

Promesonotum in profile similar to brasiliensis, somewhat flattened dorsally, short anterior face of pronotum rises to dorsal face, dorsal faces of pronotum and mesonotum subequal in length, horizontal, forming single flat surface or weakly arched and meeting at a slightly produced angle; dorsal and posterior faces of mesonotum meeting at rounded angle, posterior face dropping to propodeal suture; propodeal suture deep in dorsal view but less pronounced in profile due to lateral carinulae that bridge the suture; lateral carinulae weakly notched, lacking minute triangular teeth at propodeal suture (unlike brasiliensis); propodeal spines medium length, projecting posteriorly; propodeum with short, weakly differentiated dorsal face and long posterior declivity sloping to petiolar insertion; pronotal dorsum smooth and shining or with weakly developed longitudinal carinulae laterally; anterodorsal face of mesonotum with weak, subparallel lateral carinae, these continue onto posterodorsal face as stronger carinae that converge posteriorly, interspace concave, smooth and shining; propodeal declivity smooth and shining; side of pronotum smooth and shining; katepisternum weakly to distinctly punctate or punctatorugose; side of propodeum very faintly sculptured; mesosomal dorsum with abundant long flexuous white setae, setae on pronotal humeri longest; femora and tibiae with abundant long erect setae.

Petiole in side triangular, smooth and shining; anteroventral margin lacking tooth or rarely with a small rounded projection; posterior ring-like aperture that receives postpetiole small, posterolateral lobes of dorsal face of petiole distinctly higher than dorsal margin of aperture when petiole viewed in profile with ventral margin horizontal (unlike brasil- 
iensis, in which posterior aperture is large, dorsal margin at nearly same level as posterolateral lobes of dorsal face); dorsal face of petiole smooth and shining, elongate, widest posteriorly, regularly tapering anteriorly, with long flexuous setae along posterior border; postpetiole with distinct, subacute, short anteroventral tooth, globular in dorsal view, with abundant erect setae; fourth abdominal tergite smooth and shining, with abundant long flexuous erect white setae, no appressed pubescence.

\section{Measurements}

HL 0.641, 0.617, 0.822; HW 0.657, 0.645, 0.884; HC 0.616, 0.579, 0.833; SL 0.656, 0.659, 0.797; EL 0.137, 0.145, 0.199; A11L 0.275; A11W 0.125; A10L 0.142; A10W 0.103; A09L 0.074; A09W 0.069; A08L 0.055; A08W 0.063; WL 0.753, 0.726, 0.913; SPL 0.152, 0.171, 0.173; PTH 0.166, 0.149, 0.213; PTL 0.244, 0.241, 0.349; PTW 0.159, 0.163, 0.230; PPL 0.185, 0.168, 0.203; PPW 0.166, 0.175, 0.232; CI 102, 105, 108; OI 21, 24, 24; SI 102, 107, 97; PTHI 68, 62, 61; PTWI 65, 68, 66; PPI 90, 104, 114; SPI 20, 24, 19; ACI 1.39 .

\section{Queen (Costa Rica)}

A normal queen (dorsal face of propodeum drops steeply from postscutellum and much of propodeum appears ventral to scutellum and postscutellum, Fig. 1) with general shape, sculpture, and pilosity characters of the worker; size characters as in Figures 4 and 5; sharply bicolored, with red head, mesosoma, petiole, and postpetiole, and black gaster (based on two nest collections, one from Costa Rica, one from near Manaus, Brazil). I cannot find any consistent differences between queens of tenuicula and brasiliensis.

\section{Biology}

Crematogaster tenuicula occurs in lowland wet forest habitats, in either mature forest or second growth vegetation. In Costa Rica, the species is common on the Osa Peninsula. I have seen only one Costa Rican collection from beyond the Osa, made by D. Olson at Carara Biological Reserve. During my extensive fieldwork in Corcovado National Park in the early 1980 's, I frequently encountered tenuicula. Workers built small carton pavilions on low vegetation, covering aggregations of honeydew-producing Homoptera (Coccoidea and Membracidae) that they tended. These carton pavilions were a relatively common site on many different plant species. Isolated workers were common as foragers on low vegetation, visiting extrafloral nectaries and scavenging small dead arthropods. They could be attracted to baits of dead insects or sugar solution. Foragers were active day and night.

Several observations suggest a somewhat diffuse, polydomous nest structure, with spatial segregation of workers, reproductives, and brood of various ages and castes. When baiting, I observed columns of recruiting workers returning to the carton pavilions, within which were workers and Homoptera only. These pavilions never contained brood. In one case, workers recruited to a freshly killed tabanid from two sources: (1) a small, flat cham- 
ber under moss on a tree trunk, $50 \mathrm{~cm}$ high, containing workers only; and (2) a dead, rolledup leaf lying on the surface of the leaf litter. This leaf contained workers and many winged reproductives of both sexes, but no brood. When I disturbed the ants or watched ants returning with pieces of the bait, they always went to one of these two places. I could not find any more of the colony or any brood. In another case, I found a set of disconnected nests in a vertical, rotten tree trunk. Ants occupied elongate indentations and chambers in the hard outer wood. Again, as in the above case, all the chambers contained mainly adult workers and alates. Some contained large larvae and pupae of reproductives, but I found no chambers with worker brood. I have never seen a definitive nest center with physogastric queen and worker brood.

Beyond Costa Rica I have very little information on the biology of tenuicula. Several of the collections from beyond Costa Rica are from Winkler samples of sifted leaf litter from the forest floor, and Ward collected it "ex Tachigali," an ant plant. One worker was found in stomach contents of a dendrobatid frog from French Guiana.

\section{Comments}

The morphology of this species is quite uniform across its range. It is very similar to brasiliensis, with which it shares the ventral postpetiolar tooth. In Costa Rica the two species are easily distinguishable, because the petiole in lateral profile is elongate and low in brasiliensis, almost linear, with an anteroventral tooth, while in tenuicula it is shorter and taller, more triangular, and lacks an anteroventral tooth. However, in South America the petiole of brasiliensis becomes shorter and taller and the petiole of tenuicula may develop a small anteroventral tooth. The relationship of the posterolateral lobes of the dorsal face to the posterior aperture is consistent across the range of both species, with brasiliensis having a large aperture relative to the lobes and tenuicula having a small aperture.

Crematogaster tenuicula may also be confused with carinata, limata, and foliocrypta. Crematogaster carinata and limata lack a ventral postpetiolar tooth. Crematogaster foliocrypta has appressed tibial pilosity in contrast to the erect pilosity of tenuicula.

The MHNG syntypes were compared directly with material from Corcovado National Park. They closely matched in nearly all respects. The types were lighter colored and generally more delicate than many Corcovado specimens, but within the range of variation of Costa Rican material.

\section{Crematogaster torosa Mayr 1870}

Figure 4

Crematogaster torosa Mayr, 1870a:404. Syntype workers: Colombia, Santa Fe de Bogotá (Lindig) [NMW] (examined). Emery, 1922:136; Santschi, 1925:229: combination in C. (Orthocrema). Crematogaster brevispinosa var. tumulifera Forel, 1899:84. Syntype workers: Nicaragua, Chontales (Janson); and Costa Rica (Tonduz) [MHNG] (examined). Forel, 1908a:47: description of 
queen, male. Wheeler, G.C. and Wheeler, J. 1952:260: description of larva. Emery, 1922:134: combination in C. (Orthocrema). Forel, 1907a:25; Forel, 1908b:369; Forel, 1909:258; Forel, 1912:215: subspecies of brevispinosa. NEW SYNONYMY

Crematogaster arizonensis Wheeler, W. M. 1908b: 482, pl. 27, fig. 40. Syntype workers: USA, Arizona, Tucson and Phoenix, running on cottonwood trees (Wheeler). Wheeler, W. M. 1912: 132: description of queen, male. Emery, 1922: 134: combination in C. (Orthocrema). NEW SYNONYMY

Crematogaster brevispinosa subsp. tumulifera var. scurra Forel, 1914a:615 (unavailable name). Worker: Colombia (Gaige) [MHNG] (examined).

\section{Range}

USA at least to Colombia, southern limit of species range not defined.

\section{Description of worker (Costa Rica)}

Differing from crinosa in the following respects: mesonotum shorter, promesonotal suture more often impressed, making promesonotal profile flatter; anteroventral petiolar tooth shorter, more often forming nearly right angle rather than long acute tooth; setae on fourth abdominal tergite less abundant, especially medially, such that erect setae more dense anterolaterally.

\section{Measurements}

HL 0.682, 0.578, 1.045; HW 0.763, 0.629, 1.179; HC 0.760, 0.598, 1.123; SL 0.488, 0.443, 0.706; EL 0.170, 0.130, 0.259; A11L 0.241; A11W 0.140; A10L 0.118; A10W 0.118; A09L 0.060; A09W 0.085; A08L 0.041; A08W 0.071; WL 0.789, 0.664, 1.269; SPL 0.080, 0.057, 0.142; PTH 0.165, 0.129, 0.280; PTL 0.232, 0.175, 0.380; PTW 0.246, 0.180, 0.373; PPL 0.171, 0.150, 0.265; PPW 0.224, 0.189, 0.371; CI 112, 109, 113; OI 25, 22, 25; SI 72, 77, 68; PTHI 71, 74, 74; PTWI 106, 103, 98; PPI 131, 126, 140; SPI 10, 9 , 11; ACI 0.98 .

\section{Queen}

A normal queen (dorsal face of propodeum drops steeply from postscutellum and much of propodeum appears ventral to scutellum and postscutellum, Fig. 1) with general shape, sculpture, and pilosity characters of the worker; size characters as in Figures 4 and 5 .

\section{Biology}

Crematogaster torosa has a biology very similar to crinosa and rochai. It occurs primarily in open, seasonally dry areas, highly disturbed areas, and pasture edges, although it can also be found in the canopy of mature wet forest. In Costa Rica it is a common species in urban areas such as the various city parks in the capital, San José.

Nests are large, polydomous, distributed in a wide variety of plant cavities. Dead branches and knots in living trees are most often used. In Guanacaste Province in Costa 
Rica they often occupy ant acacias, and may invade acacias already occupied by Pseudomyrmex. They often construct small carton baffles that restrict nest entrances and small carton pavilions that shelter Homoptera on surrounding vegetation. In some instances they may inhabit cavities in live stems. I found a large nest in the live stems of a Protium branch (Burseraceae) in Corcovado National Park, and I have found nests in live stems of myrmecophytic Acacia and Triplaris. Nest chambers are sometimes filled with alate queens and males. Based on a sample size of two, colony founding is monogynous. In one case I dissected a small colony in south Texas and found a single physogastric queen in the center. In another case I found a lone foundress queen in a dead branch of a Triplaris tree in Costa Rica.

Foraging is primarily diurnal but occasional nocturnal foragers are seen. Workers are generalized scavengers and they frequently visit extrafloral nectaries. Often columns of workers move between nests.

\section{Comments}

This is a member of the crinosa complex and may not always be distinguishable from crinosa and rochai. See under crinosa for further discussion. I examined the type of torosa and compared it directly to Costa Rican material (Corcovado National Park, Sirena, JTL30May82/0830). Museum notes on one of the syntypes were as follows: HL 0.88, HW 0.97 , SL 0.61; mandible striate; clypeus feebly striate; fine striae on genae, between antennae and eyes, rest shiny; pronotum with transverse fingerprint-like swirl anteriorly, grading to fine longitudinal striae posteriorly, fading to shiny mesonotum (variable within series), grading to fine striae again near propodeal suture; dorsal face of propodeum short, irregularly striate/punctate; anteroventral petiole sharply angulate, but not produced into a projecting tooth; one flexuous short seta on frons; anterior row of four erect setae on pronotum, two on mesonotum, one each on propodeal spines, two each on petiole, postpetiole, about 11 on fourth abdominal tergite, not including row of 13 on posterior margin; setae on fourth abdominal tergite clustered laterally, leaving median bare; setae on pronotum thinner and longer, rest shorter, flattened; color light orange brown on head, pronotum, grading to dark brown on gaster.

I examined the syntypes of Forel's tumulifera and the additional Costa Rican material on which he based his description of the queen and male. They matched Mayr's torosa in every respect.

Specimens of torosa from the northern end of the range, in southeast Texas and in Arizona, are somewhat smaller and less polymorphic than Costa Rican material, but this seems to gradually change as one moves northward in Mexico. Specimens from Baja California are bicolored, with reddish head and mesosoma, and black gaster. However, the abundant material from Arizona and Costa Rica shows continuous variation in the degree of infuscation of the head and mesosoma, and some material may be clearly bicolored like the Baja material. Specimens from Baja nearly always have a long, acute anteroventral 
petiolar tooth. Specimens from the state of Arizona in the USA and Sonora and Sinaloa

states in Mexico (former arizonensis) usually have a short but sharply acute tooth as an average condition, but the tooth form varies from long and spine-like to short and right angled. Specimens from southeastern Texas and Costa Rica show a great deal of variability, but usually have a right-angle tooth and less often a short, sharply acute tooth. They never have a long spine-like tooth. For the time being I interpret all this material as torosa, differing from crinosa and rochai by the somewhat flatter promesonotum and the usually shorter petiolar tooth, and with a gastral setal pattern intermediate between crinosa, which has a uniform covering of flattened setae, and rochai, which has no erect setae.

\section{Crematogaster wardi NEW SPECIES}

Plate 7

\section{Holotype worker}

Costa Rica, Prov. Heredia, La Selva Biological Station, $10^{\circ} 26^{\prime} \mathrm{N}, 84^{\circ} 01^{\prime} \mathrm{W}, 50 \mathrm{~m}, 17$ Mar 1993 (Longino, collection code JTL3408-s) [INBC, specimen code INBIOCRI001238528].

\section{Paratypes}

One worker, same data as holotype [BMNH, specimen code INBIOCRI001238527]; one worker, same locality, 3 Mar 1989 (Longino, collection code JTL2460-s) [LACM, specimen code INBIOCRI001281212]; one worker, same locality, 18-22 Jun 1999 (INBioOET, Project ALAS collection code W/13/008) [MCZC, specimen code INBIOCRI002719786]; one worker, same data [MHNG, specimen code INBIOCRI002719787]; one worker, same data [NHMB, specimen code INBIOCRI002719788]; one worker, same locality and date (INBio-OET, Project ALAS collection code W/11/006) [UCDC, specimen code INBIOCRI002720566]; one worker, same data [USNM, specimen code INBIOCRI002720567].

Crematogaster JTL-013: Longino et al. 2002.

\section{Range}

Costa Rica.

\section{Description of worker}

Color yellow orange; workers monomorphic in size.

Mandibles feebly striate on proximal half, smooth and shining with large piligerous puncta on distal half; clypeus with two longitudinal carinulae at anterior margin, anterior margin gently convex to straight; head longer than wide, with rounded posterior border; antenna with terminal two segments enlarged to form a club, third segment from end 
somewhat enlarged, blurring distinction between two and three-segmented club; scapes with abundant suberect flexuous setae; when scapes laid back from antennal insertions, they distinctly surpass margin of vertex; face smooth and shining, with a few concentric carinulae around antennal insertion; face covered with abundant, long, erect, flexuous, white setae, no appressed pubescence; in face view setae project from lateral and posterior margins.

Promesonotum in lateral profile somewhat flattened, pronotum and anterodorsal face of mesonotum of similar length, nearly in same plane; posterior face of mesonotum short, meeting dorsal face at angle but not produced or tuberculate, dropping to propodeal suture; propodeal suture deep in dorsal view but partially obscured in profile by lateral carinulae that bridge the suture; propodeum with short, differentiated dorsal face and longer posterior face; propodeal spines medium length, spiniform, directed posteriorly and weakly curving upward; pronotal dorsum with sparse longitudinal carinulae, interspaces smooth and shining; mesonotum with parallel lateral carinae that converge toward propodeal suture; medial mesonotum concave, smooth and shining; dorsal face of propodeum feebly rugulose, posterior face smooth and shining; side of pronotum smooth and shining; katepisternum smooth and shining medially, feebly punctate at margins; side of propodeum shining, largely smooth with traces of feeble carinulae ventrally; promesonotum with long flexuous white to amber erect setae in three ranks, four across anterior pronotum, two at anterior mesonotum, and two at mesonotal midlength; humeral setae are longest $(0.21 \mathrm{~mm})$, other six are subequal in length $(0.15 \mathrm{~mm})$; propodeal dorsum with one or two pairs long setae, on base of propodeal spines and half way along spine shaft; short inconspicuous setae sparsely scattered elsewhere on mesosomal dorsum; tibiae with abundant short subdecumbent setae, none longer than maximum tibial width.

Petiole in side view trapezoidal, punctate; anteroventral tooth present, rounded, rightangle, or acute; dorsal face of petiole smooth and shining, subrectangular, longer than wide, with about eight long amber setae along posterior border; postpetiole with acute anteroventral tooth, postpetiole in dorsal view subquadrate, wider than long, with emarginate posterior margin, abundant long setae; fourth abdominal tergite smooth and shining, with abundant long suberect amber setae, no appressed pubescence.

\section{Variation}

Workers vary in robustness and coloration. Small workers are relatively paler, with weaker sculpture on the katepisternum and flatter promesonotum. Large workers are darker orange, with stronger punctate sculpture on the katepisternum, and a more arched promesonotum. The two collections I have from the Osa Peninsula are small and pale. Material from La Selva Biological Station varies from small and pale to larger and darker. Three workers collected at $1070 \mathrm{~m}$ elevation in Braulio Carrillo National Park above La Selva vary from small and pale to larger and darker orange. A series of three workers from Bajo La Hondura, an 1100m elevation site near the southeastern edge of Braulio Carrillo, 
are the largest I have seen, with distinctly arched promesonotum, and lacking the anterior

row of long setae on the pronotum. I initially had access to only these large workers and the specimens from the Osa Peninsula, and I considered them distinct species. Subsequent collections from La Selva revealed variation linking the two forms. It is likely that there is some form of clinal variation on the Atlantic slope, with small pale forms dominating in the lowlands and larger, darker forms more common at higher elevations, a pattern seen in many other ant lineages.

\section{Measurements}

Holotype: HL 0.537, HW 0.546, HC 0.493, SL 0.473, EL 0.156, WL 0.618, SPL 0.110, PTH 0.143, PTL 0.201, PTW 0.162, PPL 0.141, PPW 0.181, CI 102, OI 29, SI 88, PTHI 71, PTWI 81, PPI 128, SPI 18.

Other specimens: HL $0.581,0.547,0.669$; HW 0.615, 0.554, 0.683; HC 0.570, 0.495, 0.626; SL 0.499, 0.472, 0.640; EL 0.162, 0.168, 0.186; A11L 0.241; A11W 0.128; A10L 0.105; A10W 0.111; A09L 0.054; A09W 0.086; A08L 0.046; A08W 0.059; WL 0.676, 0.626, 0.801; SPL 0.142, 0.123, 0.163; PTH 0.168, 0.138, 0.178; PTL 0.213, 0.196, 0.267; PTW 0.194, 0.159, 0.218; PPL 0.145, 0.158, 0.177; PPW 0.209, 0.180, 0.241; CI 106, 101, 102; OI 28, 31, 28; SI 86, 86, 96; PTHI 79, 70, 67; PTWI 91, 81, 82; PPI 144, 114, 136; SPI 21, 20, 20; ACI 0.80.

\section{Etymology}

This species is named for Phillip S. Ward at the University of California at Davis. Phil taught me how to mount ants.

\section{Biology}

Crematogaster wardi occurs in mature wet forest habitats on both the Atlantic and Pacific slopes of Costa Rica. The species is known only from workers. They have been collected three times as nocturnal foragers on low vegetation, once as diurnal foragers on extrafloral nectaries of an Inga sapling, twice in Malaise traps, and three times in Winkler samples of sifted leaf litter from the forest floor.

\section{Comments}

Crematogaster wardi is uniquely characterized by the combination of (1) yellow coloration; (2) humeral setae of mesosomal dorsum long, flexuous, and longer than any other mesosomal setae; (3) relatively long propodeal spines; and (4) relatively elongate promesonotum. Similar species are minutissima and flavomicrops. 
Throughout the tropical and subtropical Americas, highly insolated habitats are often dominated by Crematogaster with the following characters:

- Colonies large and polydomous.

- Workers with pronounced size polymorphism.

- Head of large workers emarginate posteriorly.

- Scapes short, not attaining posterior margin of head when laid back (SI < 75).

- Dorsal face of petiole short, nearly as broad as or broader than long, subquadrate or more often with strongly convex sides, usually widest at midlength.

- Postpetiole lacking ventral tooth; in dorsal view globular to subquadrate, as wide as or wider than long, and sometimes with faint longitudinal median impression.

- Face with short appressed pubescence and variable number of short erect setae, never with abundant long flexuous setae.

- Setae of mesosomal and gastral dorsum always short, flattened, and stiff, never long and flexuous.

I refer to these as the crinosa complex, because Mayr's $C$. crinosa is the oldest described taxon that exhibits these characters. Habitats where these ants are dominant include mangroves, seasonal dry forests, savanna, the upper canopy of wet forests, scrub and thorn forests, and anthropogenic habitats such as pasture edges, roadsides, and urban areas. The habitats where they are absent or show greatly reduced abundance are wet forest interiors and montane areas. In many ways this group is intermediate between other Neotropical Crematogaster and the Crematogaster s.s. that dominate the North American temperate zone. Wet forest Crematogaster tend to have the petiole elongate, widest posteriorly, and tapering anteriorly. The crinosa complex shows a shortening and broadening of the petiole, and a shift of the widest portion to midlength or even more anteriorly. Crematogaster s.s. continues this trend, such that the dorsal face of the petiole has broad anterolateral lobes, is definitely widest anteriorly, and tapers posteriorly. Many rainforest Crematogaster have the postpetiole globular. The postpetiole of the crinosa complex may be globular or slightly bilobed. The postpetiole of Crematogaster s.s. is strongly bilobed with a pronounced median sulcus. Many rainforest Crematogaster have abundant long flexuous setae on the face and fourth abdominal tergite, heads that are more rounded posteriorly, and long scapes that extend to or beyond the vertex margin. The crinosa complex and Crematogaster s.s. are essentially identical in the short pubescence on the face, the generally sparse erect setae, and the short scapes. Given the prevalence of elongate petiole with posterior node among the most generalized myrmicines, the shortening and broadening of the petiole within Crematogaster is probably apomorphic. Paralleling these morphological transitions is a habitat transition from moderate to increasingly harsh environmental conditions. The pattern may reflect a phylogenetic history in which the cri- 
nosa complex was derived from a rainforest ancestor and moved out into open areas, dry areas, and the subtropics. Subsequently, under this scenario, Crematogaster s.s. was derived from a crinosa complex ancestor and moved across the frost line and into the temperate zone. The pattern could also be generated by parallel responses to natural selection, with the similarities between the crinosa complex and Crematogaster s.s. being due to similar adaptive responses to dry conditions. Also, the widespread occurrence of Crematogaster s.s. in the Old World has not been incorporated into this scenario, and begs investigation.

Other Neotropical species that share the general habitus of the crinosa complex but have long flexuous hairs are erecta, moelleri, stollii, and crucis. These are all more associated with rain forest and montane forest, compared to crinosa-group species.

Taxonomy within the crinosa complex is difficult. The following is a synopsis of character systems that vary within the crinosa complex:

The face and clypeus may be largely smooth and shining, or with varying degrees of granular to finely longitudinally striate sculpture that extends from the anterior portion of the head. Often the clypeus, malar spaces, and space between eyes and antennal insertions is finely striate. These striae may extend up the sides of the head and medially, to the point where only a thin median strip remains smooth and shiny. In some cases the entire face is uniformly striate, causing a sericeous luster or mat surface.

The position and strength of the promesonotal suture varies. In some cases the promesonotum forms a uniformly curved convex profile, with the promesonotal suture not visible in profile or dorsally. In other instances the mesonotum is enlarged and the pronotal dorsum shortened, such that the remnants of the promesonotal suture can be seen as oblique impressions laterally, but the suture is effaced in dorsal view. In very large workers the suture may be entire but strongly arching anteriorly, such that the pronotal dorsum is very short (approaching the condition in the queen). Finally, the mesonotum may be less enlarged relative to the pronotum, and the promesonotal suture visible as an impression that more evenly divides the promesonotum. In lateral view this results in a promesonotal profile that is more flat-topped.

The dorsal face of the propodeum, which is always very short relative to the posterior face, may drop steeply to the propodeal suture, such that the juncture of the dorsal and posterior faces is strongly produced as an anteroposteriorly compressed ridge. In some cases the dorsal and posterior faces meet at an obtuse angle, such that in lateral view there is a distinct v-shaped propodeal suture, a subhorizontal dorsal face, then a sloping posterior face. In some cases the dorsal and posterior faces are in the same plane, such that the propodeal suture appears very shallow with no posterior wall, and the propodeum forms a single declivity from the propodeal suture to the petiolar insertion. The transition is like a wrinkle in a rug being gradually smoothed out.

The anteroventral petiolar tooth may be long, narrowly acute, and sharp. If long and sharp, it may project anteriorly, with the entire ventral margin of the petiole, including the 
tooth, in the same plane, or the ventral margin of the tooth may curve resulting in an upwardly concave ventral margin. Alternatively, the tooth may be reduced to a nearly right angle.

The fourth abdominal tergite may have an even vestiture of erect setae over the entire surface. In other cases the setae are clustered anterolaterally, often leaving a medial strip bare. The tergite may be completely bare, or with only 1-3 setae anterolaterally.

The above character variation is continuous rather than discrete, and all combinations of characters seem to occur. However, variation is not random, and clusters of correlated characters occur that suggest distinct sympatric species. Within Costa Rica, for which abundant material is available, I have come to the conclusion that there are three sympatric species: crinosa, torosa, and rochai. However, occasional specimens exhibit combinations of characters that blur the distinctions. I have not discovered characters that are uniformly diagnostic. These three "character clusters" seem to occur widely in the Neotropics. For example, abundant collections from southeast Texas in the USA almost all match torosa, but one collection exhibits all the characters of crinosa, suggesting that two species are sympatric there. However, among the other collections I have been able to examine from scattered localities in the Neotropics, many show combinations of characters that do not match one of these three. As in other complex taxa, there is probably a combination of widespread lineages and narrow endemics. Additional collections and character analysis will be necessary to gain a clearer picture.

Given the ecological prevalence and the large character variation in the complex, many taxonomic names have been generated. In an attempt to bring some order to the nomenclature and to prepare the way for future taxonomic work, I summarize below the available names I associate with the crinosa complex (or remove from the complex). No new synonymy is proposed, but many changes in status are made to eliminate trinomials and liberate names from the various assumed relationships to other species. Species are either discussed separately or grouped by salient characters.

\section{Crematogaster ampla NEW STATUS}

Crematogaster brevispinosa var. ampla Forel, 1912: 211. Syntype workers: Colombia, Magdalena, Santa Cruz near Santa Marta (Forel) [MHNG] (examined, worker here designated LECTOTYPE). Emery, 1922: 134: combination in C. (Orthocrema).

This species has a distinctive character that distinguishes it from all other Crematogaster. The fourth abdominal tergite has a subtriangular impression posterior to the postpetiolar insertion. This impression is completely smooth and shining, contrasting with the surrounding granular microsculpture. On some small workers the fourth abdominal tergite is completely smooth and shining, but the triangular impression is still distinct. In all other Crematogaster there may be an impression anterior to the postpetiole, but not posterior to 
it. Other characters are similar to crinosa, including a long, acute, anteroventral petiolar tooth, abundant setae on the fourth abdominal tergite, dorsal and posterior faces of propodeum meeting at an angle, and a strongly arched promesonotum. Unlike other crinosa complex species, the scapes and tibiae sometimes have one or two erect setae, especially on large workers. I have seen material from three widely separated localities in Colombia (Departments of Magdalena, Huila, and Valle) and one collection from Bolivia.

The syntypes at MHNG were a combination of ampla and crinosa, necessitating designation of a lectotype.

\section{Crematogaster vicina REVISED STATUS}

Crematogaster vicina Andre, 1893b:151. Syntype worker: Jamaica, Montego Bay (M. Cockerell). Wheeler, W.M. 1917:461: description of queen, male. Emery, 1922:134: combination in $C$. (Orthocrema). Forel, 1912:212: race of brevispinosa.

Crematogaster vicina var. wighti Wheeler, W.M. 1908a:161. Syntype worker: Jamaica, St. Margaret's Bay, procession on ground in woods (Wight). Synonymy by Wheeler, W.M. 1917:461.

I cannot distinguish this species from torosa on morphological grounds. It appears to be the only crinosa complex species on Jamaica, and it is very abundant there. The workers build large, completely exposed carton nests that wrap around relatively narrow gauge stems on small trees. This nesting behavior is unique and highly distinctive within the crinosa complex. All other crinosa complex nests I have seen have been in dead wood, with at most small carton baffles around nest entrances and forming partitions inside the nest. Thus the population has been on Jamaica long enough to evolve this distinctive nesting behavior (or retained a primitive nesting behavior that has been lost everywhere else).

\section{Forms with completely striate face:}

Crematogaster atra Mayr, 1870b: 994. Syntype worker: Mexico (Norton, Bilimek) [NMW] (examined, Norton worker here designated LECTOTYPE). Emery, 1922: 134: combination in $C$. (Orthocrema).

Crematogaster sericea NEW STATUS. Crematogaster brevispinosa r. sericea Forel, 1912:214. Syntype worker: Brazil, Sao Paulo, Botucatu (Göldi) [MHNG] (examined). Emery, 1922:134; Santschi, 1923:249: combination in C. (Orthocrema).

Crematogaster uruguayensis NEW STATUS. Crematogaster atra st. uruguayensis Santschi, 1912:527. Syntype workers: Uruguay, Colonia Nueva Helvecia (von Steiger) [NHMB] (examined).

Crematogaster (Orthocrema) peristericus Menozzi, 1925:369, fig. 2. Syntype worker, queen: Brazil, Rio Grande do Sul, Porto Alegre (Wille) [DEIC] (examined).

The syntypes of atra have no more precise locality data than "Mexico," but are by two different collectors, Bilimek and Norton. The Norton series, from which the lectotype is cho- 
sen, has the general shape and pilosity characters of crinosa, the only difference being that the face is completely covered with fine, dense striae, with no smooth or shiny areas. The syntypes of sericea also have the general shape and pilosity characters of crinosa. There are two syntype workers of uruguayensis on a pin at NHMB, and I compared them to a syntype of sericea. They are a bit darker than the types of sericea, and the setal pattern on the fourth abdominal tergite is more like torosa than crinosa. I found eight worker syntypes of Menozzi's peristerica at DEIC, simply labeled "Typus," with no other label data. The specimens had a completely striate face, but were otherwise like torosa.

It is unclear whether the variation in face sculpture from smooth and shining to completely striate represents intraspecific or interspecific variation. It may be that selection gradients cause parallel changes in face sculpture among multiple sympatric lineages, such that the above forms may be synonyms of crinosa and torosa. For example, I have examined five collections from Colombia that have completely striate faces. Other than the striate face, one collection has the characters of crinosa, three have the characters of torosa, and one has the characters of rochai. Alternatively, further research may reveal that the forms with completely striate faces are found in sympatry with shiny faced forms, or show discontinuous character variation, such that they are best interpreted as distinct species. If so, it must then be determined whether these forms are distinct from each other or should be interpreted as one widespread species.

\section{Forms with deep propodeal suture:}

Crematogaster goeldii REVISED STATUS. Crematogaster goeldii Forel, 1903:255. Syntype workers: Brazil, Prov. Rio de Janeiro (Göldi) [MHNG] (examined). Gallardo, 1931:300: description of queen. Emery, 1922:135: combination in C. (Orthocrema). Santschi, 1925:229; Santschi, 1929a:294; Gallardo, 1931:300: variety of torosa.

Crematogaster stigmatica NEW STATUS. Crematogaster goeldii var. stigmatica Forel, 1911a:301. Syntype worker, male: Brazil, Minas Gerais, Mar d'Espanha (Zilsán) [MHNG] (examined). Emery, 1922:135: combination in C. (Orthocrema).

Crematogaster (Crematogaster) heathi Mann, 1916:442, pl. 3, fig. 27. Syntype workers: Brazil, Paraiba, Itamatahy near Independencia, from twigs (Mann) [MHNG, LACM] (examined). Emery, 1922:135: combination in C. (Orthocrema).

Crematogaster chodati NEW STATUS. Crematogaster goeldii var. chodati Forel, 1921:207. Syntype workers: Paraguay, from a trunk of Agonandra with Cryptocerus eduarduli (Chodat and Vischer) [MHNG] (examined). Kempf, 1972:89: combination in C. (Orthocrema).

Crematogaster (Orthocrema) unciata Santschi, 1925:228. Holotype worker: Brazil, Minas Gerais (E. Luja) [NHMB] (examined).

The distinctive feature of these forms is a deeply invaginated propodeal suture and an elevated and compressed dorsal face of propodeum. From my cursory examination, goeldii, stigmatica, and unciata were very similar. They were bicolored, with red brown head and mesosoma and contrasting black gaster. The anteroventral petiolar tooth was moderately well developed and the pilosity was much like torosa. The types of chodati were uniform 
red brown, and the setae on the mesosoma and fourth abdominal tergite were longer and less flattened. The types of heathi had the coloration of goeldii and the pilosity of chodati.

The invaginated propodeal suture is itself a variable character, grading into the condition seen in crinosa and torosa, and so the discussion regarding the forms with striate face applies here as well. Crematogaster goeldii and related forms may be synonyms of other species, multiple distinct species, or one variable species.

\section{Crematogaster rochai-like forms:}

Crematogaster brevispinosa subsp. tumulifera var. fautrix Forel, 1908b:369. Worker: Brazil, Sao Paulo (von Ihering) [MHNG] (examined). Unavailable name.

Crematogaster brevispinosa r. tumulifera var. convicta Forel, 1912:215. Worker, male: Argentina, Buenos Aires (Richter) [MHNG] (examined) Unavailable name.

Crematogaster brevispinosa r. crucis var. carminis Forel, 1914b:270. Worker: Argentina, Represa del Carmen near Alto Pencoso (Bruch) [MHNG] (examined). Unavailable name.

Crematogaster brevispinosa r. moelleri var. tucumanensis Forel, 1914b:271. Worker, queen: Argentina, Represa del Carmen, Alto Pencoso near La Plata, nest in a Prosopis branch bored by a cerambycid larva (Bruch); and Tucuman (Shipton) [MHNG] (examined). Unavailable name. Syntypes are identical to carminis.

Crematogaster malevolens NEW STATUS. Crematogaster (Orthocrema) brevispinosa st. malevolens Santschi, 1919:41. Syntype worker: Argentina, Chaco, Nueva Pompeya (Joergensen); Entre Rios, Estación Sosa (MacDonagh) [NHMB] (examined). Gallardo, 1931:298: description of queen, male.

Crematogaster russata NEW STATUS. Crematogaster (Orthocrema) brevispinosa subsp. russata Wheeler, W.M. 1925:24. Syntype worker: Bolivia, San Fermin (Holmgren) [MCZC, possibly Royal Museum of Stockholm] (MCZC workers examined).

Crematogaster subtonsa NEW STATUS. Crematogaster (Orthocrema) brevispinosa var. subtonsa Santschi, 1925:229. Syntype worker: Brazil, Minas Gerais, Pirapora (E. Garbe) [NHMB] (examined).

\section{Other unresolved crinosa complex names}

Crematogaster brevidentata NEW STATUS. Crematogaster brevispinosa var. brevidentata Forel, 1912:212. Syntype worker: Barbados, Bathseba, 200m elevation (Forel) [MHNG] (examined). Emery, 1922:134: combination in C. (Orthocrema). Workers are small, propodeal spines are tiny, there are no erect setae on head or fourth abdominal tergite, erect setae are sparse on mesosoma, and there is a strong anteroventral petiolar tooth.

Crematogaster thalia NEW STATUS. Crematogaster brevispinosa var. thalia Forel, 1911b:273. Syntype worker, queen: Paraguay, San Bernardino (Fiebrig) [MHNG] (examined). Emery, 1922:134: combination in C. (Orthocrema). The anteroventral petiolar tooth is almost spinelike; the mesosoma and fourth abdominal tergite are moderately setose; the mesosoma is large, light-colored.

Crematogaster brevispinosa subsp. tumulifera var. tumulicula Forel, 1909:258. Workers: Paraguay, San Bernardino (Fiebrig) [MHNG] (examined). Unavailable name. Two minim workers with strong petiolar tooth, scattered setae, crinosa-like.

Crematogaster montana NEW STATUS. Crematogaster (Orthocrema) brevispinosa subsp. montana Borgmeier, 1939:421. Syntype worker: Brazil, Petropolis (Borgmeier). 


\section{Crematogaster cubaensis Mann 1920 REVISED STATUS}

Crematogaster victima subsp. cubaensis Mann 1920:425. Syntype workers, queen: Cuba, Guantanamo, beneath a stone in the woods (Mann) [USNM] (examined). Menozzi, 1929:2: subspecies of steinheili. Enzmann, J. 1946:93: subspecies of laeviuscula. Kempf, 1972:90: subspecies of victima.

Crematogaster barbouri Weber 1934:24, fig. 1. Syntype workers, queens, male: Cuba, Limones Seboruco, Soledad, Cienfuegos, 22 Aug 1933, under rich humus in a depression on a limestone ledge in dense shade of forest; male from sweeping in nearby forest, 30 Aug (Weber) [USNM, LACM] (examined). Kempf, 1972: 84: combination in C. (Orthocrema). NEW SYNONYMY

The small yellow Crematogaster on Cuba share the general habitus of minutissima from Florida. They differ in that the dorsal pilosity is more like $C$. flavomicrops, relatively short, scruffy-looking, and not in three differentiable rows (although humeral setae are longer than the rest). The pronotum is completely smooth and shining.

\section{Crematogaster mancocapaci NEW STATUS}

Crematogaster brevispinosa [misspelled here as brevispina] st. mancocapaci Santschi, 1911:280 [Also described as new by Santschi, 1913:38.]. Syntype worker, queen, male: Ecuador, Chillacocha, 3900m, 1905 (Rivet) [NHMB, MHNG] (examined). Emery, 1922:134: combination in C. (Orthocrema).

This is a distinctive species, perhaps near crucis. Workers are as large or larger than limata, with long flexuous setae, but the setae are sparse, a pair on the face, a few pairs on the mesosoma; fourth abdominal tergite covered with long, sparse, fully appressed pubescence, such that if it were suberect and more dense it would be like crucis; the propodeal spines are similarly short and upturned, and there is a strong anteroventral petiolar tooth; antenna with 3-segmented club; postpetiole broad and slightly sulcate.

\section{Crematogaster levior NEW SPECIES}

Crematogaster limata r. parabiotica Forel (part): Forel, 1904b:683.

Crematogaster limata subsp. parabiotica var. levior Forel, 1911b:274. Worker: Brazil, Amazonas (H. W. Bates) [MHNG, ZSMC] (examined). Unavailable name.

Crematogaster parabiotica Forel (part): Wheeler, W.M. 1921a; Wheeler, W.M. and Darlington, 1930:109.

Crematogaster cf. limata parabiotica Forel (part): Davidson 1988, Seidel et al. 1990, Davidson et al. 1990. 
Brazil, Amazonas (H. W. Bates) [ZSMC]. There are two workers on one card. The holotype has been indicated with a black arrow drawn on the card.

\section{Range}

Amazonian portions of Brazil, Guianas, Venezuela, Colombia, Ecuador, Peru, Bolivia.

\section{Description of worker}

Pronotal dorsum almost entirely smooth and shiny, with no trace of carinulae, or with faint traces along anterolateral margins; other characters as in carinata.

\section{Measurements}

Holotype: HL 0.587, [HW, HC not visible], SL 0.586, EL 0.142, WL 0.672, SPL 0.130, PTH 0.141, PTL 0.201, PTW 0.152, PPL 0.145, PPW 0.147, OI 24, SI 100, PTHI 70, PTWI 76, PPI 101, SPI 19.

\section{Biology}

Crematogaster levior occurs in lowland wet forest habitats, where it cohabits large ant gardens with Camponotus femoratus. See carinata.

\section{DIVERSITY AND RELATIVE ABUNDANCE}

The known Costa Rican fauna is comprised of 31 species. The relative abundance relationships show a typical dominance diversity curve (Fig. 8). The data on which the curve is based are the result of subjective collecting methods by multiple collectors, rather than a more quantitative sampling program, but can nevertheless provide a rough estimate of the relative abundance distribution in the country, and can inform researchers of the likelihood of encountering particular species. A more quantitative assessment of a local Crematogaster community can be made using the results of the Project ALAS sampling at La Selva Biological Station in the Atlantic lowlands of Costa Rica (Table 2). The dominance diversity curve for this subset of 16 species is similar to the curve for the country as a whole. Table 2 also reveals the microhabitat preferences of the common species, with some species more frequently captured in fogging and Malaise samples, others more frequently found using methods that sample the forest floor.

One measure of the degree of completeness of an inventory is the number of species known from single collections (uniques). If an inventory contains a high proportion of uniques, it is likely there are additional species to be found. This study reveals a trend in which local ecological studies tend to appear less complete than studies with a larger geographic scope. For the La Selva fauna, three of the 16 known species are uniques (19\%). For Costa Rica as a whole, two of the 31 known species are uniques (6\%). Considering 

gest that the Costa Rican faunal survey reported here is essentially complete.

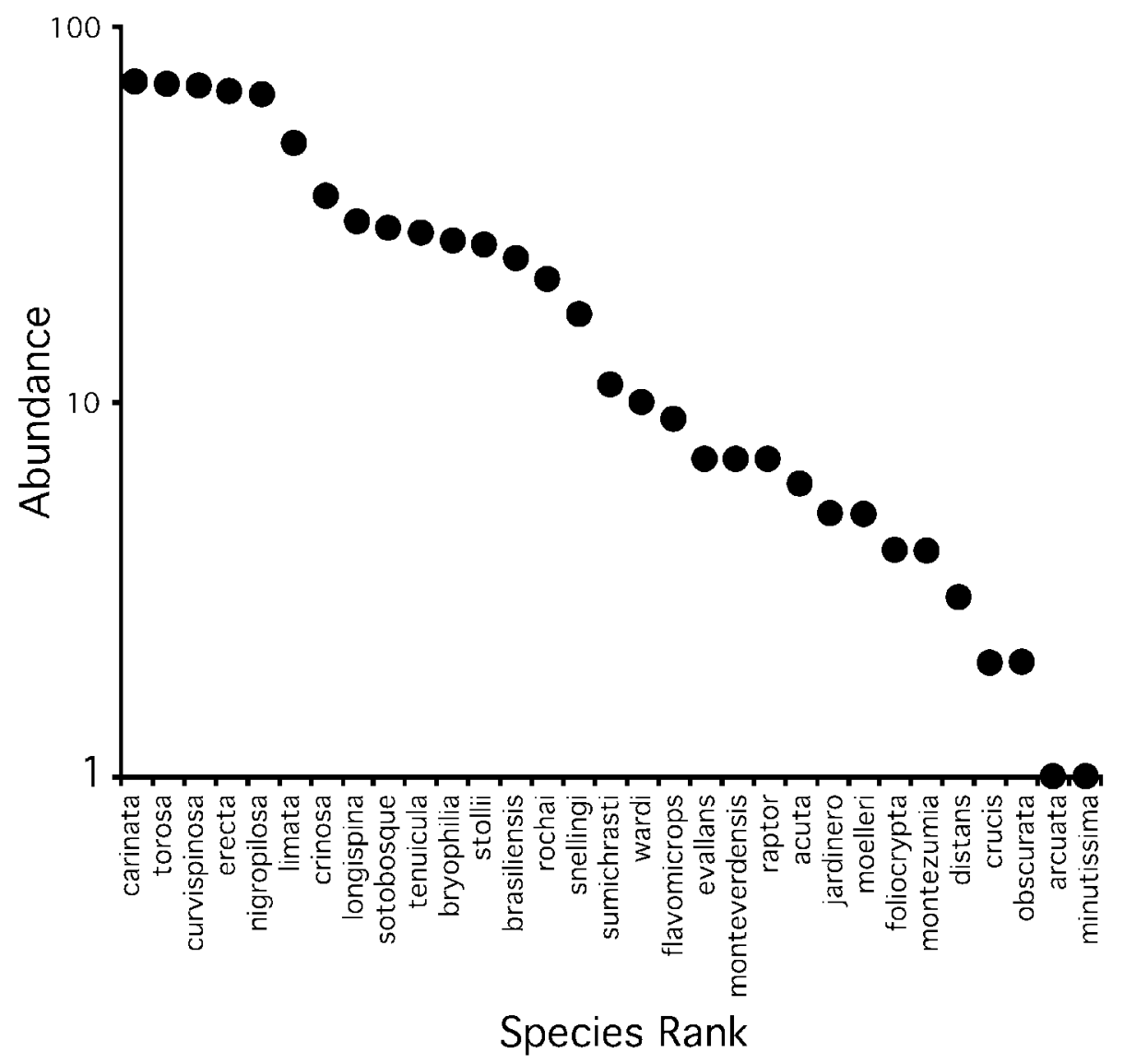

FIGURE 8. Dominance-diversity curve for Crematogaster of Costa Rica. Abundance values are number of collection events (see Table 1).

\section{ACKNOWLEDGMENTS}

The following curators were very helpful in the loan of specimens and during museum visits: Roy Snelling (LACM), C. Besuchet, D. Burckhardt, and I. Löbl (MHNG), V. Raineri (MCSN), S. Cover (MCZC), D. Smith (USNM), and P. Ward (U.C. Davis). The work benefited greatly from the abundant collections and generous contributions of Bill Mackay and Phil Ward. Casey Richart assisted with Automontage image preparation, and Melissa Barrows assisted with specimen measurements. Phil Ward thoroughly edited the manuscript. This work has been supported by the National Geographic Society, and The National Science Foundation grants BSR-9025024, DEB-9401069, DEB-9706976, and DEB-0072702. 
TABLE 2. Quantitative and qualitative survey results for the Crematogaster fauna of the La Selva Biological Station, Heredia Province, Costa Rica. Data are from Longino et al. (2002) plus additional fogging data. Cell values are number of collection events in which workers occurred. Berlese, Winkler, and "Thompson" are all methods that sample the leaf litter from the forest floor. Fogging events are the combined catch from $401 \mathrm{~m}^{2}$ funnels placed beneath a fogged canopy tree. "Longino" is my qualitative hand collecting at the site. "Other" is miscellaneous qualitative collecting by various methods and researchers. See Longino et al. (2002) for details. Species with an asterisk are known from single queens.

\begin{tabular}{|c|c|c|c|c|c|c|}
\hline & $\begin{array}{c}\text { Berlese, } \\
\text { Winkler, } \\
\text { Thompson }\end{array}$ & Fogging & Malaise & Longino & Other & Total \\
\hline carinata & 1 & 24 & 20 & 16 & 4 & 65 \\
\hline curvispinosa & 1 & 17 & 1 & 5 & 4 & 28 \\
\hline limata & 4 & 11 & 2 & 8 & 2 & 27 \\
\hline sotobosque & 18 & 5 & 0 & 0 & 2 & 25 \\
\hline torosa & 0 & 14 & 5 & 2 & 1 & 22 \\
\hline bryophilia & 0 & 7 & 1 & 1 & 0 & 9 \\
\hline brasiliensis & 0 & 4 & 2 & 2 & 0 & 8 \\
\hline nigropilosa & 1 & 2 & 0 & 2 & 0 & 5 \\
\hline crinosa & 0 & 2 & 0 & 2 & 0 & 4 \\
\hline flavomicrops & 3 & 0 & 0 & 0 & 1 & 4 \\
\hline wardi & 2 & 0 & 0 & 2 & 0 & 4 \\
\hline longispina & 0 & 2 & 0 & 1 & 0 & 3 \\
\hline distans & 0 & 1 & 0 & 1 & 0 & 2 \\
\hline snellingi & 0 & 0 & 0 & 1 & 0 & 1 \\
\hline \multicolumn{7}{|l|}{ raptor $^{\star}$} \\
\hline montezumia* & & & & & & \\
\hline
\end{tabular}

\section{LITERATURE CITED}

Adams, E. S. (1994) Territory defense by the ant Azteca trigona: maintenance of an arboreal ant mosaic, Oecologia (Berlin) 97, 203-208.

André, E. (1893b) Description de quatre espèces nouvelles de fourmis d'Amérique, Revue d'Entomologie (Caen) 12, 148-152.

Benson, W. W. \& Setz, E. Z. F. (1985) On the type localities of ants collected by James Trail in Amazonian Brazil and described by Gustav Mayr, Revista Brasileira de Entomologia 29, 587590.

Bolton, B. (1994) Identification Guide to the Ant Genera of the World, Harvard University Press, Cambridge, Massachusetts, $222 \mathrm{pp}$.

Bolton, B. (1995) A New General Catalogue of the Ants of the World, Harvard University Press, Cambridge, Massachusetts, 504 pp.

Borgmeier, T. (1929) Zur Kenntnis der brasilianischen Ameisen, EOS. Revista Española de Entomología 5, 195-214.

Borgmeier, T. (1934) Contribuição para o conhecimento da fauna mirmecológica dos cafezais de Paramaribo, Guiana Holandesa (Hym. Formicidae), Archivos do Instituto de Biologia Vegetal 
(Rio de Janeiro) 1, 93-111.

Borgmeier, T. (1939) Nova contribuição para o conhecimento das formigas neotropicas (Hym. Formicidae), Revista de Entomologia (Rio de Janeiro) 10, 403-428.

Buren, W. F. (1959, "1958") A review of the species of Crematogaster, sensu stricto, in North America (Hymenoptera: Formicidae). Part I, Journal of the New York Entomological Society 66, 119-134.

Buren, W. F. (1968) A review of the species of Crematogaster, sensu stricto, in North America (Hymenoptera, Formicidae). Part II. Descriptions of new species, Journal of the Georgia Entomological Society 3, 91-121.

Crawley, W. C. (1916) Ants from British Guiana, Annals and Magazine of Natural History (8)17, 366-378.

Creighton, W. S. (1939) A new subspecies of Crematogaster minutissima with revisionary notes concerning that species (Hymenoptera: Formicidae), Psyche (Cambridge) 46, 137-140.

Creighton, W. S. (1950) The ants of North America, Bulletin of the Museum of Comparative Zoology $104,1-585$.

Dalla Torre, K. W. von. (1893) Catalogus Hymenopterorum hucusque descriptorum systematicus et synonymicus. Vol. 7. Formicidae (Heterogyna), W. Engelmann, Leipzig, 289 pp.

Davidson, D. W. (1988) Ecological studies of neotropical ant gardens, Ecology 69, 1138-1152.

Davidson, D. W., Seidel, J. L. \& Epstein, W. W. (1990) Neotropical ant gardens II: bioassays of seed compounds, Journal of Chemical Ecology 16, 2993-3013.

Emery, C. (1890) Studii sulle formiche della fauna neotropica, Bullettino della Società Entomologica Italiana 22, 38-80.

Emery, C. (1894) Estudios sobre las hormigas de Costa Rica, Anales del Museo Nacional de Costa Rica 1888-1889, 45-64.

Emery, C. (1895) Beiträge zur Kenntniss der nordamerikanischen Ameisenfauna. (Schluss), Zoologische Jahrbücher. Abteilung für Systematik, Geographie und Biologie der Tiere 8, 257-360.

Emery, C. (1922) Hymenoptera. Fam. Formicidae. Subfam. Myrmicinae [part], Genera Insectorum 174B, 95-206.

Enzmann, J. (1946) Crematogaster lineolata cerasi, the cherry ant of Asa Fitsch; (with a survey of the American forms of Crematogaster, subgenus Acrocoelia), Journal of the New York Entomological Society 54, 89-97.

Fabricius, J. C. (1804) Systema Piezatorum secundum ordines, genera, species, adjectis synonymis, locis, observationibus, descriptionibus, C. Reichard, Brunswick, xiv + 15-439 + 30 pp.

Forel, A. (1885, "1884") Études myrmécologiques en 1884 avec une description des organes sensoriels des antennes, Bulletin de la Société Vaudoise des Sciences Naturelles 20, 316-380.

Forel, A. (1893) Formicides de l'Antille St. Vincent, récoltées par Mons. H. H. Smith, Transactions of the Entomological Society of London 1893, 333-418.

Forel, A. (1897) Quelques Formicides de l'Antille de Grenada récoltés par M. H. H. Smith, Transactions of the Entomological Society of London 1897, 297-300.

Forel, A. (1898) La parabiose chez les fourmis, Bulletin de la Société Vaudoise des Sciences Naturelles 34, 380-384.

Forel, A. (1899) Formicidae [part], Biologia Centrali-Americana, Hymenoptera 3, 81-104.

Forel, A. (1901a) Einige neue Ameisen aus Südbrasilien, Java, Natal und Mossamedes, Mitteilungen der Schweizerischen Entomologischen Gesellschaft 10, 297-311.

Forel, A. (1901b) Formiciden des Naturhistorischen Museums zu Hamburg. Neue Calyptomyrmex, Dacryon-, Podomyrma- und Echinopla-Arten, Mitteilungen aus dem Naturhistorischen Museum in Hamburg 18, 43-82.

Forel, A. (1903) Mélanges entomologiques, biologiques et autres, Annales de la Société Entomologique de Belgique 47, 249-268.

Forel, A. (1904a) Miscellanea myrmécologiques, Revue Suisse de Zoologie 12, 1-52. 
Forel, A. (1904b) In und mit Pflanzen lebende Ameisen aus dem Amazonas-Gebiet und aus Peru, gesammelt von Herrn E. Ule, Zoologische Jahrbücher. Abteilung für Systematik, Geographie und Biologie der Tiere 20, 677-707.

Forel, A. (1907a) Formicides du Musée National Hongrois, Annales Historico-Naturales Musei Nationalis Hungarici 5, 1-42.

Forel, A. (1907b) Formiciden aus dem Naturhistorischen Museum in Hamburg. II. Teil. Neueingänge seit 1900, Mitteilungen aus dem Naturhistorischen Museum in Hamburg 24, 1-20.

Forel, A. (1908a) Fourmis de Costa-Rica récoltées par M. Paul Biolley, Bulletin de la Société Vaudoise des Sciences Naturelles 44, 35-72.

Forel, A. (1908b) Ameisen aus Sao Paulo (Brasilien), Paraguay etc. gesammelt von Prof. Herm. v. Ihering, Dr. Lutz, Dr. Fiebrig, etc, Verhandlungen der Kaiserlich-Königlichen Zoologisch-Botanischen Gesellschaft in Wien 58, 340-418.

Forel, A. (1909) Ameisen aus Guatemala usw., Paraguay und Argentinien (Hym.), Deutsche Entomologische Zeitschrift 1909, 239-269.

Forel, A. (1911a) Ameisen des Herrn Prof. v. Ihering aus Brasilien (Sao Paulo usw.) nebst einigen anderen aus Südamerika und Afrika (Hym.), Deutsche Entomologische Zeitschrift 1911, 285312.

Forel, A. (1911b) Die Ameisen des K. Zoologischen Museums in München, ichte der Mathematischen-Physikalischen Klasse der Königlich Bayerischen Akademie der Wissenschaften zu München 11, 249-303.

Forel, A. (1912) Formicides néotropiques. Part I, Annales de la Société Entomologique de Belgique $56,28-49$.

Forel, A. (1913) Fourmis d'Argentine, du Brésil, du Guatémala \& de Cuba reçues de M. M. Bruch, Prof. v. Ihering, Mlle Baez, M. Peper et M. Rovereto, Bulletin de la Société Vaudoise des Sciences Naturelles 49, 203-250.

Forel, A. (1914a) Einige amerikanische Ameisen, Deutsche Entomologische Zeitschrift 1914, 615620.

Forel, A. (1914b) Formicides d'Afrique et d'Amérique nouveaux ou peu connus, Bulletin de la Société Vaudoise des Sciences Naturelles 50, 211-288.

Forel, A. (1914c) Quelques fourmis de Colombie, Mémoires de la Société Neuchâteloise des Sciences Naturelles 5(2), 9-14.

Forel, A. (1921, "1920") Fourmis trouvées dans des galles de Cordia et d'Agonandra, etc, Bulletin de la Société Botanique de Genève (2)12, 201-208.

Forel, A. (1928) The Social World of the Ants Compared with that of Man. Volume 2 [Translated by C. K. Ogden.], G. P. Putnam's Sons, London, xx+444pp.

Gallardo, A. (1931) Algunas formas sexuales aún no descriptas de las hormigas del género Crematogaster de la República Argentina, Revista de la Sociedad Entomológica Argentina 3, $297-$ 304.

Gallardo, A. (1934) Las hormigas de la República Argentina. Subfamilia Mirmicinas, segunda sección Eumyrmicinae, tribu Crematogastrini (Forel), género Crematogaster Lund, Anales del Museo Nacional de Historia Natural de Buenos Aires 38, 1-84.

Gámez, R. (1991) Biodiversity conservation through facilitation of its sustainable use: Costa Rica's National Biodiversity Institute, Trends in Ecology \& Evolution 6, 377-378.

Heinze, J., Cover, S. P. \& Hölldobler, B. (1998, "1995") Neither worker, nor queen: an ant caste specialized in the production of unfertilized eggs, Psyche (Cambridge) 102, 173-185.

Heinze, J., Foitzik, S., Oberstadt, B., Rüppell, O. \& Hölldobler, B. (1999) A female caste specialized for the production of unfertilized eggs in the ant Crematogaster smithi, Naturwissenschaften 86, 93-95.

Hillis, D. M. (1988) Systematics of the Rana pipiens complex: puzzle and paradigm, Annual Review of Ecology and Systematics 19, 39-63. 
Hölldobler, B., \& Wilson, E. O. (1990) The Ants, Harvard University Press, Cambridge, Massachusetts, xii+732pp.

Holliday, M. (1903) A study of some ergatogynic ants, Zoologische Jahrbücher. Abteilung für Systematik, Geographie und Biologie der Tiere 19, 293-328.

Kempf, W. W. (1960) Tranopeltoides Wheeler, a synonym of Crematogaster Lund (Hymenoptera, Formicidae), Entomological News 71, 173-175.

Kempf, W. W. (1968) Miscellaneous studies on Neotropical ants. IV. (Hymenoptera, Formicidae), Studia Entomologica 11, 369-415.

Kempf, W. W. (1972) Catálogo abreviado das formigas da região Neotropical, Studia Entomologica $15,3-344$.

Kleinfeldt, S. E. (1978) Ant-gardens: the interaction of codonanthe crassifolia (Gesneriaceae) and Crematogaster longispina (Formicidae), Ecology 59, 449-456.

Kusnezov, N. (1949) Crematogaster (Neocrema) descolei n. sp. (Hymenoptera, Formicidae), Acta Zoologica Lilloana 8, 587-590.

Kusnezov, N. (1953) La fauna mirmecológica de Bolivia, Folia Universitaria Cochabamba 6, 211229.

Kutter, H. (1931) Mit Bananen eingeschleppte Ameisen, Mitteilungen der Schweizerischen Entomologischen Gesellschaft 15, 61-64.

Luederwaldt, H. (1926) Observações biologicas sobre formigas brasileiras especialmente do estado de São Paulo, Revista do Museu Paulista 14, 185-303.

Longino, J. T., Colwell, R. K. \& Coddington, J. A. (2002) The ant fauna of a tropical rainforest: estimating species richness three different ways, Ecology 83, 689-702.

Maddison, W. P. (1987) Marchena and other jumping spiders with an apparent leg-carapace stridulatory mechanism (Araneae: Salticidae: Heliophaninae and Thiodininae), Bulletin of the British Arachnological Society 7, 101-106.

Mann, W. M. (1916) The Stanford Expedition to Brazil, 1911, John C. Branner, Director. The ants of Brazil, Bulletin of the Museum of Comparative Zoology 60, 399-490.

Mann, W. M. (1920) Additions to the ant fauna of the West Indies and Central America, Bulletin of the American Museum of Natural History 42, 403-439.

Mayr, G. (1862) Myrmecologische Studien, Verhandlungen der Kaiserlich-Königlichen Zoologisch-Botanischen Gesellschaft in Wien 12, 649-776.

Mayr, G. (1866) Diagnosen neuer und wenig gekannter Formiciden, Verhandlungen der KaiserlichKöniglichen Zoologisch-Botanischen Gesellschaft in Wien 16, 885-908.

Mayr, G. (1870a) Formicidae novogranadenses, Sitzungsberichte der Kaiserlichen Akademie der Wissenschaften in Wien. Mathematisch-Naturwissenschaftliche Classe [Klasse]. Abteilung I 61, 370-417.

Mayr, G. (1870b) Neue Formiciden, Verhandlungen der Kaiserlich-Königlichen Zoologisch-Botanischen Gesellschaft in Wien 20, 939-996.

Mayr, G. (1878, "1877") Formiciden gesammelt in Brasilien von Professor Trail, Verhandlungen der Kaiserlich-Königlichen Zoologisch-Botanischen Gesellschaft in Wien 27, 867-878.

Mayr, G. (1887) Südamerikanische Formiciden, Verhandlungen der Kaiserlich-Königlichen Zoologisch-Botanischen Gesellschaft in Wien 37, 511-632.

Menozzi, C. (1925) Qualche formica nuova od interessante del Deutsch. Ent. Institut di Dahlem (Form.), Entomologische Mitteilungen. Berlin-Dahlem 14, 368-371.

Menozzi, C. (1929) Formiche di Cuba e delle Isole Canarie raccolte dal Prof. Filippo Silvestri, Bollettino del Laboratorio di Zoologia Generale e Agraria della Reale Scuola Superiore d'Agricoltura. Portici 23, 1-5.

Mercado, N. K. (1962) Mutualism between Trigona compressa Latr. and Crematogaster stolli Forel (Hymenoptera: Apidae), Journal of the New York Entomological Society 70, 215-217.

Pergande, T. (1896) Mexican Formicidae, Proceedings of the California Academy of Sciences (2)5, 
$858-896$.

Roger, J. (1862) Synonymische Bemerkungen. 1. Ueber Formiciden, Berliner Entomologische Zeitschrift 6, 283-297.

Santschi, F. (1911) Formicides de diverses provenances, Annales de la Société Entomologique de Belgique 55, 278-287.

Santschi, F. (1912) Quelques fourmis de l'Amérique australe, Revue Suisse de Zoologie 20, 519534.

Santschi, F. (1913) Hyménoptères. Formicides. In: André, E. et al. (Ed) Mission du service géographique de l'armée pour la mesure d'un arc de méridien équatorial en Amérique du Sud. Tome 10. Fasc. 1. Insectes, Gauthier-Villars, Paris, 33-43.

Santschi, F. (1918) Sous-genres et synoymies [sic] de Cremastogaster (Hym. Formic.), Bulletin de la Société Entomologique de France 1918, 182-185.

Santschi, F. (1919) Nouveaux formicides de la République Argentine, Anales de la Sociedad Cientifica Argentina 87, 37-57.

Santschi, F. (1922) Description de nouvelles fourmis de l'Argentine et pays limitrophes, Anales de la Sociedad Cientifica Argentina 94, 241-262.

Santschi, F. (1923) Solenopsis et autres fourmis néotropicales, Revue Suisse de Zoologie 30, 245273.

Santschi, F. (1925) Nouveaux Formicides brésiliens et autres, Bulletin et Annales de la Société Entomologique de Belgique 65, 221-247.

Santschi, F. (1929a) Nouvelles fourmis de la République Argentine et du Brésil, Anales de la Sociedad Cientifica Argentina 107, 273-316.

Santschi, F. (1929b) Mélange myrmécologique, Wiener Entomologische Zeitung 46, 84-93.

Santschi, F. (1932) Quelques fourmis inédites de l'Amérique centrale et Cuba, Revista de Entomologia (Rio de Janeiro) 2, 410-414.

Santschi, F. (1933) Fourmis de la République Argentine en particulier du territoire de Misiones, Anales de la Sociedad Cientifica Argentina 116, 105-124.

Santschi, F. (1939) Résultats scientifiques des croisières du navire-école belge, "Mercator". XIV. Formicidae s. 1t, Mémoires du Musée Royal d'Histoire Naturelle de Belgique (2)15, 159-167.

Seidel, J. L., Epstein, W. W. \& Davidson, D. W.. (1990) Neotropical ant gardens I: chemical constituents, Journal of Chemical Ecology 16, 1791-1816.

Shepard, M., \& Gibson, F. (1972) Spider-ant symbiosis: Cotinusa spp. (Araneida: Salticidae) and Tapinoma melanocephalum (Hymenoptera: Formicidae), Canadian Entomologist 104, 19511954.

Skwarra, E. (1934a) Ökologie der Lebensgemeinschaften mexikanischer Ameisenpflanzen, Zeitschrift für Morphologie und Ökologie der Tiere 29, 306-373.

Skwarra, E. (1934b) Ökologische Studien über Ameisen und Ameisenpflanzen in Mexiko, published by author (printer R. Leupold), Königsberg, 153 pp.

Smith, F. (1857) Catalogue of the hymenopterous insects collected at Sarawak, Borneo; Mount Ophir, Malacca; and at Singapore, by A. R. Wallace [part], Journal and Proceedings of the Linnean Society of London. Zoology 2, 42-88.

Smith, F. (1858) Catalogue of Hymenopterous Insects in the Collection of the British Museum. Part VI. Formicidae, British Museum, London, 216 pp.

Soulié, J. (1961, "1960") Des considérations écologiques peuvent-elles apporter une contribution à la connaisance du cycle biologique des colonies de Cremastogaster (Hymenoptera - Formicoidea)? Insectes Sociaux 7, 283-295.

Weber, N. A. (1934) Notes on neotropical ants, including the descriptions of new forms, Revista de Entomologia (Rio de Janeiro) 4, 22-59.

Weber, N. A. (1938) New ants from stomachs of Bufo marinus L. and Typhlops reticulatus (L), Annals of the Entomological Society of America 31, 207-210. 
Wheeler, D. E. (1986) Ectatomma tuberculatum foraging biology and association with Crematogaster (Hymenoptera Formicidae), Annals of the Entomological Society of America 79, 300303.

Wheeler, G. C., \& Wheeler, J. (1952) The ant larvae of the myrmicine tribe Crematogastrini, Journal of the Washington Academy of Sciences 42, 248-262.

Wheeler, G. C., \& Wheeler, J. (1960) Supplementary studies on the larvae of the Myrmicinae (Hymenoptera: Formicidae), Proceedings of the Entomological Society of Washington 62, 132.

Wheeler, W. M. (1906) The habits of the tent-building ant (Cremastogaster lineolata Say), Bulletin of the American Museum of Natural History 22, 1-18.

Wheeler, W. M. (1908a) The ants of Jamaica, Bulletin of the American Museum of Natural History 24, 159-163.

Wheeler, W. M. (1908b) The ants of Texas, New Mexico and Arizona. (Part I.), Bulletin of the American Museum of Natural History 24, 399-485.

Wheeler, W. M. (1910) Ants: their structure, development and behavior, Columbia University Press, New York, xxv+663pp.

Wheeler, W. M. (1912) Notes on a mistletoe ant, Journal of the New York Entomological Society 20, 130-133.

Wheeler, W. M. (1917) Jamaican ants collected by Prof. C. T. Brues, Bulletin of the Museum of Comparative Zoology 61, 457-471.

Wheeler, W. M. (1918) Ants collected in British Guiana by Mr. C. William Beebe, Journal of the New York Entomological Society 26, 23-28.

Wheeler, W. M. (1921a) A new case of parabiosis and the "ant gardens" of British Guiana, Ecology 2, 89-103.

Wheeler, W. M. (1921b) The Tachigalia ants, Zoologica (N. Y.) 3, 137-168.

Wheeler, W. M. (1922a) Neotropical ants of the genera Carebara, Tranopelta and Tranopeltoides, new genus, American Museum Novitates 48, 1-14.

Wheeler, W. M. (1922b) Ants of the American Museum Congo expedition. A contribution to the myrmecology of Africa. VII. Keys to the genera and subgenera of ants, Bulletin of the American Museum of Natural History 45, 631-710.

Wheeler, W. M. (1923) Wissenschaftliche Ergebnisse der schwedischen entomologischen Reise des Herrn Dr. A. Roman in Amazonas 1914-1915. 7. Formicidae, Arkiv för Zoologi 15(7), 1-6.

Wheeler, W. M. (1925) Neotropical ants in the collections of the Royal Museum of Stockholm, Arkiv för Zoologi 17A(8), 1-55.

Wheeler, W. M. (1933) The Templeton Crocker Expedition of the California Academy of Sciences, 1932. No. 6. Formicidae of the Templeton Crocker Expedition, Proceedings of the California Academy of Sciences (4)21, 57-64.

Wheeler, W. M. (1934) Neotropical ants collected by Dr. Elisabeth Skwarra and others, Bulletin of the Museum of Comparative Zoology 77, 157-240.

Wheeler, W. M. (1936) A singular Crematogaster from Guatemala, Psyche (Cambridge) 43, 40-48.

Wheeler, W. M. (1942) Studies of Neotropical ant-plants and their ants, Bulletin of the Museum of Comparative Zoology 90, 1-262.

Wheeler, W. M. \& Darlington, P. J., Jr. (1930) Ant-tree notes from Rio Frio, Colombia, Psyche (Cambridge) 37, 107-117. 
PLATES 1-3. Dorsal and lateral views of petiole and postpetiole for selected Crematogaster species. Species are organized by petiole shape, from elongate tapering to short and quadrate to short with convex sides. Images are not to scale. Only lateral views are shown for four closely related species in the limata complex; dorsal views are similar to longispina. For unillustrated species, foliocrypta is similar to limata; bryophilia, monteverdensis, and wardi are similar to sumichrasti; flavomicrops and minutissima are similar to flavosensitiva; montezumia is similar to raptor; arcuata and evallans are similar to acuta. 
ZOOTAXA

151
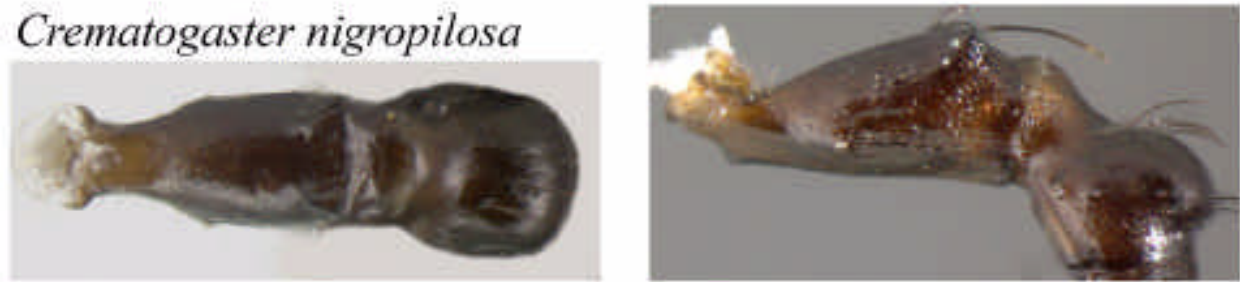

Crematogaster longispina
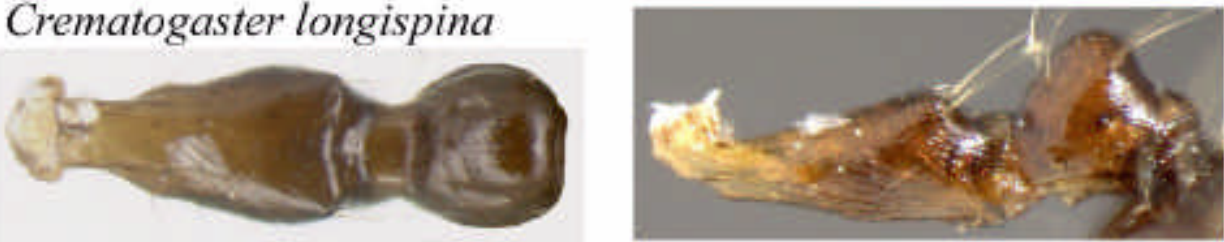

Crematogaster limata

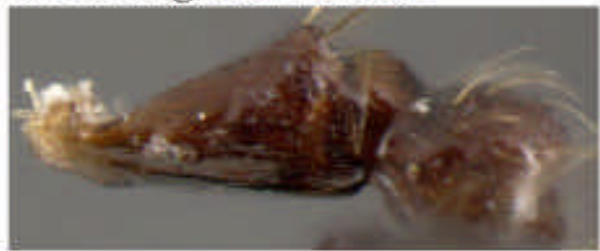

Crematogaster tenuicula

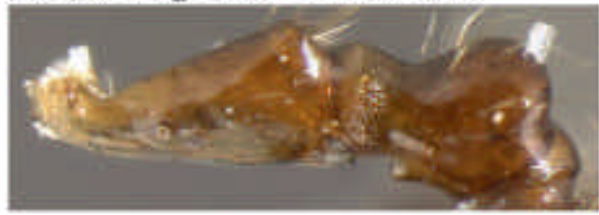

Crematogaster carinata

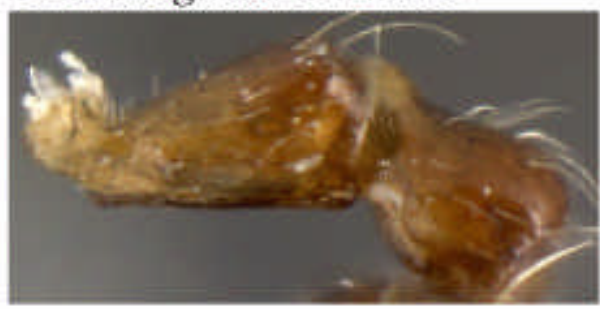

Crematogaster brasiliensis

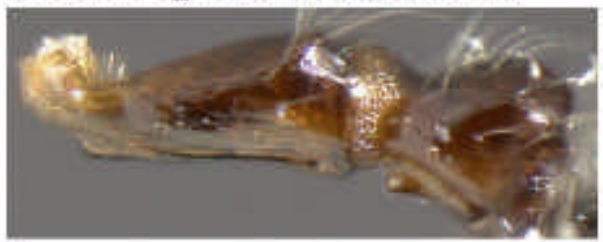

Crematogaster sotobosque
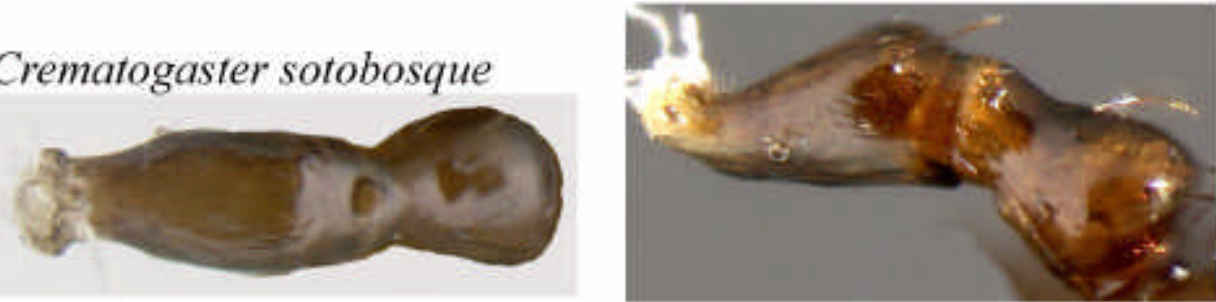

Crematogaster snellingi
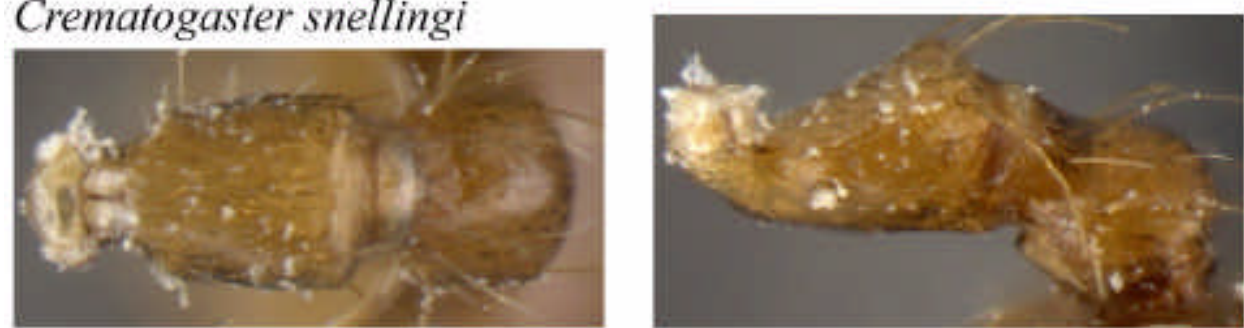

PLATE 1 
Crematogaster sumichrasti

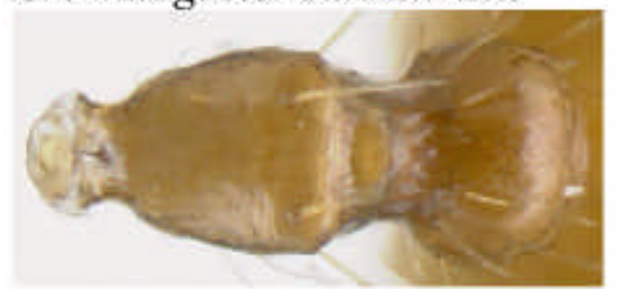

Crematogaster flavosensitiva

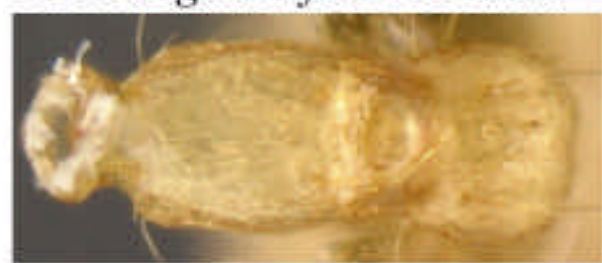

Crematogaster curvispinosa

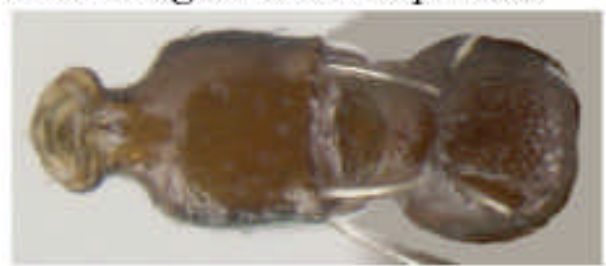

Crematogaster obscurata

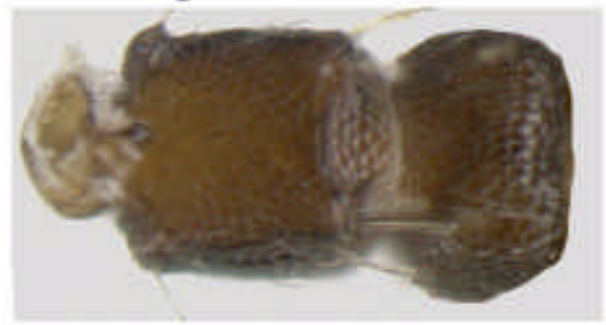

Crematogaster jardinero

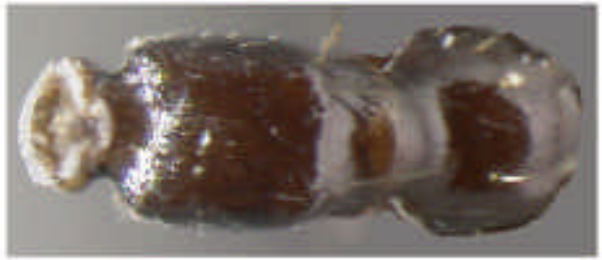

\section{Crematogaster raptor}

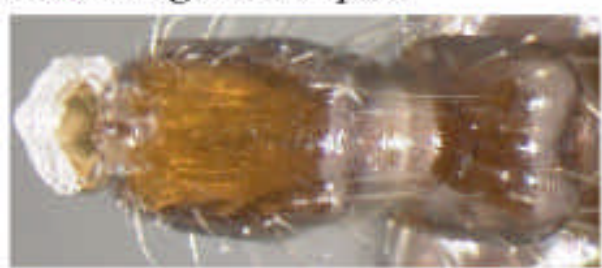

PLATE 2
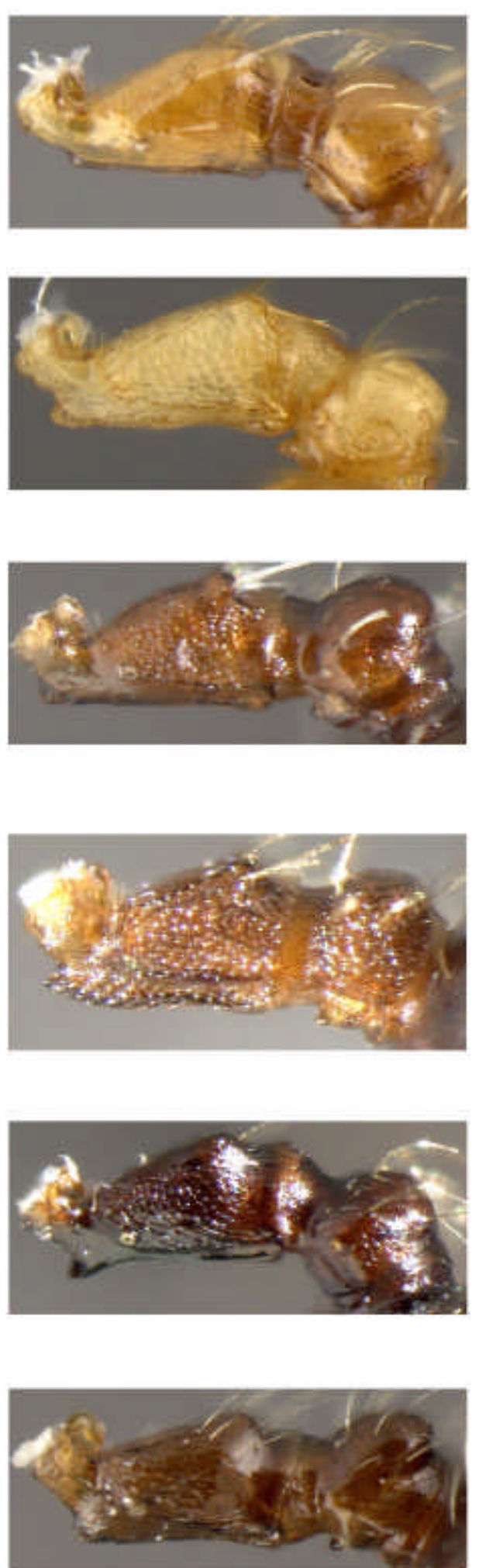

(c) 2003 Magnolia Press
ZOOTAXA

151 
ZOOTAXA

Crematogaster acuta
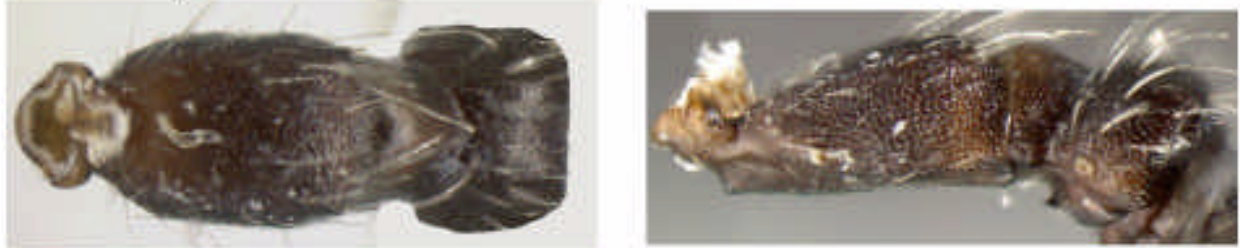

Crematogaster distans
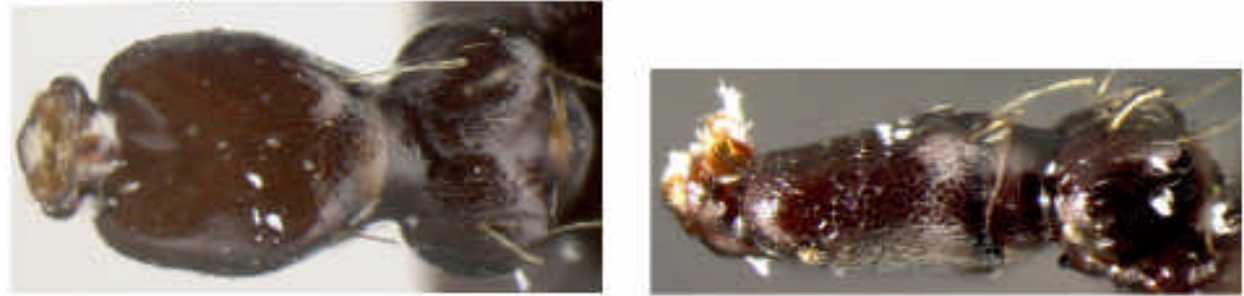

Crematogaster stollii
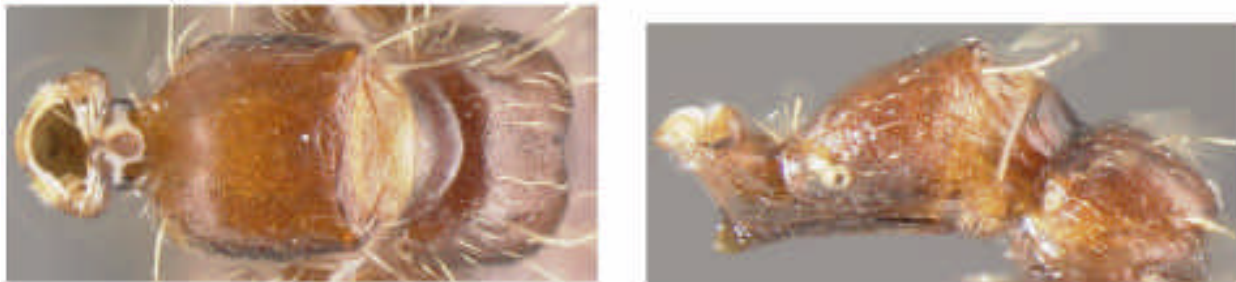

Crematogaster erecta
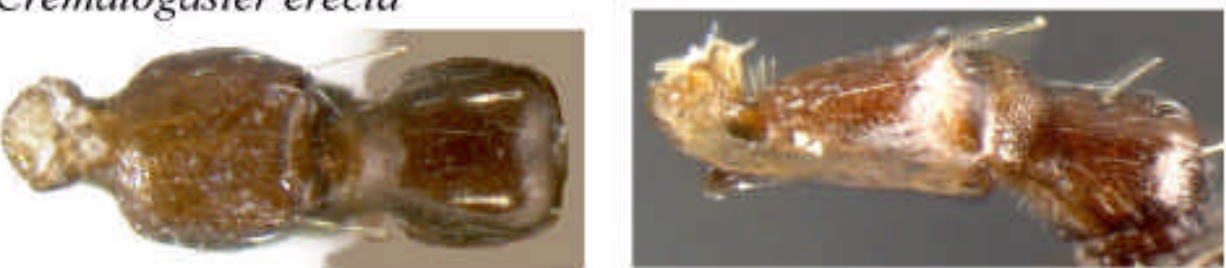

Crematogaster crucis
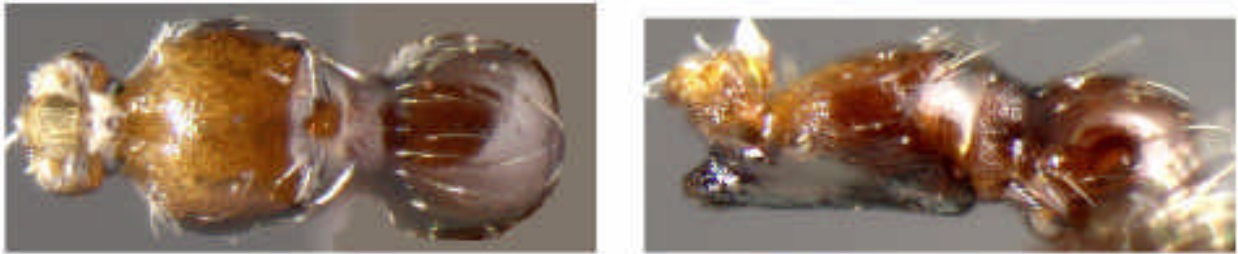

Crematogaster crinosa
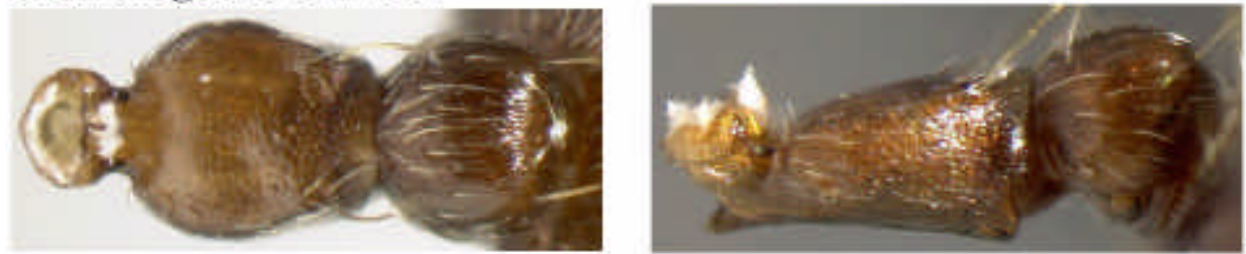

PLATE 3 
PLATES 4-8. Lateral and dorsal views of mesosoma for selected Crematogaster species. Scale bars are all $0.5 \mathrm{~mm}$. 
ZOOTAXA

151
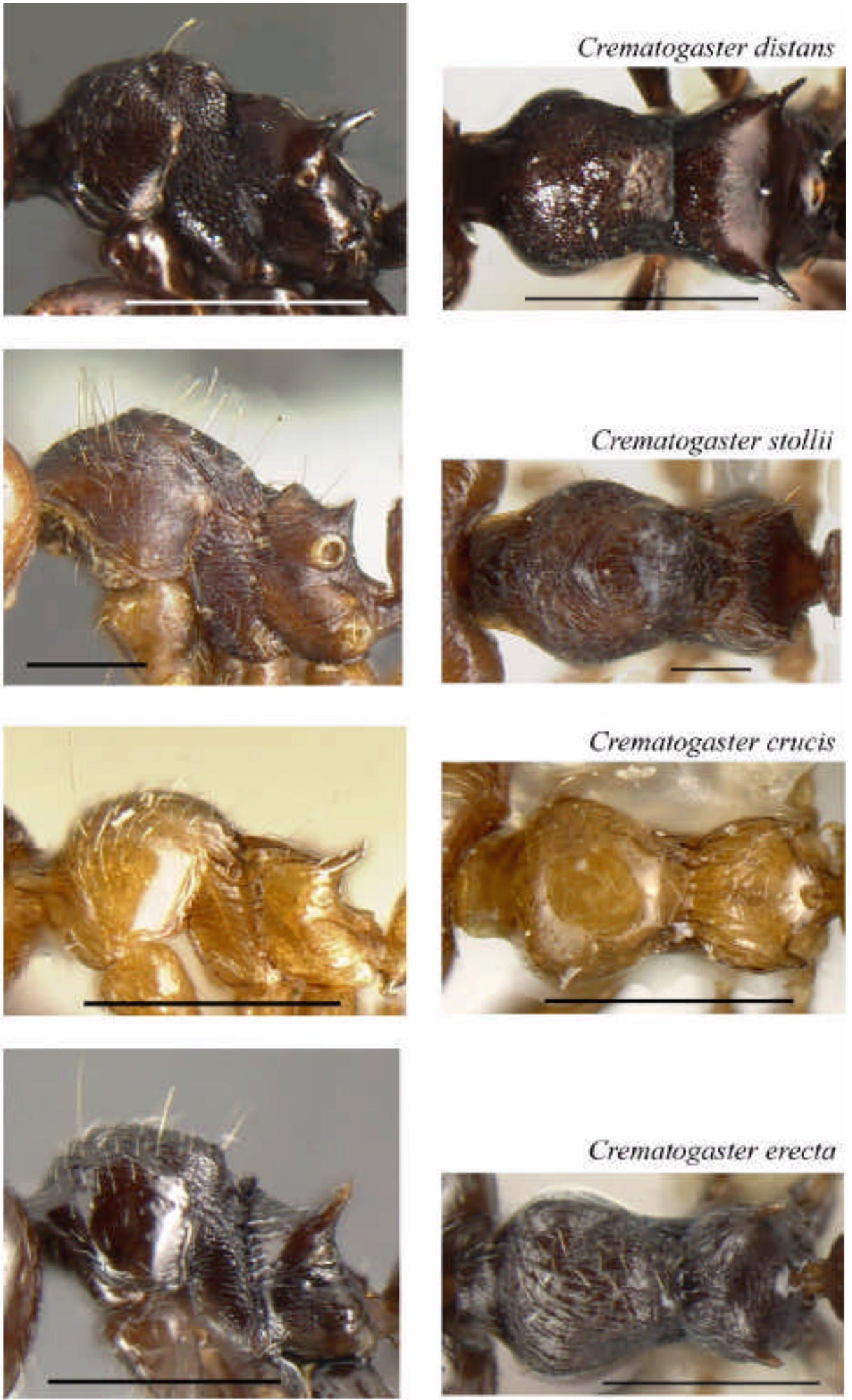

\section{Crematogaster stollii}

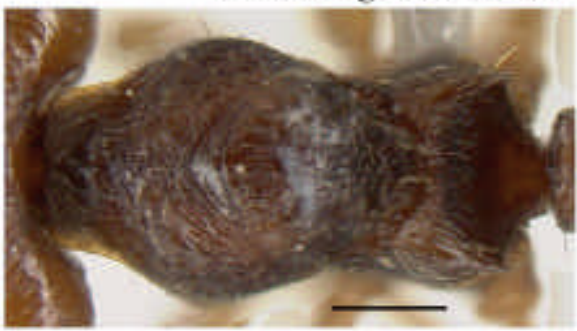

Crematogaster crucis

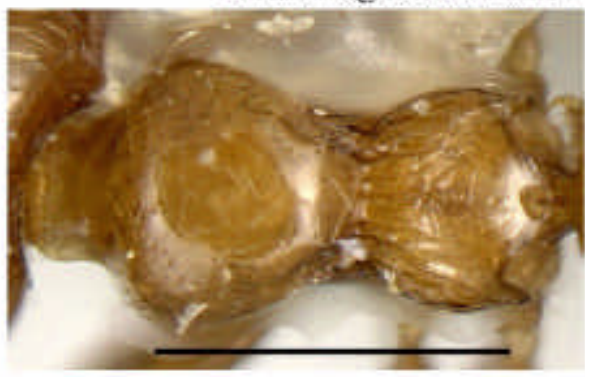

Crematogaster erecta

PLATE 4 

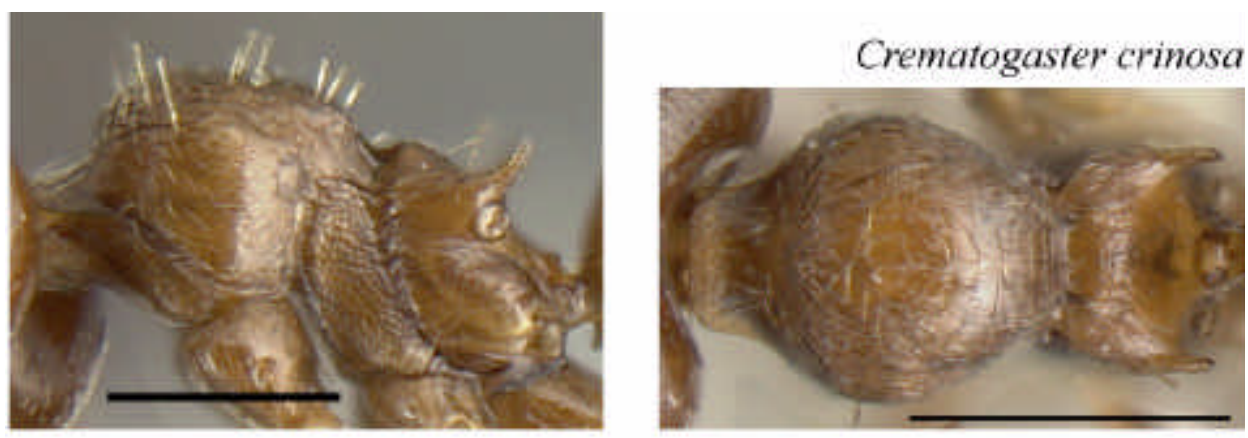

ZOOTAXA

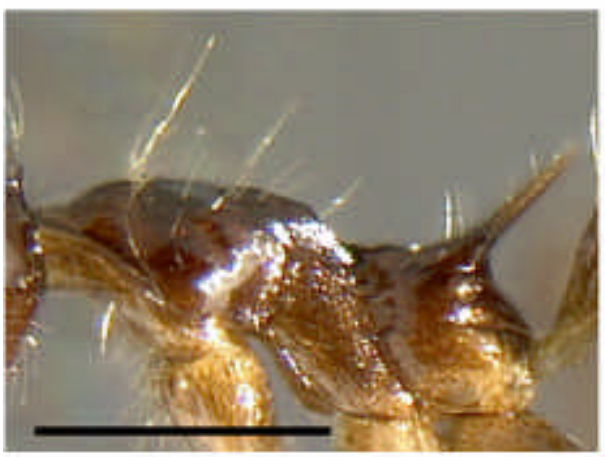

Crematogaster longispina
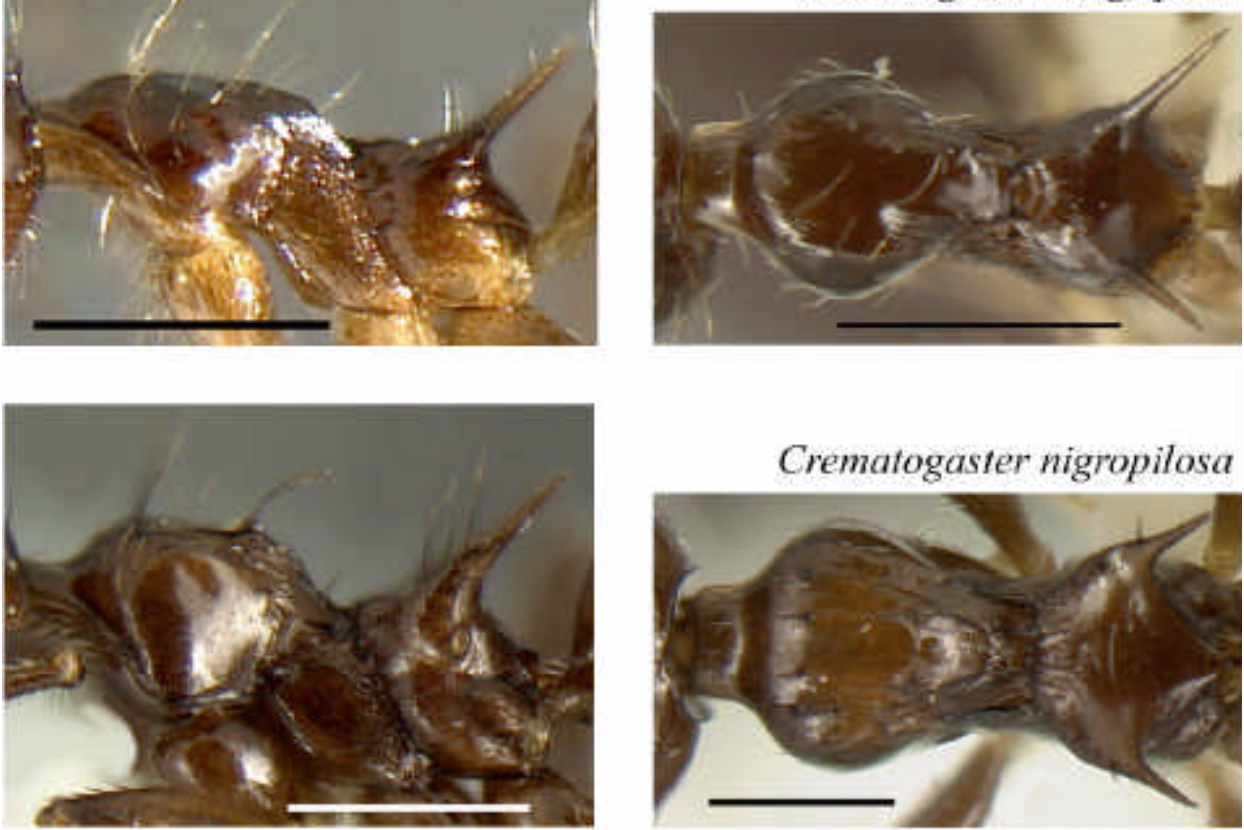

Crematogaster nigropilosa
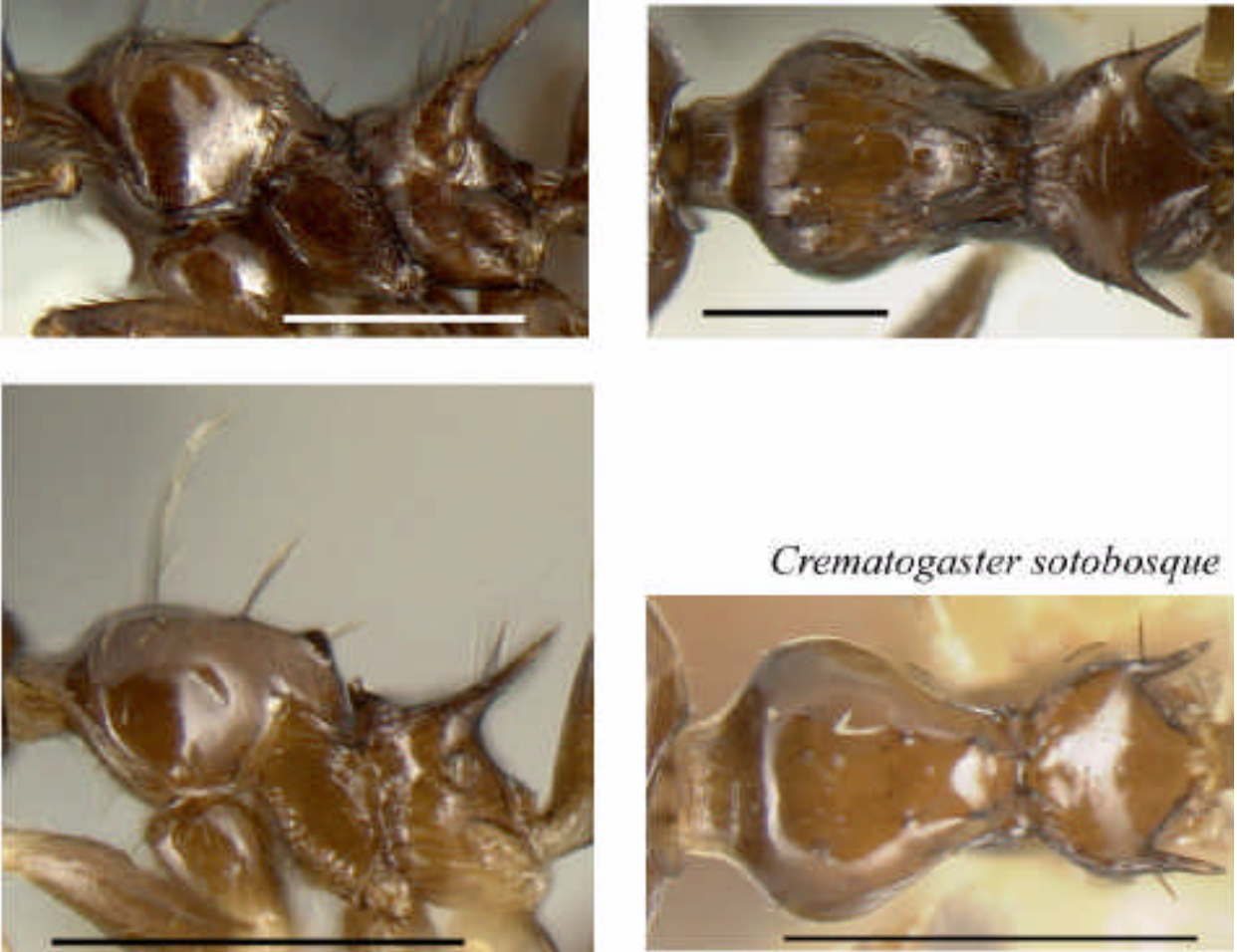

Crematogaster sotobosque

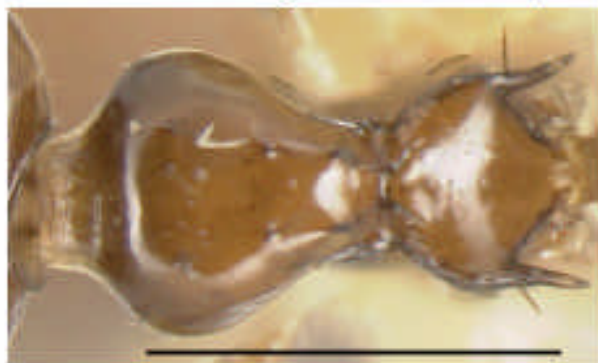

PLATE 5 
ZOOTAXA

151
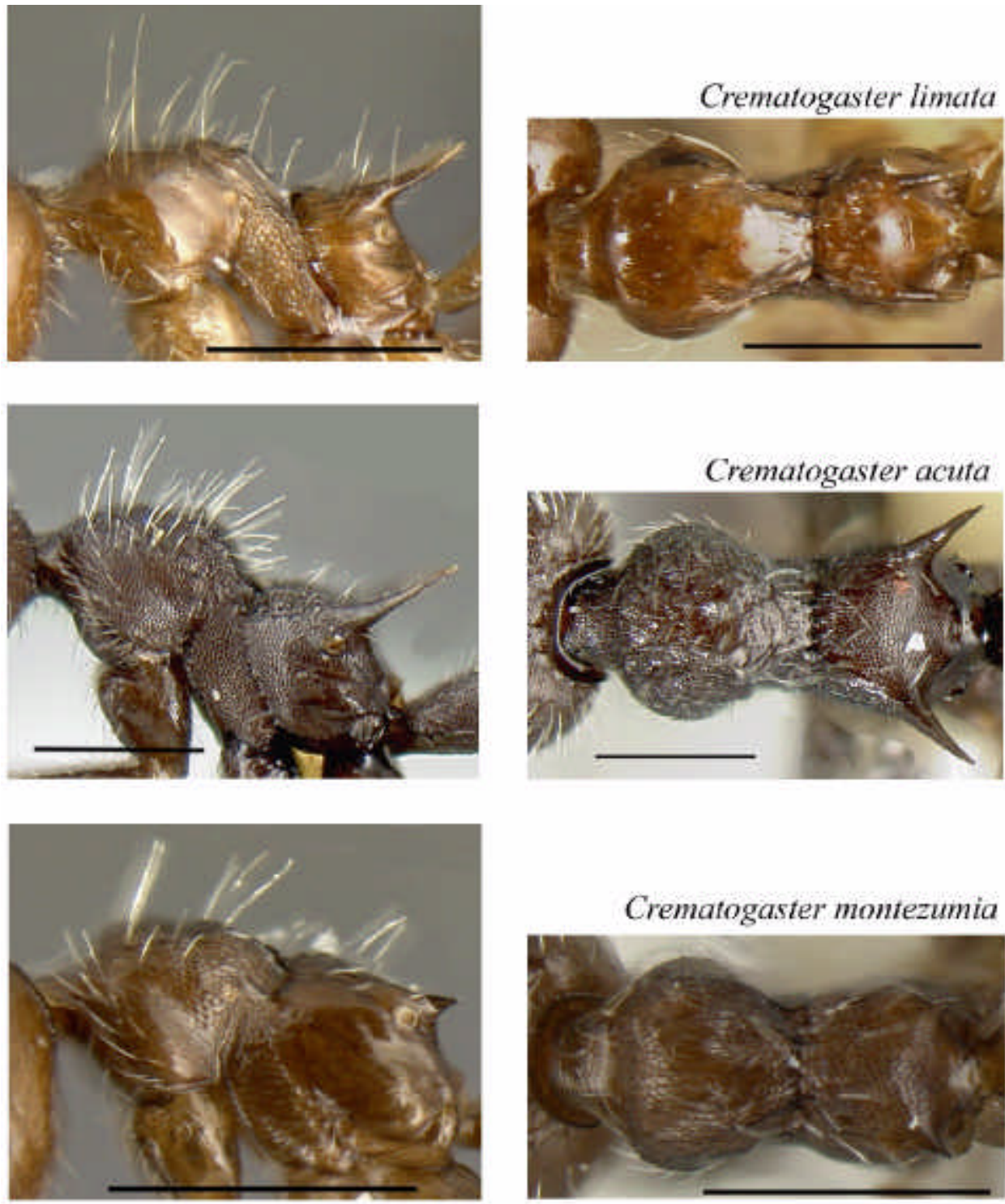

\section{Crematogaster montezumia}
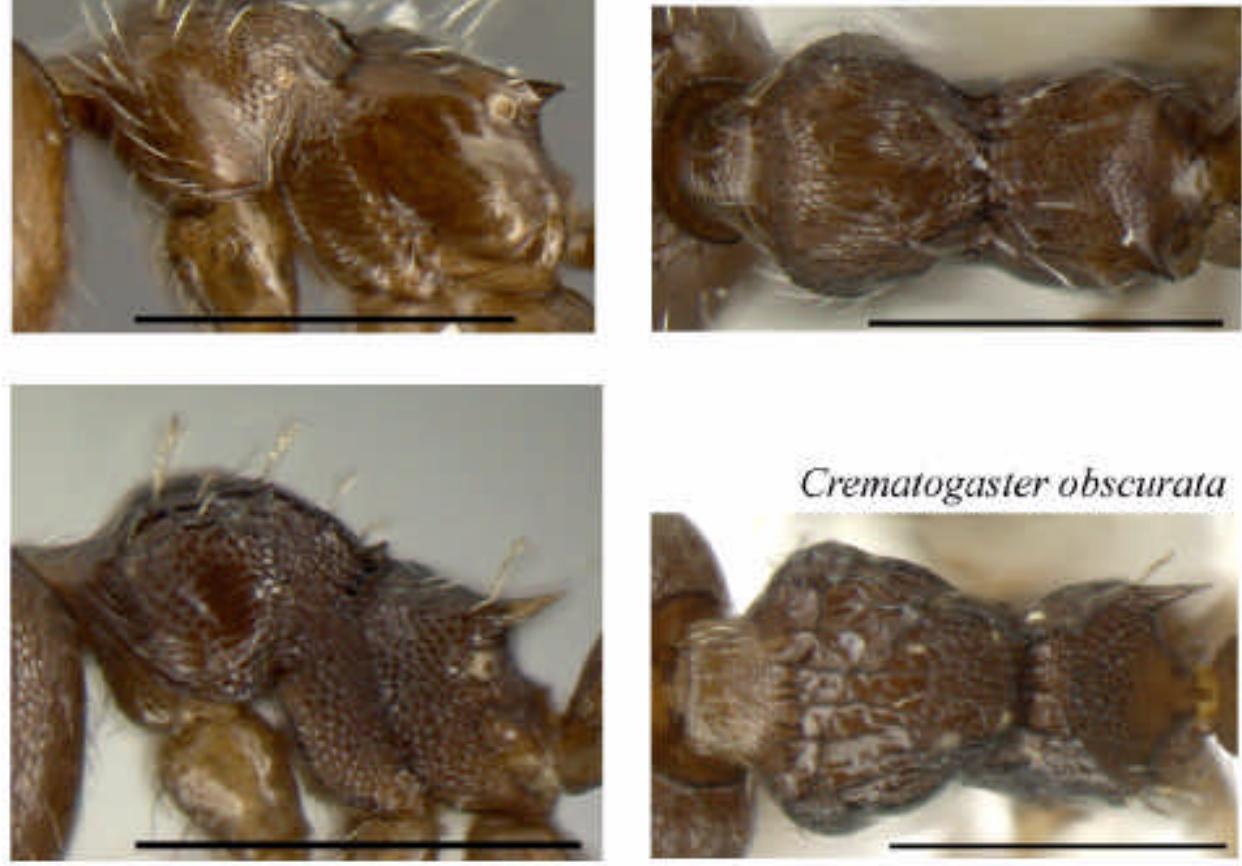

PLATE 6 


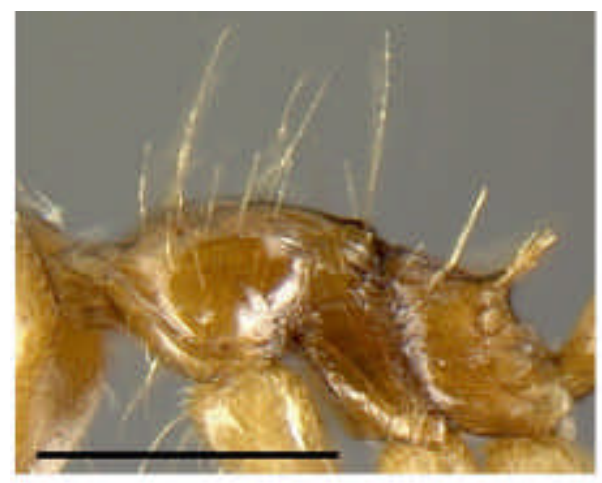

ZOOTAXA

151
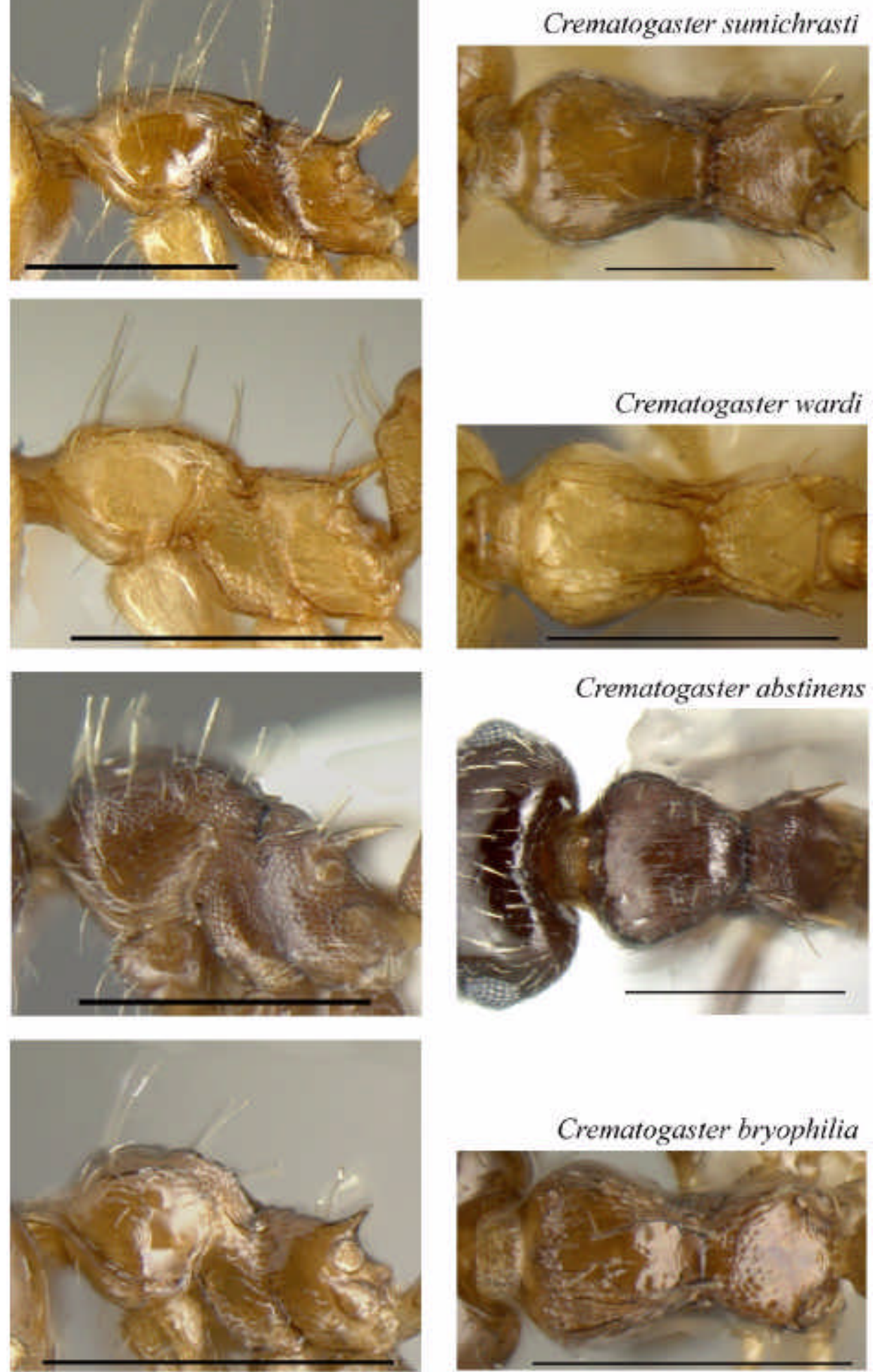

\section{Crematogaster abstinens}

PLATE 7 
ZOOTAXA

151
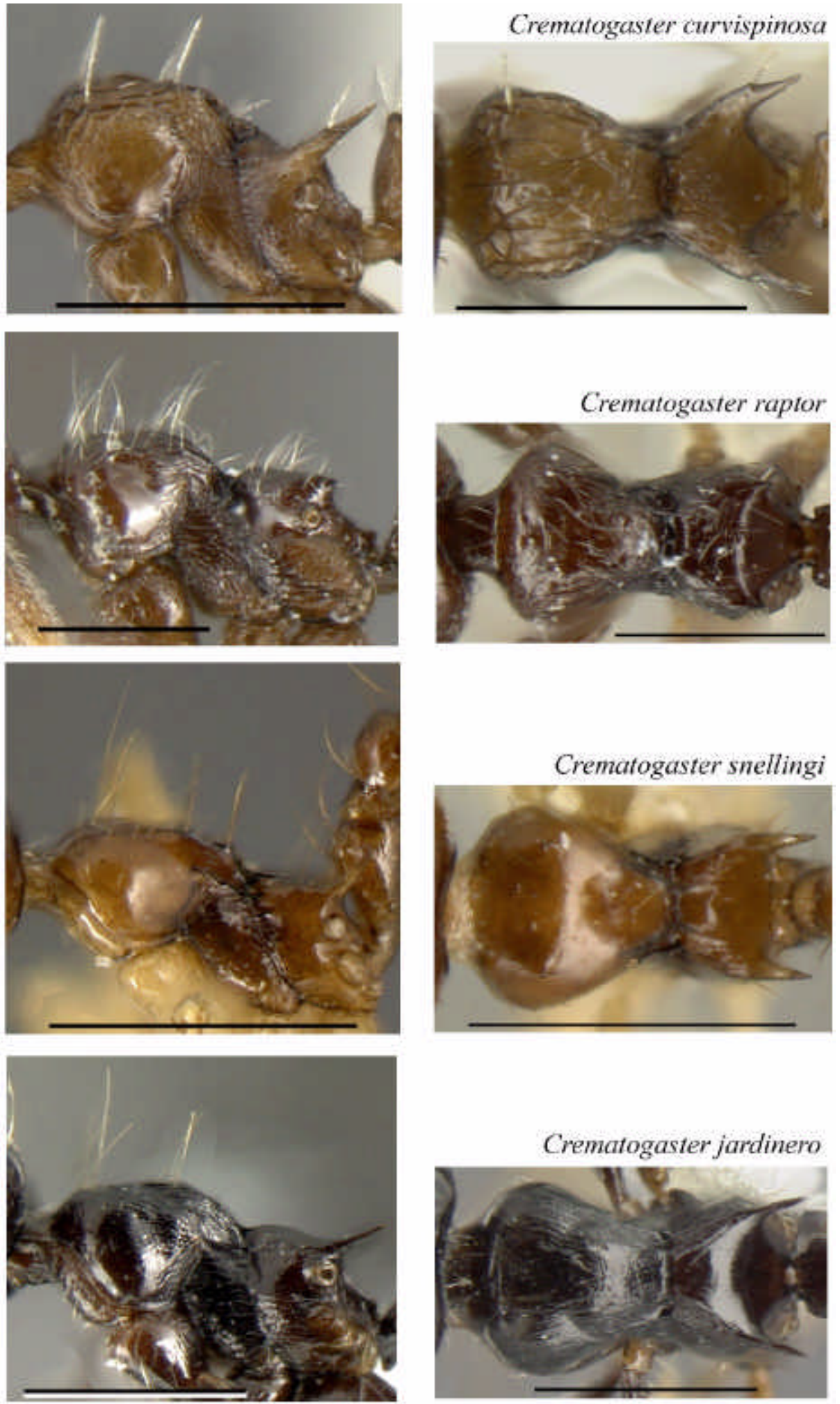

PLATE 8 